\title{
A REVIEW OF THE MEASUREMENT AND DEVELOPMENT OF CRYSTALLINITY AND ITS RELATION TO PROPERTIES IN NEAT POLY(PHENYLENE SULFIDE) AND ITS FIBER REINFORCED COMPOSITES
}

August 2004 


\section{DOCUMENT AVAILABILITY}

Reports produced after January 1, 1996, are generally available free via the U.S.

Department of Energy (DOE) Information Bridge.

Web site http://www.osti.gov/bridge

Reports produced before January 1, 1996, may be purchased by members of the public from the following source.

National Technical Information Service

5285 Port Royal Road

Springfield, VA 22161

Telephone 703-605-6000 (1-800-553-6847)

TDD 703-487-4639

Fax 703-605-6900

E-mail info@ntis.fedworld.gov

Web site http://www.ntis.gov/support/ordernowabout.htm

Reports are available to DOE employees, DOE contractors, Energy Technology Data Exchange (ETDE) representatives, and International Nuclear Information System (INIS) representatives from the following source.

Office of Scientific and Technical Information

P.O. Box 62

Oak Ridge, TN 37831

Telephone 865-576-8401

Fax 865-576-5728

E-mail reports@adonis.osti.gov

Web site http://www.osti.gov/contact.html

This report was prepared as an account of work sponsored by an agency of the United States Government. Neither the United States Government nor any agency thereof, nor any of their employees, makes any warranty, express or implied, or assumes any legal liability or responsibility for the accuracy, completeness, or usefulness of any information, apparatus, product, or process disclosed, or represents that its use would not infringe privately owned rights. Reference herein to any specific commercial product, process, or service by trade name, trademark, manufacturer, or otherwise, does not necessarily constitute or imply its endorsement, recommendation, or favoring by the United States Government or any agency thereof. The views and opinions of authors expressed herein do not necessarily state or reflect those of the United States Government or any agency thereof. 
Metals and Ceramics Division

\title{
A REVIEW OF THE MEASUREMENT AND DEVELOPMENT OF CRYSTALLINITY AND ITS RELATION TO PROPERTIES IN NEAT POLY(PHENYLENE SULFIDE) AND ITS FIBER REINFORCED COMPOSITES
}

\author{
J.E. Spruiell \\ Materials Science and Engineering, University of Tennessee, Knoxville 37996-2200 \\ Chris J. Janke \\ Oak Ridge National Laboratory, Oak Ridge, TN 37831
}

August 2004

Prepared by the

Oak Ridge National Laboratory

Oak Ridge, Tennessee 37831-6053

\author{
Managed by \\ UT-BATTELLE, LLC \\ for the \\ U.S. DEPARTMENT OF ENERGY \\ under contract DE-AC05-00OR22725
}


This page left blank intentionally. 


\section{TABLE OF CONTENTS}

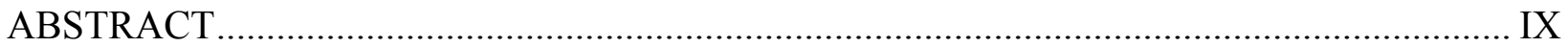

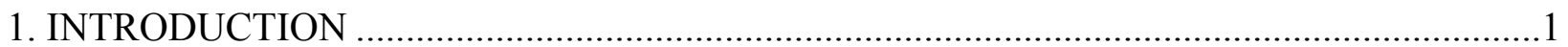

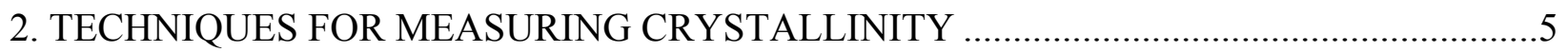

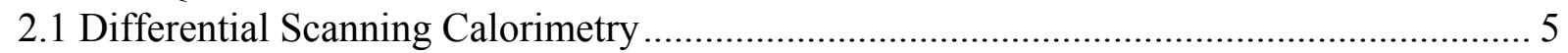

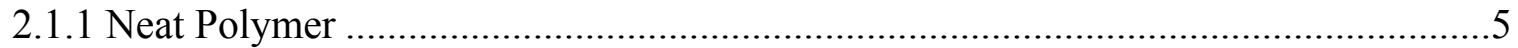

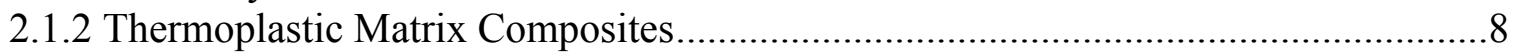

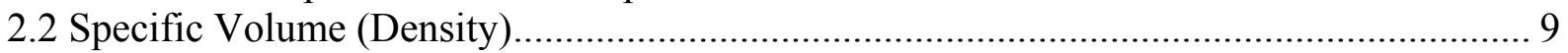

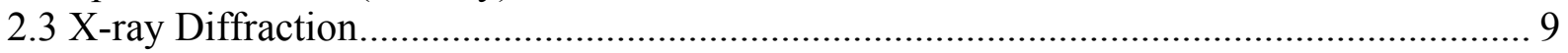

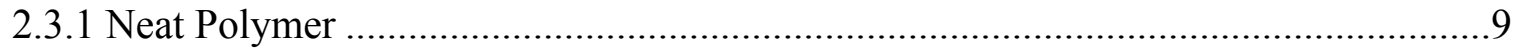

2.3.2 Thermoplastic Polymer Composites .................................................................12

2.4 Other Techniques ………………………………................................................ 12

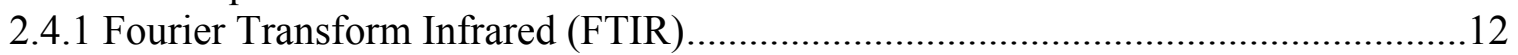

2.4.2 Dynamic Mechanical Analysis (DMA) …………..............................................13

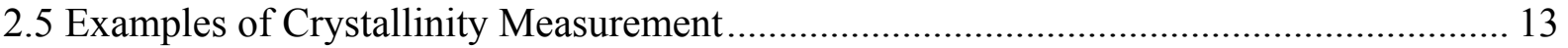

2.5.1 DSC Measurement on Neat PPS .....................................................................13

2.5.2 DSC Measurement on PPS/Carbon Fiber Composite..............................................14

2.5.3 X-ray Diffraction Measurement on PPS/Carbon Fiber Composite ............................14

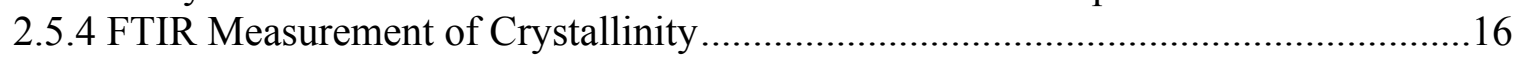

3. CRYSTALLINITY AS A FUNCTION OF PRIOR TREATMENT ………...........................19

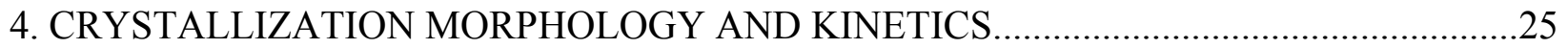

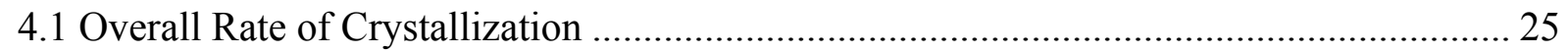

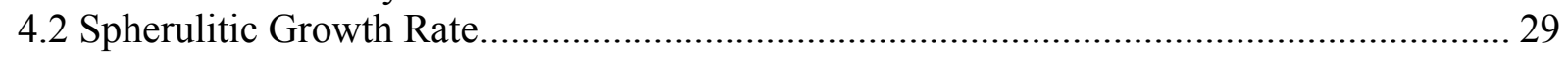

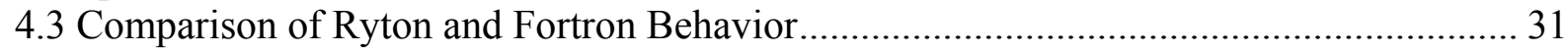

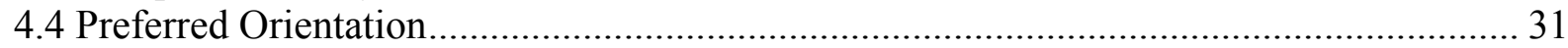

5. EFFECT OF VARIATION OF CRYSTALLINITY AND MORPHOLOGY ON

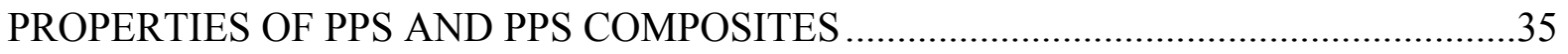

5.1 Tensile, Compressive and Flexural Properties................................................................. 35

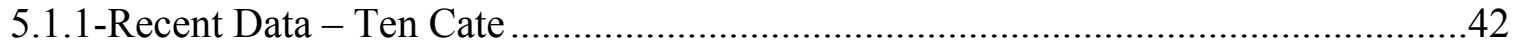

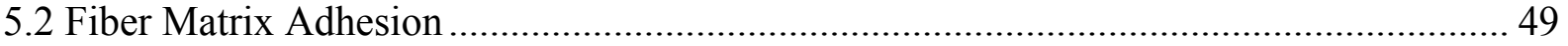

5.3 Impact Behavior and Fracture Toughness..................................................................... 50

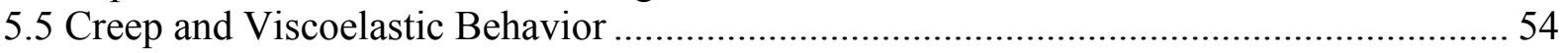

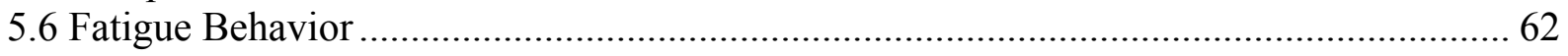

6. ENVIRONMENTAL STABILITY OF PPS AND THE ROLE OF CRYSTALLINITY .........65

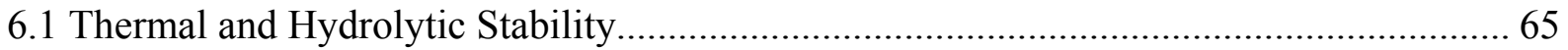

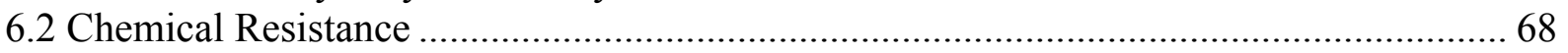

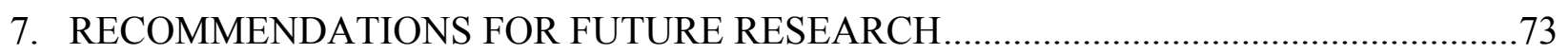

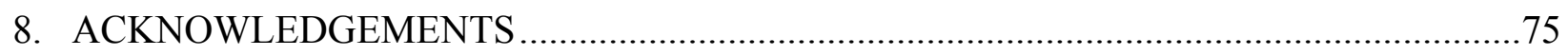

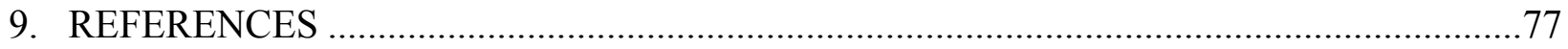

APPENDIX A. MECHANICAL PROPERTY GRAPHICAL RESULTS AND RAW DATA FROM TEN CATE ...................................................................................... A-1

APPENDIX B. MECHANICAL PROPERTY RESULTS ON CARBON FABRIC/PEI AND CARBON FABRIC/PPS LAMINATES FROM TEN CRATE COMPANY ................. 
This page left blank intentionally. 


\section{LIST OF FIGURES}

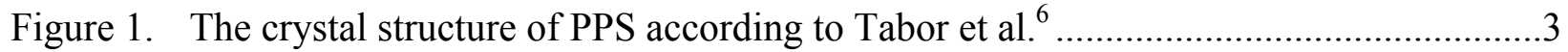

Figure 2. DSC curves of Fortron PPS film...........................................................................

Figure 3. Heat of fusion as a function of specific volume of PPS (Data of Huo and Cebe $\left.{ }^{15}\right)$.

Figure 4. X-ray diffraction pattern of neat AS4 carbon fiber.

Figure 5. Diffraction pattern of as-received PPS/AS4 Carbon Fiber Composite (60 wt.\% fiber) showing the profile fitting and separation into the crystalline and amorphous peaks from PPS and from carbon fiber.

Figure 6. Ratio of IR band intensities versus heat of crystallization measured on crystallization from the quenched amorphous state (from Cole et al. ${ }^{27}$ )

Figure 7. Effect of mold temperature and annealing on crystallinity of PPS. (•) as molded;

(ム) annealed $2 \mathrm{hrs}$ at $204^{\circ} \mathrm{C}$. $\left(\right.$ Brady $^{14}, 1976$. $)$

Figure 8. Increase of heat of fusion on annealing at $204^{\circ} \mathrm{C}$. Note that the maximum heat of fusion obtained is about $12.05 \mathrm{cal} / \mathrm{g}(50.4 \mathrm{~J} / \mathrm{g})$. $\left(\operatorname{Brady}^{14}, 1976.\right)$.

Figure 9. Crystallinity as function of crystallization temperature in Kelvin for neat PPS and some PPS composites (from Auer et al. $.^{35}, 1994$ ).

Figure 10. Crystallinity as a function of crystallization temperature for neat PPS and some carbon fiber composites (from Desio and Rebenfeld ${ }^{36}, 1992$ ).

Figure 11. Storage modulus versus temperature for $20 \%$ glass fiber/PPS composites on annealing at $204^{\circ} \mathrm{C}$ for the indicated times (from Lee et al. ${ }^{26}$ ).

Figure 12. Time to maximum in the DSC exotherm as a function of crystallization temperature for PPS.

Figure 13. Half-time of crystallization as a function of isothermal crystallization temperature for PPS and some PPS composites (from Auer, et. al. ${ }^{35}$ ).

Figure 14. Half-time of crystallization versus crystallization temperature for PPS and some of its carbon fiber composites (from Desio and Rebefeld ${ }^{36}$ ).

Figure 15. Transcrystalline morphology in the neighborhood of sized AS4 fibers in model thin film composite (from Desio and Rebenfeld ${ }^{48}$, original magnification 570X) ......30

Figure 16. Spherulite growth rate of PPS as a function of crystallization temperature. ................30

Figure 17. Amorphous and c-axis crystalline orientation factors for PPS film stretched to different stretch ratios and annealed at $150^{\circ} \mathrm{C}$

Figure 18. Tensile strength as a function of mold temperature for $40 \%$ glass-filled PPS composite.

Figure 19. (a) Tensile strength of various neat PPS samples versus melt viscosity (after Nishihata et al..$^{66}$ )

Figure 20. Tensile strength of various neat PPS samples in both the as-molded condition and after heat treating for $1 \mathrm{hr}$ at $250^{\circ} \mathrm{C}$ plotted as function of crystallinity (after Nishihata et al. ${ }^{66}$ ).

Figure 21. Tensile stress/strain curves for PPS/carbon fiber and polyamide 6/carbon fiber composites.

Figure 22. Model of failure mechanism for samples tested in axial tension.

Figure 23. Models of failure mechanisms in axial compression for carbon fiber reinforced, polymer matrix composites (after Oya and Hamada ${ }^{62}$ ).

Figure 24. Strength Properties of Glass 7781 (A1100)/PPS Composites. 
Figure 25. Modulus Properties of Glass 7781 (A1100)/PPS Composites..................................47

Figure 26. Strength Properties of T300J 5HS/PPS (Vf=50\%) Composites. .............................48

Figure 27. Modulus Properties of T300J 5HS/PPS (Vf=50\%) Composites. ...............................48

Figure 28. Impact strength versus percent crystallinity for PPS and PPS blends .......................51

Figure 29. Decrease of total impact energy (\% retention) to penetrate carbon fiber composites of PPS and PEEK as a function of aging temperature below the glass transition temperature (from Ma et al. ${ }^{75}$ ).

Figure 30. Normalized compression strength as a function of the impact energy used to damage the samples for several types of composite samples, including carbon fiber/PPS (After Spamer and Brink ${ }^{76}$ ).

Figure 31. Decrease in tensile strength and flexural strength of PPS/carbon fiber composites as a result of damage caused by impact as a function of the applied impact energy (after Ma et al. ${ }^{75}$ ).

Figure 32. Strain response for a viscoelastic material to the application of a constant engineering stress for the period from $t_{1}$ to $t_{2}$.

Figure 33. Typical strain as function of time (creep curve) showing the three stages of creep behavior. $\mathrm{t}_{\mathrm{f}}$ is the rupture time.

Figure 34. Creep modulus versus time (log-log scale) for $40 \%$ glass-filled PPS as a function of temperature (Data from Fortron PPS Design Manual ${ }^{77}$ ).

Figure 35. Relationship of storage modulus, loss modulus and phase angle $\delta$ to the complex modulus.

Figure 36. Storage modulus (a) and loss modulus (b) of PPS $/ 40 \%$ glass fiber for both cold and hot molded samples (from Sepe ${ }^{76}$ ).

Figure 37. Storage modulus of PPS and PPS composites as a function of temperature..............59

Figure 38. Creep performance at $200^{\circ} \mathrm{C}$ of selected polymers based on the FKP model...........61

Figure 39. The effect of crystallinity on creep parameters for $20 \%$ glass-filled PPS. ................61

Figure 40. Percent retention in tensile fatigue strength versus cycles to failure.........................62

Figure 41. S-N curves for several carbon fiber, thermoplastic matrix composites....................63

Figure 42. Comparison of predicted $90^{\circ} \mathrm{C}$ fatigue prediction to experimental result. ................64

Figure 43. Reduction of melt flow (increase of molecular weight) as a function of holding time at the indicated temperatures.

Figure 44. Retention of tensile strength, unnotched impact and flow in a spiral channel as a function of the number of times PPS is reground.

Figure 45. Absorption of water in carbon/PPS ( $65 \%$ by weight fiber) as a function of reduced time in $75 \%$ relative humidity and temperature: $\square 80^{\circ} \mathrm{C} ; \bigcirc 70^{\circ} \mathrm{C} ; \triangle$ $60^{\circ} \mathrm{C}$

Figure 46. Recent data from Ten Cate ${ }^{17}$ on water absorption for glass $7781 / \mathrm{PPS}$ and carbon T300J 5HS/PPS laminates.

Figure 47. Recent data from Ten Cate ${ }^{17}$ on the chemical resistance of various fluids including MEK, anti-icing fluid, jet fuel, Skydrol, and Skydrol/water on the in plane shear strength properties of glass 7781/PPS and carbon T300J 5HS/PPS laminates. 


\section{LIST OF TABLES}

Table 1. Observed Diffraction Peaks for as-Received PPS/Carbon Fiber Composite............. 16

Table 2. Influence of Annealing Temperature and Time on the Crystallinity of $20 \%$ Glass

Fiber/PPS Composite (Data of Lee et al. ${ }^{26,37}$ )..................................................... 22

Table 3. Effect of Thermal History on the Crystallinity of PPS/Carbon Fiber Composites.... 24

Table 4 Transverse Tensile Strength of Selected PPS/Carbon Fiber Composites................... 36

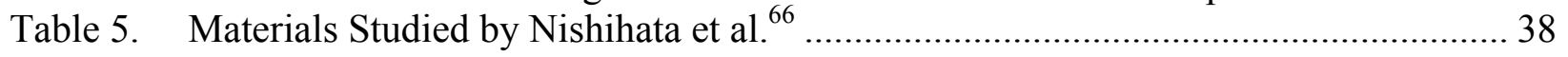

Table 6. Comparison of Unidirectional Mechanical Properties........................................... 40

Table 7. Typical PPS Composite Properties (Note: Properties Generated Prior to 1986)....... 43

Table 8. Test Conditions for Cetex Data....................................................................... 44

Table 9. Summary of Mechanical Property Test Data on Ten Cate Cetex Laminates. ........... 44

Table 10. Time Dependent Strain in 40\% Glass-filled PPS ................................................ 59

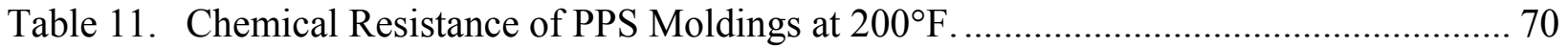


This page left blank intentionally. 


\begin{abstract}
This literature review paper was prepared for the Department of Energy Automotive Lightweighting Program to address materials interest expressed by the Automotive Composites Consortium and it summarizes the measurement and development of crystallinity and its relation to properties in poly(phenylene sulfide) (PPS) and its fiber reinforced composites. The objective of this effort was to broaden the understanding of low-cost, semi-crystalline thermoplastic resins and composites for use in potential future automotive applications. PPS has an excellent combination of attributes including good mechanical properties and thermal stability, high chemical resistance, low moisture absorption, good weathering resistance, high dimensional stability, low flammability, and excellent processability. Specific areas addressed in this report include: Structure of PPS; Techniques for measuring crystallinity; Crystallinity as a function of prior treatment; Crystallization kinetics and morphology; Effect of variation of crystallinity on properties of PPS and its composites; Environmental stability; Unusual effects of cooling rates and degree of crystallinity on mechanical properties of AS4/PPS composites; Recent PPS laminate data (Ten Cate Advanced Composites); and Recommendations for future research.
\end{abstract}


This page left blank intentionally. 


\section{INTRODUCTION}

The purpose of this review paper is to provide a thorough and up to-date summary of the existing literature on the measurement and development of crystallinity and its relation to properties in poly(phenylene sulfide) and its fiber reinforced composites. This paper was prepared for the Department of Energy Automotive Lightweighting Program to address materials interest expressed by the Automotive Composites Consortium (ACC) and it serves to broaden the understanding of low-cost, semi-crystalline thermoplastic resins and composites for use in potential future automotive applications. The outline for this report includes the following:

- Structure of PPS

- Techniques for Measuring Crystallinity

o Differential Scanning Calorimetry

o X-ray Diffraction

o Density

o Other Techniques

- Crystallinity as a Function of Prior Treatment

- Crystallization Kinetics and Morphology

- Effect of Variation of Crystallinity on Properties of PPS and Its Composites

o Tensile, Compressive and Flexural Properties

o Impact and Fracture Toughness

o Creep and Viscoelastic Behavior

o Fatigue Behavior

- Environmental Stability

o Thermal and Hydrolytic Stability

o Chemical Resistance

- Unusual Effects of Cooling Rates and Degree of Crystallinity on Mechanical Properties of AS4/PPS Composites

- Recent PPS Laminate Data (Ten Cate Advanced Composites)

- Recommendations for Future Research

Poly(phenylene sulfide) (PPS) is an engineering thermoplastic that has found numerous uses due to its excellent combination of properties, including good mechanical and thermal stability, resistance to chemical attack, flame resistance, and excellent processability. It is typically prepared by reaction of $p$-dichlorobenzene with a suitable source of sulfur such as sodium sulfide. ${ }^{1}$ The basic molecular structure is a series of alternating para-substituted phenylene rings and divalent sulfide moieties as illustrated below:

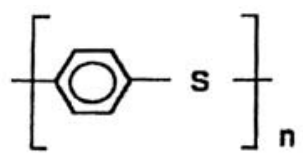

Because of its special properties and commercial significance, PPS has been the subject of many research efforts since its commercial introduction following the patent of Edmonds and $\mathrm{Hill}^{2}$ in 1967. This activity has also been the subject of several reviews and overviews. ${ }^{3-6}$ Perhaps the most complete and relevant of the reviews are those of Lopez and Wilkes ${ }^{3}$ published 
in 1989, Hill and Brady ${ }^{5}$ published in 1991, and Cebe $e^{6}$ published in 1995. The review by Hill and Brady concentrates on work done at the Phillips Petroleum Company. These reviews give a good picture of the early work on neat PPS, but coverage of composites is light. The purpose of the present review is to (1) focus attention on methods of measuring crystallinity in PPS and its composites (2) give a critical examination of the data in the literature on the development of crystallinity with the aim of clarifying the reasons for the wide variation of crystallinity values reported in the literature, and (3) discuss the influence of crystallinity on the resulting properties of PPS and its fiber reinforced composites.

Depending on the details of the polymerization and thermal treatment processes three types of PPS resin can be prepared: linear, branched or slightly crosslinked. ${ }^{3,5,7}$ The branched form is prepared by polymerization in the presence of a small amount of a trifunctional monomer. The third type is formed by heat treatment (curing) of lower molecular weight resin in the presence of oxygen. Heat treatment increases the molecular weight by chain extension and slight crosslinking of the resin. The PPS can be prepared with a wide range of molecular weights, but typical commercial grades have average molecular weights in the range 18-70,000 and polydispersities $\left(\mathrm{M}_{\mathrm{w}} / \mathrm{M}_{\mathrm{n}}\right)$ of order 4-5. The lower molecular weights allow the polymer to flow readily during processing while maintaining good physical, chemical and mechanical properties in end uses.

When cooled rapidly from the melt PPS can be quenched to an amorphous state with a glass transition temperature in the neighborhood of $89^{\circ} \mathrm{C}$ (varying slightly with polymer microstructure and thermal history). But when PPS is cooled slowly it partially crystallizes. Crystallinity can also be achieved and/or improved by annealing amorphous PPS at temperatures above its glass transition temperature. The melting point of the crystals depends on the size of the crystals and therefore on the conditions used to generate them; typical values lie in the range $280^{\circ}-295^{\circ} \mathrm{C}^{3-5}$ The ability to crystallize, i.e., to develop crystallinity, allows PPS to exhibit good high temperature properties while also being capable of remelting in order to process it into desired shapes.

By definition a crystal is a portion of matter in which the atoms, ions or molecules are arranged in a three-dimensionally periodic array in space. The development of crystallinity in polymers requires both a sufficient degree of stereoregularity in the configuration of the polymer chain and the ability to pack the chains together in an efficient manner in order to create the periodic atomic arrangement that defines the structure of crystals. Because of the entanglement of the long chains in the melt and the difficulty of achieving the basic requirements for crystallization, bulk polymers can be either totally amorphous or partially crystalline, but never $100 \%$ crystalline. Partially crystalline polymers are often referred to as semicrystalline. The structure of semicrystalline polymers is often assumed to consist of two phases - crystalline and amorphous. In this two-phase model of the structure, the existence of an interfacial region between the crystals and the amorphous phase is ignored, though logic and careful measurements indicate that such a transition region is likely present. The fraction of the polymer that is crystalline is generally referred to as its crystallinity, and it is most commonly quoted as a mass fraction or a weight percentage. However, it must be recognized that some methods of measuring crystallinity tend to give a value that includes the transition region as part of the crystalline fraction and other methods may give a value that does not. For this reason and the fact that different techniques measure different quantities related to the crystallinity, they often give different values of the crystallinity for the same sample. Further, errors in application of the techniques can also be significant as discussed in subsequent paragraphs. 
The crystal structure of PPS was first studied by Tabor et al. ${ }^{8}$ and later confirmed by Lovinger et al. ${ }^{9}$ and Uemura et al. ${ }^{10}$ These investigators found that the unit cell is orthorhombic, space group Pbcn, with $\mathrm{a}=8.67 \AA, \mathrm{b}=5.61 \AA$ and $\mathrm{c}$ (chain axis) $=10.26 \AA$. Each unit cell contains four monomer units. Two polymer chains pass through each unit cell with one chain passing through the origin of the cell and the other through the center of the cell. The phenylene rings are alternately disposed at 45 and 135 degrees to the (100) plane as illustrated in Figure 1. Under certain conditions of preparation another structure was suggested, ${ }^{11,12}$ but the structure of Tabor appears to be the one obtained by different thermal and mechanical treatments. ${ }^{13}$
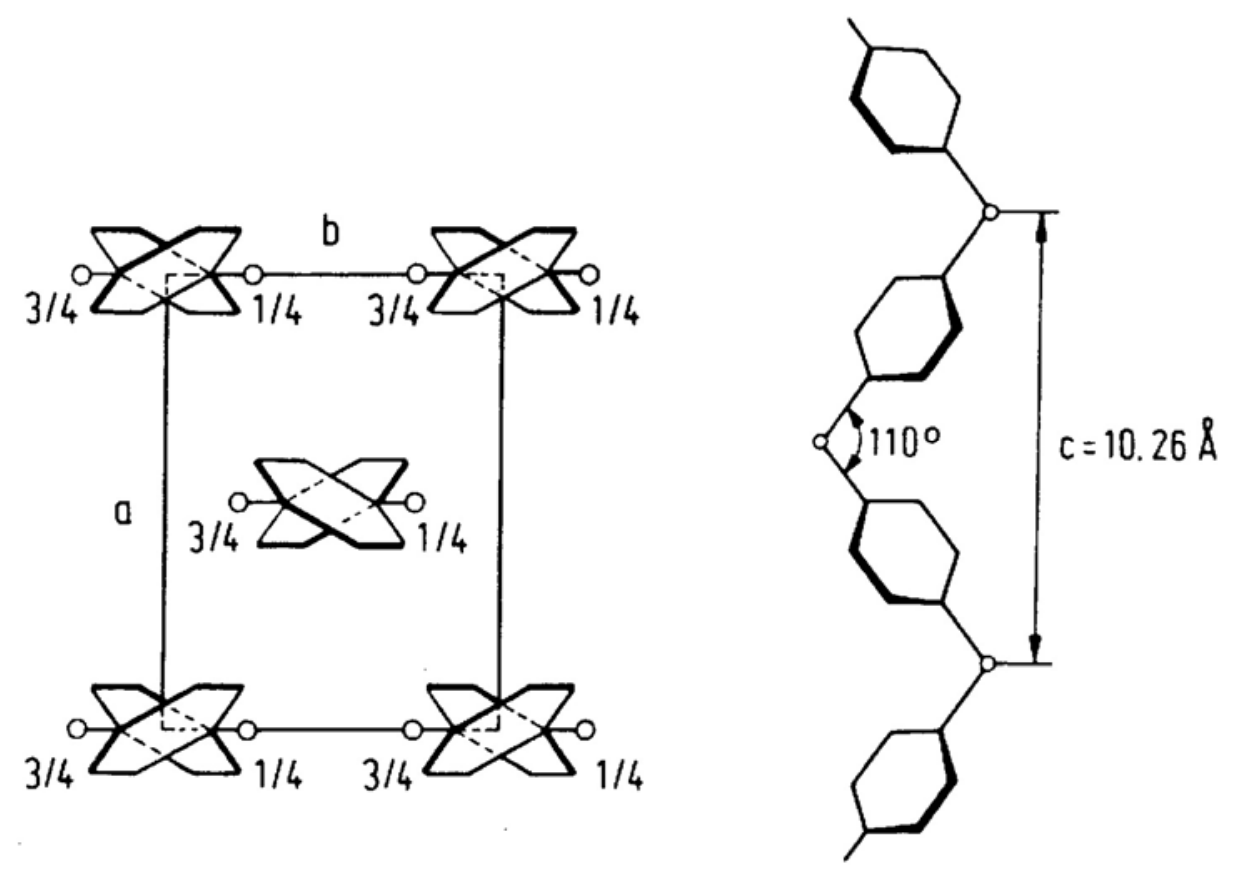

Figure 1. The crystal structure of PPS according to Tabor et al. ${ }^{6}$ At left is a projection on the $a-b$ plane; right shows the conformation of the chain and the $c$-axis repeat. 
This page left blank intentionally. 


\section{TECHNIQUES FOR MEASURING CRYSTALLINITY}

\subsection{Differential Scanning Calorimetry}

\subsubsection{Neat Polymer}

The most popular method of measuring crystallinity of polymers is by measuring the specific enthalpy of fusion (heat of fusion) of a partially crystalline sample and comparing this value to the value that would have been measured if the sample were $100 \%$ crystalline. The mass fraction crystalline, $X_{c}$, is given by

$$
X_{c}=\frac{\Delta H_{f}}{\Delta H_{f}^{o}} \text {. }
$$

This measurement is normally carried out using a differential scanning calorimeter (DSC). The popularity of this technique is based on its simplicity, ease of measurement, and the ready availability and highly developed technology of the DSC. The units of $\Delta H_{f}$ are energy/unit mass, e.g., J/g.

The technique requires a small sample, typically $2.0-15.0 \mathrm{mg}$, which is heated and melted in the DSC. The principle of the DSC is that the amount of energy required to heat the sample is monitored and compared to that required to heat a reference sample that does not undergo any phase change in the range of interest. The difference in energy between that required to heat the reference and that required to heat the sample gives an accurate measure of the thermal effects occurring in the sample.

In addition to its apparent simplicity a major advantage of the DSC method is that other thermal effects can also be measured. Examples include the glass transition temperature of the non-crystalline fraction, the cold crystallization temperature and enthalpy, and degradation effects. The cold crystallization temperature is the temperature at which crystallization initiates on heating an amorphous sample. A typical example of DSC curves for a PPS sample is shown in Figure 2. The sample was initially amorphous according to the manufacturer. Figure 2(a) shows the first heating cycle for the sample. In this example the glass transition temperature, $\mathrm{T}_{\mathrm{g}}$, is observed at $89^{\circ} \mathrm{C}$, a cold crystallization exotherm is observed at $126.54^{\circ} \mathrm{C}$, and the peak of the melting endotherm is observed at $280.48^{\circ} \mathrm{C}$.

The direct application of Equation 1 would only give the crystallinity after heating to a temperature just below the melting endotherm, and not the crystallinity of the original sample. Consequently, if the crystallinity of the original sample is desired, it is necessary to subtract the heat associated with the cold crystallization exotherm from the melting endotherm:

$$
X_{c}=\frac{\Delta H_{f}+\Delta H_{c}}{\Delta H_{f}^{o}} \text {. }
$$

Note that by convention, $\Delta H_{f}$ is positive and $\Delta H_{c}$ is negative. In the case of Figure 2(a) the heat of crystallization and of fusion have nearly the same magnitude and the sample has little or no crystallinity regardless of the value of $\Delta H^{0}$ used. 

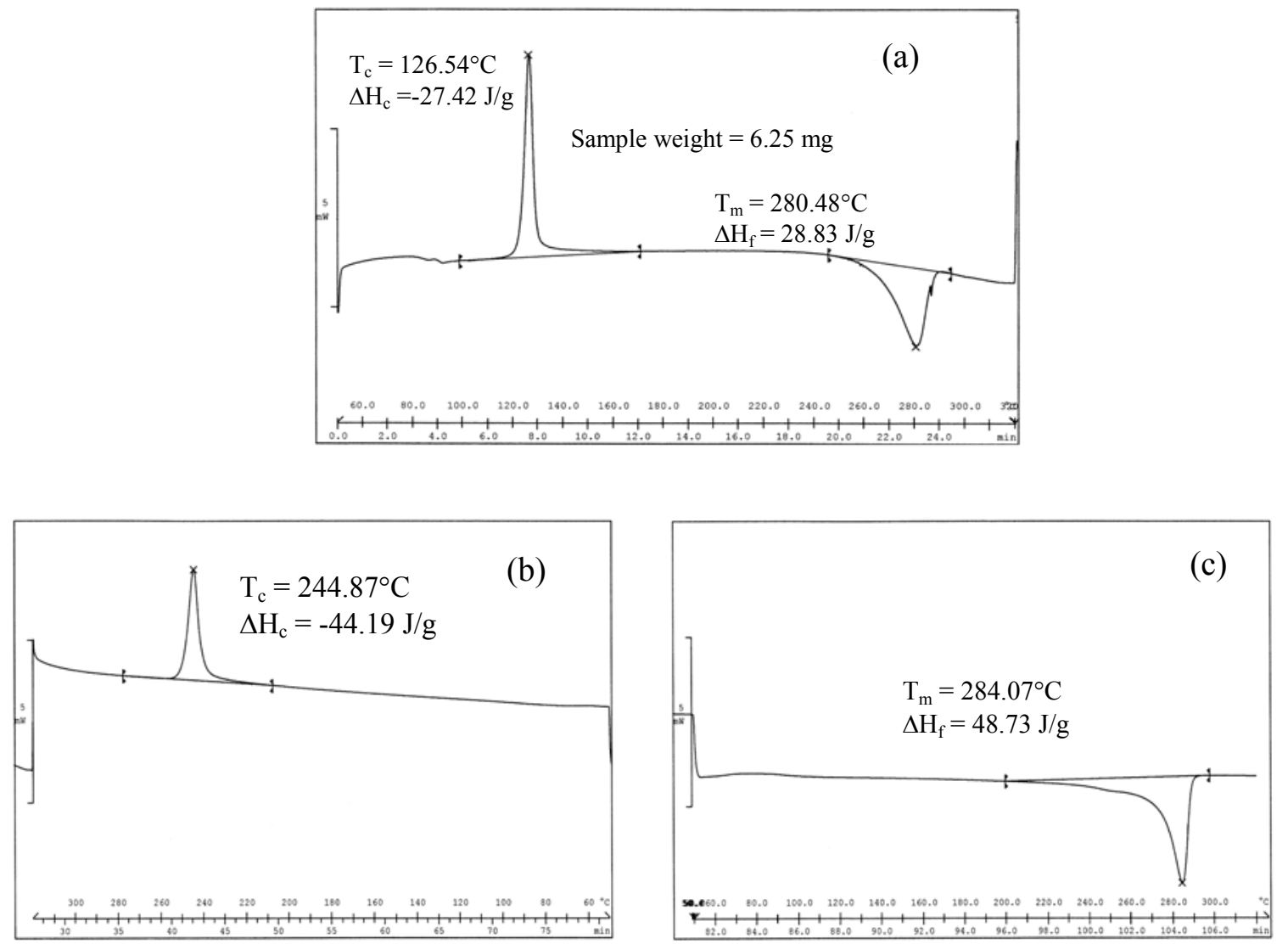

Figure 2. DSC curves of Fortron PPS film. According to manufacturer, sample is initially amorphous. (a) First heating cycle; (b) cooling cycle; (c) second heating cycle (reheat after slow cool).

The major sources of error in the measurement of crystallinity by DSC are: (1) accurate determination of $\Delta H_{f}^{0}$, (2) accurate measurement of $\Delta H_{c}$, and (3) dealing with recrystallization effects.

Values of $\Delta H_{f}^{0}$ found in the literature for PPS range from about $50 \mathrm{~J} / \mathrm{g}$ to $150.4 \mathrm{~J} / \mathrm{g}$. These differences are much too large to be due to differences in the nature of the polymers studied. The difficulty of obtaining an accurate value of $\Delta H_{f}^{0}$ is caused by the impossibility of obtaining a $100 \%$ crystalline sample. It is therefore necessary to obtain $\Delta H_{f}^{0}$ by indirect means. The most common methods of finding $\Delta H_{f}^{0}$ are (1) by extrapolation of measured values of $\Delta H_{f}$ as a function of some property such as specific volume or crystallinity (measured by some other technique such as X-ray diffraction, see later section) to an intercept corresponding to the value for $100 \%$ crystalline material, and (2) the measurement of melting point depression caused by addition of a low molecular weight diluent. Many investigators have used a value of $\Delta H_{f}^{0} \cong 80$ $\mathrm{J} / \mathrm{g}$, based on the early work of Brady. ${ }^{14}$ More recently, Huo and Cebe ${ }^{15}$ measured heat of fusion as a function of measured sample specific volume. Their result is presented in Figure 3 for a series of PPS samples of varying crystallinity. The theoretical specific volume of the crystalline phase is accurately obtained from its crystal structure. In the present case this is $0.6993 \mathrm{~cm}^{3} / \mathrm{g}$. Extrapolation of the data in Figure 3 to this value gives $24.8 \pm 0.8 \mathrm{cal} / \mathrm{g}$ or $103.8 \mathrm{~J} / \mathrm{g}$ for $\Delta H_{f}^{0}$. These authors also plotted measured heat of fusion versus crystallinity determined by X-ray diffraction. This resulted in a higher value of $\Delta H_{f}^{0}=112 \mathrm{~J} / \mathrm{g}$. Maemura et al. ${ }^{16}$ obtained a 
substantially higher value of $\Delta H_{f}^{0}=146.2 \mathrm{~J} / \mathrm{g}$ from extrapolation of $\Delta H_{f}$ versus specific volume. An even higher value of $\Delta H_{f}^{0}=150.4 \mathrm{~J} / \mathrm{g}$ was quoted by Ten Cate Advanced Composites. ${ }^{17}$ This value was determined in cooperation with University of Twente by a combination of X-ray diffraction and density measurements. ${ }^{18}$

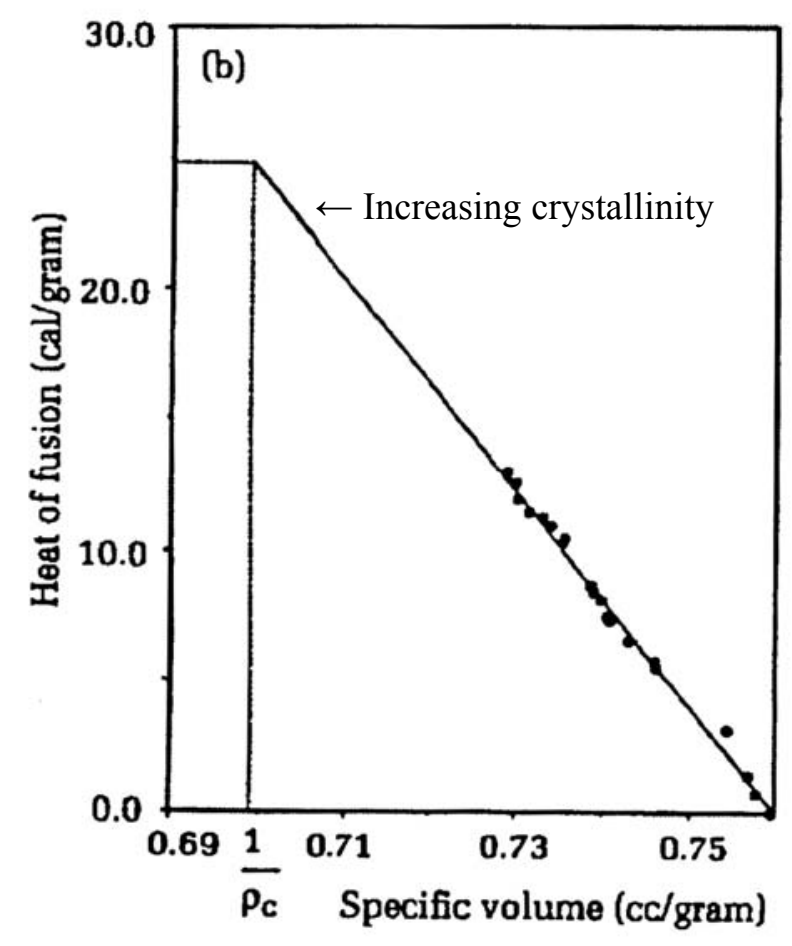

Figure 3. Heat of fusion as a function of specific volume of PPS (Data of Huo and Cebe ${ }^{15}$ ).

Extrapolation to the specific volume of the crystalline phase gives the value of

$$
\Delta H_{f}^{0}=24.8 \pm 0.8 \mathrm{cal} / \mathrm{g}(103.8 \mathrm{~J} / \mathrm{g}) .
$$

The measurement of $\Delta H_{f}^{0}$ based on melting point depression is feasible based on the theory of melting point depression developed by Flory ${ }^{19,20}$ and Huggins. ${ }^{21,22}$ Provided the diluent forms an ideal solution with the polymer or that the diluent is present in small concentrations, the following thermodynamic relationship is valid:

$$
\frac{1}{T_{m}}-\frac{1}{T_{m}^{o}}=-\frac{R}{\Delta H_{f}^{o}} \ln X_{A}
$$

where $T_{m}^{o}$ is the melting point of pure homopolymer and $T_{m}$ is the melting point of the sample containing mole fraction $X_{A}$ of polymer and $X_{B}$ of diluent. A plot of $1 / T_{m}$ versus $\ln X_{A}$ gives $\Delta H_{f}^{0}$ from the slope. To the authors' knowledge, this method has not yet been used to obtain the value of $\Delta H_{f}^{0}$ for PPS.

It is clear that the literature values of $\Delta H_{f}^{0}$ vary by substantial amounts and no one value is established well enough for acceptance. Consequently, if DSC measurements of crystallinity 
are to be used for anything other than "relative" measures of crystallinity, it is important that the value of $\Delta H_{f}^{0}$ be confirmed.

The use of Equation 2 also requires accurate measurement of both $\Delta H_{f}$ and $\Delta H_{c}$. When crystallinity is low, the error can be particularly high, as we are measuring a small difference between two larger numbers. The problem of accurate measurement of $\Delta H_{c}$ is caused by the fact that the heat of crystallization is often spread over a wide range of temperature making choice of baseline very inaccurate. There is also the possibility of a change in the heat capacity with crystallinity that can cause a shift in the baseline somewhat similar to that observed at the glass transition temperature. Even a slight variation in the choice of baseline can produce errors in both $\Delta H_{c}$ and $\Delta H_{f}$. These errors are compounded by the method of calculation of the crystallinity.

A final source of error is caused by the tendency for certain polymers, including PPS, to undergo melting and recrystallization during the heating required to measure $\Delta H_{f}$. The reason why this can occur is associated with the fact that the melting point of polymer crystals depends on the crystal size due to the influence of the crystal/amorphous interfacial energy. In most inorganic crystals the surface energy has a negligible effect on melting point due to the fact that it is small compared to the total energy of the crystal. But polymer crystals are generally much smaller and the surface energy is a much greater fraction of the total energy. This causes the melting point to decrease rapidly with decreasing crystal size. When crystallization from the melt is carried out at low temperatures or a partially amorphous polymer undergoes cold crystallization, the crystal size may be so small that the crystals melt and then recrystallize again on further heating. This sometimes leads to the observation of multiple melting peaks in DSC scans due to two sets of crystals in the sample with differing average crystal sizes. Multiple melting peaks are commonly observed in PPS. ${ }^{23,24,25}$ In the case that amorphous PPS samples were annealed at a temperature and time sufficient to eliminate the cold crystallization in the DSC scan, a small endotherm is often observed at a temperature somewhat above the annealing temperature (often about $15^{\circ} \mathrm{C}$ above the annealing temperature) ${ }^{26,27}$ This endotherm is thought to be associated with melting of small crystals formed during the annealing process, probably associated with secondary crystallization effects. In any case, this small endotherm should be included in the value of $\Delta H_{f}$ when applying Equation 2 or Equation 4, below.

\subsubsection{Thermoplastic Matrix Composites}

When DSC is used to measure the crystallinity of the thermoplastic matrix of composites we must account for the fact that the sample contains a certain weight fraction of the reinforcing fiber; e.g., carbon or glass fiber. In this case, Equation 2 must be rewritten as ${ }^{21}$

$$
X_{c}=\frac{\Delta H_{f}+\Delta H_{c}}{\left(1-W_{f}\right) \Delta H_{f}^{o}} \text {. }
$$

Here, $W_{f}$ is the weight fraction of reinforcing fiber in the composite.

Obviously, the error in $W_{f}$ also contributes to the error in $X_{c}$ as do all the other errors discussed above for the neat polymer. This error can be substantial due to variations in packing density from one point to another in the sample. 


\subsection{Specific Volume (Density)}

The mass fraction crystalline, $X_{c}$ is linearly related to the specific volume: ${ }^{28}$

$$
X_{c}=\frac{v-v_{a}}{v_{c}-v_{a}}
$$

Here, $v$ is the specific volume of the sample, $v_{a}$ is the specific volume of the amorphous fraction and $v_{c}$ is the specific volume of the crystalline fraction. Since $v=1 / \rho$ where $\rho$ is density, Equation 5 can be written as

$$
X_{c}=\frac{\frac{1}{\rho}-\frac{1}{\rho_{a}}}{\frac{1}{\rho_{c}}-\frac{1}{\rho_{a}}}=\frac{\rho_{c}}{\rho}\left(\frac{\rho-\rho_{a}}{\rho_{c}-\rho_{a}}\right)
$$

The volume fraction crystallinity can also be obtained:

$$
V_{c}=\frac{\rho-\rho_{a}}{\rho_{c}-\rho_{a}}=\frac{\rho}{\rho_{c}} X_{c}
$$

since $\rho$ and $\rho_{c}$ generally differ by a few percent, it is necessary to take care to specify ${ }^{8}$ whether volume or mass fraction has been determined.

Sample densities can be measured by pycnometer or by density gradient column. The density of the crystal, $\rho_{c}$, is computed from the crystal structure as previously mentioned and the amorphous density can be measured directly provided the polymer can be quenched to the amorphous state. If this is not possible, the density of molten polymer is measured as a function of temperature and then extrapolated to the temperature at which densities of the samples will be measured. In the case of PPS the former is possible. For PPS, $\rho_{c}=1.439 \mathrm{~g} / \mathrm{cm}^{3}$ based on the crystal structure of Tabor et al. Tabor quoted an amorphous density equal to $1.32 \mathrm{~g} / \mathrm{cm}^{3}$. Huo and Cebe ${ }^{13}$ later confirmed this value; they obtained a value of $1.3195 \mathrm{~g} / \mathrm{cm}^{3}$.

To apply this method to composites the density of the reinforcement must also be considered. In general, the method is not very useful for composites as tiny voids at the polymer/fiber interface and slight variations in fiber packing density can completely overshadow small changes in density associated with a change in crystalline fraction of the polymer.

\subsection{X-ray Diffraction}

\subsubsection{Neat Polymer}

$\mathrm{X}$-ray diffraction measures crystallinity directly, as opposed to other techniques that measure some property that depends on crystallinity. The presence of sharp Bragg peaks in a diffraction pattern is direct evidence of the existence of crystallinity in the material. The basis of crystallinity measurement by X-ray diffraction is the fact that the total coherent scattering from a sample is constant independent of the arrangement of the atoms in the sample. Thus, 


$$
\int I(\mathbf{s}) d V^{*}=\text { const. }
$$

here, I is the scattered intensity, $s$ is the diffraction vector whose magnitude $s=2 \sin \theta / \lambda$ where $\theta$ is the diffraction angle and $\lambda$ is the wavelength of the radiation, and $V^{*}$ is the volume element in reciprocal (diffraction) space. For a sample with no preferred orientation this integral can be written as

$$
\int I(\mathbf{s}) d V^{*}=4 \pi \int_{0}^{\infty} s^{2} I(s) d s
$$

and for a two-phase crystalline/amorphous system

$$
4 \pi \int_{0}^{\infty} s^{2} I(s) d s=4 \pi \int_{0}^{\infty} s^{2} I_{c}(s) d s+4 \pi \int_{0}^{\infty} s^{2} I_{a}(s) d s
$$

The integral on the left of Equation 10 is proportional to the total number of atoms, $N_{T}$, irradiated and the integrals on the right are proportional to the number in the crystalline phase, $N_{c}$, and in the amorphous phase, $N_{a}$, respectively. For a homopolymer, the composition of the crystalline and amorphous phase is the same. Therefore,

$$
X_{c}=\frac{N_{c}}{N_{T}}=\frac{\int_{0}^{\infty} s^{2} I_{c}(s) d s}{\int_{0}^{\infty} s^{2} I(s) d s} .
$$

The application of Equation 11 has taken several forms, the most rigorous being the analysis of Ruland. ${ }^{29}$ This analysis accounts for the fact that distortions of the first kind, such as thermal motion, and distortions of the second kind (paracrystallinity) both reduce the measured intensity of the sharp crystalline Bragg peaks and contribute a diffuse component that may be mistaken as part of the scattering from the amorphous phase. Ruland's analysis also corrects for the incoherent Compton modified scattering that is always present in the experimental data but is not included in Equation 11. Although Ruland's analysis is the most rigorous, it also requires considerable effort to perform, including conversion of the intensity to absolute units, and measurement over a wide range of scattering angles. Consequently, most investigators have used simpler, but less rigorous, methods to apply Equation 11. The most common approach appears to be a simple peak resolution method in which Equation 12 approximates Equation 11. Here, $A_{c}$ is the integrated intensity of the crystalline reflections, i.e., the area under the crystalline Bragg peaks on a plot of I versus $2 \theta, A_{a}$ is the area under the amorphous halo, and $\mathrm{K}$ is a constant that adjusts for the approximations made in Equation 12 compared to Equation 11. In the absence of better information $\mathrm{K}$ is often set equal to 1 . Subtraction of a background correction is also normally done. The range of $2 \theta$ values in which the equation is applied is often about 5-40 degrees, as this covers the most intense Bragg peaks for most semicrystalline polymers. Values of $X_{c}$ calculated by Equation 12 are frequently called "crystallinity indices" to distinguish them from actual crystalline fractions. 


$$
X_{c}=\frac{A_{c}}{A_{c}+K A_{a}} .
$$

Mo and Zhang ${ }^{30}$ introduced a slightly more rigorous approach that incorporates some of the ideas used in normal crystal structure analysis. Their analysis, referred to as the "graphic multipeak resolution method," modifies Equation 12 so as to account for the variations in atomic scattering factors and Lorentz-polarization factors with change in scattering angle. Equation 12 then becomes

$$
X_{c}=\frac{\sum_{i} C_{i, h k l} A_{i, h k l}}{\sum_{i} C_{i, h k l} A_{i, h k l}+k_{i} C_{a} A_{a}}
$$

where $A_{i, h k l}$ is the integrated intensity of the $h k l$ Bragg peak, $C_{i, h k l}$ is a correction factor for the crystalline Bragg peaks, $C_{a}$ is a correction factor for the amorphous scatter, and $k_{i}$ is the relative scattering coefficient which is the ratio of calculated diffraction intensity $\left(\sum I_{i, c a l}\right)$ to the total measured intensity for the crystalline polymer specimen of unit weight. Here

$$
C_{i, h k l}^{-1}=\left(\frac{1+\cos ^{2} 2 \theta}{\sin ^{2} \theta \cos \theta}\right) e^{-2 B(\sin \theta / \lambda)^{2}} \sum_{i} N_{i} f_{i}^{2}
$$

and $f_{i}$ is the atomic scattering factor of the atoms of type $i$ at the position of the $h k l$ Bragg peak and $N_{i}$ is the number of atoms of type $i$ in the polymer repeat unit. The first quantity in parentheses in Equation 14 is the familiar Lorentz/polarization factor with $\theta$ equal to the Bragg angle. The second term accounts for the effect of temperature in reducing the intensity of the Bragg peaks. The authors suggest that $2 \mathrm{~B}=10$ is a reasonable approximation for most polymers. An equation similar to Equation 14 is also used to compute $C_{a}$.

For PPS, Mo and Zhang have evaluated Equation 13 and give the result as

$$
X_{c}=\frac{A_{c}}{A_{c}+0.92 A_{a}}
$$

where $\mathrm{A}_{\mathrm{c}}=0.79 \mathrm{~A}_{110}+1.06 \mathrm{~A}_{200}+2.07 \mathrm{~A}_{112}+2.63 \mathrm{~A}_{211}$. Generally, this equation would be expected to give somewhat higher values of crystallinity than would be given by direct application of Equation 12.

The major advantages of X-ray scattering for measurement of crystallinity are:

(1) The method measures crystallinity of the sample in whatever state the sample exists; no crystallization or recrystallization effects occur that change the state of the sample. Likewise the method does not depend on the absence of voids in the sample.

(2) The method depends only on measurement of the intensity of scattering and not on the accuracy of some independent quantity that itself is difficult to measure. For this reason, when carried out properly, the X-ray technique is considered by most investigators to give the most reliable values of crystallinity of any of the available techniques. 
The major disadvantage of the X-ray technique is that its proper application requires careful time-consuming measurements and detailed analysis. These factors cause the technique to be expensive to apply. The technique generally requires larger samples than the DSC or density techniques. Major sources of error in the technique include:

(1) The accuracy with which the diffraction pattern is recorded. This is usually related to the counting statistics associated with recording the intensity data. Longer counting times and higher incident beam intensities give better counting statistics for a given sample.

(2) The accuracy of the background correction associated with removal of extraneous scattering from such sources as air scatter.

(3) The accuracy of the separation of the scattering from the crystalline and amorphous fractions. This process is improved with modern curve fitting routines, but is almost always an important source of error.

(4) The approximations used in the analysis; i.e., whether Ruland's method or some other more approximate method is used.

\subsubsection{Thermoplastic Polymer Composites}

The presence of a reinforcing fiber will inevitably cause some overlap of scattering from the fiber with that from the thermoplastic matrix. This will make the analysis of crystallinity in the matrix polymer somewhat more difficult as the scattering from the fiber must be separated from the scattering from the matrix. ${ }^{31}$ Earlier methods often made approximations that led to substantial error. However, curve-fitting software available with modern diffractometers makes separation both feasible and accurate. An example of this for the case of carbon fiber reinforced PPS is discussed below.

\subsection{Other Techniques}

\subsubsection{Fourier Transform Infrared (FTIR)}

The infrared spectrum of semicrystalline polymers often contains peaks that are sensitive to the amount of crystallinity in the sample. The ratio of the intensity of such a peak to that of a peak that is insensitive to the level of crystallinity is often used as a relative measure of crystallinity. Various types of infrared spectra can be obtained depending on the nature of the sample and equipment arrangement and capability. For example, spectra are often obtained in transmission for very thin films or powdered samples, while specular or diffuse reflection can be used for bulk samples. Attenuated total reflection is used to examine a thin surface layer on the surface of a sample. A major advantage of FTIR is that the technique is rapid and nondestructive. But its use for an absolute measure of crystallinity depends on careful correlation with some other method of crystallinity measurement. In addition, in order to fully characterize the crystallinity of the sample several FTIR spectra should be obtained due to the penetration limitations of the IR light source and the homogeneity of the crystalline phase distribution across the sample. Depending upon the processing history of the sample, the crystallinity could vary throughout the thickness, especially for thicker samples, possibly yielding increasingly higher levels of crystallinity towards the middle of the sample where the rate of cooling could have been lower compared to that of the sample surface. 


\subsubsection{Dynamic Mechanical Analysis (DMA)}

A few authors have used measurement of dynamic storage modulus, $E$ ', as a function of temperature to extract crystallinity data. This method would seem, at first examination, to be a fairly sensitive method as the modulus of an amorphous polymer decreases by about 3 orders of magnitude on passing through the glass transition temperature. For a semicrystalline polymer the drop is much less as the crystals increase the modulus compared to the amorphous rubbery state. Thus, the fractional drop in modulus on heating through the $\mathrm{T}_{\mathrm{g}}$ should be a good indicator of the degree of crystallinity present in the sample. Khanna ${ }^{32}$ proposed the following empirical equation for this purpose:

$$
X_{c}=1-\frac{\left[\log E^{\prime}\left(T_{g}\right)-\log E^{\prime}\left(T_{m}\right)\right]_{\text {sample }}}{\left[\log E^{\prime}\left(T_{g}\right)-\log E^{\prime}\left(T_{m}\right)\right]_{\text {amorphous }}} .
$$

This approach appears to yield good relative values of $X_{c}$, and would be useful for obtaining qualitative differences between samples having varying degrees of crystallinity, but is not capable in this form to give true quantitative crystalline fractions. It would also seem to give better results for samples with low crystallinity. For more elaboration on the DMA technique, see the later section on creep and viscoelasticity.

\subsection{Examples of Crystallinity Measurement}

\subsubsection{DSC Measurement on Neat PPS}

The data of Figure 2 illustrate the measurement of crystallinity for neat PPS film. As already mentioned the value of crystallinity for this as-received film sample is very low regardless of the value of $\Delta H_{f}^{o}$ used, since $\Delta H_{c}=-27.42 \mathrm{~J} / \mathrm{g}$ and $\Delta H_{f}=28.83 \mathrm{~J} / \mathrm{g}$ and their sum is very small. But if we wish to know the crystallinity after cooling back to room temperature from $320^{\circ} \mathrm{C}$, the value of $\Delta H_{f}^{o}$ used is critical. Assuming that the heat of crystallization measured during cooling represents the negative of the heat of the heat required to melt the sample, and using the value of $112 \mathrm{~J} / \mathrm{g}$ proposed by Huo and Cebe ${ }^{15}$ based on extrapolation of X-ray crystallinity data gives

$$
X_{c}=\frac{\Delta H_{f}+\Delta H_{c}}{\Delta H_{f}^{o}}=\frac{44.19}{112}=0.395 .
$$

If the value of $80 \mathrm{~J} / \mathrm{g}$ used by many investigators is used

$$
X_{c}=0.552 \text {. }
$$

But if the Ten Cate value of $150.4 \mathrm{~J} / \mathrm{g}$ is used then

$$
X_{c}=0.294
$$


These substantial differences show the overriding importance of obtaining an accurate value of $\Delta H_{f}^{o}$ if accurate crystallinity values are to be obtained by DSC.

Finally, application of Equation 2 to the data for the second heating cycle (reheat after cooling from $320^{\circ} \mathrm{C}$ ) with the Ten Cate ${ }^{17}$ value of $\Delta H_{f}^{o}$, gives $X_{c}=0.324$. The difference between this value and the value for cooling, Equation 19, indicates that some additional crystallization occurred during the second heating cycle.

\subsubsection{DSC Measurement on PPS/Carbon Fiber Composite}

A sample of PPS/carbon fiber composite was examined in the as-received condition. The sample consisted of 40 wt.\% Ticona Fortron 0214 PPS and 60 wt.\% Hexcel AS4 carbon fiber. The processing conditions were unknown except that the sample had been prepared by common composite preparation techniques and given a cooling cycle aimed at obtaining good mechanical properties. The original sample was in the form of a $20 \mathrm{X} 18$ in. rectangular sheet about $1 / 8^{\text {th }}$ in. thick. Several small pieces were cut from this sheet for the DSC measurements. A DSC scan on one of these pieces weighing $14.4 \mathrm{mg}$ at a scan rate of $10^{\circ} \mathrm{C} /$ second exhibited a glass transition at $89^{\circ} \mathrm{C}$, a small exotherm associated with "cold crystallization" during the heat-up at about $110^{\circ} \mathrm{C}$, and a peak melting temperature of $280^{\circ} \mathrm{C}$. The measured specific enthalpy of melting $\Delta H_{f}=22.9$ $\mathrm{J} / \mathrm{g}$ and the enthalpy associated with the cold crystallization $\Delta H_{c}=-3.4 \mathrm{~J} / \mathrm{g}$. Again, using the value of $\Delta H_{f}^{o}$ proposed by Huo and Cebe of $112 \mathrm{~J} / \mathrm{g}$, Equation 4 gives

$$
X_{c}=\frac{22.9-3.4}{(0.4)(112)}=0.435
$$

But, if the value quoted by Ten Cate is used

$$
X_{c}=\frac{22.9-3.4}{(0.4)(150.4)}=0.324
$$

Because of the lack of knowledge of the true value of $\Delta H_{f}^{o}$, some investigators have used only a relative measure of crystallinity based on the maximum experimentally measured value of $\Delta H_{f}$ for the given polymer. The result is given as a percentage of the maximum crystallinity. In the present case, this approach would give a value of order $85 \%$.

\subsubsection{X-ray Diffraction Measurement on PPS/Carbon Fiber Composite}

A measurement of crystallinity by X-ray diffraction was also carried out on a second asreceived composite sample of the same PPS materials used for the DSC measurement described above. In this case a 1-inch square X-ray sample was cut from the original sheet. The X-ray scattering was measured by a Philips MRD X-ray diffractometer operated at $45 \mathrm{kV}$ and $40 \mathrm{~mA}$ using $\mathrm{CuK} \alpha$ radiation monochromated by a graphite crystal. The data were collected using 0.02 degree increments between data points and a 3 second dwell time. A diffraction pattern of the neat AS4 fiber was also obtained using the same conditions. The raw diffraction pattern of the AS4 fiber is presented in Figure 4, while Figure 5 shows the pattern of the as-received 
composite. It is clear that the 002 and 100/101 reflections of the carbon fiber overlap significantly the pattern for the PPS matrix. Figure 5 also shows the pattern components as separated by the Profit peak fitting software supplied with the Philips diffractometer.

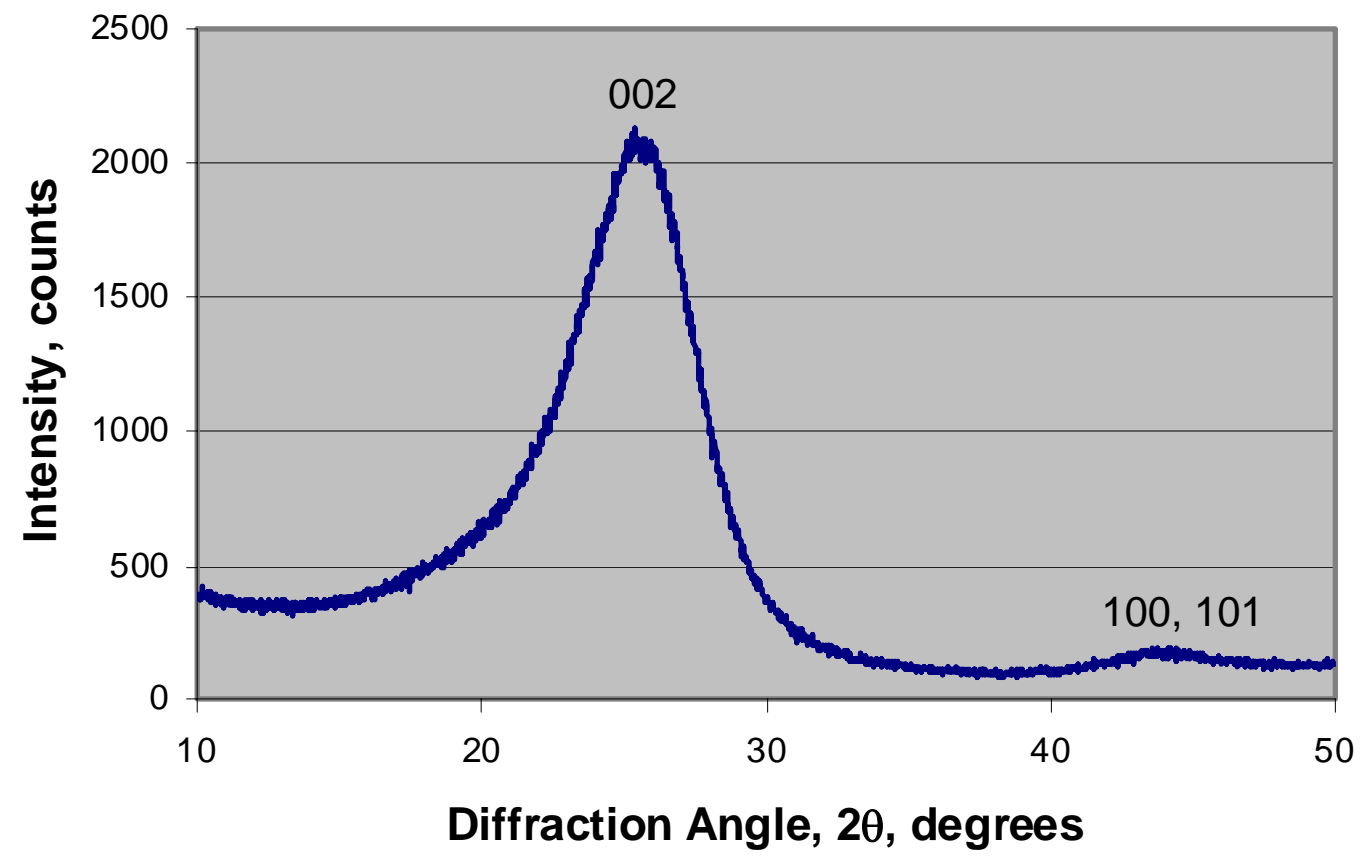

Figure 4. X-ray diffraction pattern of neat AS4 carbon fiber.

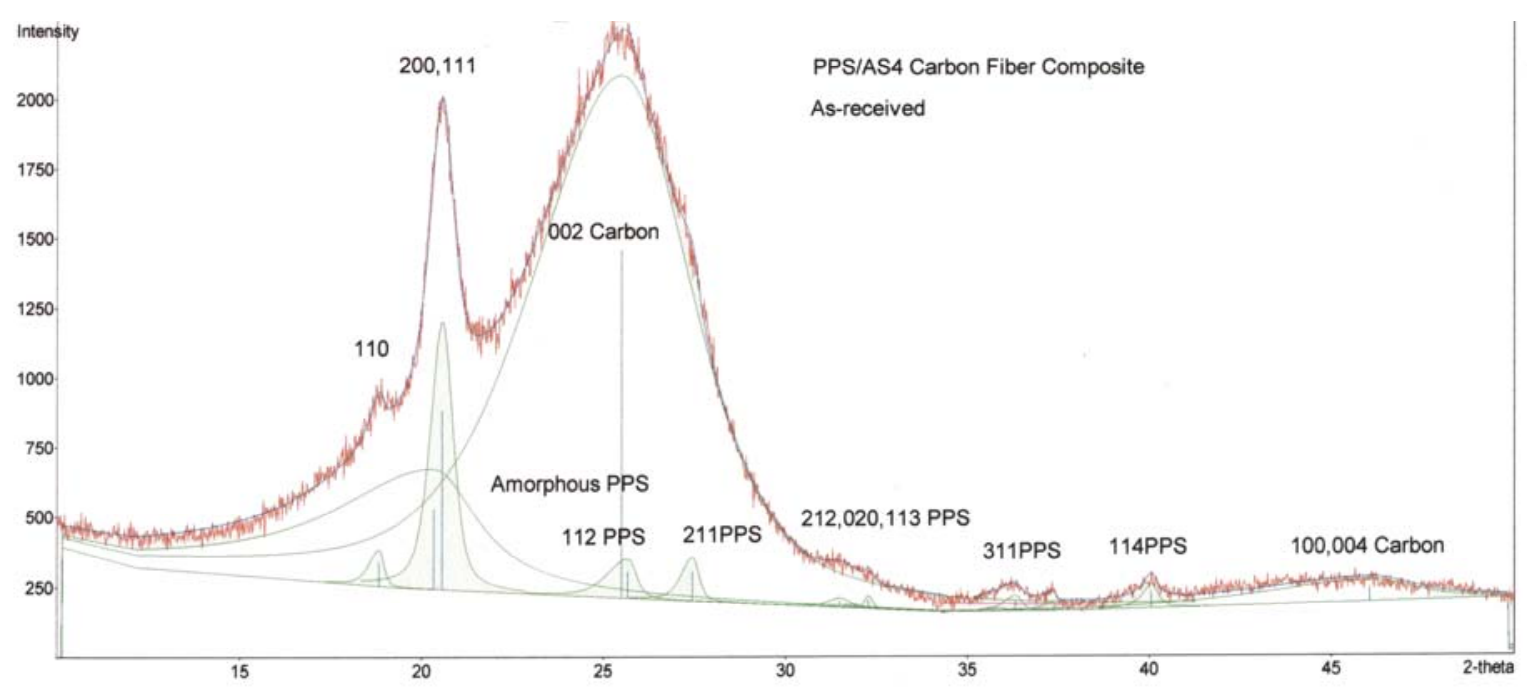

Figure 5. Diffraction pattern of as-received PPS/AS4 Carbon Fiber Composite (60 wt.\% fiber) showing the profile fitting and separation into the crystalline and amorphous peaks from PPS and from carbon fiber. 
The software also gives the integrated intensities of each component of the pattern. These values are tabulated in Table 1.

Table 1. Observed Diffraction Peaks for as-Received PPS/Carbon Fiber Composite

\begin{tabular}{ccccc}
\hline Peak & hkl & $2 \theta$ & Integrated Intensity & Material \\
\hline 1 & 110 & 18.84 & 2,790 & PPS \\
2 & -- & 20.34 & 109,150 & Amorphous PPS \\
3 & 200,111 & 20.57 & 31,281 & PPS \\
4 & 002 & 25.52 & 430,057 & Carbon Fiber \\
5 & 112 & 25.68 & 5,807 & PPS \\
6 & 211 & 27.45 & 3,955 & PPS \\
7 & 212 & 31.51 & 1,081 & PPS \\
8 & 020 & 31.92 & 368 & PPS \\
9 & 113 & 32.28 & 543 & PPS \\
10 & 311 & 36.31 & 1,429 & PPS \\
11 & 114 & 40.05 & 2,231 & PPS \\
12 & 100,101 & 46.05 & 17,235 & Carbon Fiber \\
\hline
\end{tabular}

Application of Equation 12 with $\mathrm{K}=1$ gives

$$
X_{c}=\frac{51,172}{51,172+109,150}=0.319
$$

but, application of Equation 15 gives

$$
X_{c}=\frac{57,782}{57,782+0.92(109,150)}=0.365
$$

Note that in this example, the latter value is in reasonable agreement with the value obtained from the DSC measurement only if the Ten Cate value of $\Delta H_{f}^{o}$ is used to interpret the DSC data. This result suggests, but does not prove, that this may be the more accurate value.

Since it has been argued in the literature ${ }^{33}$ that measurement of crystallinity by X-ray diffraction includes both the crystalline core and the interphase region while DSC measures only the core we expect the crystalline fraction determined by X-ray to be greater than that determined by DSC. This is the case only if we compare the result of Equation 23 to that of Equation 21. A somewhat higher value of X-ray crystallinity would, no doubt, be obtained using Ruland's method. Unfortunately, this method is not readily applied to the composite samples. On the other hand, it seems unlikely that the value would be equal to or greater than the value found using DSC and Huo and Cebe's value of $\Delta H_{f}^{o}$.

\subsubsection{FTIR Measurement of Crystallinity}

The work of $\mathrm{Yu}$ et $\mathrm{al}^{34}$ provides a recent example of the use of FTIR to measure crystallinity of PPS. These authors carried out measurements in transmission on $12 \mu \mathrm{m}$ thick films. They argued that the intensity of the absorption peak at $1073 \mathrm{~cm}^{-1}$ is determined by the 
amount of amorphous material present in the sample. Thus, this absorption band can be used to estimate the relative amount of amorphous phase.

Cole et al. ${ }^{27}$ have developed a diffuse reflection FTIR technique to measure the crystallinity of PPS/carbon fiber composites. They found a good correlation between the specific enthalpy of crystallization (not fusion) measured by DSC and the ratio of peak heights at 1075 and $1093 \mathrm{~cm}^{-1}$. A plot of the peak ratio versus specific enthalpy of crystallization measured by DSC is shown in Figure 6 for initially amorphous prepreg annealed at $105^{\circ} \mathrm{C}$. The following relation with a squared correlation coefficient of 0.983 gives the correlation:

$$
\frac{I_{1075}}{I_{1093}}=0.442+0.0117 \Delta H_{\text {crys }} .
$$

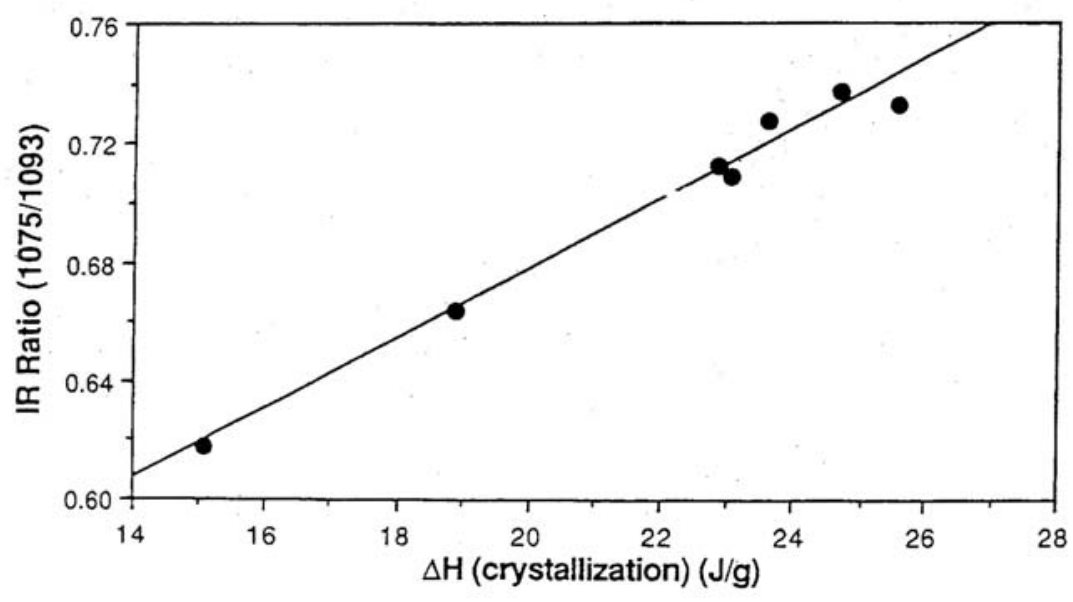

Figure 6. Ratio of IR band intensities versus heat of crystallization measured on crystallization from the quenched amorphous state (from Cole et al. ${ }^{27}$ )

These authors also suggested a relationship between the IR intensity ratio and crystallinity. This relation is in error, however, due to the fact that it is based on the value of $\Delta H_{f}^{o}=80 \mathrm{~J} / \mathrm{g}$. It does appear that this method could be adapted to measure crystallinity using an appropriate value of the specific enthalpy of fusion of $100 \%$ crystalline PPS. Since it is a reflection technique, it can be applied to bulk samples and is also nondestructive. Thus, it might be useful as a quality control method.

It is worth noting that whatever technique is ultimately used to fully determine the crystallinity of a sample, several measurements should be obtained throughout the sample thickness. This is especially true for thicker samples since differential cooling rates could have possibly been experienced throughout the sample thickness resulting in varying degrees of crystallinity. 
This page left blank intentionally. 


\section{CRYSTALLINITY AS A FUNCTION OF PRIOR TREATMENT}

The crystallinity of PPS and its fiber-reinforced composites varies greatly with processing conditions, especially the cooling rate from the melt and any annealing treatments. An examination of the literature also shows that the values obtained by different investigators for similar polymers and processing conditions also vary widely. The most probable reason for this is that different investigators used different techniques to determine crystallinity. And, even when the same technique was used, large differences arose from the details of the application of the technique. In particular, most early investigators using the DSC technique used a value of $\Delta H_{f}^{o} \cong 80 \mathrm{~J} / \mathrm{g}$, while more recent investigators favor the much higher values described above. In what follows, we give typical results from the literature without any attempt to be exhaustive in describing all the conditions that have been studied or in dealing with the numerous references that have involved measurement of crystallinity of PPS. For DSC values, we give both the original values and values that are normalized to the case of $\Delta H_{f}^{\circ}=150.4 \mathrm{~J} / \mathrm{g}$ so that all results can be compared on the same basis.

One of the earliest (1976) and most quoted papers dealing with crystallinity development in PPS is that of Brady. ${ }^{14}$ Brady examined several methods to determine crystallinity. He found that density values were erratic and unreliable, perhaps due to the presence of tiny voids in the samples. Infrared techniques were also judged to be inadequate. He found heat of fusion values to be consistent, but did not convert these data to crystallinity values due to "complications" associated with the "tendency of amorphous samples to crystallize during analysis." There was also no readily available value of $\Delta H_{f}^{o}$ to use at the time of this early work. Brady determined a "crystallinity index" by X-ray diffraction and concluded that this was the most reliable and reproducible technique. His method was essentially that described by Equation 12 with $\mathrm{K}=1$. By this method he found that crystallinity increased rapidly on heating an amorphous sample above $\mathrm{T}_{\mathrm{g}}$ and then much more slowly with increased annealing time at temperature. For example, annealing at $204^{\circ} \mathrm{C}$ for 5 minutes resulted in a crystallinity index of about $55 \%$ and further annealing (240 minutes) increased this value to about $65 \%$. The data in Figure 7 shows that asmolded PPS crystallinity is a strong function of mold temperature. Mold temperatures below $\mathrm{T}_{\mathrm{g}}$ give very low values of the crystallinity index on the surface of the molded sample $(\leq 5 \%)$. The crystallinity index increases as mold temperature increases above $T_{g}$ and becomes asymptotic to the curve for samples annealed at $204^{\circ} \mathrm{C}$ for 120 minutes at temperatures approaching the annealing temperature. This value is about $60 \%$.

Figure 8 shows heat of fusion data presented by Brady for initially amorphous samples that were annealed at $204^{\circ} \mathrm{C}$. These data indicate a specific enthalpy of fusion of about $50.2 \mathrm{~J} / \mathrm{g}$ after annealing for 160 minutes. Later investigators appear to have combined this result with the $\mathrm{X}$-ray crystallinity index result to give

$$
\Delta H_{f}^{o}=\frac{\Delta H_{f}}{X_{c}}=\frac{50.4}{0.60}=84 \mathrm{~J} / \mathrm{g} .
$$

Many investigators then used this value to obtain crystallinity from their DSC data. As already mentioned, this value appears to be too low as established by later investigators. Reinterpretation 
of Brady's heat of fusion data using $\Delta H_{f}^{o}=150.4 \mathrm{~J} / \mathrm{g}$ gives $X_{c}=0.334$ or about $33 \%$ crystallinity for the sample annealed 160 minutes at $204^{\circ} \mathrm{C}$.

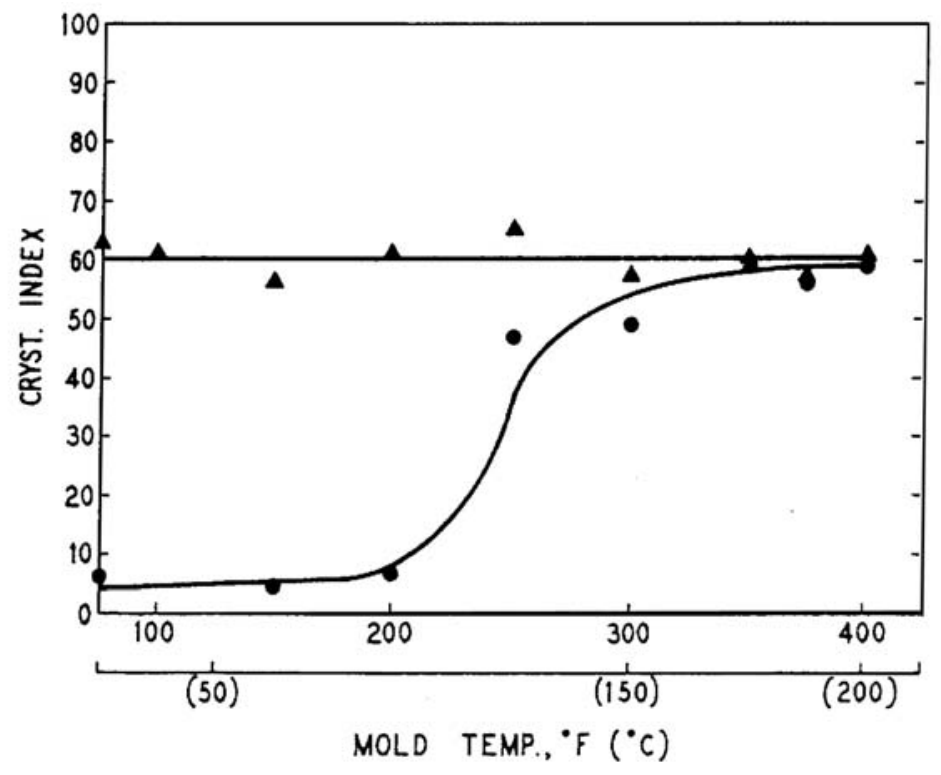

Figure 7. Effect of mold temperature and annealing on crystallinity of PPS. (•) as molded; (ム) annealed $2 \mathrm{hrs}$ at $204^{\circ} \mathrm{C} .\left(\operatorname{Brady}^{14}, 1976.\right)$

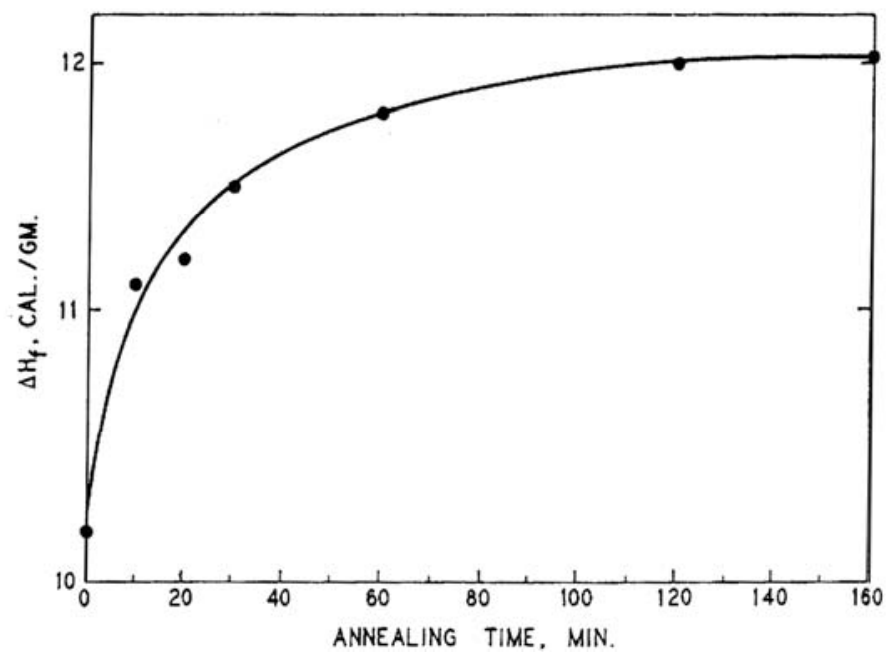

Figure 8. Increase of heat of fusion on annealing at $204^{\circ} \mathrm{C}$. Note that the maximum heat of fusion obtained is about $12.05 \mathrm{cal} / \mathrm{g}(50.4 \mathrm{~J} / \mathrm{g})$. $\left(\right.$ Brady $\left.^{14}, 1976.\right)$

Auer et al. ${ }^{35}$ measured the degree of crystallinity of isothermally crystallized neat PPS and composites containing glass, carbon and aramid fibers. The measurements were made by determining the specific enthalpy given up during the crystallization process at the isothermal holding temperature rather than reheating the sample after completion of crystallization. They 
used the value of $\Delta H_{f}^{o}=80 \mathrm{~J} / \mathrm{g}$ to obtain the final crystalline fractions. Their results are shown in Figure 9 where it is observed that the crystallinity varies with both the crystallization temperature and the presence and nature of the reinforcing fibers. According to Figure 9, the \% crystallinity appears to saturate at about $60 \%\left(X_{c}=0.60\right)$. However, when this value is normalized to $\Delta H_{f}^{o}=150.4 \mathrm{~J} / \mathrm{g}$ the maximum crystallinity is found to be about $32 \%$. The values on the low end of the range given as $35 \%$ are only $18.6 \%$ when normalized.

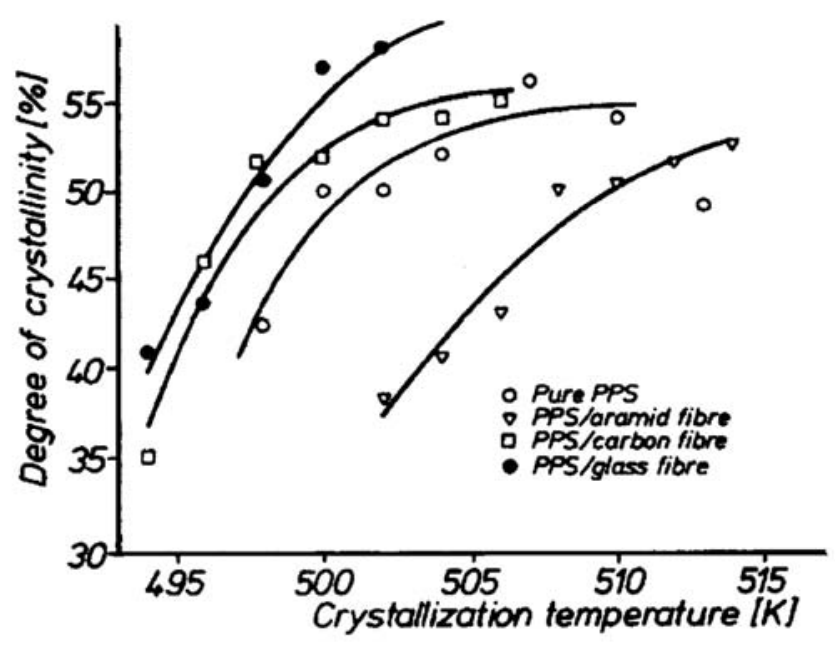

Figure 9. Crystallinity as function of crystallization temperature in Kelvin for neat PPS and some PPS composites (from Auer et al. ${ }^{35}$, 1994).

Desio and Rebenfeld ${ }^{36}$ also studied the effect of fiber reinforcement on the crystallinity of PPS as a result of isothermal crystallization. They prepared model composites from Ryton PPS resin and a variety of carbon, glass and aramid fibers. The final crystallinity of the neat resin was similar to that found by Auer et al., though the rate of crystallization differed (see later section on kinetics). And they observed a decrease of crystallinity with the addition of carbon fiber as opposed to the increase observed by Auer et al. They also observed a difference in the final crystallinity and its variation with temperature depending whether the carbon fiber had been sized or not. Their results for the carbon fiber composites are shown in Figure 10. The strange behavior of the composites containing sized AS4 and Thornel T300 fibers were not fully explained. Note that the crystallinity values were computed assuming $\Delta H_{f}^{o}=80 \mathrm{~J} / \mathrm{g}$.

T.H. Lee et al. ${ }^{26}$ used DSC and DMA to study the effects of annealing on the crystallinity of PPS/glass fiber composites. They obtained experimental data for both $20 \%$ and $40 \%$ glassfilled PPS. The samples were first quenched from $320^{\circ} \mathrm{C}$ and then annealed at different temperatures and times. Selected data for $20 \%$ glass fiber are shown in Table 2. Annealing for longer than 30 minutes at $140^{\circ} \mathrm{C}$ eliminated the exotherm associated with cold crystallization. At temperatures and times where cold crystallization was not observed, a small endotherm $\Delta H_{m}$ was observed prior to the major endotherm associated with final melting of the sample. This small endotherm is presumably associated with melting of small crystals that were produced during the annealing treatment and were assigned to the secondary crystallization process. These quantities were therefore included as a part of the final specific enthalpy of melting for the purpose of computing crystallinity. These authors reported very high values of crystallinity as noted in 
column 6 of Table 2, but these values are based on a totally erroneous value of $\Delta H_{f}^{o}=50.0 \mathrm{~J} / \mathrm{g}$. In column 7 we give the values of DSC crystallinity based on $\Delta H_{f}^{o}=150.4 \mathrm{~J} / \mathrm{g}$. Using either these values or comparing the $\Delta H_{f}+\Delta H_{c}$ values directly, their results are similar in magnitude to other values reported above. Comparable values were obtained for $40 \%$ glass-filled composites. Their results also show that, while crystallinity increases somewhat with crystallization temperature (up to $204^{\circ} \mathrm{C}$ ) and time, most of the crystallization occurred at a critical annealing time that decreased with increasing temperature.

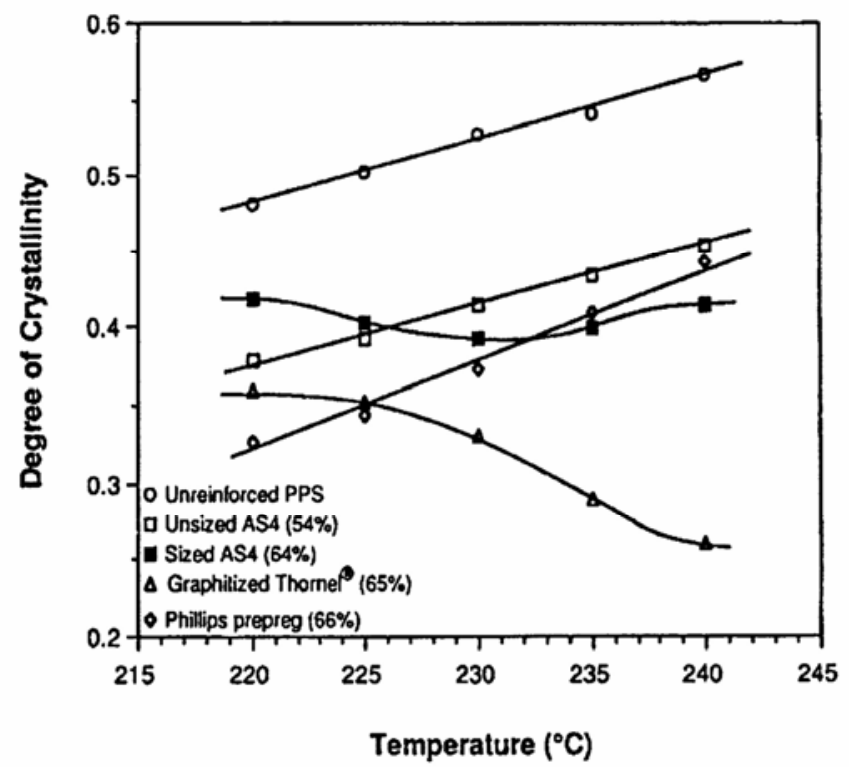

Figure 10. Crystallinity as a function of crystallization temperature for neat PPS and some carbon fiber composites (from Desio and Rebenfeld ${ }^{36}$, 1992).

Table 2. Influence of Annealing Temperature and Time on the Crystallinity of $20 \%$ Glass Fiber/PPS Composite (Data of Lee et al. ${ }^{26,37}$ )

\begin{tabular}{ccccccccc}
\hline & Time & $\Delta \mathrm{H}_{\mathrm{c}} / \Delta \mathrm{H}_{\mathrm{m}}$ & $\Delta \mathrm{H}_{\mathrm{f}}$ & $\Delta \mathrm{H}_{\mathrm{f}}+\Delta \mathrm{H}_{\mathrm{c}}$ & $\mathrm{X}_{\mathrm{c}}(50 \mathrm{~J} / \mathrm{g})$ & $\mathrm{X}_{\mathrm{c}}(150.4 \mathrm{~J} / \mathrm{g})$ & $\mathrm{X}_{\mathrm{c}}(\mathrm{XRD})$ & $\mathrm{X}_{\mathrm{c}}(\mathrm{DMA})$ \\
\hline $\mathrm{T}=140^{\circ} \mathrm{C}$ & 10 & -15.959 & 26.198 & 10.239 & 0.2560 & 0.0851 & 0.0 & 0.0453 \\
& 30 & -16.781 & 31.091 & 14.31 & 0.3578 & 0.1189 & 0.0 & 0.0291 \\
& 60 & 0.309 & 27.852 & 28.161 & 0.7040 & 0.2341 & 0.534 & 0.6226 \\
& 120 & 0.811 & 28.171 & 28.982 & 0.7246 & 0.2409 & 0.526 & 0.6331 \\
$\mathrm{~T}=180^{\circ} \mathrm{C}$ & 10 & -18.923 & 29.962 & 11.039 & 0.2760 & 0.0917 & 0.0 & 0.0281 \\
& 30 & 1.019 & 30.546 & 31.565 & 0.7891 & 0.2623 & 0.561 & 0.7141 \\
& 60 & 1.163 & 32.77 & 33.933 & 0.8483 & 0.2820 & 0.582 & 0.6972 \\
$\mathrm{~T}=204^{\circ} \mathrm{C}$ & 10 & -17.102 & 24.603 & 7.501 & 0.1875 & 0.0623 & 0.0 & 0.0695 \\
& 30 & 1.034 & 30.436 & 31.47 & 0.7868 & 0.2616 & 0.645 & 0.7680 \\
& 60 & 1.548 & 27.647 & 29.195 & 0.7299 & 0.2426 & 0.604 & 0.7655 \\
& 120 & 2.147 & 29.993 & 32.14 & 0.8035 & 0.2671 & 0.640 & 0.7754 \\
\hline
\end{tabular}


DMA data for some of the $20 \%$ glass-filled samples annealed at $204^{\circ} \mathrm{C}$ are shown in Figure 11. Based on these data they modified Equation 16 to use the values of $E$ ' just before the onset of $\mathrm{T}_{\mathrm{g}}$ and just after the completion of the transition. These values were taken at quite different temperatures depending on the level of crystallinity in the sample. Some examples of the results of the DMA measurements are given in the last column of Table 2.

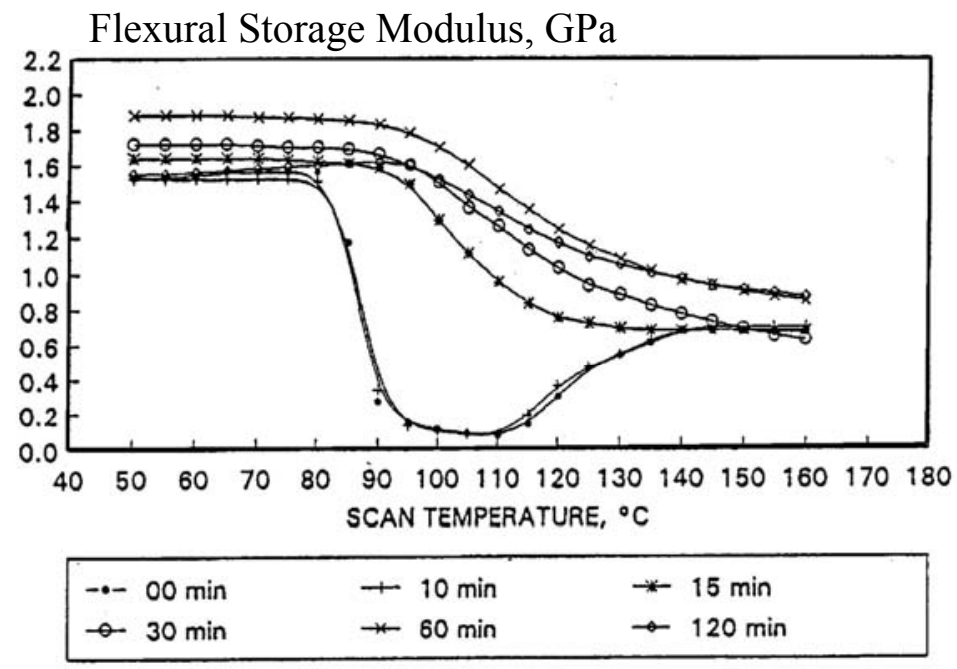

Figure 11. Storage modulus versus temperature for $20 \%$ glass fiber/PPS composites on annealing at $204^{\circ} \mathrm{C}$ for the indicated times (from Lee et al. ${ }^{26}$ ). .

Lee et al. ${ }^{37}$ also used an X-ray diffraction technique to obtain the crystallinity of some of their 20 and $40 \%$ glass-filled PPS composite samples. The method described was similar to the simple peak resolution method as embodied in Equation 12. They removed the scatter associated with the glass fiber by a curve fitting technique similar to that discussed for the carbon fiber composite in section 2.5.3. Their values of crystallinity obtained by this method, presented in column 8 of Table 2, were lower than the values they obtained by DSC (column 6), but they were considerably higher than those in column 7. Note that X-ray shows no crystallinity at short exposure times for either of the temperatures examined, while their DSC values are quite significant, regardless of the $\Delta H_{f}^{o}$ value used. This indicates substantial recrystallization during heat-up in the DSC for the low crystallinity samples.

Deporter and Baird ${ }^{38}$ studied the effect of thermal history on the structure of PPS/carbon fiber composites. They studied two types of composites. One consisted of a standard PPS ( $\mathrm{M}_{\mathrm{w}} \cong$ 50,000) with AS4 PAN-based carbon fiber (Ryton, Phillips Petroleum Company); the other composite had a modified PPS matrix (AS4/XLC40-66) that exhibited higher crystallinity and crystallization rate than the standard PPS. The samples both contained $66 \mathrm{wt} \%$ fiber. The unidirectional composites were fabricated using varying cooling rates from $68^{\circ} \mathrm{C} / \mathrm{s}$ to $0.4^{\circ} \mathrm{C} /$ minute. They also crystallized samples isothermally at selected temperatures. All samples were heated to $315^{\circ} \mathrm{C}$ for 10 minutes prior to the crystallization treatment. Table 3 shows their results for the Ryton samples. All samples were crystallized from the melt except the two marked 
with an "A" in Table 3. The latter were quenched to room temperature and then annealed at the indicated temperatures. They used DSC to determine crystallinity based on Equation 4 and $\Delta H_{f}^{o}=105 \mathrm{~J} / \mathrm{g}$.

Based on the data in Table 3 Deporter and Baird observed that crystallinity increased, passed through a maximum, and then decreased as temperature increased. They also used SEM to examine the spherulite sizes present. They found that spherulite size tended to increase with increase in crystallization temperature or with a decrease of the cooling rate. They suggested that this was due to a greater primary nucleation rate at greater supercooling (lower temperature).

Table 3. Effect of Thermal History on the Crystallinity of PPS/Carbon Fiber Composites

\begin{tabular}{cccc}
\hline $\begin{array}{c}\text { Isothermal Crystallization } \\
\text { Temperature, }{ }^{\circ} \mathrm{C}\end{array}$ & $\begin{array}{c}\text { Cooling Rate, }{ }^{\circ} \mathrm{C} / \mathrm{min} \\
\text { (nonisothermal cryst.) }\end{array}$ & $\mathrm{X}_{\mathrm{c}}(105 \mathrm{~J} / \mathrm{g})$ & $\mathrm{X}_{\mathrm{c}}(150.4 \mathrm{~J} / \mathrm{g})$ \\
\hline 140 & & $0.20 \pm 0.010$ & 0.14 \\
160 & & $0.22 \pm 0.011$ & 0.15 \\
180 & & $0.25 \pm 0.013$ & 0.17 \\
200 & & $0.32 \pm .016$ & 0.22 \\
220 & & $0.28 \pm 0.014$ & 0.20 \\
$\mathrm{~A} 160$ & & $0.26 \pm 0.013$ & 0.18 \\
$\mathrm{~A} 200$ & 0.4 & $0.29 \pm 0.015$ & 0.20 \\
& 1.0 & $0.46 \pm 0.023$ & 0.32 \\
& 4.0 & $0.28 \pm 0.014$ & 0.20 \\
& 10.0 & $0.30 \pm 0.015$ & 0.21 \\
& & $0.28 \pm 0.014$ & 0.20 \\
& & $0.10 \pm 0.005$ & 0.07 \\
\hline
\end{tabular}




\section{CRYSTALLIZATION MORPHOLOGY AND KINETICS}

As with most other polymers, the basic morphology of crystallization of PPS is to form spherulites when crystallized from the melt under quiescent conditions and in the absence of reinforcing fibers. ${ }^{25,35,36}$ The spherulites consist of lamellae and/or fibril shaped crystals growing radially outward from the primary nucleation site. ${ }^{25,35,36}$ It has been established that the growth direction of the crystals is along the b-axis of the unit cell. ${ }^{10}$ Also, the spherulites generally exhibit a negative birefringence. ${ }^{10}$ This means that the index of refraction in the tangential direction is greater than that in the radial direction of the spherulites and implies that the polymer chain axes (c-axis of crystals) are normal to the radial direction. This suggests the existence of folded chain crystals similar to many other semicrystalline polymers.

Many investigators ${ }^{23-25,35,36,39-56}$ studied the crystallization kinetics of PPS and its composites. Most of these studies were reviewed previously, ${ }^{3,6}$ so the approach taken here will be an overview of the most important observations. Generally, polymers crystallize slowly at temperatures slightly above their glass transition temperature due to low mobility of the molecules at this temperature. Likewise, polymers crystallize slowly at temperatures slightly below their equilibrium melting point due to low driving force for crystal nucleation at these temperatures. The maximum crystallization rate occurs at a temperature approximately midway between the glass transition and equilibrium melting temperatures where the combination of nucleation and crystal growth rates is optimized. For PPS, depending on the molecular architecture (linear versus branched, crosslinked, molecular weight) and crystallinity, the glass transition typically occurs in the range $80^{\circ}-95^{\circ} \mathrm{C}$ and the equilibrium melting temperature is typically in the range $298^{\circ}-330^{\circ} \mathrm{C} . .^{25,42,43,50,51}$ (Note that this temperature range is higher than the observed DSC melting range, $\mathrm{Tm}=280^{\circ}-295^{\circ} \mathrm{C}$.) This suggests that the maximum crystallization rate should be in the neighborhood of $180^{\circ}-190^{\circ} \mathrm{C}$.

\subsection{Overall Rate of Crystallization}

Most investigators have used DSC to study the overall rate of isothermal crystallization. The technique involves heating well above the melting point to obtain a homogeneous melt followed by a rapid cool to a previously selected crystallization temperature where the temperature is held constant until crystallization is complete. The progress of crystallization is followed by determining the integrated heat evolved at this temperature as a function of time. In most studies, only the relative weight fraction crystallinity, $X_{r}$, and not the absolute value is determined according to

$$
X_{r}=\int_{0}^{t}\left(\frac{d H}{d t}\right) d t / \int_{0}^{\infty}\left(\frac{d H}{d t}\right) d t
$$

where $d H / d t$ is the rate of evolution of heat as a function of time. Note that the value of $X_{r}$ ranges from zero to one. This procedure is referred to as "cooling mode" or "crystallization from the melt." The range of accessible crystallization temperatures is limited on the high temperature side by the slow rate of heat evolution at low undercooling and the sensitivity of the DSC. On the low temperature side, the range is limited by the fact that, due to the relatively slow cooling rates available in the DSC, crystallization will begin during the cool down before the crystallization temperature can be reached. Since the kinetics of PPS crystallization is slow enough to allow 
quenching to an amorphous state there has also been considerable interest in examining the crystallization rate on heating up after quenching. As already mentioned, this is often called "cold crystallization."

The crystallization half-time $t_{1 / 2}$, defined as the time required for $X_{r}$ to reach 0.5 , is often used to give a primary indication of the crystallization rate as a function of temperature. A similar value, also used, is the time to reach the peak maximum in the DSC crystallization exotherm. A plot of the time to reach the peak maximum for two grades of Ryton PPS $\left(\mathrm{M}_{\mathrm{w}} \approx\right.$ 15,000 and $\mathrm{M}_{\mathrm{w}} \approx 60,000$ ) is shown in Figure 12 as a function of crystallization temperature. These data are from the work of Chung and Cebe. ${ }^{23}$ The data above $150^{\circ} \mathrm{C}$ were determined in the cooling mode, while the data below $150^{\circ} \mathrm{C}$ were determined by quenching followed by reheating to the crystallization temperature. Several features of this plot are interesting. First, the time to reach the peak maximum, $\mathrm{t}_{\mathrm{m}}$, is quite long above $200^{\circ} \mathrm{C}$ and below $130^{\circ} \mathrm{C}$, being of order 100 seconds at these two temperatures. The value of $t_{\mathrm{m}}$ increases with increasing temperature above $200^{\circ} \mathrm{C}$, but increases with decreasing temperature below $150^{\circ} \mathrm{C}$ as the glass transition temperature is approached. There is a clear effect of molecular weight. At a given temperature, the lower $\mathrm{M}_{\mathrm{w}}$ resin crystallizes more rapidly (shorter time to peak maximum) than the higher $\mathrm{M}_{\mathrm{w}}$ resin. Lopez and Wilkes ${ }^{42}$ observed a similar effect of molecular weight. Note that the minimum value of $t_{m}$ was not determined experimentally due to equipment limitations, but appears to lie in the range $160^{\circ}-180^{\circ} \mathrm{C}$.

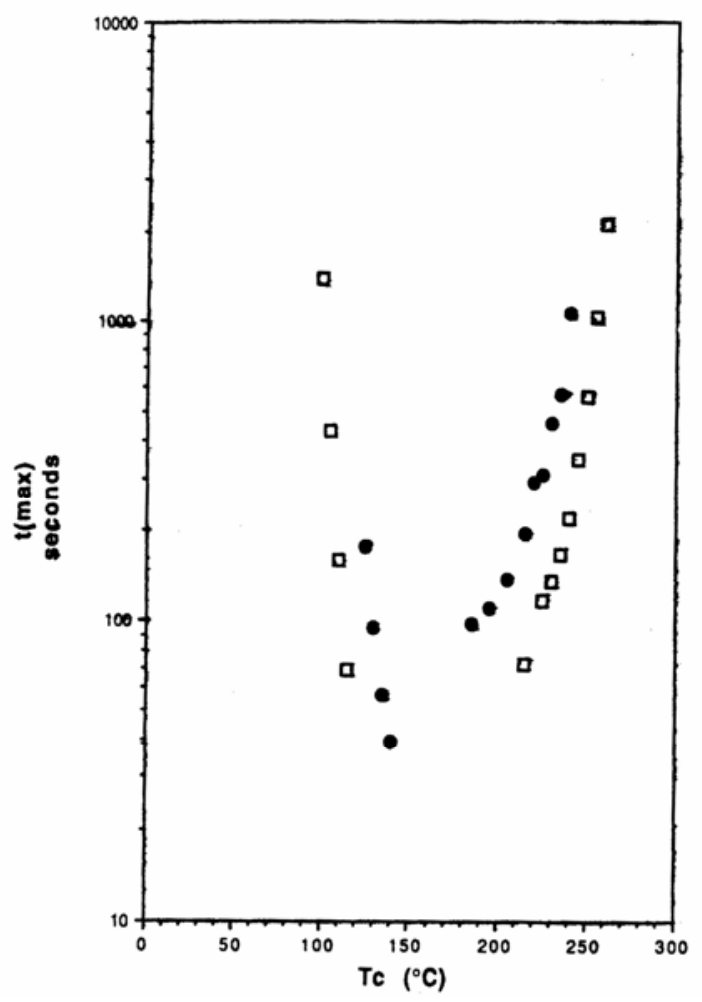

Figure 12. Time to maximum in the DSC exotherm as a function of crystallization temperature for PPS. $(\bullet) \mathrm{MW} \approx 60,000$; () $\mathrm{Mw} \approx 15,000$ (from Chung and $\mathrm{Cebe}^{23}$ ). 
The data in Figure 12 were obtained using a melt holding temperature of $310^{\circ} \mathrm{C}$ for the lower $\mathrm{M}_{\mathrm{w}}$ resin and $320^{\circ} \mathrm{C}$ for the higher $\mathrm{M}_{\mathrm{w}}$ resin. Budgell and Day, ${ }^{24}$ Caramaro et al ${ }^{57}$ and Auer et al. ${ }^{35}$ demonstrated that the rate of crystallization is dependent on the precrystallization melt holding temperature and time. Higher melt holding temperature up to about $330^{\circ} \mathrm{C}$ (for short periods) tends to increase the time required to crystallize PPS. This is thought to be due to better homogeneity of the melt and melting of tiny crystals that could serve as nuclei during crystallization with increase in melt holding temperature. This effect could also be partially responsible for the difference attributed to molecular weight in Figure 12. Further, PPS is known to undergo degradation, chain extension and crosslinking reactions in the presence of oxygen and temperatures near or above the melting point for extended periods of time. ${ }^{3,14,53}$ These reactions can reduce crystallization rate and ultimate crystallinity. Thus, long exposures to high temperatures, often referred to as "curing," are to be avoided unless these reactions are desired. More detail on this topic is discussed in Section 6.1.

Lopez et al. ${ }^{43}$ also studied the effect of chain branching and end-group counter-atom. They found that branching, produced by the addition of a branching agent during polymerization, decreased the crystallization rate, nucleation density and heat of crystallization (crystallinity). Changing the end-group counter-atom seemed to have an effect on the nucleation density, but it was not possible to account systematically for the dependence of crystallization behavior on the nature of the end-group.

The well-known Avrami equation or some modification of it was often used to analyze the overall crystallization kinetics. This equation is given by

$$
X_{r}=1-\exp \left[-k t^{n}\right]
$$

where $k$ is called the crystallization rate constant and $n$ is the Avrami exponent. The value of $n$ is a function of the nucleation and growth rate of the spherulites formed during crystallization. Most investigators have found values of $n$ between 2 and 3 for PPS isothermal crystallization $^{24,25,35,36,41-43,48,50,56}$ with crystallization from the melt giving values nearer 3 and cold crystallization giving values nearer 2 . The values for crystallization from the melt have generally been interpreted to indicate three-dimensional growth of predetermined nuclei. The observation of spherulites is consistent with this interpretation.

The influence of the addition of reinforcing fibers on the crystallization half-time of PPS as determined by Auer et al. ${ }^{35}$ is shown in Figure 13. These data show that the addition of glass fiber and carbon fiber slow the overall crystallization rate while the addition of aramid fiber increases it. Desio and Rebenfeld ${ }^{36}$ found that carbon fiber additions increased the crystallization rate. These authors showed that the type of carbon fiber and the presence or absence of sizing could affect the crystallization rate substantially, as shown in Figure 14.

It should be noted that the crystallization half-time of the neat resin used by Desio and Rebenfeld is much greater than that for the neat resin used by Auer et al. It can, therefore be concluded that the base resins used by these two research teams are quite different in spite of the fact that both studied Ryton resin. It is known that during the early 1990's Phillips Petroleum Company reported several "improvements" of their Ryton resins in an effort to obtain better fiber/matrix adhesion and matrix dominated properties. ${ }^{58,59}$ The improved PPS resins have faster crystallization rates and higher nucleation densities (similar to the XLC40-66 resin described in the studies of Deporter and Baird ${ }^{38}$ ). Thus, a potential explanation for the differences in behavior observed by Desio and Rebenfeld (1992) and Auer et al. (1994) is that the former was using the 
older version of Ryton resin in their study, while the latter used the improved resin. One might expect that the addition of fiber might nucleate crystallization in the slower crystallizing resin more effectively than in a faster crystallizing resin.

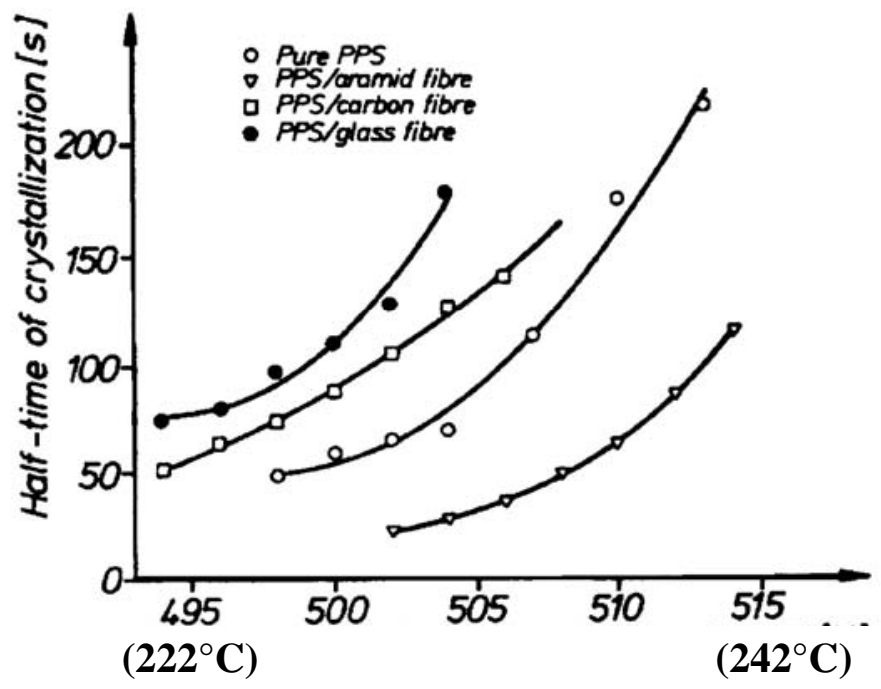

Crystallization temperature $T_{c}(K)$

Figure 13. Half-time of crystallization as a function of isothermal crystallization temperature for PPS and some PPS composites (from Auer, et. al. ${ }^{35}$ ).

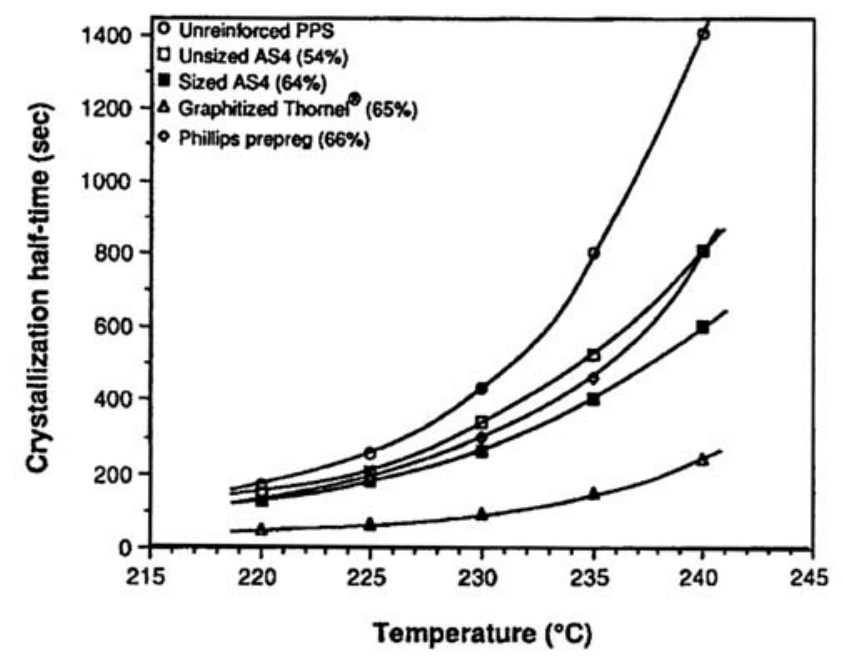

Figure 14. Half-time of crystallization versus crystallization temperature for PPS and some of its carbon fiber composites (from Desio and Rebefeld ${ }^{36}$ ).

Another factor may be the melt holding temperature prior to cooling to the crystallization temperature. Caramaro et al. ${ }^{57}$ found that crystallization half time was substantially shorter when the samples were held at $300^{\circ} \mathrm{C}$ compared to holding at $350^{\circ} \mathrm{C}$ prior to cooling. They also noted that carbon fiber reduced the half-time when their samples were held at $350^{\circ} \mathrm{C}$, but had no effect when the samples were held at $300^{\circ} \mathrm{C}$. They suggest that this result is due to the fact that holding 
at $350^{\circ} \mathrm{C}$ was sufficient to melt all prior crystals and produce a homogeneous melt, whereas holding at $300^{\circ} \mathrm{C}$ was not. In the former case the carbon fiber reduced the half-time due to its ability to nucleate the crystallization. At the lower holding temperature, the effect of the carbon fiber was negligible compared to other sources of nucleation. Microstructural examination of samples containing carbon fiber showed a large number of small spherulites in samples held at $300^{\circ} \mathrm{C}$, but the samples held at $350^{\circ} \mathrm{C}$ exhibited larger spherulites away from the fibers and transcrystalline growth near the fibers.

The presence of reinforcing fiber also reduces the value of the Avrami exponent. Desio and Rebenfeld ${ }^{48}$ found that the decrease of the Avrami exponent, $n$, is dependent on the relative amount and nature of the fiber, and whether the fiber was sized or not. Two types of system were found. One type followed the standard Avrami equation and exhibited a linear plot of $\ln \left(-\ln \left(1-X_{t}\right)\right.$ versus $\ln \mathrm{t}$. The other type exhibited nonlinear behavior on such a plot. The greatest decrease of $n$ was observed in systems that exhibited this "nonlinear Avrami behavior." The values of $n$ for the systems that exhibited linear behavior ranged from 1.7 to 2.7 , the latter value being for the neat polymer. The value of $n$ ranged from 1.5 to 2.1 in systems that exhibited the "nonlinear" behavior. The linear behavior was observed for the glass fiber and unsized AS4 carbon fiber filled composites. Nonlinear behavior was observed for sized AS4 (PAN-based) and Thornel (graphitized pitch-based) carbon fiber and aramid fiber composites. These authors also found that the Avrami rate constants, $k$, were substantially higher at any given crystallization temperature for the composites that exhibited nonlinear Avrami behavior. This is consistent with a shorter crystallization half-time for these materials.

Microstructural examination of model thin film composites containing fibers that gave rise to nonlinear behavior were observed to exhibit a transcrystalline growth morphology near the fibers. The composites that exhibited linear Avrami behavior did not exhibit the transcrystalline growth morphology. An example of this for sized AS4 containing composite is shown in Figure 15. The formation of transcrystalline regions appears to be the result of high crystal nucleation rates on the surface of the fibers. The nucleation density is so high on these surfaces that growth can only occur perpendicular to the fiber due to impingement with other growing nuclei. Neyman et al. ${ }^{60}$ also studied transcrystalline growth in PPS composites. These authors also found differences between carbon fibers produced from different precursor materials. They established that the growth direction in the transcrystalline regions was the baxis direction as it is in ordinary spherulites. Other parameters that could also influence the transcrystalline behavior of PPS composites include the degree of smoothness on the surface of the carbon fiber, its surface porosity, and its surface energy.

\subsection{Spherulitic Growth Rate}

The nucleation density of spherulites and the rate of radial growth of the spherulites determine the overall rate of crystallization. The nucleation density is difficult to measure independently, but several investigators determined the spherulite growth rate of PPS. Polarized optical microscopy is the technique of choice for growth rate measurements. The spherulite radius, $r$, is measured as a function of time at the crystallization temperature. The isothermal growth rate, $\mathrm{G}$, is normally linear and given by

$$
G=\frac{d r}{d t}
$$




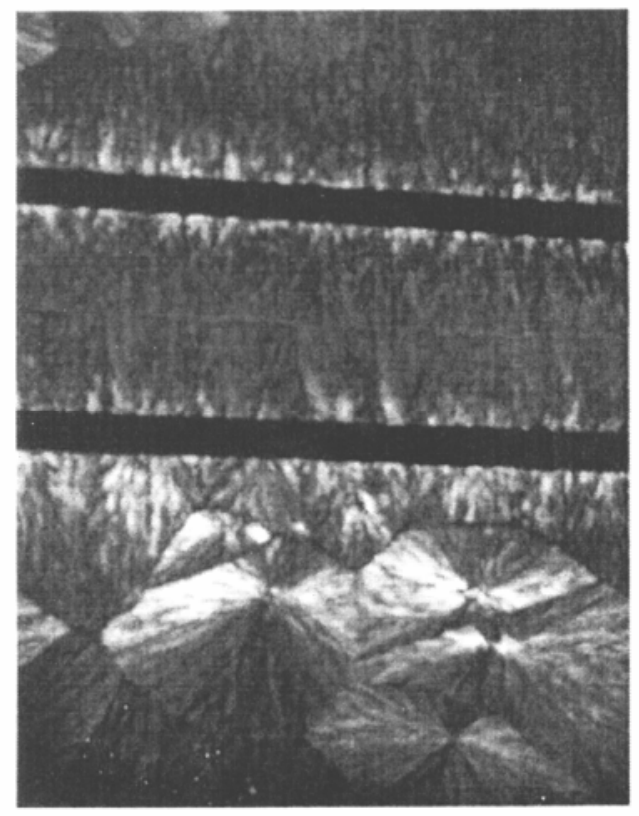

Figure 15. Transcrystalline morphology in the neighborhood of sized AS4 fibers in model thin film composite (from Desio and Rebenfeld ${ }^{48}$, original magnification 570X).

Lovinger et al. ${ }^{51}$ measured spherulite growth rates over a very wide range of crystallization temperatures $-100^{\circ}-280^{\circ} \mathrm{C}$. Their data are shown in Figure 16 for a low molecular weight resin and a moderate molecular weight resin $\left(\mathrm{M}_{\mathrm{w}} \approx 15,000\right.$ and $\left.\mathrm{M}_{\mathrm{w}} \approx 51,000\right)$. The maximum growth rate appears to be about $180^{\circ} \mathrm{C}$, with the growth rate dropping rapidly as the temperature is either increased or decreased from this value. It is clear that the dependence of growth rate on temperature is largely responsible for the variation in the overall crystallization rate with temperature. Lopez et al. ${ }^{42,43}$ found that the growth rate decreased with increase in either molecular weight or chain branching. Different end-group counter-atoms also caused differences in the growth rate, but no systematic trend was discerned.

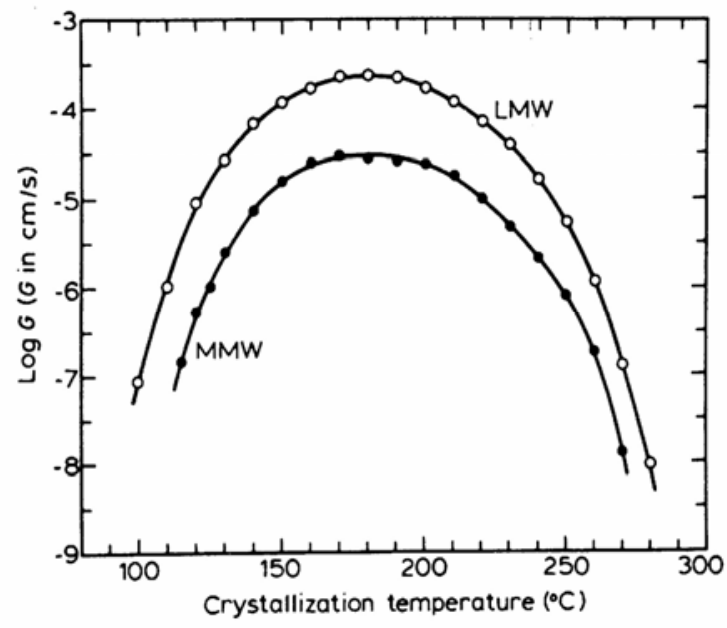

Figure 16. Spherulite growth rate of PPS as a function of crystallization temperature. $\mathrm{LMW}=15,000 ; \mathrm{MMW}=51,000$ (from Lovinger et al. ${ }^{51}$ ) 


\subsection{Comparison of Ryton and Fortron Behavior}

Jog et al. ${ }^{52}$ attempted a direct comparison of the difference in crystallization behavior for resins produced by two major suppliers of PPS resins. They compared Ryton V-I (called PPS1) supplied by Philips Petroleum with Fortron W203 (PPS 2) supplied by Hoechst Celanese. They used DSC techniques to examine both their isothermal and nonisothermal crystallization behavior. Substantial differences observed between these two polymers included: (1) the peak melting temperature of PPS1 was $284^{\circ} \mathrm{C}$ and that of PPS2 was $293^{\circ} \mathrm{C}$; (2) crystallization during cooling from the melt occurs at a higher temperature for PPS2 than for PPS1; 3 ) the heat of fusion of samples crystallized by cooling from the melt at $10^{\circ} \mathrm{C} / \mathrm{min}$ was higher for PPS 2 (45.8 $\mathrm{J} / \mathrm{g}$ ) than for PPS1 (38.2 J/g); (4) the isothermal crystallization half-times measured at equivalent undercooling was greater for PPS1 than for PPS2; (5) the crystallization rate constant, k, was about an order of magnitude higher for PPS2 than for PPS1 when measured at equivalent undercooling; (6) the nucleation rate appeared to be greater for PPS2 based on the presence of smaller spherulites in PPS2; and finally (7) curing these resins at $385^{\circ} \mathrm{C}$ resulted in a decrease in heat of fusion for both polymers, but the rate of decrease was greater for PPS2 than for PPS1. These authors explained their results in terms of differences in the molecular architecture of the two polymers. Specifically, they suggested that PPS 2 (Fortron) is more linear than PPS1 (Ryton) and therefore exhibits higher crystallization and melting temperature, higher nucleation rates, faster overall crystallization kinetics and more rapid decrease of heat of fusion with curing at temperatures well above the melting point.

\subsection{Preferred Orientation}

Processing of amorphous polymers often leads to preferred orientation of the polymer molecules with respect to sample reference axes, for example the direction parallel to the length of a fiber; e.g., the fiber axis. In the case of semicrystalline polymers, both the amorphous chains and the crystals exhibit preferred orientation. Uniaxial orientation is often specified in terms of Hermans-Stein orientation factors ${ }^{61,62}$ defined by

$$
f_{i}=\frac{3\left\langle\cos ^{2} \phi_{i}\right\rangle-1}{2} .
$$

For amorphous polymers, $i$ represents the chain axis direction of the molecules and $\phi_{i}$ is the angle between the chain axis and the sample reference axis. The brackets indicate that the average value of the square of the cosine of $\phi_{i}$ is to be taken. For the crystalline fraction of semicrystalline polymers, the subscript $i$ normally refers to a crystallographic axis $(i=\mathrm{a}, \mathrm{b}$ or $\mathrm{c})$. The values of $f_{i}$ range from -0.5 to 1.0. The latter value indicates that the chain or crystallographic axis is parallel to the sample reference axis, while the former value indicates that the chain or crystallographic axis is perpendicular to the reference axis. A sample that has no preferred orientation will have $f_{i}=0$.

For amorphous polymers, the orientation factor can be obtained from a measurement of birefringence, $\Delta n$, provided the "intrinsic birefringence," $\Delta^{o}$ is known. 


$$
f_{i}=\frac{\Delta n}{\Delta^{o}}
$$

For the crystalline fraction of semicrystalline polymers, the values of the $f_{i}$ are normally determined using X-ray diffraction to calculate the $\left\langle\cos ^{2} \phi_{i}\right\rangle$ from the azimuthal intensity distribution diffracted from appropriate crystallographic planes. For the case that the diffracted intensity can be measured from $h \mathrm{kl}$ planes that are perpendicular to the crystallographic axis, the following relationship holds:

$$
\left\langle\cos ^{2} \phi_{i}\right\rangle=\frac{\int_{0}^{\pi / 2} I_{h k l}(\phi) \cos ^{2} \phi \sin \phi d \phi}{\int_{0}^{\pi / 2} I_{h k l}(\phi) \sin \phi d \phi} .
$$

The orientation in the amorphous fraction of a semicrystalline polymer cannot be determined directly, but must be determined from some property such as birefringence. In this case, it is usually assumed that ${ }^{62}$

$$
\Delta n=X_{c} f_{c} \Delta_{c}^{o}+\left(1-X_{c}\right) f_{a m} \Delta_{a m}^{0}+\Delta n_{f o r m}
$$

Here, the subscript am refers to the chain direction in the amorphous phase and the subscript $c$ refers to the chain direction (normally the c-axis) in the crystals. The last term is the form birefringence; it is usually assumed to be negligible. By measuring $f_{c}$ and $X_{c}$ and knowing the intrinsic birefringences of the respective phases, the value of $f_{a m}$ can be calculated.

Maemura et al. ${ }^{16}$ used this method to measure the orientation developed in PPS films that were uniaxially stretched to different draw ratios followed by annealing for $1 \mathrm{hr}$ at $150^{\circ} \mathrm{C}$. Their results are shown in Figure 17. As is generally observed in semicrystalline polymers, the crystalline orientation developed to a much greater extent than the amorphous orientation.

A similar, but more complex method, was described for characterizing biaxial orientation in polymers, ${ }^{63}$ and this method has been applied to PPS film. ${ }^{64}$ A more common approach is to use "pole figures" to describe the preferred orientation of materials. A pole figure gives the distribution of the poles of a certain set of $h k l$ planes plotted on the surface of a reference sphere and projected stereographically onto a two dimensional page. As such, pole figures are not limited to any specific type of preferred orientation. Their major disadvantage is that plots showing changes in the orientation with processing variables, such as that shown in Figure 17, are not feasible. The orientation factor gives a simple second moment average of the orientation that allows such plots to be made. 


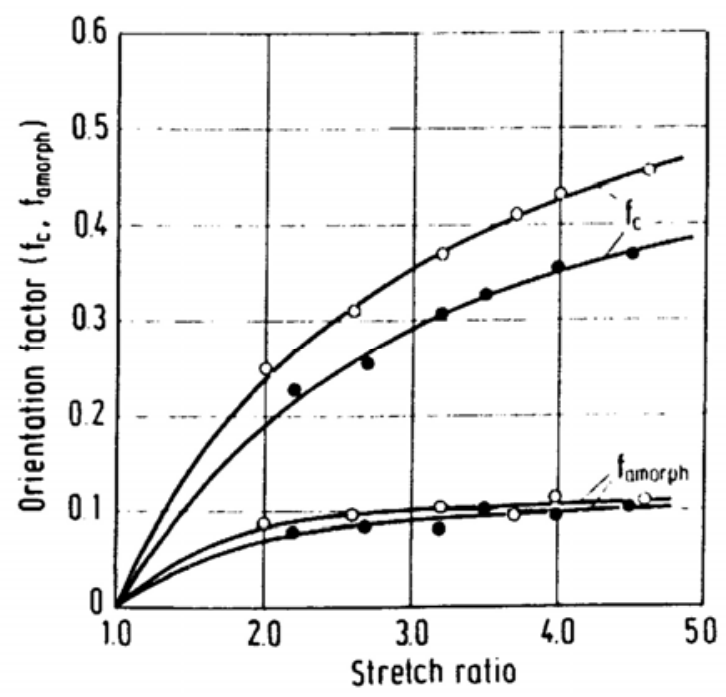

Figure 17. Amorphous and c-axis crystalline orientation factors for PPS film stretched to different stretch ratios and annealed at $150^{\circ} \mathrm{C}$. Open symbols stretched at $100^{\circ} \mathrm{C}$; closed symbols stretched at $110^{\circ} \mathrm{C}$. (From Maemura et al. ${ }^{16}$ ) 
This page left blank intentionally. 


\section{EFFECT OF VARIATION OF CRYSTALLINITY AND MORPHOLOGY ON PROPERTIES OF PPS AND PPS COMPOSITES}

\subsection{Tensile, Compressive and Flexural Properties}

Several investigators studied the tensile and/or compressive mechanical properties of PPS and PPS composites. ${ }^{14,38,65-67}$ In his 1976 paper, Brady ${ }^{14}$ showed that the tensile strength depended on prior history of the sample. Figure 18 shows his plot of tensile strength versus mold temperature for as-molded samples of $40 \%$ glass-filled Ryton polymer and compares these data to that for molded samples that were subsequently annealed at $204^{\circ} \mathrm{C}$ for $2 \mathrm{hrs}$. This figure shows that tensile strength decreases with increase of mold temperature (slower cooling rate) and with annealing, especially for samples that were molded at low mold temperatures (faster cooling rates). He also observed that tensile strength decreased with time at the annealing temperature for both unfilled and glass-filled polymers, and that the changes occur rather rapidly at temperatures above the glass transition temperature. Brady suggested that these changes were associated with the changes in crystallinity in the samples (see Figures 7 and 8 above). This result was rather surprising since, in most polymers, increasing crystallinity produces higher tensile strengths rather than the lower values observed in PPS and its composites. But, other investigators ${ }^{65,66}$ later confirmed this finding. Additional information on this topic is discussed later in this section.

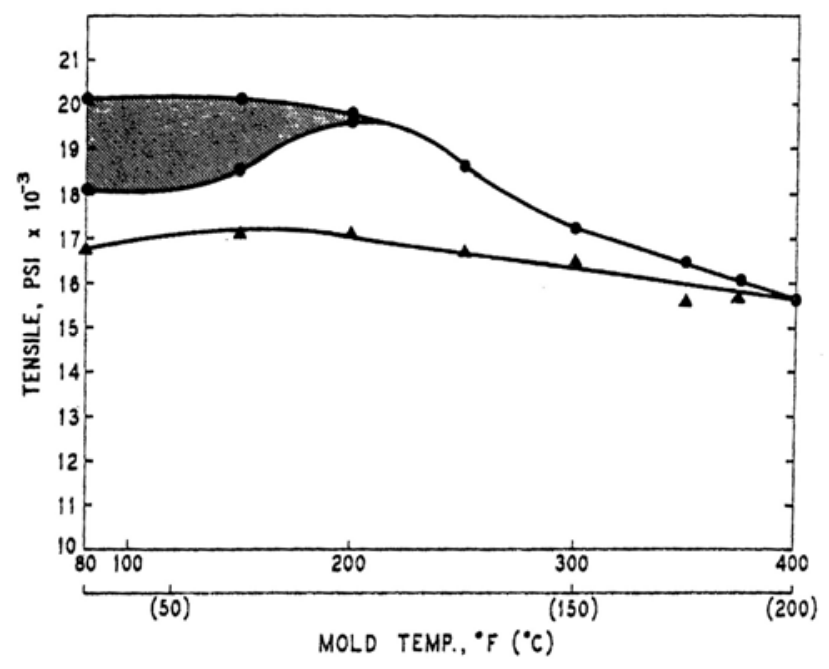

Figure 18. Tensile strength as a function of mold temperature for $\mathbf{4 0} \%$ glass-filled PPS composite. $(\bullet)$ as-molded; ( $(\bullet)$ annealed $204^{\circ} \mathrm{C}, 2 \mathrm{~h}\left(\right.$ from Brady $\left.^{14}\right)$.

Deporter and Baird ${ }^{38}$ measured flexural strength, flexural modulus and transverse tensile strength of the uniaxial carbon/PPS fiber composites whose crystallinity was discussed earlier (see Table 3). The variations in crystallinity and morphology that were caused by varying thermal history also produced variations in the mechanical properties of the composites. The $0^{\circ}$ flexural strength and modulus of the Ryton composites increased as the cooling rate decreased. The increase in modulus was attributed to an increase in the crystallinity of the samples. This trend was not as clear when evaluating the matrix-dominated properties. Although there was a slight increase in the transverse tensile modulus for both materials at the slower cooling rates (increased degree of crystallinity) and an increase in the transverse tensile strength of the 
AS4/XLC40-66 material, there was a decrease in the transverse tensile strength with the AS4/PPS composite. This decrease in transverse tensile strength was attributed to a much lower degree of crystallinity for the AS4/PPS material. At slower cooling rates the AS4/PPS material has a greater number of larger spherulites with better defined boundaries, thus serving as areas of higher stress concentration, thereby producing a more brittle material having lower transverse tensile strengths. On the other hand, the morphology of the AS4/XLC40-66 material is characterized by a larger number of smaller and more homogeneously distributed spherulites, due to its faster crystallization rate, as well as having a higher degree of crystallinity, compared to the Ryton AS4/PPS material, thus yielding an increase in the transverse tensile strength and modulus. When the Ryton AS4/PPS material was cooled at two different rates, $1{ }^{\circ} \mathrm{C} / \mathrm{min}$ and $10^{\circ} \mathrm{C} / \mathrm{min}$, the same degree of crystallinity was developed, however, the material that was cooled at the faster rate $\left(10^{\circ} \mathrm{C} / \mathrm{min}\right)$ had a slightly higher transverse tensile strength. Examination of the morphologies showed that the slower cooled material $\left(1^{\circ} \mathrm{C} / \mathrm{min}\right)$ had a greater number of larger spherulites with more well-defined boundaries, thus resulting in a more brittle and lower strength material. Thus, the flexural strength and transverse tensile strength appear to be related to other features of the morphology, such as the nature and size of the spherulites, as well as the fraction crystalline. For example the data in Table 4 shows results of transverse tensile strength for samples with similar crystalline fractions, but which were prepared in very different ways and which had different morphological features.

Table 4 Transverse Tensile Strength of Selected PPS/Carbon Fiber Composites

\begin{tabular}{ccc}
\hline Preparation Condition $^{\mathrm{a}}$ & Crystalline Fraction $^{\mathrm{b}}, \mathrm{X}_{\mathrm{c}}$ & Trans. Tensile Strength (Mpa) \\
\hline Nonisoth. $1.0^{\circ} \mathrm{C} / \mathrm{min}$ & $0.28 \pm 0.014$ & $4.1 \pm 0.6$ \\
Annealed $200^{\circ} \mathrm{C}$ & $0.29 \pm 0.015$ & $5.9 \pm 0.6$ \\
Isothermal $200^{\circ} \mathrm{C}$ & $0.32 \pm 0.016$ & $14.0 \pm 1.6$ \\
Nonisoth. $4.0^{\circ} \mathrm{C} / \mathrm{min}$ & $0.30 \pm 0.015$ & $6.0 \pm 1.7$ \\
Nonisoth. $0.4^{\circ} \mathrm{C} / \mathrm{min}$ & $0.46 \pm 0.023$ & $7.0 \pm 1.5$ \\
\hline
\end{tabular}

${ }^{\mathrm{a}}$ See Section 3 for preparation condition details.

${ }^{b}$ Based on heat of fusion for perfect crystal equal to $105 \mathrm{~J} / \mathrm{g}$.

Deporter and Baird also found that the degree of crystallinity or the morphology of the matrix had no effect on the tensile properties of non-unidirectional laminates of either material. No variation in tensile strength or modulus was observed on either AS4/PPS or AS4/XLC40-66 cross-plied, $0 / 90$ laminates that were fabricated by varying the cooling rates from $0.4 \mathrm{C} / \mathrm{min}$ to $68 \mathrm{C} / \mathrm{s}$. It is assumed that the principal reason that the level of crystallinity or the matrix morphology had no effect on the tensile properties of non-unidirectional laminates is because the tensile test is predominately fiber-dominated and any changes in matrix crystallinity or matrix morphology would have only minimal impact on the tensile properties of the composite. This would definitely not be the case with matrix-dominated tests, i.e. interlaminar shear, $+45 /-45$ inplane shear, creep, and impact, which would reflect differences in strength and modulus properties due to morphological changes and/or varying degrees of crystallinity in the matrix.

As discussed earlier, Deporter and Baird ${ }^{38}$ found that the 0 degree flexural strength and flexural modulus properties of unidirectional AS4/PPS (Ryton PPS) and AS4/XLC40-66 (Ryton PPS - higher crystallization rate) composites exhibited an increase in both properties as the cooling rate (from the melt) decreased and as the degree of crystallinity (DOC) increased. For the AS4/PPS composite, the 0 degree flexural strength increased $111 \%$ from 0.9 to $1.9 \mathrm{GPa}$ 
(130.5 to $275.5 \mathrm{ksi}$ ) and the 0 degree flexural modulus increased $18 \%$ from 100 to $118 \mathrm{GPa}(14.5$ to $17.1 \mathrm{msi}$ ) as the cooling rate decreased from $68 \mathrm{C} / \mathrm{s}$ to $0.4 \mathrm{C} / \mathrm{min}$ and as the DOC increased from $10 \%$ to $46 \%$ based on $\Delta H_{f}^{o}$ of $105 \mathrm{~J} / \mathrm{g}\left(7 \%\right.$ to $32 \%$ based on $\Delta H_{f}^{o}$ of $\left.150.4 \mathrm{~J} / \mathrm{g}\right)$. Similarly, for the AS4/XLC40-66 composite, the 0 degree flexural strength increased $82 \%$ from 1.1 to 2.0 GPa (159.5 to $290 \mathrm{ksi}$ ) and the 0 degree flexural modulus increased $15 \%$ from 115 to $132 \mathrm{GPa}$ (16.7 to $19.1 \mathrm{msi}$ ) as the cooling rate decreased between the aforementioned values and as the DOC increased from 28 to $46 \%$ based on $\Delta H_{f}^{o}$ of $105 \mathrm{~J} / \mathrm{g}\left(20 \%\right.$ to $32 \%$ based on $\Delta H_{f}^{o}$ of 150.4

$\mathrm{J} / \mathrm{g}$ ). Although one could conceivably attribute the increase in the flexural modulus values to increased DOC of the PPS matrix, it is difficult to understand the large magnitude increase for the 0 degree flexural strength properties, especially in light of the fact that no increase was observed for either the tensile strength or tensile modulus properties for $0 / 90$ cross-plied laminates that were processed in the same fashion. The flexural strength and flexural modulus of unreinforced PPS having a high DOC is $0.13 \mathrm{GPa}(18.8 \mathrm{ksi})$ and $3.8 \mathrm{GPa}(0.56 \mathrm{msi})$, respectively, and the tensile strength and tensile modulus of AS4 fibers is $4.3 \mathrm{GPa}$ (624 ksi) and $228 \mathrm{GPa}(33.1 \mathrm{msi})$, respectively. Since flexural properties are influenced by tensile, compressive, and shear modes one would expect that increasing the crystallinity of either the AS4/PPS or AS4/XLC40-66 composite could result in an increase in both the flexural strength and flexural modulus properties. However, the level of increase in the flexural strength properties that was observed for both of these AS4 composite materials cannot be explained at this time and is worthy for further investigation. These findings are very significant and clearly illustrate that the processing history (i.e., cooling rates) and the DOC of the PPS matrix can significantly influence some of the mechanical properties of PPS composites.

It is also important to note that no transcrystallinity (preferential nucleation at the fiber surface compared to nucleation in the bulk resin matrix) was observed in any of the AS4/PPS or AS4/XCL40-66 unidirectional or cross-plied laminates that were fabricated by isothermal, nonisothermal, or quenched/annealed conditions. Most of the transcrystallinity that has been reported in the literature has involved a single fiber embedded in a sea of matrix and covered with a glass slide. ${ }^{36,60,68}$ In addition, the only reported evidence of transcrystallinity that has been observed in an actual composite involved a carbon/PEEK materia $l^{69}$ which was fabricated under extremely slow cooling conditions and, in this case, trancrystallinity was present in only localized areas of the composite.

The work of Nishihata et al. ${ }^{66}$ adds substantially to the above observations. These authors made measurements on injection-molded samples (melt temperature $320^{\circ} \mathrm{C}$, mold temperature $140^{\circ} \mathrm{C}$ ) prepared from differing PPS polymer types and melt viscosities (molecular weights). The polymer type varied from linear to branched to lightly crosslinked due to heat treatment at elevated temperature. The samples, their type and melt viscosities measured at $1200 \mathrm{~s}^{-1}$ are given in Table 5. The molecular weights as measured by Gel Permeation Chromatography (GPC) for the linear samples and the heat-treatments used for producing lightly crosslinked samples are also given. Sample EH was prepared from a low molecular weight polymer with a melt viscosity, before heat treatment, of $10 \mathrm{~Pa}$-s. Samples GH and FH were prepared by heat treatment of samples AL and BL, respectively. 
Table 5. Materials Studied by Nishihata et al. ${ }^{66}$

\begin{tabular}{cccccc}
\hline Sample & $\begin{array}{c}\text { Melt Viscosity } \\
1200 \mathrm{~s}^{-1}(\mathrm{~Pa}-\mathrm{s})\end{array}$ & Type & Heat Treatment & $\begin{array}{c}\text { Mn } \\
\mathrm{g} / \mathrm{mole}\end{array}$ & $\begin{array}{c}\mathrm{Mw} \\
\mathrm{g} / \mathrm{mole}\end{array}$ \\
\hline $\mathrm{AL}$ & 49 & Linear & & 9,200 & 37,800 \\
$\mathrm{BL}$ & 113 & Linear & & 11,000 & 51,100 \\
$\mathrm{CL}$ & 193 & Linear & & 14,500 & 68,700 \\
$\mathrm{DL}$ & 442 & Linear & & 15,100 & 71,800 \\
$\mathrm{EH}$ & 173 & Heat-treated & $250^{\circ} \mathrm{C}, 7 \mathrm{hr}$ & & \\
$\mathrm{FH}$ & 150 & Heat-treated & $250^{\circ} \mathrm{C}, 2 \mathrm{hr}$ & & \\
$\mathrm{GH}$ & 217 & Heat-treated & $250^{\circ} \mathrm{C}, 1 \mathrm{hr}$ & & \\
$\mathrm{HB}$ & 350 & Branched & & & \\
\hline
\end{tabular}

The tensile strength of the as-molded samples is shown as a function of melt viscosity in Figure 19(a) while Figure 19(b) shows their percent elongation. In Figure 19(a) it is observed that samples AL and EH had low strength compared to the other samples. This was explained on the basis that these samples were quite brittle, Figure 19(b). The strength of the other samples decreased with increasing melt viscosity while their percent elongation increased.
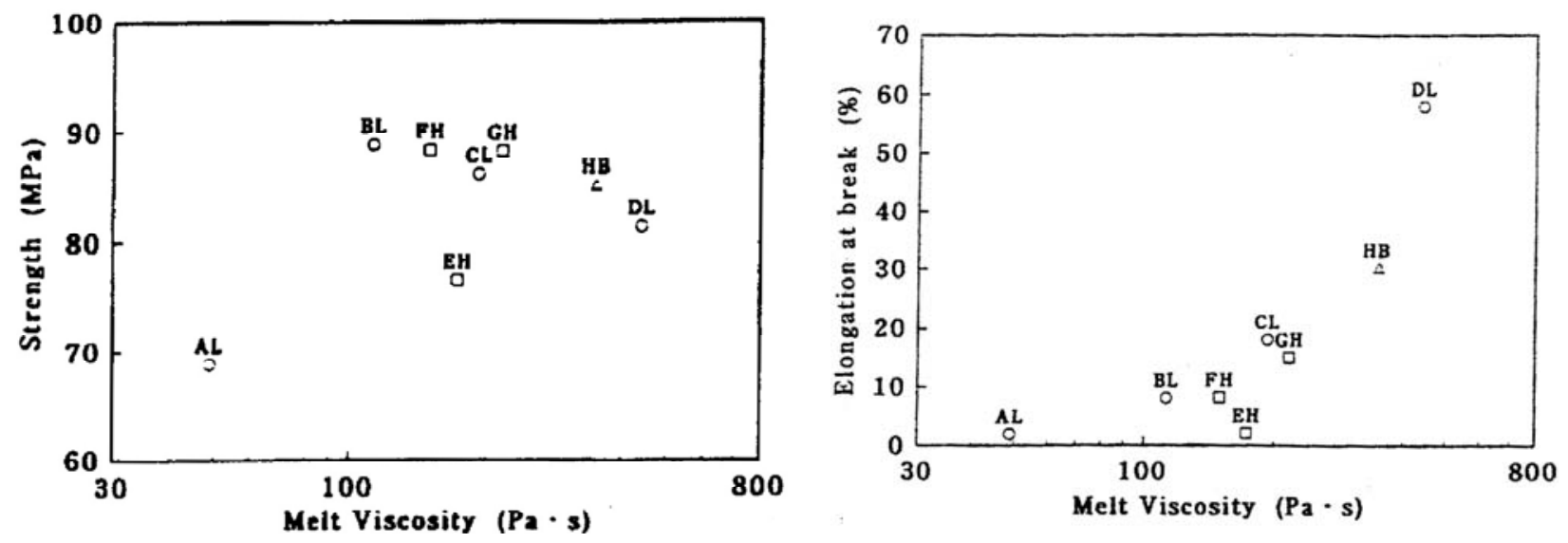

Figure 19. (a) Tensile strength of various neat PPS samples versus melt viscosity (after Nishihata et al. $\left.{ }^{66}\right)$. ( $\left.\bigcirc\right)$ Linear PPS; $(\square)$ Heat treated; $(\triangle)$ Branched. (b) Elongation at break for samples whose strength is shown in (a).

Figure 20 shows the tensile strength plotted versus crystallinity of both the as-molded samples and for samples that were heat treated for $1 \mathrm{hr}$ at $250^{\circ} \mathrm{C}$. The low and moderate melt viscosity samples show a decrease in tensile strength with increase of crystallinity similar to that observed by Brady. But the higher melt viscosity samples show an increase of tensile strength with increasing crystallinity. These results indicate that for samples that exhibit low elongation in the as-molded state, an increase of crystallinity due to annealing is detrimental, but for samples that have higher elongation in the as-molded state, increased crystallinity due to annealing has the usual effect of increasing the tensile strength. 


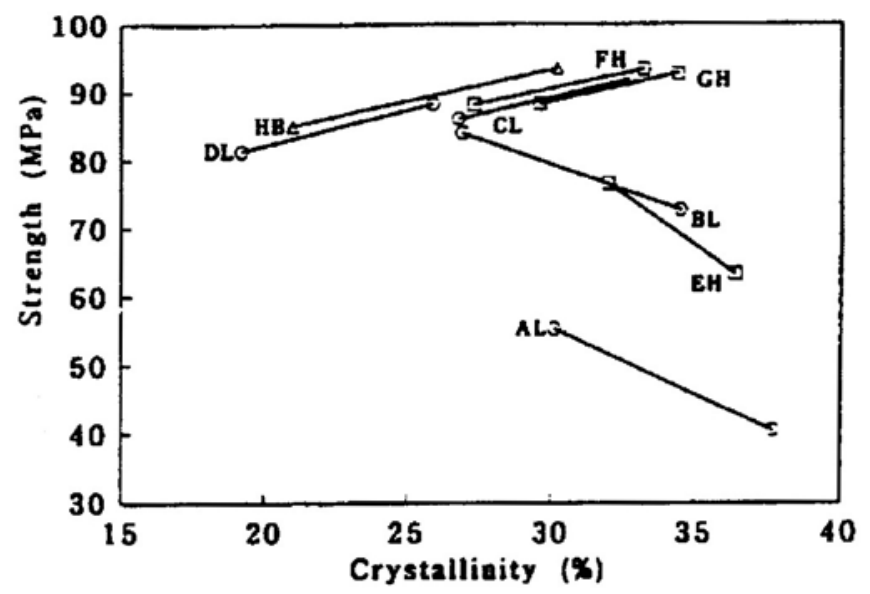

Figure 20. Tensile strength of various neat PPS samples in both the as-molded condition and after heat treating for $1 \mathrm{hr}$ at $250^{\circ} \mathrm{C}$ plotted as function of crystallinity (after Nishihata et al. $\left.{ }^{66}\right)$. ( $\left.\bigcirc\right)$ Linear PPS; $(\square)$ Heat treated; $(\triangle)$ Branched.

Oya and Hamada ${ }^{67}$ evaluated the room temperature, Mode I intralaminar fracture toughness, axial tension, transverse tension, and axial compression properties of unidirectional carbon fiber composite laminates. The laminates were composed of AT-400/PPS and AT400/Nylon 6 and were tested using center-cracked tensile test specimens for Mode I determination, ASTM D3039 for tensile testing and ASTM D3410 for compression testing (Celanese compression test fixture). The tensile properties for the AT-400 carbon fiber, from Asahi Chemical Industry Company Ltd., are comparable to Toray's T300 and Hexcel's AS4 carbon fibers. The tensile modulus for Nylon 6 is lower than that for PPS and they have about the same tensile strength, however, Nylon 6 is considerably more ductile owing to its significantly higher $\%$ strain-to-failure of about $60 \%$ vs. about $2 \%$ for PPS. For comparison purposes to the two thermoplastic resins, Nylon 6 and PPS, two thermoset epoxy resins, \#3601 and \#3631 were included. The AT-400/PPS laminates were processed in an autoclave at $340^{\circ} \mathrm{C}$ for $60 \mathrm{~min}$ and cooled to room temperature at $6^{\circ} \mathrm{C} / \mathrm{min}$ It is worth noting that this processing method differs from that recommended by Ten Cate for their CETEX carbon fiber/PPS laminates. They suggest $300^{\circ}-320^{\circ} \mathrm{C}$ for $20-50 \mathrm{~min}$ with a cooling rate of $10^{\circ}-20^{\circ} \mathrm{C} / \mathrm{min}$ (see later discussion of these data).

The results for the unidirectional mechanical properties for the AT-400/PPS, AT400/Nylon 6, and the two thermoset systems are presented in Table 6. Examples of tensile test results for the thermoplastic matrix composites are shown in Figure 21. Figure 21(a) shows axial data while Figure 21(b) shows the transverse tensile data. The strain to failure in tension parallel to the fibers is fairly similar for the two matrices, due, probably, to the fact that the fiber reinforcement is the same in both cases. However, when tested transverse to the fiber direction, the strain to failure is much higher for the more ductile Nylon 6 matrix composite than for the low ductility PPS matrix composite. Note that the tensile stress in the axial direction is much higher than in the transverse direction, as expected. Compressive stress-strain curves were quite similar for composites prepared with either resin as can be ascertained from the data in Table 6 . 
Table 6. Comparison of Unidirectional Mechanical Properties

\begin{tabular}{lllll}
\hline \multicolumn{1}{c}{ Composite } & AT400/PPS & AT400/nylon6 & T300/\#3601 & T300/\#3631 \\
\hline $\begin{array}{l}\text { Mode I intralaminar } \\
\text { fracture toughness, } \mathrm{K}_{\mathrm{Ic}}\end{array}$ & 1.5 & 3.1 & & \\
$\begin{array}{l}\text { (MPa m } \\
\text { (1/2) }\end{array}$ & & & & \\
$\begin{array}{l}\text { Axial tensile str. (MPa) } \\
\text { Axial tensile strain-to- } \\
\text { failure (\%) }\end{array}$ & 1560 & 1511 & 1515 & 1740 \\
$\begin{array}{l}\text { Axial tensile mod. (GPa) } \\
\text { Trans. tensile str. (MPa) }\end{array}$ & 116 & 1.3 & 1.1 & 1.2 \\
$\begin{array}{l}\text { Trans. tensile strain-to- } \\
\text { failure (\%) }\end{array}$ & 0.25 & 114 & 139 & 136 \\
$\begin{array}{l}\text { Trans. tensile mod. (GPa) } \\
\text { Axial compressive str. }\end{array}$ & 7.9 & 1.5 & 87.3 & 99.3 \\
(MPa) & 820 & 7.3 & 1.0 & 1.3 \\
$\begin{array}{l}\text { Axial compressive strain- } \\
\text { to-failure } \% \text { ) }\end{array}$ & 0.80 & 813 & 9.4 & \\
$\begin{array}{l}\text { Axial compressive mod. } \\
\text { (GPa) }\end{array}$ & 101 & 0.78 & & \\
\hline
\end{tabular}
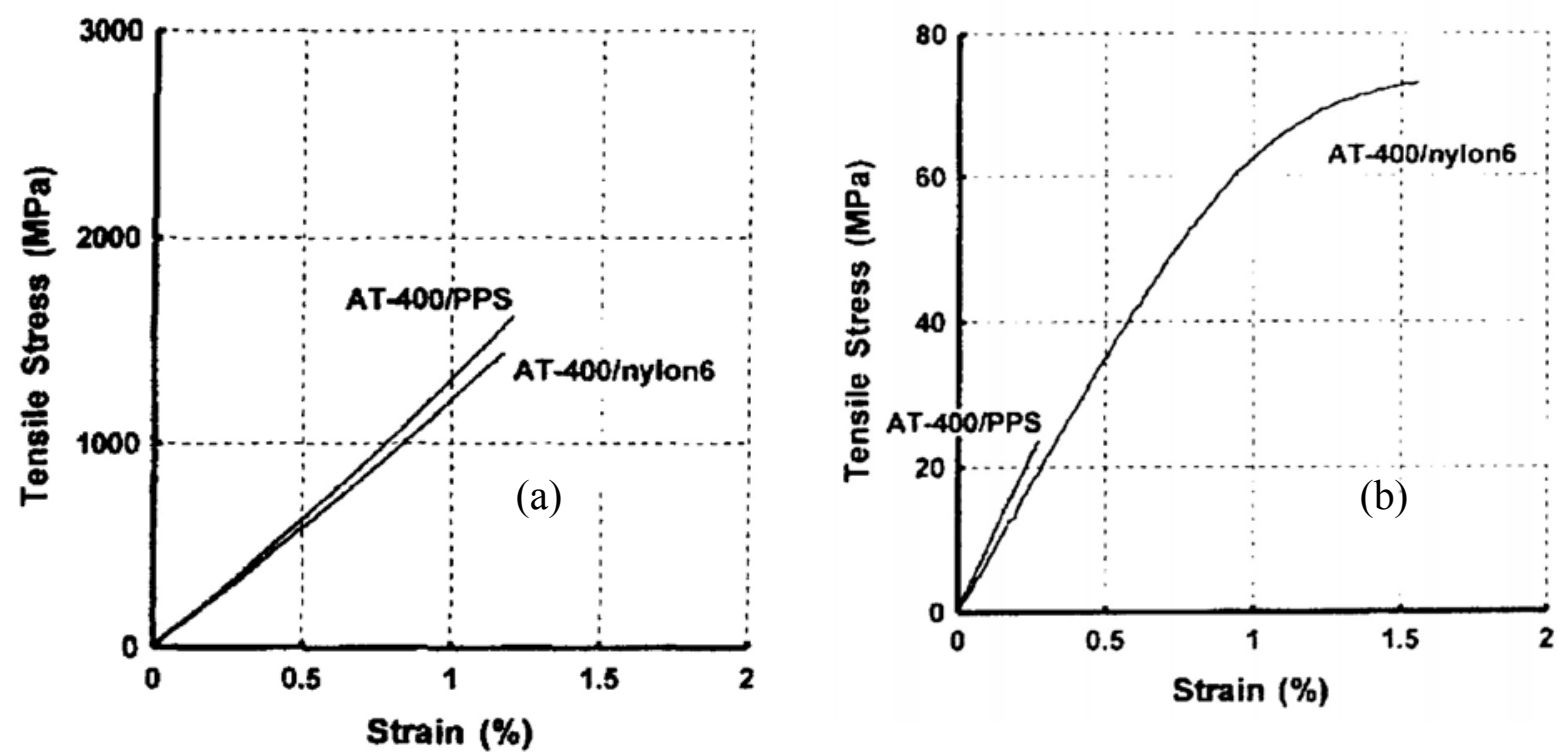

Figure 21. Tensile stress/strain curves for PPS/carbon fiber and polyamide 6/carbon fiber composites. (a) Tensile axis parallel to fibers; (b) tensile axis transverse to fibers (data of Oya et al. $\left.{ }^{67}\right)$.

While the axial tensile and compressive properties were comparable, the mode I fracture toughness of AT-400/nylon 6 was more than double that of AT-400/PPS. Note also, that the 
properties of the Nylon matrix composites were generally similar to the properties of the thermosets.

Fractures from axial tensile tests of the Nylon 6 matrix composites exhibited two modes of failure referred to as "straight" and "brush-like." The straight failures broke perpendicular to the test direction and across the fibers; the brush fractures exhibited many splitting cracks parallel to the fibers. The PPS matrix composites only exhibited the brush-like fracture mode. Two kinds of fracture were also observed in the compression tests: a "shear" mode and a "transverse" mode. In the "shear" mode the fracture was approximately at $45^{\circ}$ to the compression axis.

SEM images of the various samples suggested that debonding between the matrix and fiber occurred for the PPS composites while fracture through the matrix was dominant in the Nylon 6 composites.

Models that describe the suggested failure mechanisms of these materials were proposed. They are illustrated in Figures 22 and 23. The basic difference between the failures was explained on the basis that cracks originating in the fiber propagated through the matrix for the polyamide 6 composites, but they propagated, in part, along the fiber interface in the PPS composites.

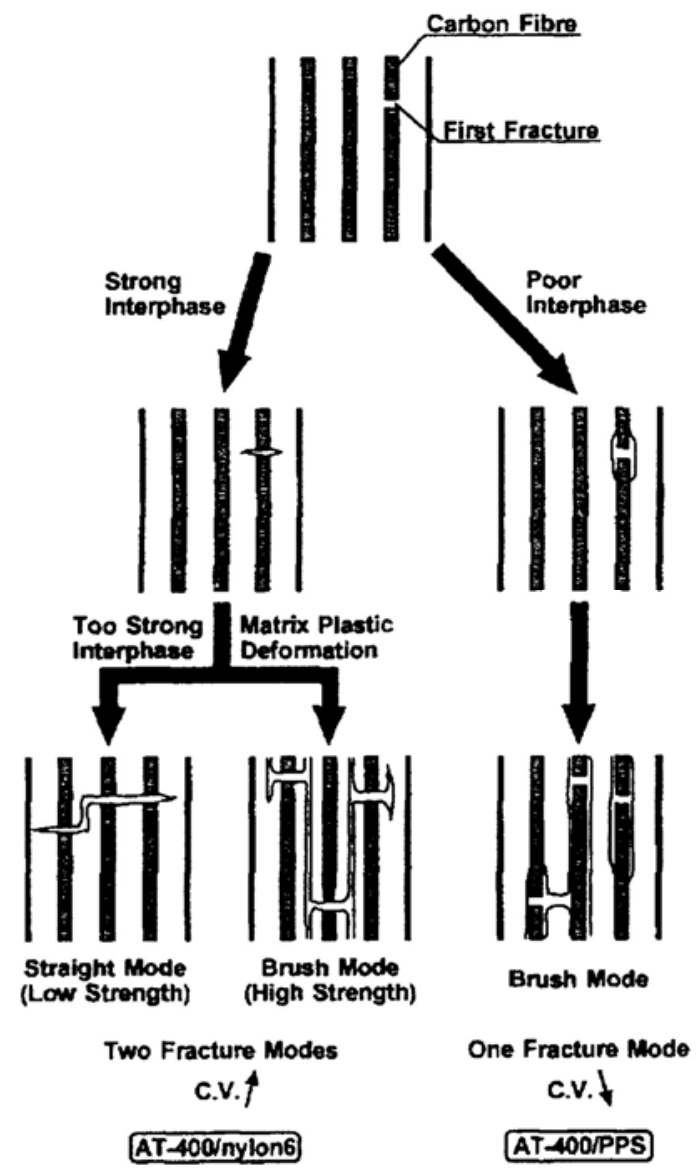

Figure 22. Model of failure mechanism for samples tested in axial tension (after Oya and Hamada ${ }^{67}$ ). 

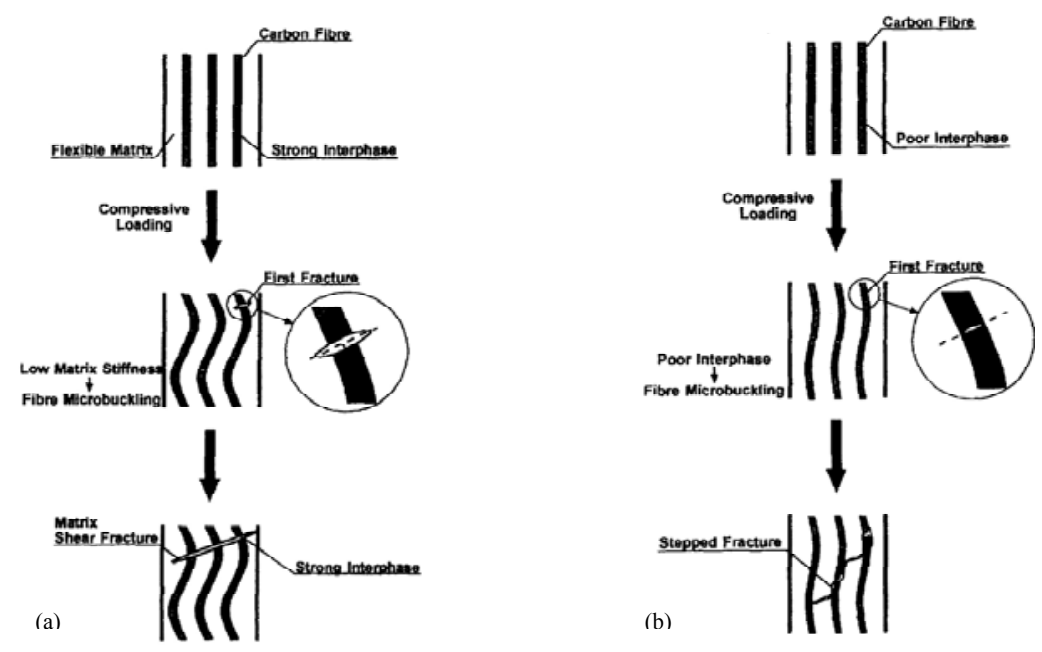

Figure 23. Models of failure mechanisms in axial compression for carbon fiber reinforced, polymer matrix composites (after Oya and Hamada ${ }^{62}$ ). (a) Model for strong interphase as for polyamide 6; (b) Model for weak interphase as for PPS.

Typical PPS composite properties on both carbon and glass fibers in various fiber forms are presented in Table 7..$^{\circ}$ It is worth noting that these properties were generated prior to 1986 and should not be considered optimum since issues such as fiber-wetting and laminate processing were in the early stages of development.

\subsection{1 - Recent Data - Ten Cate}

Over the last several years, the Ten Cate Company has generated a large amount of mechanical property data on composite laminates fabricated from Ten Cate's CETEX prepreg material and tested in accordance with MIL-HNBK-17. ${ }^{70}$ This effort was part of a major qualification program in support of the new, commercial Airbus A380 airplane and included material systems comprised of carbon/PPS, glass/PPS, carbon/polyetherimide (PEI), and glass/PEI. The PPS resin that was used in the manufacture of the prepreg was based on Ticona's 0214 PPS material. Since these data were part of a major European Aircraft Program it can safely be assumed that the processing, level of crystallinity, and resulting mechanical property data for the glass/PPS and carbon/PPS laminates have been optimized.

The principal fibers and resins used in the manufacture of these laminates included Toray's T300J 3K carbon fiber with PPS resin in either plain weave or 5 harness satin (5HS) weave; Toray's T300 3K carbon fiber with PEI resin, in either plain weave, 5HS weave, or unidirectional form; and lastly, E-glass fiber (Fabric Style 7781) with PPS or PEI resin. The fiber properties for the T300J and T300 carbon fibers include tensile strength's of 4,120 MPa (611 ksi) and 3,530 $\mathrm{MPa}(512 \mathrm{ksi})$, tensile moduli for both of $230 \mathrm{GPa}(33.4 \mathrm{msi})$, and percent strains of $1.8 \%$ and $1.5 \%$, respectively. There were two different glass fiber sizings used with the glass/PPS laminates including A1100 and 8548. The type of fiber sizings used on the carbon fibers was not disclosed. All of the glass/PPS and carbon/PPS laminates had nominal fiber volumes of $50 \%$, a $\mathrm{T}_{\mathrm{g}}$ (DSC-amorphous) of $85^{\circ} \mathrm{C}$, a $\mathrm{T}_{\mathrm{c}}$ (DSC-cold crystallization temperature) of $120^{\circ} \mathrm{C}$, and a $\mathrm{T}_{\mathrm{m}}$ of $280^{\circ} \mathrm{C}$. 
Table 7. Typical PPS Composite Properties (Note: Properties Generated Prior to 1986)

\begin{tabular}{|c|c|c|c|c|c|c|c|}
\hline \multirow[b]{2}{*}{ Property } & \multirow[b]{2}{*}{$\begin{array}{c}\text { ASTM } \\
\text { test }\end{array}$} & \multicolumn{4}{|c|}{ Carbon reinforcement" } & \multicolumn{2}{|c|}{ Glass reinforcement ${ }^{\phi}$} \\
\hline & & Unidirectional & $\begin{array}{c}\text { Quasi- } \\
\text { cross-plied }\end{array}$ & Isotropic & $\begin{array}{l}\text { Woven } \\
\text { fabric }\end{array}$ & $\begin{array}{l}\text { Woven } \\
\text { fabric }\end{array}$ & Unidirectional \\
\hline density, $\mathrm{g} / \mathrm{cm}^{3}$ & & 1.6 & 1.6 & 1.6 & 1.6 & 1.7 & 2.0 \\
\hline void content, vol $\%$ & & $<1$ & $<1$ & $<1$ & $<1$ & $<1$ & $<1$ \\
\hline tensile modulus, $\mathrm{GPa}^{d}$ & D3039 & 120 & 51 & 40 & 59 & 17 & 50 \\
\hline tensile strength, $\mathrm{MPa}$ & D3039 & 1700 & 580 & 615 & 635 & 180 & 910 \\
\hline flexural modulus, $\mathrm{GPa}^{d}$ & D790 & 110 & 62 & 40 & 55 & 15 & 44 \\
\hline flexural strength, $\mathrm{MPa}^{\circ}$ & D790 & 1586 & 690 & 655 & 655 & 270 & 1160 \\
\hline compressive modulus, $\mathrm{GPa}^{d}$ & $\begin{array}{l}\text { D3410 } \\
\text { IITRI }\end{array}$ & 110 & & & 63 & 19 & 49 \\
\hline compressive strength, $\mathrm{MPa}^{r}$ & $\begin{array}{l}\text { D3410 } \\
\text { IITRI }\end{array}$ & 890 & & 365 & 365 & 145 & 760 \\
\hline short beam shear, $\mathrm{MPa}^{r}$ & D2344 & 70 & 28 & & 48 & & 48 \\
\hline $\mathrm{HDT}, 1.8 \mathrm{MPa}^{c},{ }^{\circ} \mathrm{C}$ & D648 & 280 & 280 & & 280 & 273 & 275 \\
\hline $\begin{array}{l}\text { Izod impact strength, } \mathrm{kJ} / \mathrm{m}^{f} \\
\text { notched, } 0.3 \mathrm{~cm} \\
\text { unnotched, } 0.3 \mathrm{~cm}\end{array}$ & & $\begin{array}{l}1.60 \\
3.15\end{array}$ & & & $\begin{array}{l}0.67 \\
1.15\end{array}$ & $\begin{array}{l}0.43 \\
0.91\end{array}$ & \\
\hline fracture toughness $\left(G_{1 c}\right)^{k}, \mathrm{~kJ} / \mathrm{m}^{2 h}$ & & $0.53-0.88$ & & & & & 1.23 \\
\hline 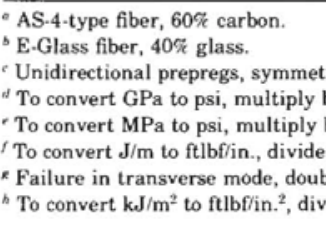 & $\begin{array}{l}45 ; 0 ;- \\
\times 10^{6} \\
38 . \\
\text { ilever be } \\
2.10 \text {. }\end{array}$ & & & & & & \\
\hline
\end{tabular}

The laminates were processed and consolidated at temperatures of $300^{\circ}-320^{\circ} \mathrm{C}$ in a laminate press or autoclave. Subsequent to consolidation in the press, the laminates were demolded and cooled to about $160^{\circ} \mathrm{C}$ for about one minute to achieve optimum crystallinity or, if processed in an autoclave, the laminates were cooled at $10^{\circ}-20^{\circ} \mathrm{C} / \mathrm{min}$ while under $6-10$ bar (87$145 \mathrm{psi}$ ) pressure.

The mechanical property tests that were performed included:

1. Tensile strength (Warp direction, direction perpendicular to fabric width direction)

2. Tensile strength (Weft direction, direction parallel to fabric width direction)

3. Tensile modulus (Warp direction)

4. Tensile modulus (Weft direction)

5. Compression strength (Warp direction)

6. Compression strength (Weft direction)

7. Compression modulus (Warp direction)

8. Compression modulus (Weft direction)

9. Flexural strength (Warp direction)

10. Flexural modulus (Warp direction)

11. Inplane shear strength

12. Inplane shear modulus

13. Open hole tensile strength

14. Open hole compressive strength

15. Compression after impact strength

16. Ultimate bearing strength

The various test temperatures and types of pre-conditioning that were used during the evaluation of the laminates are given in Table 8 .

A summary of the mechanical property test results for the glass/PPS and carbon/PPS laminates are shown in Table 9. Representative graphical results are presented in Figures 24-27. Additional graphical results and raw data ${ }^{18}$ are presented in Appendix A. 
Table 8. Test Conditions for Cetex Data.

\begin{tabular}{lll}
\hline Test Temp. & Pre-Conditioning & Abbreviation \\
\hline$-55^{\circ} \mathrm{C}$ & Dry & $-55 /$ Dry \\
\hline $23^{\circ} \mathrm{C}$ & $50 \% \mathrm{RH}$ & $23 \mathrm{C}$ \\
$80^{\circ} \mathrm{C}$ & Dry & $80 \mathrm{C} /$ Dry \\
$23^{\circ} \mathrm{C}$ & $\left(70^{\circ} \mathrm{C} / 85 \% \mathrm{RH}\right)$ & $23 \mathrm{C} /$ Wet \\
$80^{\circ} \mathrm{C}$ & $\left(70^{\circ} \mathrm{C} / 85 \% \mathrm{RH}\right)$ & $80 \mathrm{C} /$ Wet \\
$100^{\circ} \mathrm{C}$ & $\left(70^{\circ} \mathrm{C} / 85 \% \mathrm{RH}\right)$ & $100 \mathrm{C} /$ Wet \\
\hline
\end{tabular}

Table 9. Summary of Mechanical Property Test Data on Ten Cate Cetex Laminates.

Test temperatures/Pre-conditions: -55C/Dry, 23C, 80C/Dry, 23C/Wet, 80C/Wet, 100C/Wet

\begin{tabular}{|c|c|c|c|c|}
\hline $\begin{array}{l}\text { Mechanical } \\
\text { Property }\end{array}$ & T300J Plain/PPS & T300J 5HS/PPS & Glass 7781 (8548)/PPS & Glass 7781 (A1100)/PPS \\
\hline $\begin{array}{l}\text { Tensile } \\
\text { Strength } \\
\text { (Warp } \\
\text { Direction) }\end{array}$ & $\begin{array}{c}\text { Generally } \\
\text { equivalent at all } \\
\text { test } \\
\text { temperatures/pre- } \\
\text { conditions; Plain } \\
\text { weave properties } \\
\text { were higher than } \\
\text { 5HS weave } \\
\text { properties }\end{array}$ & $\begin{array}{c}\text { Generally equivalent at } \\
\text { all test } \\
\text { temperatures/pre- } \\
\text { conditions }\end{array}$ & $\begin{array}{l}\text { Highest at }-55 \mathrm{C} / \mathrm{Dry} \text {, } \\
\text { then decreased with } \\
\text { increasing temp. in the } \\
\text { order }-55 / \text { Dry }>23 \mathrm{C}> \\
\text { 80C/Dry; Wet condition } \\
\text { 23C/Wet }>80 \mathrm{C} / \text { Wet }> \\
\text { 100C/Wet; } 8548 \\
\text { properties higher than } \\
\text { A1100 properties except } \\
\text { at } 80 \text { C/Dry and } \\
\text { 100C/Wet (slightly } \\
\text { lower) }\end{array}$ & $\begin{array}{l}\text { Highest at }-55 \mathrm{C} / \text { Dry, then } \\
\text { decreased with increasing } \\
\text { temp. in the order }-55 / \text { Dry } \\
>23 \mathrm{C}>80 \mathrm{C} / \mathrm{Dry} \text {; Wet } \\
\text { condition } 100 \mathrm{C} / \text { Wet }> \\
23 \mathrm{C} / \text { Wet }=80 \mathrm{C} / \text { Wet }\end{array}$ \\
\hline $\begin{array}{l}\text { Tensile } \\
\text { Strength } \\
\text { (Weft } \\
\text { Direction) }\end{array}$ & $\begin{array}{l}\text { Highest at - } \\
\text { 55C/Dry, then } \\
\text { decreased with } \\
\text { increasing temp. } \\
\text { in the order - } \\
\text { 55/Dry > 23C > } \\
\text { 80C/Dry; Wet } \\
\text { condition 80C/Wet } \\
>\text { 80C/Dry }\end{array}$ & $\begin{array}{c}\text { Generally equivalent at } \\
\text { all test } \\
\text { temperatures/pre- } \\
\text { conditions; } 5 \mathrm{HS} \\
\text { properties were higher } \\
\text { than Plain weave } \\
\text { properties }\end{array}$ & $\begin{array}{l}\text { Highest at }-55 \mathrm{C} / \mathrm{Dry} \text {, } \\
\text { then decreased with } \\
\text { increasing temp. in the } \\
\text { order }-55 / \text { Dry }>23 \mathrm{C}> \\
80 \mathrm{C} / \text { Dry; Wet condition } \\
\text { 23C/Wet }>80 \mathrm{C} / \text { Wet }> \\
\text { 100C/Wet; } 8548 \\
\text { properties higher than } \\
\text { A1100 properties except } \\
\text { at } 80 \mathrm{C} / \text { Dry (comparable) }\end{array}$ & $\begin{array}{l}\text { Highest at }-55 \mathrm{C} / \text { Dry, then } \\
\text { decreased with increasing } \\
\text { temp. in the order }-55 / \text { Dry } \\
>23 \mathrm{C}>80 \mathrm{C} / \mathrm{Dry} \text {; Wet } \\
\text { condition } 23 \mathrm{C} / \text { Wet }> \\
\text { 80C/Wet }>100 / \text { Wet }\end{array}$ \\
\hline $\begin{array}{l}\text { Tensile } \\
\text { Modulus } \\
\text { (Warp } \\
\text { Direction) }\end{array}$ & $\begin{array}{l}\text { Lowest at - } \\
55 \mathrm{C} / \mathrm{Dry}, \text { then } \\
\text { slightly increased } \\
\text { at } 23 \mathrm{C} \text {, then } 23 \mathrm{C} \\
=80 \mathrm{C} / \mathrm{Dry}= \\
\text { 80C/Wet; Plain } \\
\text { weave properties } \\
\text { slightly higher } \\
\text { than } 5 \mathrm{HS} \text { weave } \\
\text { properties except } \\
\text { at -55C/Dry } \\
\text { (comparable) } \\
\end{array}$ & $\begin{array}{c}\text { Lowest at }-55 \mathrm{C} / \text { Dry, } \\
\text { then slightly increased at } \\
23 \mathrm{C} \text {, then } 23 \mathrm{C}= \\
80 \mathrm{C} / \text { Dry }=80 \mathrm{C} / \mathrm{Wet}\end{array}$ & $\begin{array}{c}\text { Generally equivalent at } \\
\text { all test } \\
\text { temperatures/pre- } \\
\text { conditions }\end{array}$ & $\begin{array}{l}\text { Generally equivalent at all } \\
\text { test temperatures/pre- } \\
\text { conditions; A1100 } \\
\text { properties slightly higher } \\
\text { than } 8548 \text { properties }\end{array}$ \\
\hline
\end{tabular}




\section{Table 9. Summary of Mechanical Property Test Data on Ten Cate Cetex Laminates Continued.}

\begin{tabular}{|c|c|c|c|c|}
\hline $\begin{array}{l}\text { Mechanical } \\
\text { Property }\end{array}$ & T300J Plain/PPS & T300J 5HS/PPS & Glass 7781 (8548)/PPS & Glass 7781 (A1100)/PPS \\
\hline $\begin{array}{l}\text { Tensile } \\
\text { Modulus } \\
\text { (Weft } \\
\text { Direction) }\end{array}$ & $\begin{array}{c}\text { Generally } \\
\text { equivalent at all } \\
\text { test } \\
\text { temperatures/pre- } \\
\text { conditions; Plain } \\
\text { weave properties } \\
\text { comparable to } \\
5 \mathrm{HS} \text { weave } \\
\text { properties at - } \\
\text { 55C/Dry, 23C, } \\
\text { and 80C/Wet and } \\
\text { slightly lower at } \\
\text { 80C/Dry }\end{array}$ & $\begin{array}{c}\text { Generally equivalent at } \\
\text { all test } \\
\text { temperatures/pre- } \\
\text { conditions }\end{array}$ & $\begin{array}{l}\text { Highest at }-55 \mathrm{C} / \text { Dry and } \\
23 \mathrm{C} \text {, then slightly } \\
\text { decreased with } \\
\text { increasing temperature } \\
\text { at } 80 \mathrm{C} / \mathrm{Dry} \text {; Wet } \\
\text { conditions - properties } \\
\text { decreased with } \\
\text { increasing temperature } \\
\text { 23C/Wet > 80C/Wet }> \\
100 \mathrm{C} / \text { Wet; }\end{array}$ & $\begin{array}{c}\text { Highest at }-55 \mathrm{C} / \text { Dry and } \\
23 \mathrm{C} \text {, then slightly } \\
\text { decreased with increasing } \\
\text { temperature at } 80 \mathrm{C} / \mathrm{Dry} ; \\
\text { Wet conditions - properties } \\
\text { decreased with increasing } \\
\text { temperature } 23 \mathrm{C} / \text { Wet }> \\
80 \mathrm{C} / \text { Wet }>100 \mathrm{C} / \mathrm{Wet} ; \\
\text { A1100 properties slightly } \\
\text { higher than } 8548 \\
\text { properties }\end{array}$ \\
\hline $\begin{array}{l}\text { Compression } \\
\text { Strength } \\
\text { (Warp } \\
\text { Direction) }\end{array}$ & $\begin{array}{l}\text { Highest at - } \\
\text { 55C/Dry, then } \\
\text { decreased with } \\
\text { increasing temp. } \\
\text { and decreased } \\
\text { from dry to wet } \\
\text { condition (-55/Dry } \\
>23 \mathrm{C}>80 \mathrm{C} / \text { Dry } \\
>80 \mathrm{C} / \text { Wet }\end{array}$ & $\begin{array}{l}\text { Highest at }-55 \mathrm{C} / \text { Dry, } \\
\text { then decreased with } \\
\text { increasing temp. and } \\
\text { decreased from dry to } \\
\text { wet condition (-55/Dry > } \\
23 \mathrm{C}>80 \mathrm{C} / \text { Dry }> \\
\text { 80C/Wet }\end{array}$ & $\begin{array}{c}\text { Highest at }-55 \mathrm{C} / \text { Dry, } \\
\text { then decreased with } \\
\text { increasing temp. and } \\
\text { decreased from dry to } \\
\text { wet condition }(-55 / \text { Dry }> \\
23 \mathrm{C}>80 \mathrm{C} / \text { Dry }= \\
23 \mathrm{C} / \text { Wet }>80 \mathrm{C} / \text { Wet }> \\
100 \mathrm{C}\end{array}$ & $\begin{array}{l}\text { Highest at }-55 \mathrm{C} / \text { Dry, then } \\
\text { decreased with increasing } \\
\text { temp. and decreased from } \\
\text { dry to wet condition (- } \\
\text { 55/Dry }>23 \mathrm{C}>80 \mathrm{C} / \mathrm{Dry}> \\
\text { 23C/Wet }>80 \mathrm{C} / \mathrm{Wet} \\
>100 \mathrm{C} / \mathrm{Wet} \text {; A1100 } \\
\text { properties slightly or } \\
\text { significantly higher than } \\
8548 \text { properties }\end{array}$ \\
\hline $\begin{array}{l}\text { Compression } \\
\text { Strength } \\
\text { (Weft } \\
\text { Direction) }\end{array}$ & $\begin{array}{l}\text { Highest at - } \\
55 \mathrm{C} / \mathrm{Dry} \text {, then } \\
\text { decreased with } \\
\text { increasing temp. } \\
\text { and decreased } \\
\text { from dry to wet } \\
\text { condition (-55/Dry } \\
>23 \mathrm{C}>80 \mathrm{C} / \mathrm{Dry} \\
>23 \mathrm{C} / \mathrm{Wet}> \\
80 \mathrm{C} / \mathrm{Wet}\end{array}$ & $\begin{array}{l}\text { Highest at }-55 \mathrm{C} / \text { Dry, } \\
\text { then decreased with } \\
\text { increasing temp. and } \\
\text { decreased from dry to } \\
\text { wet condition (-55/Dry > } \\
23 \mathrm{C}>80 \mathrm{C} / \mathrm{Dry}> \\
80 \mathrm{C} / \text { Wet; } 5 \mathrm{HS} \\
\text { properties higher than } \\
\text { Plain weave properties }\end{array}$ & $\begin{array}{l}\text { Highest at }-55 \mathrm{C} / \text { Dry, } \\
\text { then decreased with } \\
\text { increasing temp. and } \\
\text { decreased from dry to } \\
\text { wet condition }(-55 / \text { Dry }> \\
23 \mathrm{C}>80 \mathrm{C} / \text { Dry }< \\
23 \mathrm{C} / \text { Wet, then } 23 \mathrm{C} / \text { Wet } \\
>80 \mathrm{C} / \text { Wet }>100 \mathrm{C}\end{array}$ & $\begin{array}{c}\text { Highest at }-55 \mathrm{C} / \text { Dry, then } \\
\text { decreased with increasing } \\
\text { temp. and decreased from } \\
\text { dry to wet condition }(- \\
\text { 55/Dry }>23 \mathrm{C}>80 \mathrm{C} / \mathrm{Dry}> \\
\text { 23C/Wet }>80 \mathrm{C} / \mathrm{Wet} \\
>100 \mathrm{C} / \text { Wet; A1100 } \\
\text { properties higher than } \\
8548 \text { properties }\end{array}$ \\
\hline $\begin{array}{l}\text { Compression } \\
\text { Modulus } \\
\text { (Warp } \\
\text { Direction) }\end{array}$ & $\begin{array}{c}\text { Generally } \\
\text { equivalent at all } \\
\text { test } \\
\text { temperatures/pre- } \\
\text { conditions }\end{array}$ & $\begin{array}{c}\text { Comparable and highest } \\
\text { at } 23 \mathrm{C}=80 \mathrm{C} / \mathrm{Dry}= \\
80 \mathrm{C} / \text { Wet, then slightly } \\
\text { lower at }-55 \mathrm{C} / \mathrm{Dry}\end{array}$ & $\begin{array}{c}\text { Highest at }-55 \mathrm{C} / \text { Dry and } \\
23 \mathrm{C} \text {, then in the order }- \\
55 \mathrm{C} / \text { Dry }=23 \mathrm{C}>23 / \text { Wet } \\
>80 \mathrm{C} / \text { Dry }=80 \mathrm{C} / \text { Wet }> \\
100 \mathrm{C} / \text { Wet }\end{array}$ & $\begin{array}{l}\text { Generally equivalent at all } \\
\text { test temperatures/pre- } \\
\text { conditions; A1100 } \\
\text { properties slightly higher } \\
\text { than } 8548 \text { properties }\end{array}$ \\
\hline $\begin{array}{l}\text { Compression } \\
\text { Modulus } \\
\text { (Weft } \\
\text { Direction) }\end{array}$ & $\begin{array}{c}\text { Generally } \\
\text { equivalent at all } \\
\text { test } \\
\text { temperatures/pre- } \\
\text { conditions }\end{array}$ & $\begin{array}{c}\text { Generally equivalent at } \\
\text { all test } \\
\text { temperatures/pre- } \\
\text { conditions; } 5 \mathrm{HS} \\
\text { properties slightly higher } \\
\text { than Plain weave } \\
\text { properties } \\
\end{array}$ & $\begin{array}{c}\text { Comparable and highest } \\
\text { at }-55 \mathrm{C} / \text { Dry }=23 \mathrm{C}= \\
23 \mathrm{C} / \text { Wet, then } \\
\text { decreased in order } \\
80 \mathrm{C} / \text { Dry }=80 \mathrm{C} / \text { Wet }> \\
100 \mathrm{C} / \text { Wet }\end{array}$ & $\begin{array}{l}\text { Generally equivalent at all } \\
\text { test temperatures/pre- } \\
\text { conditions; A1100 } \\
\text { properties higher than } \\
8548 \text { properties except at - } \\
\text { 55C/Dry and 23C/Wet } \\
\text { (comparable) }\end{array}$ \\
\hline $\begin{array}{l}\text { Flexural } \\
\text { Strength } \\
\text { (Warp } \\
\text { Direction) }\end{array}$ & & & & $\begin{array}{l}\text { Highest at }-55 \mathrm{C} / \text { Dry, then } \\
\text { decreased in the order - } \\
55 \mathrm{C} / \text { Dry }>23 \mathrm{C}>80 \mathrm{C} / \text { Dry } \\
>23 \mathrm{C} / \text { Wet }=80 \mathrm{C} / \mathrm{Wet}\end{array}$ \\
\hline
\end{tabular}




\section{Table 9. Summary of Mechanical Property Test Data on Ten Cate Cetex Laminates Continued.}

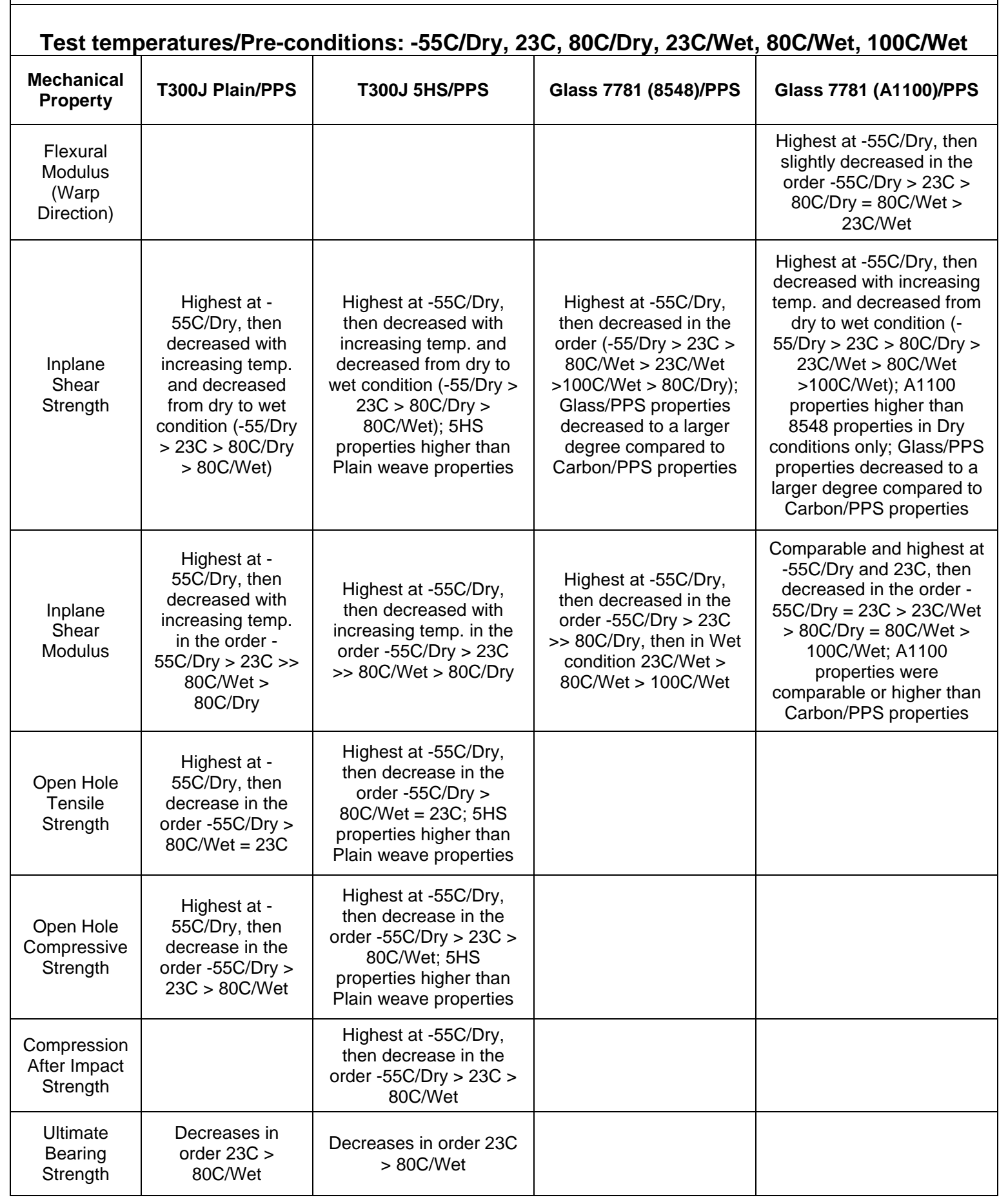




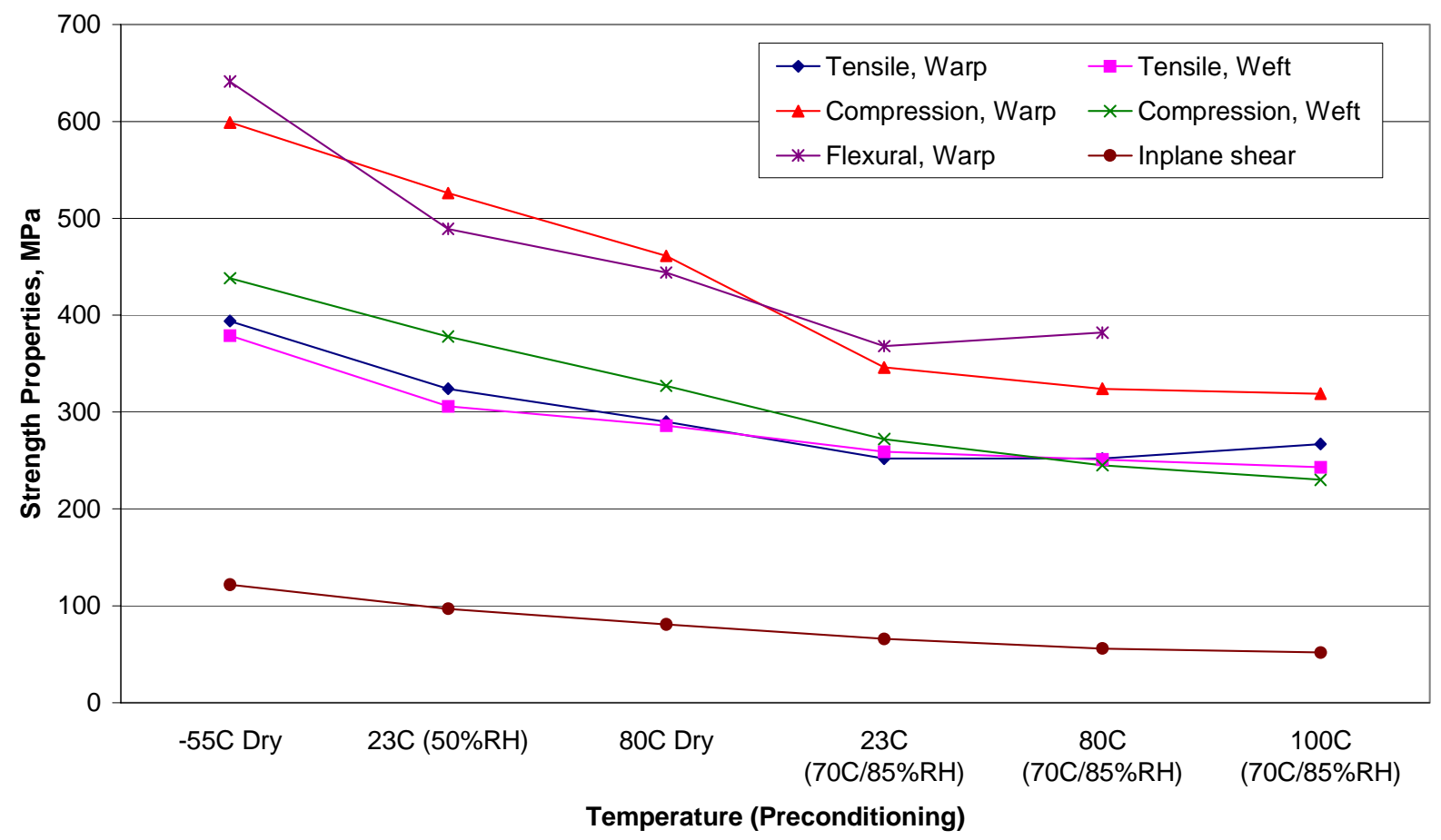

Figure 24. Strength Properties of Glass 7781 (A1100)/PPS Composites.

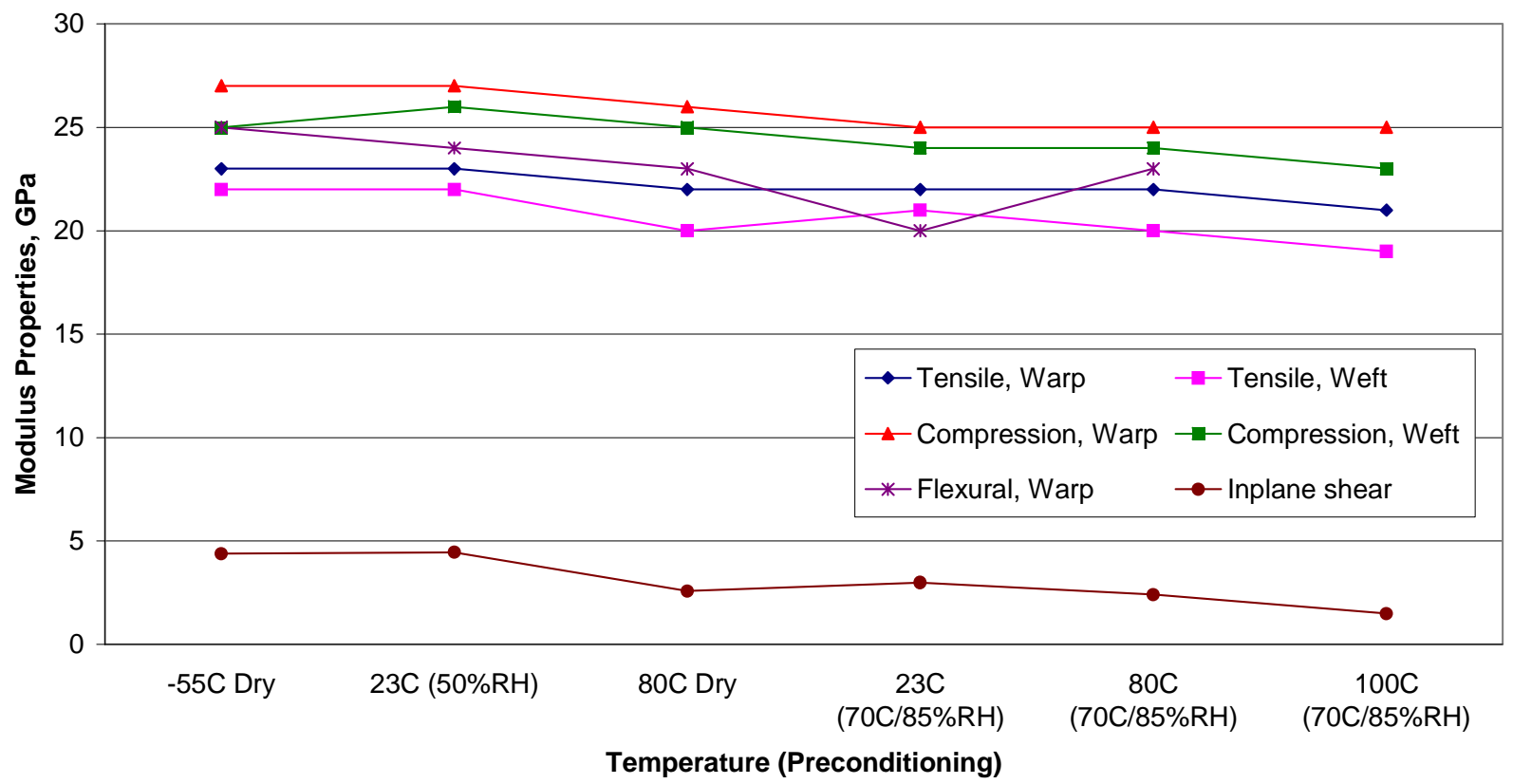

Figure 25. Modulus Properties of Glass 7781 (A1100)/PPS Composites. 


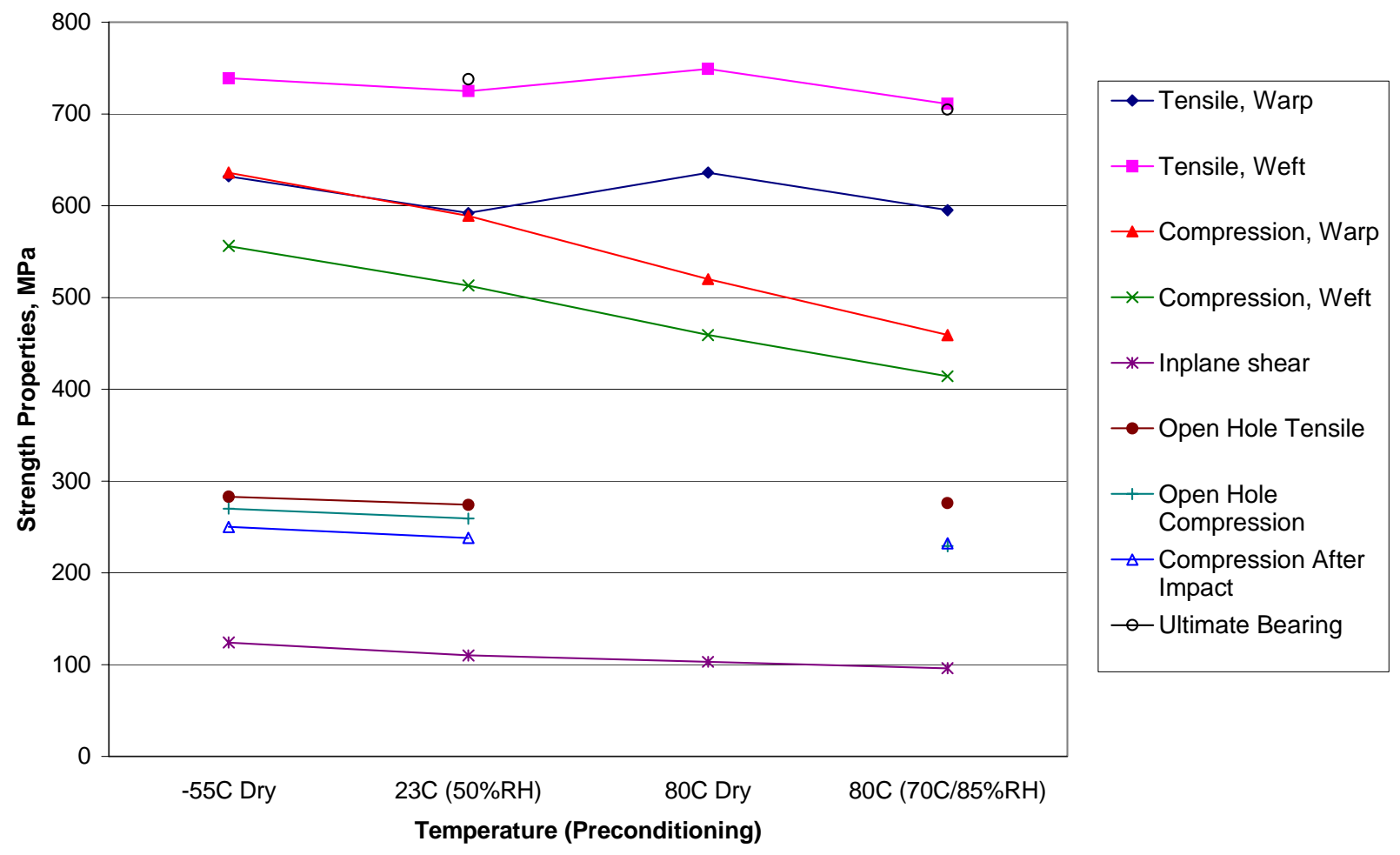

Figure 26. Strength Properties of T300J 5HS/PPS (Vf=50\%) Composites.

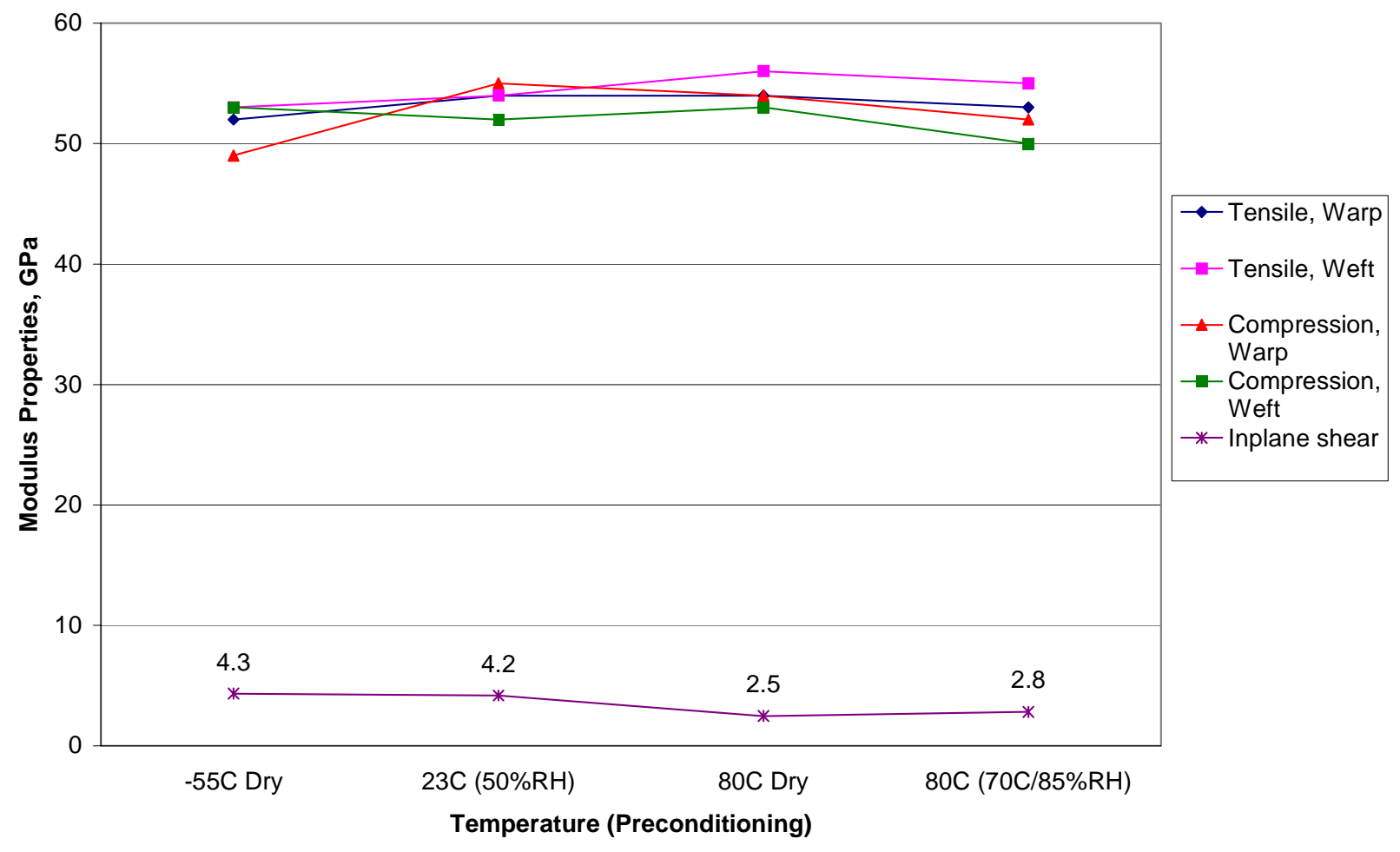

Figure 27. Modulus Properties of T300J 5HS/PPS (Vf=50\%) Composites. 
Figure 24 illustrates the strength properties for glass 7781 (A1100)/PPS laminates. These properties were at their highest at $-55^{\circ} \mathrm{C} /$ Dry. The flexural, compressive, and in-plane shear samples lost $43-57 \%$ of their strength, respectively, from $-55^{\circ}-100^{\circ} \mathrm{C}$, and the tensile samples lost the least amount of strength (36\%) over this temperature range. Figure 25 shows the modulus properties for glass 7781 (A1100)/PPS laminates which were less sensitive to the test conditions versus the corresponding strength properties, losing from $7-20 \%$ of their modulus from $-55^{\circ}-100^{\circ} \mathrm{C}$, except for the in-plane shear modulus samples which decreased $66 \%$ throughout the same temperature range. Generally, the glass/PPS samples tested at $-55^{\circ} \mathrm{C}$ had the highest modulus.

Figure 26 illustrates the strength properties for carbon T300J 5HS/PPS laminates which fared much better in strength retention versus the glass/PPS laminates. From $-55^{\circ}-80^{\circ} \mathrm{C}$ the open-hole tension, bearing strength, compression-after-impact, and tensile samples lost the least amount of strength (3-7\%), whereas the open-hole compression, in-plane shear, and compression samples lost the most strength (15-28\%). The modulus properties for the carbon T300J 5HS/PPS laminates are shown in Figure 27 and these properties were relatively unaffected by test condition, except for the in-plane shear samples which decreased in modulus from $35-41 \%$ over the temperature range $-55^{\circ}-80^{\circ} \mathrm{C}$.

Included in Appendix B are the mechanical property results on carbon fabric/PEI and carbon fabric/PPS laminates from the Ten Cate Company ${ }^{18}$ including T300 plain weave/PEI, T300J plain weave/PPS, T300 5HS/PEI, and T300 5HS/PPS.

\subsection{Fiber Matrix Adhesion}

Lin Ye, et. al. ${ }^{68}$ evaluated the effects of processing temperatures and cooling rates on the matrix morphology and fiber-matrix interfacial shear strength of T700S/PPS composites using a hot stage microscope. Fiber pull-out samples consisted of single, unsized T700S fiber (Toray) and PPS (Ryton) resin and were fabricated by heating the samples at $20^{\circ} \mathrm{C} / \mathrm{min}$ to $320^{\circ} \mathrm{C}$, then holding for $2 \mathrm{~min}$, followed by cooling to $30^{\circ} \mathrm{C}$ using three different cooling rates of $20^{\circ} \mathrm{C} / \mathrm{min}$, $3^{\circ} \mathrm{C} / \mathrm{min}$ and $1{ }^{\circ} \mathrm{C} / \mathrm{min}$ At faster cooling rates of $20^{\circ} \mathrm{C} / \mathrm{min}$ the size of the spherulites were smaller and averaged approximately 60 micrometers, whereas for slower cooling rates of $1{ }^{\circ} \mathrm{C} / \mathrm{min}$ the spherulites averaged approximately 200 micrometers in size. Other than the differences in the sizes of the spherulites, which can be attributed to the different cooling rates, no change in the morphology at the fiber-matrix interfacial area was observed due to the presence of the T700S fiber and this area was equivalent to that observed in the bulk matrix.

Although no transcrystallization was observed during normal processing conditions around the unsized T700S fiber, following a special processing history could induce this effect. Transcrystallinity around the fiber was achievable by simply touching the fiber between $240^{\circ}-250^{\circ} \mathrm{C}$, after cool-down from the $320^{\circ} \mathrm{C}$ melt temperature at a cooling rate of $20^{\circ} \mathrm{C} / \mathrm{min}$, then isothermally crystallizing the sample for $10 \mathrm{~min}$ at $227^{\circ} \mathrm{C}$ followed by cooling at $20^{\circ} \mathrm{C} / \mathrm{min}$ to $30^{\circ} \mathrm{C}$.

Fiber pull-out tests on T700S/PPS samples exhibited two types of failure, cohesive and interfacial. Shear strength on samples that failed cohesively were independent of the cooling rate and the matrix morphology surrounding the fiber and averaged approximately $37 \mathrm{MPa}$. However, the shear strength on samples that failed interfacially were dependent on cooling rate and matrix morphology, that is, for slow cooling rates and samples having transcrystallinity the values were higher compared to those with faster cooling rates. In general, the overall average 
bond strengths, for samples that failed both cohesively and interfacially, were higher for slower cooling rates and transcrystalline morphology, however, the transcrystalline samples did not have statistically significantly higher shear strength. In general the fiber-matrix adhesion of unsized T700S/PPS was relatively poor since the interfacial shear strength for this system was 39 MPa which is about $60 \%$ of the tensile strength of unreinforced PPS resin which is about 65.5 MPa. ${ }^{71}$ The poor interfacial shear strength exhibited by carbon/PPS composites can be attributed to poor adhesion (poor compatibility) between the carbon fiber and the PPS resin. This is in sharp contrast to another system that was tested using the same unsized T700S fiber and PET resin. For T700S/PET there was a definite increase in the interfacial shear strength at slower cooling rates. This system exhibited excellent fiber-matrix adhesion at slower cooling rates. For example, at a rate of $5^{\circ} \mathrm{C} / \mathrm{min}$ the shear strength was $60 \mathrm{MPa}$ which is comparable to the tensile strength value of $70 \mathrm{MPa}$ for the neat PET resin, whereas for faster cooling rates, i.e. $20^{\circ} \mathrm{C} / \mathrm{min}$, the shear strength was lower (43 MPa) and only reached about $60 \%$ of the neat PET.

\subsection{Impact Behavior and Fracture Toughness}

In the 1980's Davies, et. al. ${ }^{72}$ determined the fracture toughness properties on $3 \mathrm{~mm}$ and 20 $\mathrm{mm}$ thick, unidirectional AS4/PPS laminates supplied by Phillips Petroleum Company using double cantilever beam Mode I (opening mode) testing, and both end notch flexure and end loaded split Mode II (shear mode) testing. The laminates were quenched from the molten state (highly amorphous) or quenched from the melt, then annealed (low level of crystallinity). The annealing condition for the thin samples was $150^{\circ} \mathrm{C}$ for $1 \mathrm{hr}$ and for the thick samples was $200^{\circ} \mathrm{C}$ for $2 \mathrm{hrs}$. The X-ray diffraction method of Johnson and Ryan ${ }^{31}$ was used to determine the degree of crystallinity; they found values of 5 and $30 \%$ for non-annealed and annealed thin samples, and 22 and $31 \%$ for the non-annealed and annealed thick samples. The Mode I and Mode II results were relatively insensitive with respect to the added annealing step. The $\mathrm{G}_{\mathrm{IC}}$ results on thin and thick quenched samples were 918 and $818 \mathrm{~J} / \mathrm{m}^{2}$, respectively, versus 799 and $756 \mathrm{~J} / \mathrm{m}^{2}$ for samples quenched, then annealed. However, for the quenched, then annealed AS4/PPS thick samples there was an increase in the resin ductility when Mode I testing was performed at increasingly higher temperatures $\left(25^{\circ} \mathrm{C}\right.$ to $\left.120^{\circ} \mathrm{C}\right)$. The $\mathrm{G}_{\text {IIC }}$ results on samples that were quenched compared to those samples quenched, then annealed were 933 and $802 \mathrm{~J} / \mathrm{m}^{2}$, respectively.

Nishihata et al. ${ }^{66}$ also measured the fracture toughness of the materials whose tensile properties were described in Section 5.1 above. For linear PPS, the plane strain fracture toughness, $\mathrm{K}_{\mathrm{Ic}}$, increased with melt viscosity. The fracture toughness of the linear PPS was higher than either heat-treated or branched PPS. Fracture toughness generally decreased with increase of crystallinity, but the effect of melt viscosity and molecular structure on the fracture toughness was more dramatic.

Lu et al. ${ }^{73}$ measured the Izod impact strength and crystallinity change of PPS and a series of PPS blends prepared using a twin-screw extruder. The components blended with the PPS included ethylene vinyl acetate (EVA), polyarylester (PAR), nanometer particles of $\mathrm{SiO}_{2}$, polypropylene (PP), and $\mathrm{PP}$ grafted with maleic anhydride (MAH) and with glycidyl methacrylate (GMA). In most cases, the blends contained from 5-20\% of the second component. In addition to blends, the initial PPS was heat treated (hPPS) by heat treating in air for $5 \mathrm{hrs}$ at $265^{\circ} \mathrm{C}$ in order to increase its molecular weight and lightly crosslink it. Izod samples were prepared from these materials by injection molding. These authors found a correlation between 
the crystallinity and the impact strength of these samples, as shown in Figure 28. Note that the crystallinity values are given in percent and were determined from DSC measurements. Unfortunately, the authors did not specify what value of $\Delta H_{f}^{o}$ that they used, but it appears to be a rather low value based on the high value of crystallinity reported for the neat PPS. In any case, the data clearly show a trend toward increased impact strength as crystallinity decreases. It is interesting to note that the impact strength for $\mathrm{hPPS}\left(270^{\circ} \mathrm{C}, 5 \mathrm{~h}\right)$ was 14 times higher than unheat-treated PPS.

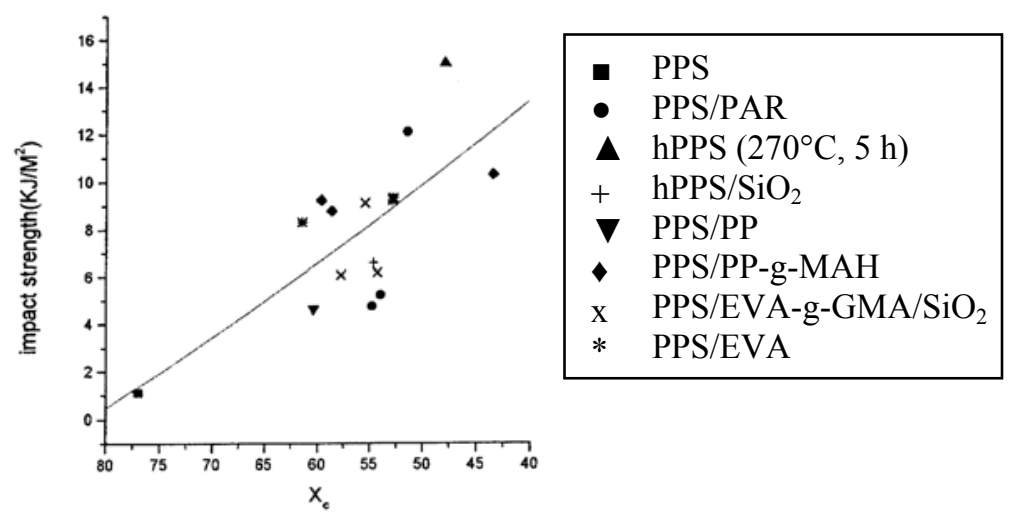

Figure 28. Impact strength versus percent crystallinity for PPS and PPS blends (after Lu et al. ${ }^{73}$ ).

Ma et al. ${ }^{74}$ showed that aging below the glass transition reduces the impact toughness of PPS/carbon fiber composites as measured by a penetration impact test. The samples were fabricated by interleaving Ryton PPS resin film, from Phillips Petroleum Co., with woven, 3K carbon fabric, provided by the Toho Company (Style $\# 3101,200 \mathrm{~g} / \mathrm{m}^{2}$ ), then heated to $306^{\circ} \mathrm{C}$ for $20 \mathrm{~min}$ at contact pressure, then compressed at 200 psi for $20 \mathrm{~min}$, and subsequently transferred to a cold press. It is important to note that since these samples were transferred to a cold press from the melt, it is assumed that they have a relatively low DOC.

The test was carried out using an instrumented falling weight technique (Rheometrics Drop Weight Tester, RDT-5000). A $12.7 \mathrm{~mm}$ hemispherical tip penetrator impacted a $100 \mathrm{x}$ $100 \mathrm{~mm}$ composite panel supported on a $38 \mathrm{~mm}$ ring with a test speed of $2.64 \mathrm{~m} / \mathrm{s}$. The forcetime curve was obtained from which several parameters related to the toughness could be computed, including damage initiation force, $\mathrm{Fi}$, damage initiation energy, $\mathrm{Ei}$, a damage propagation energy, Ep, total impact energy expended during penetration of the sample, Ei+Ep, and a ductility index defined as the ratio Ep/Ei. Figure 29 shows the decrease in total impact energy required to penetrate the sample as a function of aging temperature for a 48-hour aging treatment. The data for PPS/carbon fiber is also compared to that for poly(ether ether ketone) $(\mathrm{PEEK}) /$ carbon fiber composite on a percent retention basis. Note that the glass transition temperature for PEEK (about $144^{\circ} \mathrm{C}$ ) is much higher than that of PPS (about $89^{\circ} \mathrm{C}$ ). The impact energy drops rapidly as the aging temperature approaches the glass transition temperature. A similar result was found for the damage initiation force, energy of initiation and damage propagation energy. Ma et al. attribute these changes to relaxation and densification of the amorphous phase after aging. This causes a gradual loss of the molecular segment mobility, increased brittleness and a decrease of impact resistance for the composite. Their data indicate that, although C/PEEK exhibits higher initial damage resistance, as evidenced by higher Fi and 
Ei values, the C/PPS is an inherently tougher material due to its higher value of Ep (higher resistance to split propagation) and higher ductility index (4.26 vs. 0.89).

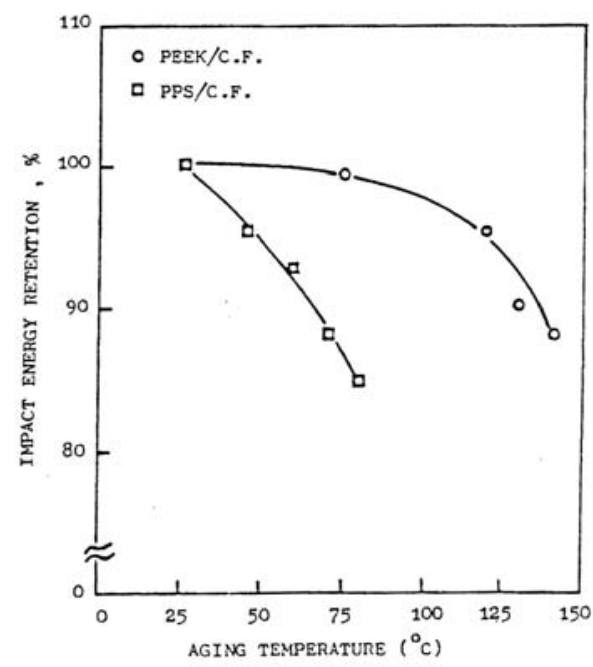

Figure 29. Decrease of total impact energy (\% retention) to penetrate carbon fiber composites of PPS and PEEK as a function of aging temperature below the glass transition temperature (from Ma et al. ${ }^{75}$ ). Samples were aged for $48 \mathrm{hrs}$ at the specified temperatures.

Ma et al. investigated the effect of aging time by measuring the impact properties of the composites as a function of time about $15^{\circ} \mathrm{C}$ below the respective glass transition temperatures of each of the two matrix materials $\left(70^{\circ} \mathrm{C}\right.$ for PPS and $130^{\circ} \mathrm{C}$ for PEEK). Results indicated that the impact energy significantly decreased for both materials during the early stages of aging time $\left(1^{\text {st }} 50 \mathrm{hrs}\right.$ ), then continued to decrease minimally beyond this time period until reaching about $85 \%$ retention for both materials after aging $336 \mathrm{hrs}$. The ductility of the composites also decreased with time, although there was only a minimal decrease for C/PPS. After 336 hrs of aging the C/PPS and C/PEEK composites retained about $98 \%$ and $89 \%$ of their ductility, respectively.

Other investigators studied the effect of impact damage on the tensile or compressive properties of the composites. In the late 1980's Spamer and Brink ${ }^{76}$ investigated the compression after impact strength (CAI) and double cantilever beam Mode I fracture toughness properties of AS4/PPS and AS4/PEEK thermoplastic composites and untoughened, AS4/3501-5A thermoset epoxy composites. In this study all panels had a quasi-isotropic lay-up produced from either tape prepreg (48 plies) or fabric laminate (24 plies). Phillips Petroleum Company supplied the PPS; the processing of the tape and fabric quasi-isotropic AS4/PPS laminates was identical. The processing included preheating the press containing the laminates to $329^{\circ} \mathrm{C}\left(625^{\circ} \mathrm{F}\right)$ at 0.175 $\mathrm{MPa}$ (25 psi) for 3 minutes, then increasing the press pressure to $1.045 \mathrm{MPa}$ (150 psi) for 3 minutes at $329^{\circ} \mathrm{C}$, followed by transferring the laminate to a cooling press having a temperature of $18^{\circ} \mathrm{C}(65 \mathrm{~F})$ and a pressure of $1.045 \mathrm{MPa}$ for 3 minutes. Although the degree of crystallinity of the PPS in the laminates was not determined, it is assumed to be very low and should be considered amorphous due to cooling taking place well below the PPS $\mathrm{T}_{\mathrm{g}}$ of $88^{\circ} \mathrm{C}$. Manufacturers typically recommend mold temperatures of at least $140^{\circ} \mathrm{C}$ to maximize 
crystallinity and achieve optimum properties. A $12.7 \mathrm{~mm}$ steel tip impactor was used on samples that were $254 \mathrm{~mm}$ by $127 \mathrm{~mm}$ by approximately $6.35 \mathrm{~mm}$ thick.

The compressive strength decreased with increase in impact energy expended in damaging the sample. After normalizing the results by dividing by the compression strength of the undamaged materials, a strong correlation existed between normalized compression strength and impact energy as shown in Figure 30. This figure also shows that thermoset matrix composites are more readily damaged than the thermoplastic matrix composites. A similar correlation was found between normalized strength and the damage area measured by C-Scan.

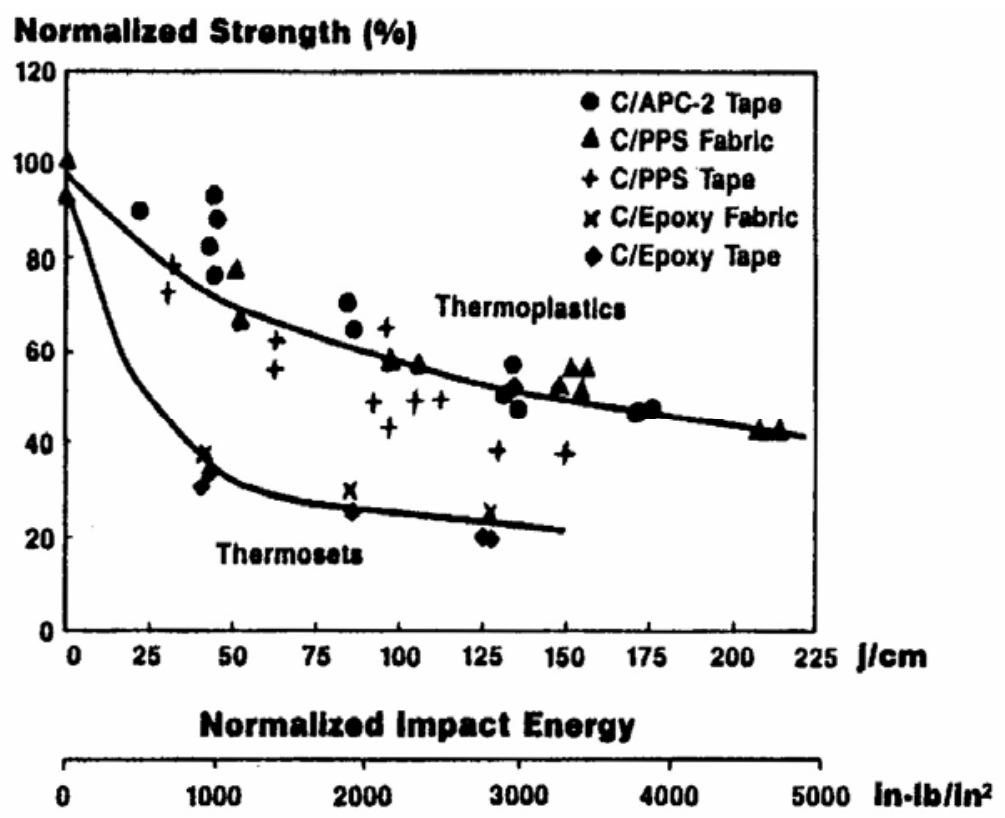

Figure 30. Normalized compression strength as a function of the impact energy used to damage the samples for several types of composite samples, including carbon fiber/PPS (After Spamer and Brink ${ }^{76}$ ).

Results on CAI strength and $\mathrm{G}_{\mathrm{IC}}$ Mode I fracture toughness for the AS4/PPS tape laminates were approximately $150 \mathrm{MPa}$ and $0.8 \mathrm{~kJ} / \mathrm{m}^{2}$, whereas for the AS4/PPS fabric laminates the results were slightly higher at $175 \mathrm{MPa}$ and $1.0 \mathrm{~kJ} / \mathrm{m}^{2}$, respectively. The CAI results for both the AS4/PPS tape and fabric laminates correspond to those typically observed on untoughened, AS4/3501-5A epoxy laminates, whereas the $\mathrm{G}_{\mathrm{IC}}$ properties for the PPS laminates were more than twice the toughness observed on the untoughened, tape and fabric epoxy laminates. More recent data from Ten Cate on their CETEX T300J/PPS fabric (5-harness satin) laminates, having a high level of crystallinity, demonstrated about $40 \%$ higher CAI strength (240 MPa) compared to the AS4/PPS fabric laminates (175 MPa) reported by Spamer and Brink. On the other hand, the CAI strength and $\mathrm{G}_{\mathrm{IC}}$ properties for AS4/PEEK tape laminates were significantly higher than the AS4/PPS tape laminates and averaged about $350 \mathrm{MPa}$ and $1.4 \mathrm{~kJ} / \mathrm{m}^{2}$, respectively. These results for AS4/PEEK compare favorably to those typically found on AS4 laminates containing toughened epoxies.

The SEM photographs of the impact regions for both the tape and fabric AS4/PPS laminates showed extreme delamination, intra-ply cracking, and poor fiber/matrix adhesion 
while the tape AS4/PEEK laminates displayed much less delamination and intra-ply cracking and excellent fiber/matrix adhesion. The increased incidence of intra-ply cracking and low fiber/matrix adhesion for the AS4/PPS laminates signifies poor compatibility between the carbon fiber and the PPS resin. As has been demonstrated with carbon/epoxy composites in the past, the compatibility between carbon fiber and PPS resin can be significantly improved (increased fiber matrix adhesion) by using more compatible fiber surface treatments, fiber sizings, and/or coupling agents.

Compression fatigue data on impact damaged AS4/PPS laminates demonstrated higher fatigue strength for the fabric laminates versus the tape laminates, however, both of these materials exhibited less fatigue life compared to untoughened, AS4/3501-5A epoxy laminates.

$\mathrm{Ma}$ et al. ${ }^{75}$ also measured the tensile and flexural properties of composites as a function of impact energy applied to damage them. The samples and testing methods were the same as that used in the aging study described above. The amount of impact energy applied was $25 \%$, $50 \%$ and $75 \%$ of the penetration energy. The tensile strength, flexural strength and flexural modulus after impact are shown as a function of impact energy in Figure 31. As expected, all properties decrease as a result of impact, but the decrease appears to be in a more or less gradual manner.
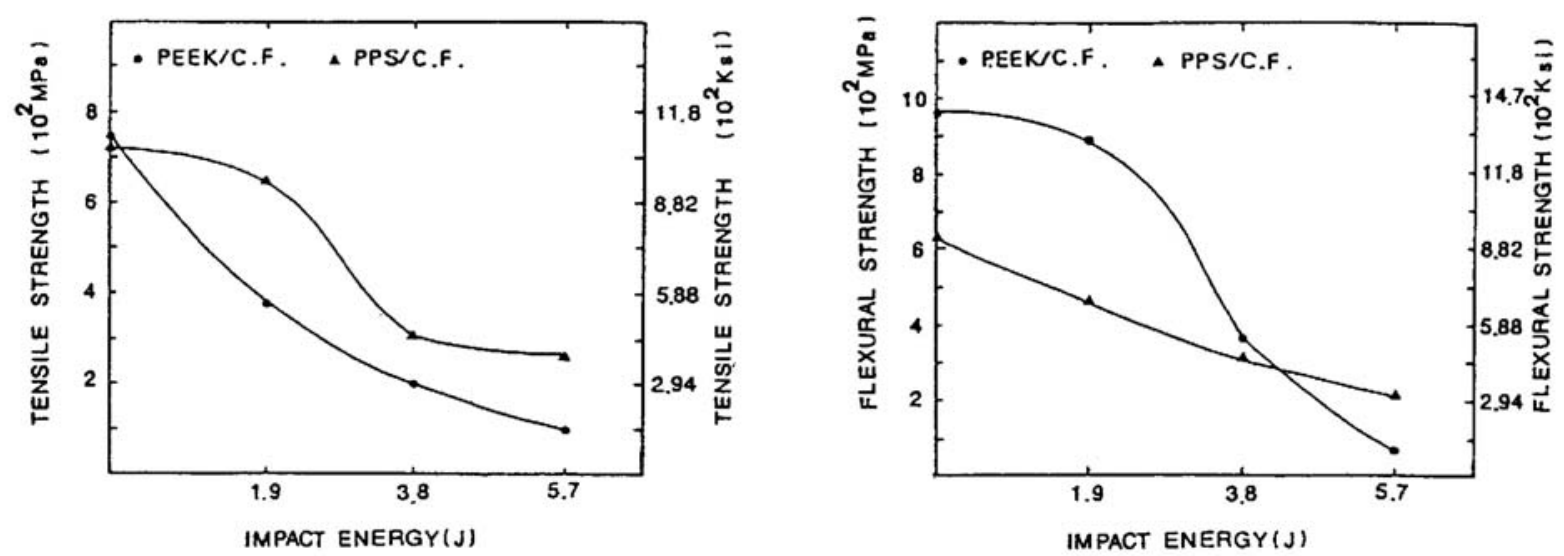

Figure 31. Decrease in tensile strength and flexural strength of PPS/carbon fiber composites as a result of damage caused by impact as a function of the applied impact energy (after Ma et al. ${ }^{75}$ ).

\subsection{Creep and Viscoelastic Behavior}

Creep is defined as the slow, gradual, time dependent plastic deformation of a material due to the application of a load that may be well below the load necessary to cause plastic deformation during a short-term test such as an ordinary tensile test. Creep can lead to stress rupture, but, just as importantly, it plays a very significant role in component dimensional stability. Polymers are, by nature, viscoelastic. That is, they exhibit both elastic strains and viscous, time dependent plastic strain (creep) when subjected to loads. Typical behavior is illustrated in Figure 32. If an engineering stress $\sigma_{o}$ is applied at time $t_{1}$ and held until time $t_{2}$, there will be a time dependent strain $\varepsilon(\mathrm{t})$. The initial instantaneous strain $\varepsilon\left(\mathrm{t}_{1}\right)$ represents the elastic component of strain; this is followed by the time dependent viscous (creep) component. Removal of the stress at $t_{2}$ results in recovery of the elastic component and a portion of the time 
dependent component (anelastic component), but a permanent strain remains. This permanent plastic deformation results from viscous flow, i.e., movement of molecules relative to one another without a mechanism for recovery. The anelastic component is caused by time dependent molecular relaxation after the stress is removed.
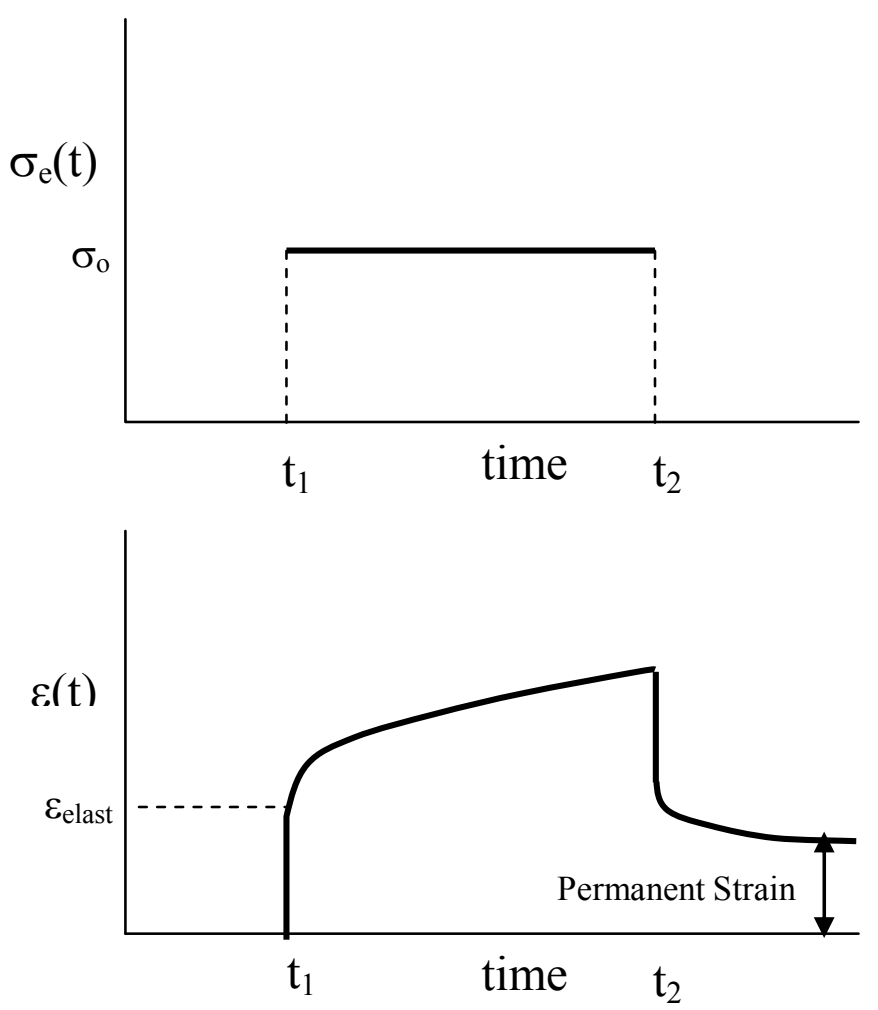

Figure 32. Strain response for a viscoelastic material to the application of a constant engineering stress for the period from $t_{1}$ to $t_{2}$.

If the stress is allowed to remain on the sample indefinitely, the sample will eventually fail by stress rupture. The complete creep curve for such a sample is illustrated in Figure 33. This curve is often divided into three time dependent stages indicated by the dotted vertical lines in Figure 33. In the first stage the strain rate decreases and approaches a final value that remains approximately constant through stage 2 . In stage 3 the strain rate increases again until the sample ruptures at $t_{\mathrm{f}}$. Curves such as those shown in Figure 32 and 33 are quite dependent on the sample temperature and applied stress. Higher temperature and stress cause the strain rate in stage 2 to increase.

In polymers, creep involves the slippage or flow of molecules past one another. On this basis, creep strain is expected to be relatively slow below the glass transition temperature of the polymer, and to increase rapidly as the temperature exceeds the glass transition temperature due to the increase of free volume and molecular mobility. Creep of thermoset polymers is greatly influenced by the presence and density of the cross-links that make the polymer a thermoset. Generally, the crosslinks inhibit the slow flow of polymer molecules past one another that is responsible for creep in polymers. In the absence of crosslinks, sliding of molecules in an amorphous polymer occurs quite readily as temperature increases above the glass transition. Therefore, amorphous thermoplastic polymers are quite susceptible to creep deformation. In the 
case of semicrystalline thermoplastics, the crystals act as "physical crosslinks" and inhibit the slippage of molecules past one another. This suggests that creep of semicrystalline thermoplastics should depend significantly on the degree of crystallinity developed in the polymer. The presence of the reinforcing material in composites should also have marked effects on the creep behavior of the composite compared to the neat polymer used as the matrix.

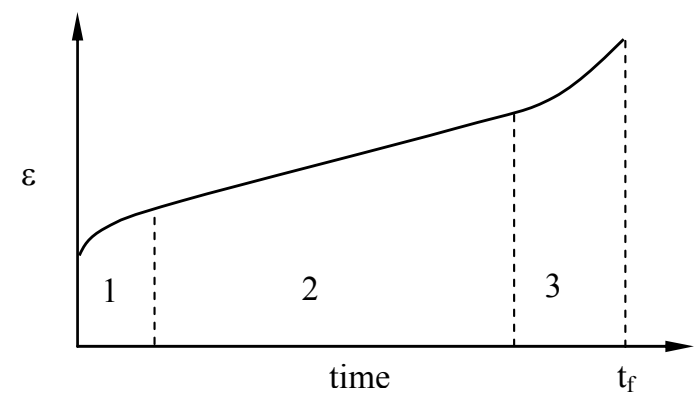

Figure 33. Typical strain as function of time (creep curve) showing the three stages of creep behavior. $t_{f}$ is the rupture time.

Data of the sort illustrated in Figure 33 are often plotted as an apparent "creep modulus" defined as

$$
\text { Creep Modulus }=\frac{\sigma_{o}}{\varepsilon(t)}
$$

When plotted on a log-log scale, the creep modulus is generally linear with the time. This is convenient for comparison of such plots as a function of temperature and/or applied stress. Figure 34 shows the creep modulus of $40 \%$ glass-filled PPS as a function of time for three different temperatures under an applied stress of 5000 psi for times up to 10,000 hrs given by the Fortron PPS Design Manual. ${ }^{77}$ Such creep data can be obtained in simple tension, compression, shear, or bending modes. The creep data plotted in Figure 34 were determined in three point bending.

For comparison of the creep behavior of different materials, the creep strain at a fixed time is often plotted as a function of applied stress.

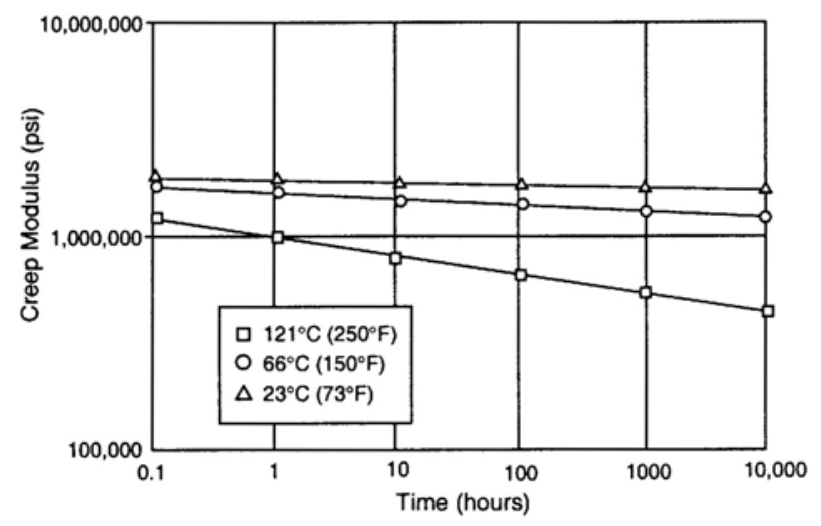

Figure 34. Creep modulus versus time (log-log scale) for $\mathbf{4 0} \%$ glass-filled PPS as a function of temperature (Data from Fortron PPS Design Manual ${ }^{77}$ ). 
As indicated above, creep and viscoelasticity of polymers are slightly different ways of describing the same basic phenomena. Thus, information about creep behavior can be obtained from static tests in which the strain is measured as a function of time at given temperature and stress conditions, or it can be obtained from classical viscoelasticity measurements. A major tool used to study the viscoelastic properties of polymers is dynamic mechanical analysis (DMA). This technique is based on the application of linear viscoelasticity theory. As such, it provides a powerful method to obtain information about the viscoelastic behavior at low strain levels, but we must note that it may not predict accurately the creep behavior at high levels of deformation. A modern DMA apparatus is generally capable of doing tests in several different modes, including creep relaxation, stress relaxation, fixed frequency and resonant frequency modes. The creep mode is similar to the static test; the strain is measured as a function of time at a given temperature and stress. Then temperature is increased and the cycle repeated. The time period for application of the stress may be specified, but is often relatively short compared to other types of static tests. The fixed frequency mode applies an oscillatory strain to the sample with a fixed frequency. This mode is widely used in the study of the viscoelastic properties of polymers. Consequently, it is discussed in some detail below.

Let a periodic strain be applied to the sample such that

$$
\varepsilon(t)=\varepsilon_{o} \sin (\omega t)
$$

where $\varepsilon_{o}$ is the amplitude of the strain and $\omega$ is the angular frequency of oscillation. The stress response will also be periodic. We may represent it as

$$
\sigma(t)=\sigma_{o} \sin (\omega t+\delta)
$$

where $\sigma_{0}$ is the stress amplitude and $\delta$ is the phase angle between the stress and strain. Note that for a perfectly elastic Hookean solid,

$$
\sigma(t)=E \varepsilon(t)=E \varepsilon_{0} \sin (\omega t)
$$

the stress and strain are in phase, i.e., $\delta=0$ and $\sigma_{0}=E \varepsilon_{0}$. For an ideal Newtonian viscous fluid

$$
\sigma=\eta \frac{d \varepsilon}{d t}
$$

where $\eta$ is the viscosity and $\mathrm{d} \varepsilon / \mathrm{dt}$ is the strain rate. Thus for a perfect Newtonian viscous material

$$
\sigma(t)=\eta \omega \varepsilon_{o} \cos (\omega t)=\eta \omega \varepsilon_{o} \sin \left(\omega t+\frac{\pi}{2}\right)
$$

we see that $\sigma_{0}=\eta \omega \varepsilon 0$ and $\delta=\pi / 2$ radians or $90^{\circ}$. For a viscoelastic material, the phase angle, $\delta$, lies somewhere between 0 and $90^{\circ}$, depending on the relative contribution of the viscous and elastic components of strain. It is conventional to define a dynamic or complex modulus, $\mathrm{E}^{*}$, by dividing the stress by the strain. In general, this is made up of both a viscous and an elastic 
component. Since these two components are $90^{\circ}$ out of phase, we can represent them as the real and imaginary components of the modulus in complex number notation (see Figure 35). Thus,

$$
E^{*}=E^{\prime}+i E^{\prime \prime}
$$

here, $E^{\prime}$ is called the storage modulus and $E$ " is called the loss modulus. $E$ ' is related to the elastic component of deformation and $E$ ” is related to the viscous component. Figure 35 also shows that

$$
\tan \delta=\frac{E^{\prime \prime}}{E^{\prime}}
$$

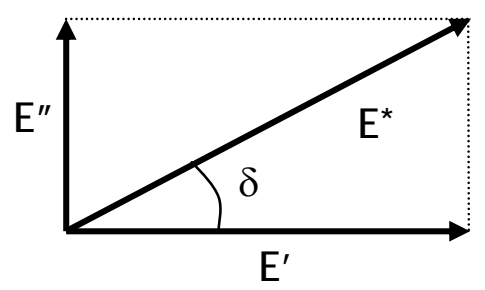

\section{Figure 35. Relationship of storage modulus, loss modulus and phase angle $\delta$ to the complex modulus.}

While we have discussed the viscoelastic behavior in terms of tensile stress, strain and modulus, it is clear that similar relationships can be developed for the application of a shear stress leading to a complex shear modulus.

Experimental data of Sepe ${ }^{78}$ for the storage and loss modulus as a function of temperature for two different PPS samples is shown in Figure 36. The samples contained 40\% glass fiber and a nucleating agent to increase the crystallization rate of the PPS above that of neat resin. DMA scans were made on injection molded tensile bars in flexure with a fixed frequency of $0.3 \mathrm{~Hz}$ and a scan rate of $2^{\circ} \mathrm{C} / \mathrm{min}$. One of the samples was injection molded into a "cold mold" maintained at $50^{\circ} \mathrm{C}$ while the second was prepared in a "hot mold" kept at $150^{\circ} \mathrm{C}$. The sample that was molded cold has lower storage modulus over the entire range of temperatures, Figure 36(a). This result is associated with the fact that it has a very low crystallinity compared to the sample molded hot. A rapid drop in E' occurs in the neighborhood of the glass transition temperature, but note that this drop is more drastic for the cold molded sample and is completed at a lower temperature. The small "bump" on the curve near $125^{\circ} \mathrm{C}$ for the cold molded sample is due to the onset of cold crystallization during the heat-up in the DMA. Finally, the two curves approach one another at high temperatures due to continued crystallization of the cold molded sample and, ultimately, partial melting of both samples. The data in Figure 36(a) are similar to that shown in Figure 11 for samples that had been annealed for different amounts of time at $204^{\circ} \mathrm{C}$.

The loss modulus, E", also exhibits major differences between the hot molded and cold molded samples, Figure 36(b). The peak in the loss modulus curve is nearly twice as high for the cold molded sample as for the hot molded one, and it occurs at about $20^{\circ} \mathrm{C}$ lower temperature. Since loss modulus is related to the viscous energy dissipation, this behavior is also related to the observed increase in impact toughness with decrease of crystallinity described above. On the other hand, the lower crystallinity will result in poorer dimensional stability (more creep), 
especially if the material gets heated to the neighborhood of the glass transition temperature or above. This is clearly indicated in Sepe's data taken in the creep mode in which he applied a fixed stress and monitored the strain for up to $100 \mathrm{hrs}$. These results are illustrated in Table 10.

The strong influence of the reinforcing agent on the storage modulus of PPS composites is illustrated in Figure 37.
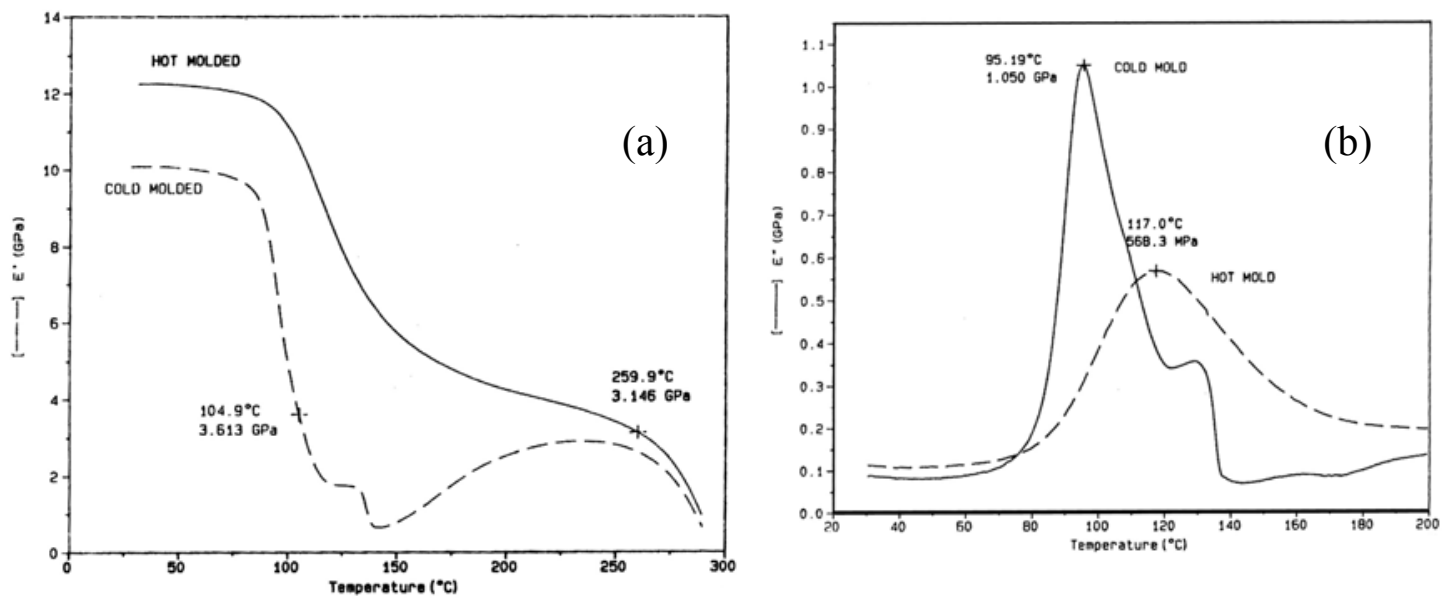

Figure 36. Storage modulus (a) and loss modulus (b) of PPS/40\% glass fiber for both cold and hot molded samples (from Sepe ${ }^{76}$ ).

Table 10. Time Dependent Strain in 40\% Glass-filled PPS

\begin{tabular}{llll}
\hline Creep Temp. $\left({ }^{\circ} \mathrm{C}\right)$ & Mold Temp. $\left({ }^{\circ} \mathrm{C}\right)$ & $10 \mathrm{hStrain}(\%)$ & $100 \mathrm{hStrain}(\%)$ \\
\hline 60 & 50 (cold) & 0.72 & 0.85 \\
60 & 150 (hot) & 0.57 & 0.61 \\
80 & 50 (cold) & 1.71 & 2.19 \\
80 & 150 (hot) & 0.72 & 0.77 \\
\hline
\end{tabular}

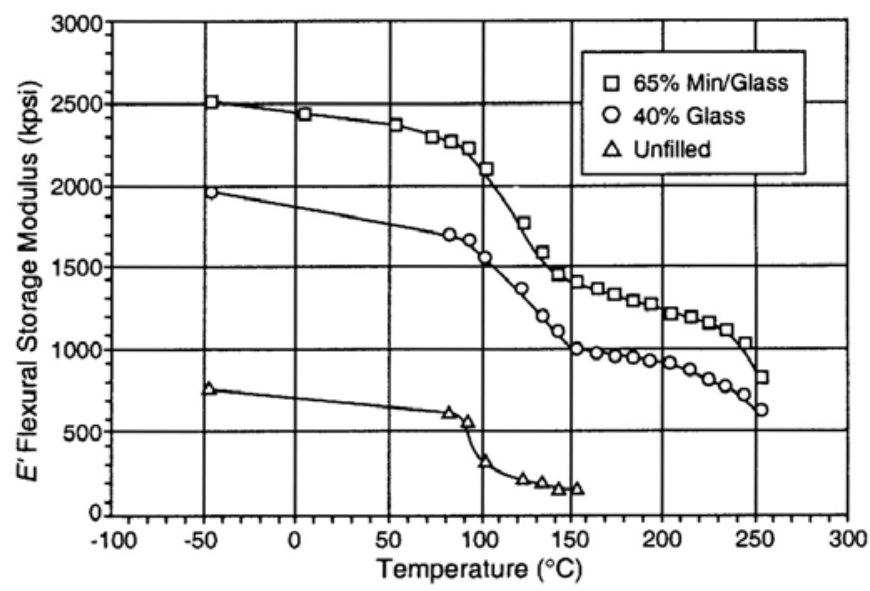

Figure 37. Storage modulus of PPS and PPS composites as a function of temperature. (Data from Fortron PPS Design Manual ${ }^{77}$.) 
Several models have been used to describe creep. Some investigators have used mechanical models developed from viscoelasticity theory while others have used empirical models. An empirical model proposed by Findley, Kholsa and Petersen (FKP) ${ }^{79,80}$ was used by Carriere et al. $^{81}$ to analyze the short term creep performance of selected glass-filled semicrystalline polymers, including PPS. They followed the creep in a flexure experiment for 600 seconds and evaluated the model parameters from these data. The form of the FKP model they used can be expressed as

$$
\varepsilon=\varepsilon^{o}+\varepsilon_{o}^{+} \exp \left[\frac{-\left(E_{a}-\alpha \sigma\right)}{R T}\right] t^{m}
$$

where $\varepsilon^{o}$ is the strain at zero time, $\sigma$ is the applied stress, $E_{a}$ is an activation energy for the creep process, $\varepsilon_{0}{ }^{+}$is a pre-exponential factor, $\alpha$ is a factor that moderates the stress dependence of the activation energy, $\mathrm{R}$ is the gas constant, $\mathrm{T}$ is the temperature, and $m$ is a power law exponent. The value of $m$ was also assumed to be an activated, stress dependent quantity given by

$$
m=m_{o} \exp \left[\frac{-\left(E_{a}^{*}-\alpha^{*}\right)}{R T}\right]
$$

The model was found to give good agreement with the experimental data for all of the polymers examined. The values found for the model parameters for $40 \%$ glass-filled PPS are:

$\varepsilon_{o}^{+}=0.0046 \pm 0.0005, E_{a}(\mathrm{~kJ} / \mathrm{mol})=14.8 \pm 1.1, \alpha(\mathrm{kJ} / \mathrm{mol}-\mathrm{MPa})=3.49 \pm 0.13$ $m_{o}=6.94 \pm 0.8, \mathrm{E}_{\mathrm{a}}^{*}(\mathrm{~kJ} / \mathrm{mol})=20.0 \pm 1.2, \alpha(\mathrm{kJ} / \mathrm{mol}-\mathrm{MPa})=0.0 \pm 0.09$.

Figure 38 shows a comparison of model predictions made for each of the materials studied. This figure shows that glass-filled PPS composite exhibits much lower strain under equal stress of $2.1 \mathrm{MPa}$ at $200^{\circ} \mathrm{C}$ than glass-filled isotactic polystyrene (GF-sPS) and poly(butylene terephthalate) (GF-PBT).

Another model used to describe creep is often stated as follows:

$$
\varepsilon=\frac{\sigma_{o}}{E_{o}}+B \sigma^{n} \exp \left(-\frac{Q}{R T}\right) t^{m}
$$

Here, the first term gives the elastic strain due to the initial application of the load; $Q$ is the activation energy for creep and controls the temperature dependence; $n$ is the power dependence of strain on the stress $\sigma$; and $m$ is the power dependence of strain on the time $t$. For constant stress and temperature, the creep rate is dependent on the value of $m$. Boey et al. ${ }^{82}$ used this model to study the effect of matrix crystallinity on glass filled PPS composites containing 20 and $40 \%$ glass. They varied the crystallinity by annealing at $140^{\circ}$ or $160^{\circ} \mathrm{C}$ after first quenching from $340^{\circ} \mathrm{C}$. The crystallinity was measured by the same X-ray method used by Lee el al. ${ }^{37}$ as discussed earlier. This technique gave rather high values of crystallinity, so the absolute values of crystallinity quoted should be viewed with caution. The creep deformation was then 
determined using a Perkin Elmer DMA7 with the sample loaded in three-point bending. Their analysis allowed them to obtain the values of $n$ and $m$ in Equation 43 as a function of annealing time and, hence, of crystallinity. The value of $n$ and $m$ as a function of crystallinity found by Boey et al. are shown in Figure 39 for the 20\% glass-filled PPS composite. The different symbols correspond to different stress levels applied. It is quite clear from these data that both $n$ and $m$ are quite sensitive to the level of crystallinity, with both $n$ and $m$ decreasing rapidly as crystallinity increases. The results for the $40 \%$ glass-filled PPS composite were similar to those for the $20 \%$ glass-filled composite in spite of the greater amount of reinforcing fiber. This suggested that a dominantly matrix-based creep mechanism was present and is in agreement with the very similar values obtained for $30 \%$ and $40 \%$ glass-filled polystyrene found by Carriere et al. and illustrated in Figure 38.

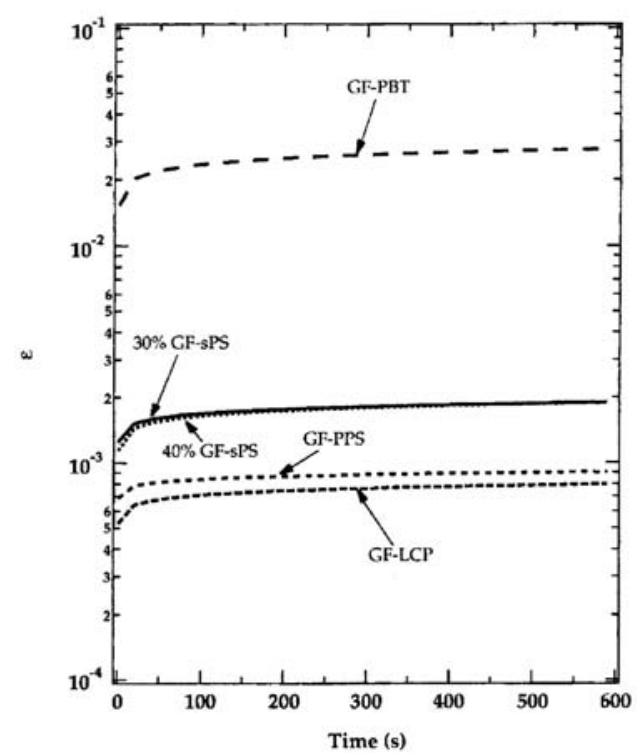

Figure 38. Creep performance at $200^{\circ} \mathrm{C}$ of selected polymers based on the FKP model. The applied stress was assumed equal to $2.1 \mathrm{MPa}$ (from Carriere et al. ${ }^{81}$ )

n

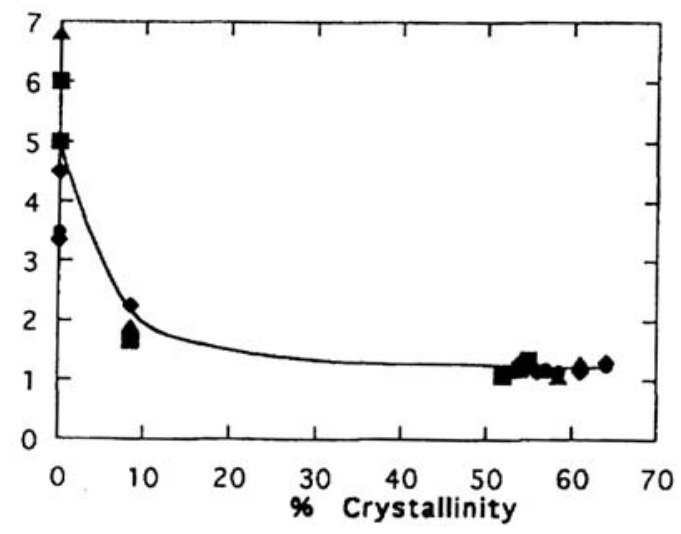

$\mathrm{m}$

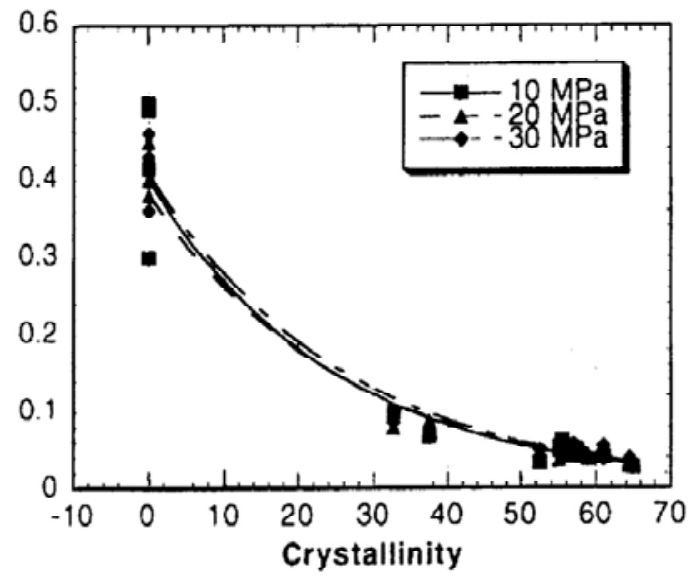

Figure 39. The effect of crystallinity on creep parameters for $\mathbf{2 0 \%}$ glass-filled PPS. (a) The stress exponent, $\mathrm{n}$; (b) the time exponent, m. Data of Boey et al. ${ }^{80}$ 
Gibson et al. ${ }^{83}$ studied the compressive creep behavior of glass/PPS composites using a frequency-time transformation method. This method assumes that the creep compliance can be obtained as a function of time from an inverse Fourier transform of the reciprocal of the complex modulus as a function of frequency of a cyclic stress. They made measurements on both "dry" and "wet" (saturated with moisture) composites. They found that the creep compliance was considerably higher for the wet composite compared to the dry case (creep modulus is lower for the wet composite).

\subsection{Fatigue Behavior}

There is relatively little data available in the literature on the fatigue behavior of PPS and its composites. The tensile fatigue resistance of a $40 \%$ glass/PPS composite is shown in Figure $40{ }^{77}$ These data show that the fatigue strength decreases continuously with the number of cycles of load application at $23^{\circ} \mathrm{C}$.

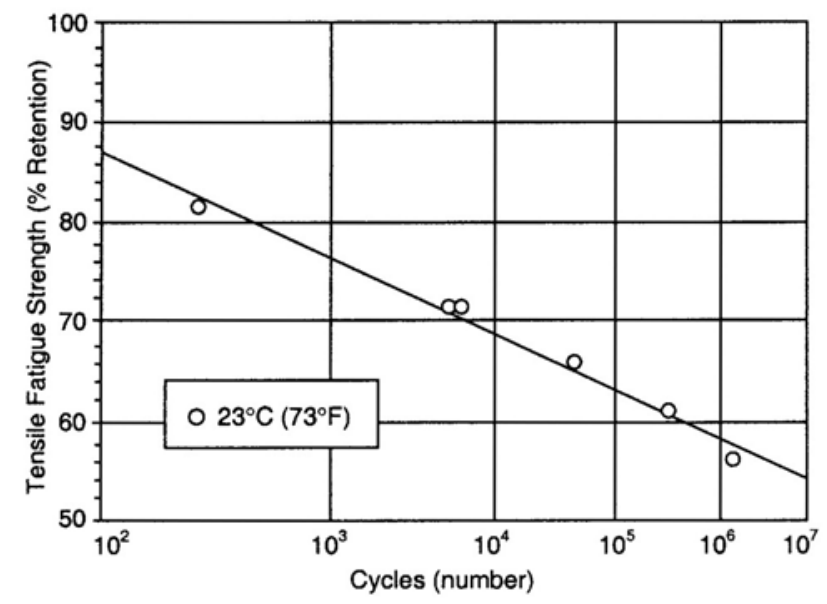

Figure 40. Percent retention in tensile fatigue strength versus cycles to failure. (Data of Oya, et. al. ${ }^{67}$ )

Mandell et al. ${ }^{84}$ gave S-N curves for several injection molded thermoplastics and their glass or carbon-filled short fiber composites including those of PPS. The measurements were made at room temperature in a uniaxial tension-tension mode with minimum stress/maximum stress equal to 0.1. Frequency of stress application varied, but was kept low enough to avoid appreciable heating of the samples. There was no evidence of a fatigue limit for any of the thermoplastic matrix composites studied within the range of stress and number of cycles studied (up to $10^{6}$ cycles). The $\mathrm{S} / \mathrm{N}$ curves of all of the thermoplastic composites could be described by an equation of the form:

$$
S=U T S-B \log N
$$

where UTS is the single cycle ultimate strength, B is the slope of the S-N curve in MPa per decade of cycles, and $\mathrm{N}$ is the number of cycles to failure at the maximum stress, $\mathrm{S}$. Normalizing the results by dividing the maximum stress by the UTS value, showed that all the glass-filled composites degrade at a similar rate with $\log \mathrm{N}$. This was not true of the carbon fiber composites 
as shown in Figure 41, which shows the normalized curve fits, using Equation 44, for all of the different carbon fiber composites studied. This figure shows that PPS carbon fiber composites exhibited the slowest degradation rate with $\log \mathrm{N}$ of any of the composites studied. More generally, carbon-filled composites with ductile matrices degraded more rapidly than those with brittle matrices. The authors suggested that some of the ductile matrix thermoplastic composites tend to fail at a cumulative strain similar to the ultimate static strain. Other matrices fail by a crack propagation mechanism. PPS composites were among the latter type. Their results suggest that matrix ductility and fiber/matrix bond quality are both important parameters in the fatigue of thermoplastic composites. The fibers tend to bridge the cracks and slow the rate of degradation more effectively in the brittle matrix materials such as PPS.

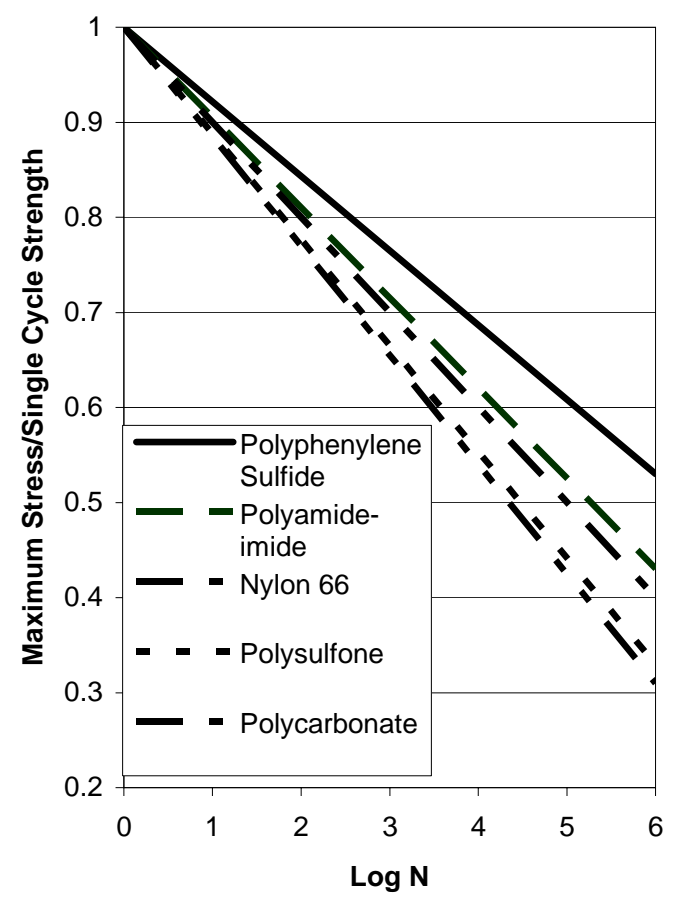

Figure 41. S-N curves for several carbon fiber, thermoplastic matrix composites. (Data of Mandell et al. ${ }^{84}$ )

Karger-Kocsis ${ }^{85}$ also studied fracture and fatigue of temperature resistant thermoplastic composites with discontinuous fibers. He found that the microstructure of the composite has a major influence on its fracture and fatigue resistance, and he developed a microstructural efficiency concept to predict the relative change in fracture toughness and fatigue behavior. The concept is based on analogies between static fracture and fatigue crack propagation.

Leverich et al. ${ }^{86}$ developed a life prediction model that could be used to predict the effects of two different failure mechanisms acting in combination from data for the individual mechanisms. They used this approach to predict the combined effects of creep and fatigue (i.e., elevated temperature fatigue) for a PPS/AS4 carbon fiber composite from data for elevated temperature tensile rupture and room temperature fatigue data ( $\mathrm{S}-\mathrm{N}$ curve). Their model is based on damage accumulation concepts. They argue that a particular fraction of life under one condition is equivalent to that for a second condition only if it gives the same reduction in remaining strength. They postulate that normalized remaining strength is an internal state 
variable for a damaged material system and develop equations for the model. Figure 42 shows their prediction for the PPS/AS4 composite for fatigue at $90^{\circ} \mathrm{C}$ and compares it to experimental data for this condition. Also shown are the curve fits for the $90^{\circ} \mathrm{C}$ tensile rupture and room temperature fatigue data.

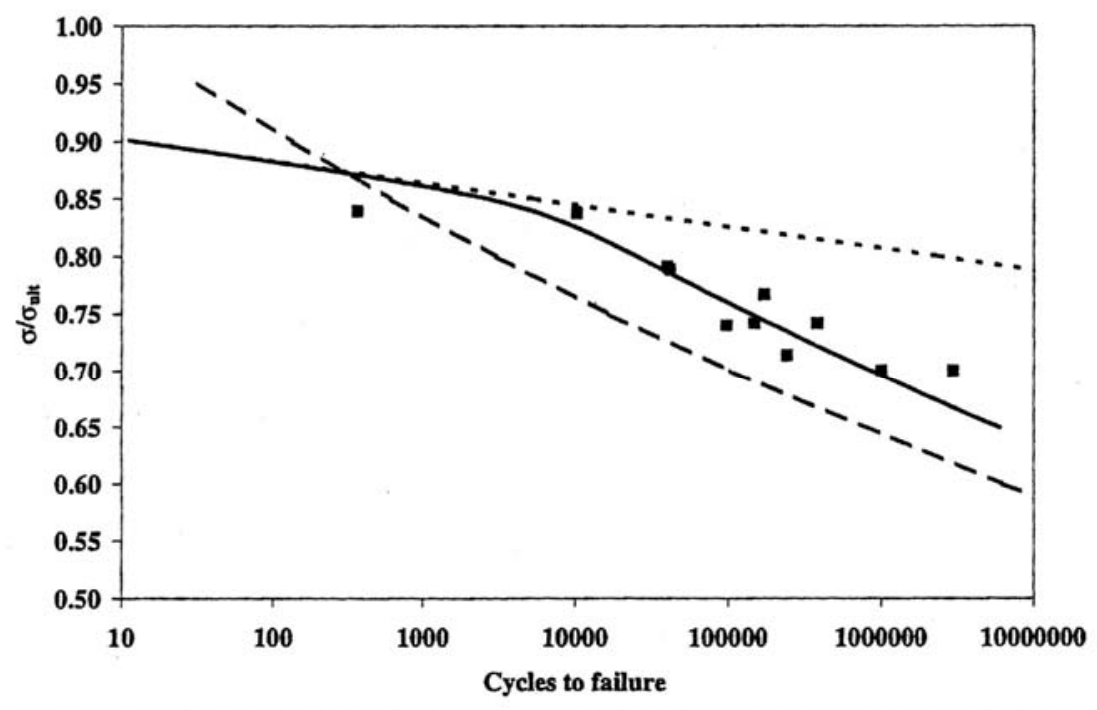

- Fatigue Prediction $990^{\circ} \mathrm{C}-\cdots$ Room Temperature Fatigue Fit $--90^{\circ} \mathrm{C}$ Rupture Fit $90^{\circ} \mathrm{C}$ Fatigue Data

Figure 42. Comparison of predicted $90^{\circ} \mathrm{C}$ fatigue prediction to experimental result. Data and model prediction of Loverich et al. ${ }^{86}$

Lhymn $^{87}$ studied a form of fatigue involving repeated application of impact blows (impact-fatigue) for a PPS $/ 40 \%$ glass fiber composite. The composites were plaques about $1 / 8$ inch thick consisting of three layers. The top and bottom layers had short glass fibers laid parallel to one another while the center layer had the glass fibers aligned $90^{\circ}$ to the top and bottom layer. Impact-fatigue samples measuring $1 / 8$-inch by $1 / 8$-inch by 4 -inches were cut from the plaques in two different orientations. In one type sample the fibers in the top and bottom layers were parallel to the long dimension of the sample. In the other type sample the fibers in top and bottom layers were perpendicular to the long direction in the sample. He measured the number of impacts necessary to cause failure as a function of the applied impact energy. There was a large amount of scatter in the data for both types of sample, but the lifetime of the sample with the glass fiber in the top and bottom layers aligned parallel to the long axis of the specimen was longer than for the other type specimen. Lhymn also concluded that there was a lower limit of impact energy below which no impact failure occurs. 


\section{ENVIRONMENTAL STABILITY OF PPS AND THE ROLE OF CRYSTALLINITY}

\subsection{Thermal and Hydrolytic Stability}

From the early studies of PPS and its composites by Brady ${ }^{14}$ and Hill and Brady ${ }^{7,88}$ it was clear that thermal treatments of PPS in the presence of oxygen generally produce an increase in the average molecular weight of the polymer through chain extension and crosslinking. This fact was used to control the melt flow rate of the polymer, as illustrated in Figure 43. Starting with a relatively low molecular weight and high melt flow rate polymer, the melt flow could be decreased (molecular weight increased) by heating in order to obtain a polymer with the proper melt flow rate for other applications such as injection molding. This process is referred to in the literature as "curing." It can take place at temperatures both above and below the melting temperature of PPS, and tends to occur more rapidly with increase in temperature. There is little tendency to undergo curing below $300^{\circ} \mathrm{F}\left(149^{\circ} \mathrm{C}\right)$, but as Figure 43 shows, curing becomes quite rapid at $550^{\circ} \mathrm{F}\left(288^{\circ} \mathrm{C}\right)$. At temperatures well above the melting point and after several hrs of heating, the polymer gels into an infusible mass. Fortunately, this is a rather slow process; so that PPS can be remelted several times (for short periods above the melting point) before the molecular weight becomes too high to melt process. This allows PPS to be processed as other thermoplastics, including the opportunity to recycle and reuse the polymer and to add regrind to operations such as injection molding. There is, however, some loss of properties compared to virgin material as illustrated in Figure 44, which shows the change in tensile strength, un-notched impact and flowability as a function of the number of times the material is reprocessed. Thus, a downside of this behavior is that the temperature and length of time in the melt state can influence the structure and properties of the resulting material, as has been discussed in previous sections of this review.

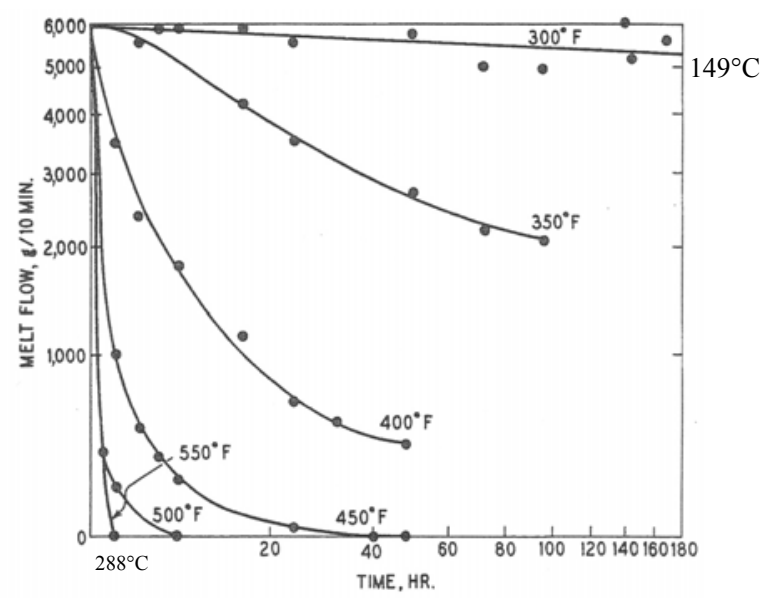

Figure 43. Reduction of melt flow (increase of molecular weight) as a function of holding time at the indicated temperatures.(Data of Hill and Brady. ${ }^{7}$ )

Elevated temperature stability tests on unidirectional E-glass/PPS laminates were conducted by performing $0^{\circ}$ degree flexure and $0^{\circ}$ degree 4-point shear strength testing at various temperatures. ${ }^{58}$ It was determined that the strength retention for both properties was above $80 \%$ up to $115^{\circ} \mathrm{C}$. Due to the semi-crystalline nature of the PPS material the mechanical 
properties experienced excellent retention beyond the $\mathrm{T}_{\mathrm{g}}$ of PPS $\left(89^{\circ} \mathrm{C}\right)$. This is in sharp contrast to thermoset or amorphous resins that show dramatic drop-offs in properties at or above their $\mathrm{T}_{\mathrm{g}}$. Although PPS composites have excellent stability above their $\mathrm{T}_{\mathrm{g}}$, the recommended usage temperature for structural applications is under $90^{\circ} \mathrm{C}$; however, for non-structural applications the material can be used at higher temperatures.

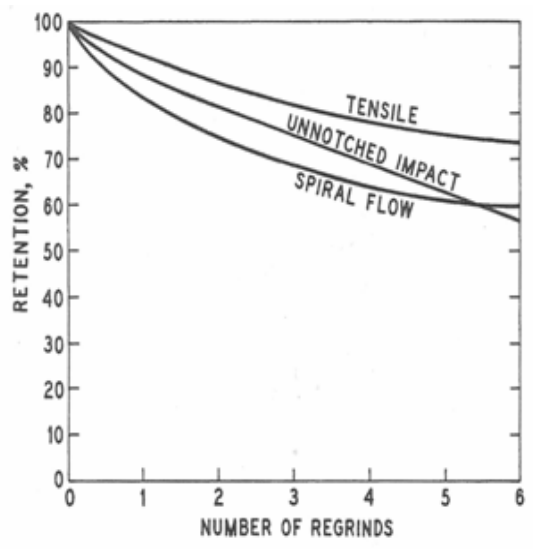

Figure 44. Retention of tensile strength, unnotched impact and flow in a spiral channel as a function of the number of times PPS is reground. (Data of Hill and Brady. ${ }^{7}$ )

The resistance to hydrolysis and its effects on properties is very good for PPS. According to the early study of Lou and Murtha ${ }^{89}$ the tensile and flexural strength of neat PPS decrease by less than $10 \%$ after an exposure in water at $200^{\circ} \mathrm{F}\left(93^{\circ} \mathrm{C}\right)$ for 140 days. Composites exhibited somewhat greater reductions in strength during exposure to hot water. An exposure of $40 \%$ glass-filled composite to $200^{\circ} \mathrm{F}$ water for 30 days resulted in a $20 \%$ reduction in tensile strength. The greater susceptibility of composites to loss of properties on exposure to hot water was attributed to reduced adhesion to the glass reinforcement. The weight gain due to moisture content was about $0.5 \%$ for these composites.

As noted earlier Phillips Petroleum reported several improvements during the early 1990's on their Ryton PPS resins and glass/PPS composites. They also developed a proprietary sizing for E-glass fibers. ${ }^{58,59}$ These improvements focused on three main areas: fiber/matrix interface improvements; resin modifications; and prepreg processing improvements. The older versions including AG40-70 and AG31-60 unidirectional and fabric E-glass/PPS composites suffered from low matrix-dominated properties. For example, the transverse tensile strength for the older unidirectional composite materials having a fiber volume of $55 \%$ was $11.0 \mathrm{MPa}$ (1.6 ksi). This is in sharp contrast with the newer E-glass/PPS composites that have a transverse tensile strength of $51.9 \mathrm{MPa}$ ( $7.5 \mathrm{ksi})$. The improved PPS resins have faster crystallization rates and higher nucleation densities. These material and process improvements resulted in significant increases in the mechanical and environmental resistance properties of the neat resin and fiberreinforced composites (known as AVTEL ${ }^{\mathrm{TM}}$ ). The newer PPS version from Ryton that was developed has a melt crystallization temperature of $235^{\circ} \mathrm{C}$ versus $182^{\circ} \mathrm{C}$ for the original Ryton PPS material. Both materials have a $\mathrm{T}_{\mathrm{g}}$ of $89^{\circ}-90^{\circ} \mathrm{C}$ and about the same melting temperature $\left(275^{\circ} \mathrm{C}\right.$-Original vs. $280^{\circ} \mathrm{C}$-Improved). In addition, the improved version has a cold crystallization temperature of $125^{\circ} \mathrm{C}$ versus $146^{\circ} \mathrm{C}$ for the original material. These improvements produced a material with wider processing windows and significantly higher fracture toughness properties $\left(3.79 \mathrm{~kJ} / \mathrm{m}^{2}\right.$ vs. $\left.0.65 \mathrm{~kJ} / \mathrm{m}^{2}\right){ }^{59}$ The improved PPS materials also 
have more uniform crystallinity and a finer spherulitic structure. In addition, a more compatible glass fiber sizing was developed by Phillips Petroleum that led to an improvement in the glass fiber/PPS matrix adhesion. Phillips Petroleum also developed a functionalized version of PPS for use in making carbon/PPS composites that improved the adhesion between the carbon fiber and the PPS resin. ${ }^{90}$ This resulted in an improvement in the environmental resistance and GIC Mode I fracture toughness for E-glass/PPS and AS4/PPS composites. $\mathrm{G}_{\mathrm{IC}}$ values for E-glass/PPS composites doubled in fracture toughness and increased from $0.8 \mathrm{~kJ} / \mathrm{m}^{2}$ to $2.0 \mathrm{~kJ} / \mathrm{m}^{2}$. In the case of AS4/PPS, the $\mathrm{G}_{\mathrm{IC}}$ values increased from $1.25 \mathrm{~kJ} / \mathrm{m}^{2}$ to $2.2 \mathrm{~kJ} / \mathrm{m}^{2}$.

Yau et al. ${ }^{58}$ also reported that the improved PPS and sizing combination for composites improved fracture toughness and decreased the loss of tensile strength and other properties due to exposure to high humidity and elevated temperature environments. They claimed weight gain less than $0.1 \%$ for E-glass fiber reinforced composites and less than $0.05 \%$ for AS4/PPS carbon fiber reinforced composites after six weeks of exposure to $95 \%$ relative humidity at $71^{\circ} \mathrm{C}$ or at $49^{\circ} \mathrm{C}$ in salt water $(2 \%$ brine solution). The E-glass/PPS and AS4/PPS unidirectional composite laminates were processed in an autoclave under vacuum. Processing included heating the laminates to $330^{\circ} \mathrm{C}$ at $1{ }^{\circ} \mathrm{C} / \mathrm{min}$ while subjected to $70 \mathrm{KPa}$ pressure, then increasing the pressure to $1035 \mathrm{KPa}$ and maintaining for 30 minutes. The laminates were then cooled to $193^{\circ} \mathrm{C}$ followed by relieving the pressure. The percent strength retention for the E-glass/PPS laminates after conditioning for six weeks at $71{ }^{\circ} \mathrm{C} / 95 \% \mathrm{RH}$ was about $70 \%$ for $0^{\circ}$ tensile strength, and $80 \%$ for $0^{\circ}$ flexure and $0^{\circ}$ compression strength. For the $49^{\circ} \mathrm{C}$ seawater conditioning, the percent strength retention was about $80 \%$ for tensile and flexure strength and $75 \%$ for compression strength. In comparison, after six weeks conditioning at $71^{\circ} \mathrm{C}$ and $95 \% \mathrm{RH}$, a typical E-glass/epoxy composite would retain about $50 \%$ and $70 \%$ for 0 degree tensile and flexure strengths, respectively.

According to the Fortron Design Manual ${ }^{77}$, the $\%$ water absorbed by $40 \%$ glass-filled PPS at room temperature $\left(23^{\circ} \mathrm{C}\right)$ is only about $0.03 \%$. A similar result was given by Ma and Yur $^{91}$ for the amount of water absorbed by a carbon fiber reinforced PPS composite. Compression molded composite laminates of carbon/PPS, having fiber contents of $65 \%$ by weight and $1.2 \mathrm{~mm}$ thick, were fabricated by interleaving PPS resin film from Phillips Petroleum with woven, $3 \mathrm{~K}$ carbon fabric from the Toho Company (Style \#3101, $200 \mathrm{~g} / \mathrm{m}^{2}$ ), then preheated to $306^{\circ} \mathrm{C}$ for $20 \mathrm{~min}$ at contact pressure, then compressed at $200 \mathrm{psi}$ for $20 \mathrm{~min}$, and subsequently transferred to a cold press. It is important to note that since these samples were transferred to a cold press from the melt it is assumed that they have a relatively low DOC, and would therefore have higher absorption values compared to samples having a higher DOC. Subsequent to vacuum drying to constant weight at $50^{\circ} \mathrm{C}, \mathrm{C} / \mathrm{PPS}$ samples were exposed to constant humidity and temperature conditions. Results indicated that the water absorption for the C/PPS material followed Fick's law, absorbed relatively low amounts of water, and reached a steady state within 2-3 days as illustrated in Figure 45.

At $80^{\circ} \mathrm{C}, 75 \% \mathrm{RH}$ and $85 \% \mathrm{RH}$, the saturated water absorption values for the samples were 0.059 wt. $\%$ and 0.130 wt. $\%$, respectively. Correspondingly, the water absorption values for C/PEEK (fiber content - 63\% by weight) samples were higher and experienced values of 0.138 wt. $\%$ and 0.153 wt. $\%$ at $80^{\circ} \mathrm{C}, 75 \% \mathrm{RH}$ and $85 \% \mathrm{RH}$, respectively. In addition, they also measured the water absorption of $\mathrm{C} /$ Epoxy composites and found these samples to be greater than C/PPS by almost an order of magnitude. They also found that annealed ( $2 \mathrm{hs}$ at $204^{\circ} \mathrm{C}$ ) C/PPS samples, having a higher level of crystallinity, had lower water absorption values compared to the non-annealed C/PPS samples and were the lowest of any of the materials that 
were tested. The loss of tensile strength of the carbon fiber composites amounted to about $32 \%$ after exposure to $1400 \mathrm{hrs}$ at $95^{\circ} \mathrm{C}$ and $75 \%$ relative humidity. They attributed these changes to the fact that water diffuses into the fiber/matrix interface, causing stress concentration and damage to the material.

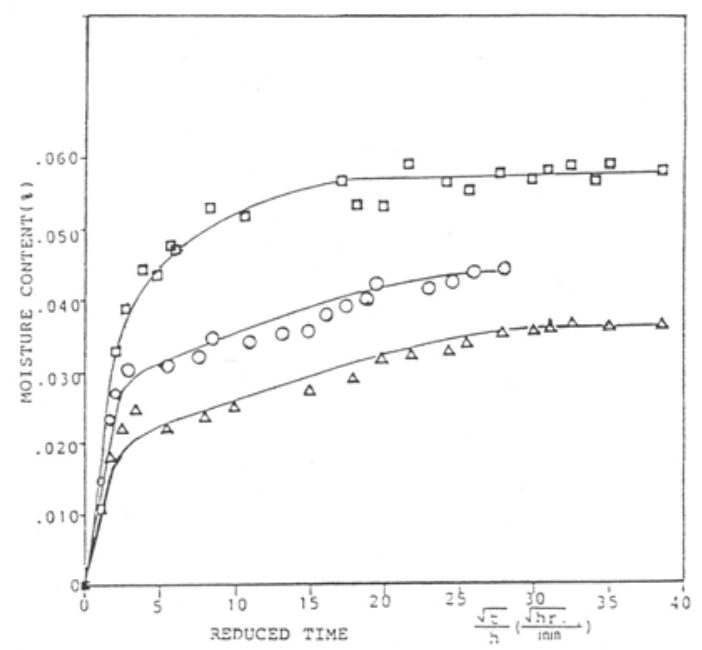

Figure 45. Absorption of water in carbon/PPS (65\% by weight fiber) as a function of reduced time in $75 \%$ relative humidity and temperature: $\square 80^{\circ} \mathrm{C} ; \bigcirc 7^{\circ} \mathrm{C} ; \triangle 60^{\circ} \mathrm{C}$. (Data of Ma and Yur. $^{91}$ )

Recent data from Ten Cate ${ }^{17}$ on water absorption for glass $7781 / \mathrm{PPS}$ and carbon T300J 5HS/PPS laminates is presented in Figure 46. The carbon/PPS fabric laminate is designated CD0286 and is comprised of a 5HS carbon (T300J-3K carbon fiber) fabric having a PPS fiber volume of $50+-3 \%$ and a weight ratio of warp:weft fibers of 50:50. The glass/PPS fabric laminate is designated SS0303 and is comprised of glass fabric style 7781 (E-glass fiber, 8 harness satin weave) having a PPS fiber volume of $50+-3 \%$ and a weight ratio of warp:weft fibers of 51:49. Both of these laminates were processed using equivalent conditions discussed in Section 5.1.1. Results indicate about $0.16 \%$ increase for the glass/PPS laminates and about $0.12 \%$ increase for the carbon/PPS laminates after $1000 \mathrm{hrs}$ exposure time at $70^{\circ} \mathrm{C}-85 \% \mathrm{RH}$. These results illustrate that both the glass and carbon PPS laminates absorb very little water with most of the absorption occurring during the first $50 \mathrm{hrs}$, then slightly increasing from 200$1000 \mathrm{hrs}$. The water absorption values were slightly higher for the glass/PPS composites and, in general, PPS composites absorb less water compared to PEEK composites and an order of magnitude less than epoxy composites.

\subsection{Chemical Resistance}

Chemical resistance involves several aspects of the interaction of chemicals with polymers and composites. Chemicals may dissolve the polymer, or they may be absorbed and cause swelling, plasticization, crazing or, in some cases, solvent induced crystallization of the polymer. In any case, exposure to chemicals often leads to degradation of the properties of the polymer. While the chemical resistance of composites depends significantly on the inertness of 
the matrix polymer, the fiber/matrix interface is also susceptible to attack. Thus, it is important to bear these factors in mind when considering the chemical resistance of polymers and composites.

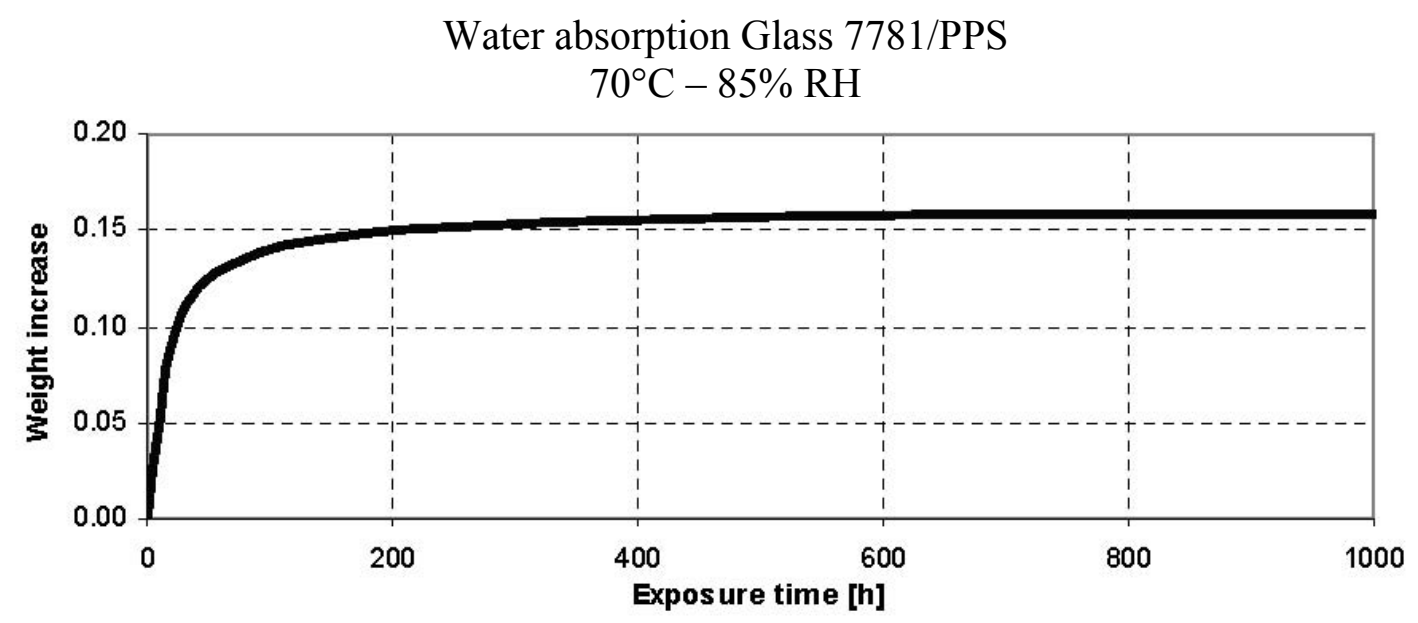

Water absorption Carbon T300J 5HS/PPS

$70^{\circ} \mathrm{C}-85 \% \mathrm{RH}$

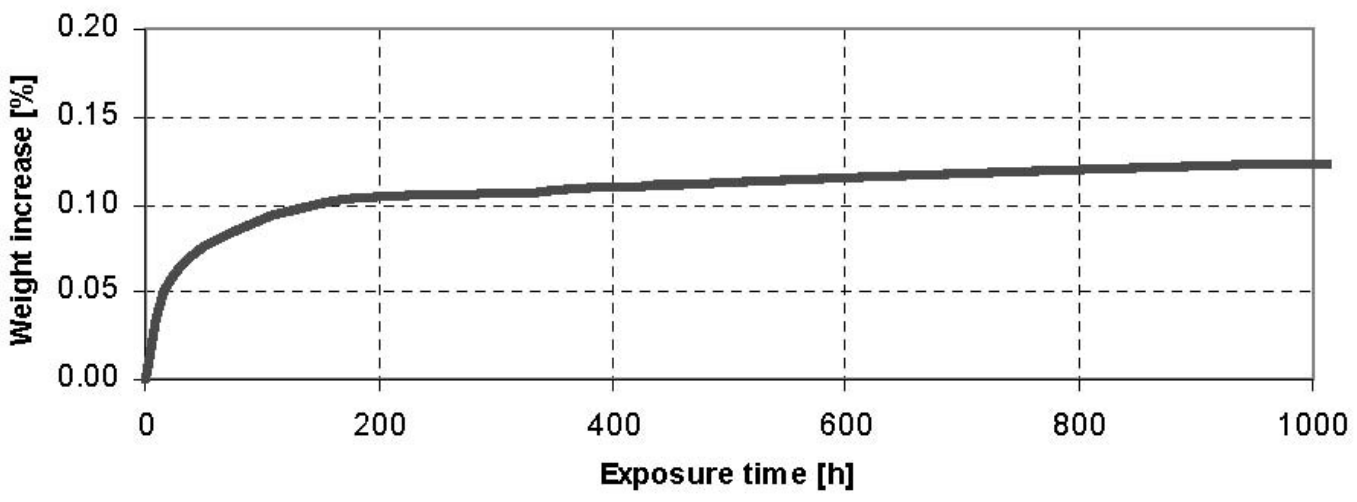

Figure 46. Recent data from Ten Cate ${ }^{17}$ on water absorption for glass 7781/PPS and carbon T300J 5HS/PPS laminates.

The short-term resistance of PPS moldings was first reported by Brady and Hill. ${ }^{92}$ This original work reported the percent tensile strength retained by the moldings after a 24-hour, $200^{\circ} \mathrm{F}$ exposure to a wide range of chemicals. These authors later extended their measurements to a much longer exposure time of 3 months for many of the chemicals. ${ }^{7}$ Their results for both the unfilled resin and a 40\% glass fiber reinforced composite are reprinted in Table 11 . The table indicates excellent resistance to sulfuric and phosphoric acids, but limited resistance to hydrochloric and nitric acids. Resistance to $\mathrm{NaOH}$ also appears to be quite good, while resistance to butyl amine is quite poor.

The Fortron Design Manual ${ }^{77}$ also gives information about chemical resistance of PPS. They rank chemical resistance according to the following scale recommended by "Modern Plastics Encyclopedia": 
$\mathrm{A}=$ No significant effect: $<0.5 \%,<0.2 \%$, and $<10 \%$ change in weight, dimension, and strength, respectively; slight discoloration.

$\mathrm{B}=$ Significant, but usually not conclusive: $0.5-1.0 \%, 0.2-0.5$, and $10-20 \%$ change in weight, dimension and strength, respectively; discolored.

$\mathrm{C}=$ Usually significant: $>1.0 \%,>0.5 \%$, and $>20 \%$ change in weight, dimension, and strength, respectively; warped, softened, or crazed.

Using these criteria, 40\% glass-filled PPS composite is given a rating of "A" for most hydrocarbons at temperatures of $60^{\circ}-80^{\circ} \mathrm{C}$ for exposures up to about 180 days. Some exceptions include weight loss and thickness change for $95 \%$ fuel $\mathrm{A} / 5 \%$ ethanol which were rated only "C". For more detail and ratings on other chemicals, the reader is referred to reference 77 . It should be noted that the chemical resistance of PPS can vary slightly depending upon the manufacturer and the particular grade of PPS that is being investigated.

Table 11. Chemical Resistance of PPS Moldings at $200^{\circ} \mathrm{F}$

\begin{tabular}{|c|c|c|c|c|}
\hline \multirow[b]{3}{*}{ Chemical } & \multicolumn{4}{|c|}{ Percent tensile retained } \\
\hline & \multicolumn{2}{|c|}{ Unfilled resin } & \multicolumn{2}{|c|}{$\begin{array}{c}40 \text { Percent } \\
\text { glass-filled } \\
\text { resin }\end{array}$} \\
\hline & $24 \mathrm{hrs}$ & 3 months & $24 \mathrm{hrs}$ & 3 months \\
\hline $37 \% \mathrm{HCl}$ & 93 & 56 & 72 & 34 \\
\hline $10 \% \mathrm{HNO}_{3}$ & 96 & 31 & 91 & 0 \\
\hline $30 \% \mathrm{H}_{2} \mathrm{SO}_{4}$ & 100 & 100 & 94 & 89 \\
\hline $85 \% \mathrm{H}_{3} \mathrm{PO}_{4}$ & 100 & 100 & 100 & 99 \\
\hline $30 \% \mathrm{NaOH}$ & 100 & 100 & 100 & 89 \\
\hline $\mathrm{H}_{2} \mathrm{O}$ & 100 & 100 & 99 & 99 \\
\hline $5 \% \mathrm{NaOCl}$ & 84 & 90 & 94 & 97 \\
\hline Butyl alcohol & 100 & 100 & 100 & 100 \\
\hline Cyclohexanol & 96 & 81 & 100 & 100 \\
\hline Butyl amine & 50 & 0 & 96 & 46 \\
\hline Aniline & 96 & 87 & 100 & 86 \\
\hline 2-Butanone & 100 & 70 & 100 & 100 \\
\hline Benzaldehyde & 84 & 90 & 97 & 47 \\
\hline \multicolumn{5}{|l|}{ Carbon } \\
\hline tetrachloride & 100 & 77 & 100 & 48 \\
\hline Chloroform & 87 & 79 & 81 & 77 \\
\hline Ethyl acetate & 100 & 100 & 100 & 88 \\
\hline Butyl ether & 100 & 100 & 100 & 89 \\
\hline$p$-Dioxane & 88 & 75 & 100 & 96 \\
\hline Gasoline & 100 & 87 & 100 & 99 \\
\hline Toluene & 98 & 74 & 100 & 70 \\
\hline Benzonitrile & 100 & 77 & 100 & 79 \\
\hline Nitrobenzene & 100 & 85 & 100 & 63 \\
\hline Phenol & 100 & 100 & 100 & 92 \\
\hline \multicolumn{5}{|l|}{ Cresyldiphenyl } \\
\hline $\begin{array}{l}\text { phosphate } \\
\text { N-Methyl }\end{array}$ & 100 & 100 & 100 & 100 \\
\hline pyrrolidone & 94 & 74 & 100 & 92 \\
\hline Air & - & 90 & - & 96 \\
\hline
\end{tabular}

Ma et al ${ }^{93}$ measured the weight gain of compression molded carbon fiber composites with PPS or PEEK matrices when exposed to certain solvents and aircraft fluids. The solvents included methylene chloride, methyl ethyl ketone (MEK), MIL-T-5624JP-4 jet fuel, MIL-H5606 hydraulic fluid, and MIL-R-83936 paint stripper. Specimens were immersed in the solvents at room temperature. The samples were fabricated by interleaving Ryton PPS resin film, from 
Phillips Petroleum Co., with woven, 3K carbon fabric, provided by the Toho Company (Style $\# 3101,200 \mathrm{~g} / \mathrm{m}^{2}$ ), then preheated to $306^{\circ} \mathrm{C}$ for $20 \mathrm{~min}$ at contact pressure, then compressed at $200 \mathrm{psi}$ for $20 \mathrm{~min}$, and subsequently transferred to a cold press. It is important to note that since these samples were transferred to a cold press from the melt, it is assumed that they have a relatively low DOC, thus the chemical resistance properties listed here should be considered conservative and would be expected to be better for PPS materials having a higher DOC.

The results for the equilibrium \% weight gain for the C/PPS samples were in the following order: JP-4 $<$ hyrdraulic fluid $<$ MEK $<$ methylene chloride. The data indicates very little absorption of JP-4 $(0.1 \%)$ or hydraulic fluid $(0.2 \%)$ after about 70 days exposure at room temperature, however, the \% weight gain for the MEK exposed samples was approximately $2.6 \%$ and even worse for the methylene chloride samples at about 5\%. In comparison to the C/PPS, the trends observed for the C/PEEK samples at equilibrium for the $\%$ weight gain using these same fluids were generally similar except that JP-4 was absorbed to a larger extent compared to hydraulic fluid $(0.4 \%$ vs. $0.2 \%)$. In addition, the C/PEEK samples absorbed a higher percentage of methylene chloride (7\% vs. 5\%), but a lower amount of MEK (1.2\% vs. $2.6 \%)$ compared to the C/PPS samples.

The effect of fluids on the tensile (ASTM D3039) and flexural properties (ASTM D790) of woven C/PPS composites indicated that hydraulic fluid had a negligible effect on the fiberdominated tensile strength of the C/PPS composite while the JP-4 and MEK exposed samples yielded about $90 \%$ retention. However, the samples exposed to paint stripper (MIL-R-83936) and methylene chloride fared the worst and retained only about $85 \%$ and $80 \%$ tensile strength, respectively. In addition, these fluids significantly affected the more matrix-dominated flexural strength properties and yielded \% strength retention values only in the range of $40-85 \%$ with paint stripper exhibiting the worst performance: JP-4 $(85 \%)>$ hydraulic fluid $(65 \%)>$ methylene chloride $(60 \%)>\operatorname{MEK}(50 \%)>$ paint stripper $(40 \%)$.

$\mathrm{X}$-ray diffraction patterns showed that paint stripper, methylene chloride and MEK were able to induce additional crystallization in PPS composites after 108 days exposure. This is in agreement with the prior study of Johnson and Ryan ${ }^{31}$, who reported that PPS quenched from the molten state (i.e., amorphous PPS) is quite susceptible to solvent induced crystallization by methylene chloride. They found that the degree of crystallinity of quenched PPS after treatment with methylene chloride at room temperature for $24 \mathrm{hrs}$ is approximately equal to PPS that was quenched from the melt and annealed $2 \mathrm{hrs}$ at $200^{\circ} \mathrm{C}$.

Recent data from Ten Cate ${ }^{17}$ on the chemical resistance of various fluids including MEK, anti-icing fluid, jet fuel, Skydrol (aircraft grade hydraulic fluid), and Skydrol/water on the in plane shear strength properties of glass 7781/PPS and carbon T300J 5HS/PPS laminates is presented in Figure 47. The carbon/PPS fabric laminate is designated CD0286 and is comprised of a $5 \mathrm{HS}$ carbon (T300J-3K carbon fiber) fabric having a PPS fiber volume of $50+-3 \%$ and a weight ratio of warp:weft fibers of 50:50. The glass/PPS fabric laminate is designated SS0303 and is comprised of glass fabric style 7781 (E-glass fiber, 8 harness satin weave) having a PPS fiber volume of $50+-3 \%$ and a weight ratio of warp:weft fibers of 51:49. Both of these laminates were processed using equivalent conditions discussed in Section 5.1.1. Results indicate that these fluids had very minimal, if any, effect on the in plane shear strength properties relative to the reference samples. 
Chemical Resistance

Glass 7781/PPS

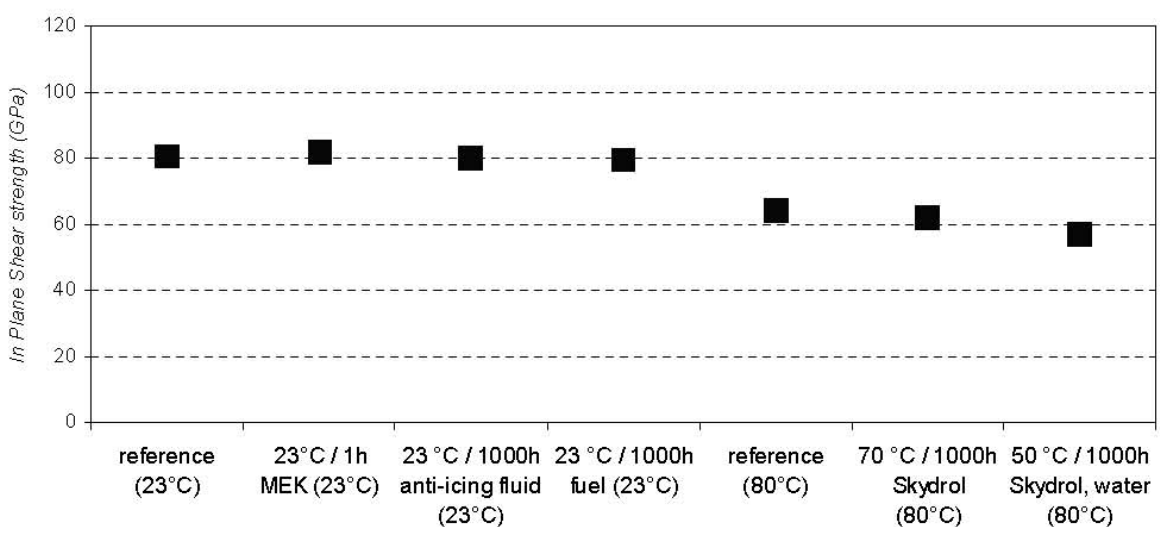

Chemical Resistance

Carbon T300J 5HS/PPS

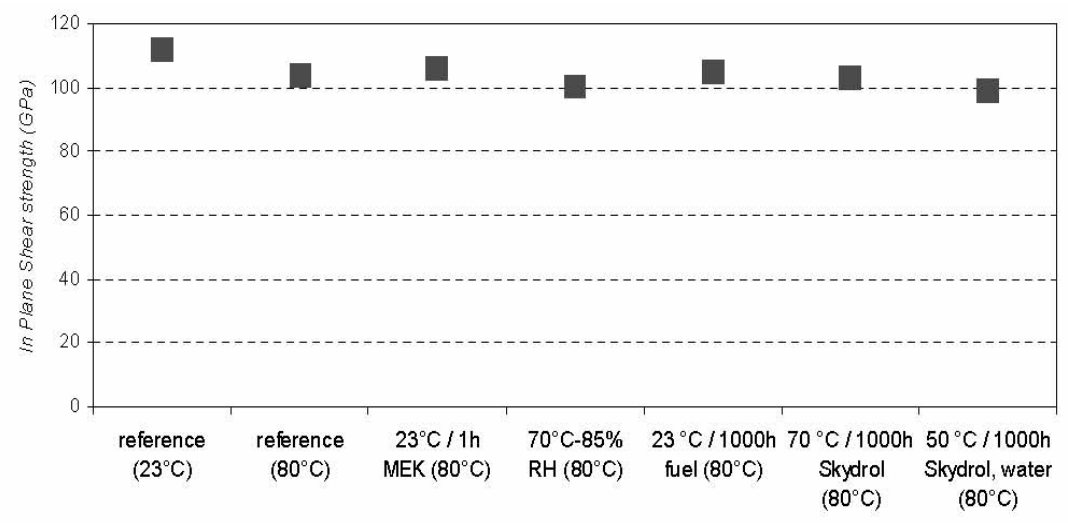

Figure 47. Recent data from Ten Cate ${ }^{17}$ on the chemical resistance of various fluids including MEK, anti-icing fluid, jet fuel, Skydrol, and Skydrol/water on the in plane shear strength properties of glass 7781/PPS and carbon T300J 5HS/PPS laminates. 


\section{RECOMMENDATIONS FOR FUTURE RESEARCH}

Several areas in need of further research were discovered in the course of this review. We briefly summarize those areas here.

(1) In order to obtain accurate crystallinity values from DSC measurements, the value of $\Delta H_{f}^{o}$ needs to be reevaluated and the proper value confirmed. As shown in this review, the present spread of values in the literature result in wide disparities in the crystalline fractions determined by different investigators for similar processing and treatment conditions. This situation produces considerable confusion in interpreting the results quoted by different investigators for the structure and properties of their samples.

(2) It is also clear that DSC measurements of crystallinity are likely to be in error for another reason when the samples have very low values of crystallinity. This appears to be a result of recrystallization effects during the heat-up in the DSC that usually result in measured values that are too high. An understanding of the source of double melting peaks often observed would be an important part of this effort, as double melting can be due to recrystallization effects, different lamellae thicknesses or the presence of two crystalline phases. More research on the significance of this effect and the conditions for which it is important would help investigators to know when DSC measurements of crystallinity are reliable.

(3) Simulate molding conditions using a simple DSC technique applicable to any semicrystalline polymer and streamline the selection of process conditions. Use DSC cool down curves similar to Figure 2(b) to determine crystalline fraction after cooling to room temperature as a function of process parameters such as melt temperature, melt holding time, cooling rate, and interrupted cooling conditions. This approach will eliminate recrystallization effects that cause errors in determining the crystalline fraction. Use this screening test to significantly reduce the number of actual molding tests required to identify the optimum molding conditions. Use polarized optical microscopy and a programmable hot stage to follow microstructural changes in spherulite size and distribution that occur during processing and relate this information to properties. Use DMA method to obtain viscoelastic property measurements (storage and loss modulus, creep behavior) on samples that have been prepared using both the simulated and actual molding conditions described above. Use DMA to study the effects of water and other chemicals using clamping systems that are submergible in liquids. Such clamps are commercially available. A model of the crystallinity versus process conditions versus mechanical and chemical properties could be developed using this approach and used to help identify economically feasible processes.

(4) One of the excellent properties of PPS is its inherent chemical resistance to a variety of fluids, however, it is difficult to bond PPS to various substrates including glass and carbon fibers. Poor fiber/matrix adhesion was a consistent theme throughout the literature and it was responsible for compromising the matrix-dominated properties of PPS composites including interlaminar shear strength, in-plane shear strength, transverse tensile strength and other interfacial related properties. Understanding and optimizing fiber/matrix adhesion is a prerequisite to improving the matrix-dominated properties and overall mechanical properties of PPS composites. Areas recommended for optimizing fiber/matrix adhesion in PPS composites include the development of PPS compatible fiber surface treatments, fiber/matrix coupling agents, and fiber sizings, as well as functionalization/modification of the PPS resin system. The optimization study should also 
include performing the appropriate matrix-dominated and fiber-dominated mechanical property tests for downselecting the best possible solutions.

(5) The crystallization rate, the degree of crystallinity, spherulitic size, spherulitic distribution, and thus the ultimate properties of fiber-reinforced PPS composites are dependent upon a number of factors including the type/grade of PPS, the thermal history of the composite (i.e., melt and mold temperature/time and thermal conditioning/annealing), the type/amount of fiber, fiber sizing, and fiber surface treatment (i.e., ozone, electrochemical, plasma, other - level of surface activation, surface energy may be very important), and the type/amount of any nucleating agents or other additives that may be present. All of these factors need to be evaluated when any new material or processing changes are being considered with PPS composites.

(6) The impact properties of unreinforced PPS can be improved by blending with other materials and/or by heat-treating in air. Further investigation of these methods is suggested with fiber reinforced PPS composites.

(7) Investigate the substantial effect of crystallinity on the 0 degree flexural properties of AS4/PPS unidirectional composites versus the 0/90 cross-ply tensile properties (see reference 38, pp. 204, 208, 211.

(8) Since the data in the existing literature was restricted to composites containing high cost, aerospace grade carbon fibers, the properties of composites produced using low cost carbon fibers should be evaluated.

(9) Conventional adhesive bonding of PPS composites to various substrates is an area needing further study. Suggested areas include the evaluation/development of surface treatment techniques (i.e. abrasion, corona, plasma) and suitable adhesive systems for improving the adhesive properties and the durability of bonded joints.

(10) PPS is suitable for welding to itself and to other materials. Evaluation of various joining techniques and their effect on properties with PPS composites is suggested including ultrasonic welding, induction (electromagnetic) welding, friction welding, resistance welding, and laser welding. 


\section{ACKNOWLEDGEMENTS}

This research was sponsored by the U.S. Department of Energy, Assistant Secretary for Energy Efficiency and Renewable Energy, Office of FreedomCAR and Vehicle Technologies, as part of the Automotive Lightweighting Materials Program, under contract DE-AC0500OR22725 with UT-Battelle, LLC.

The authors thank the Automotive Composites Consortium (ACC) for their support for conducting this review. The authors extend special thanks to Jingyao Cao for providing some miscellaneous help during the preparation of the manuscript. They also thank Xiaoyun Ling for providing the DSC data presented in Figure 2 and to Jeanne Phillips for preparation of the report. 
This page left blank intentionally. 


\section{REFERENCES}

1. Brady, D. G. In Engineering Plastics; ASM International, Metals Park, Ohio, 1988; Vol. 2, pp 186-191.

2. Edmonds, J. T.; Hill Jr., H. W.; Phillips Petroleum Company: US Patent 3,354,129, 1967.

3. Lopez, L. C.; Wilkes, G. L. J. Macromol. Sci., Rev. Macromol. Chem. Phys. 1989, C29, 83-151.

4. Geibel, J. F.; Cambell, R. W. In Encyclopedia of Chemical Processing and Design; Marcel Dekker, New York, 1992; Vol. 40, p 94.

5. Hill Jr., H. W. a. B., D.G. In High Performance Polymers and Composites; Kroschwitz, J. I., Ed.; John Wiley \& Sons: New York, 1991; pp 551-577.

6. Cebe, P. Polymers \& Polymer Composites 1995, 3, 239-266.

7. Hill, J., H.W. and Brady, D.G. Polymer Engineering and Science 1976, 16, 831-835.

8. Tabor, B. J.; Magre, E. P.; Boon, J. European Polymer Journal 1971, 7, 1127-1133.

9. Lovinger, A. J.; Padden, F. J., Jr.; Davis, D. D. Polymer 1988, 29, 229-232.

10. Uemura, A.; Isoda, S.; Tsuji, M.; Ohara, M.; Kawaguchi, A.; Katayama, K. Bulletin of the Institute for Chemical Research, Kyoto University 1986, 64, 66-77.

11. Jurga, J. Polymer 1993, 34, 4203.

12. Garbarczyk, J. Polym. Commun. 1986, 27, 335.

13. Napolitano, R.; Pirozzi, B.; Salvione, A. Macromolecules 1999, 32, 7682-7687.

14. Brady, D. G. Journal of Applied Polymer Science 1976, 20, 2541-2551.

15. Huo, P.; Cebe, P. Colloid and Polymer Science 1992, 270, 840-852.

16. Maemura, E.; Cakmak, M.; White, J. L. International Polymer Processing 1988, 3, 7985.

17. In CETEX - PPS Guide Lines; Ten Cate Advanced Composites: Nijverdal, Netherlands, 2003; p 32.

18. Lenferink, R.; Ten Cate Advanced Composites: Personal Communication, 2003.

19. Flory, P. J. Principles of Polymer Chemistry; Cornell Press, Ithaca, NY, 1953.

20. Flory, P. J. J. Phys. Chem. 1942, 10, 51-61.

21. Huggins, M. L. J. Am. Chem. Soc. 1942, 64, 1712-1719.

22. Huggins, M. L. J. Phys. Chem. 1942, 46, 151-158.

23. Chung, J. S.; Cebe, P. Polymer 1992, 33, 2312-2324.

24. Budgell, D. R.; Day, M. Polymer Engineering and Science 1991, 31, 1271-1278.

25. Silvestre, C.; Di Pace, E.; Napolitano, R.; Pirozzi, B.; Cesario, G. Journal of Polymer Science, Part B: Polymer Physics 2001, 39, 415-424.

26. Lee, T. H.; Boey, F. Y. C.; Khor, K. A. Composites Science and Technology 1995, 53, 259-274.

27. Cole, K. C.; Noel, D.; Hechler, J. J. Journal of Applied Polymer Science 1990, 39, $1887-$ 1902.

28. Welsh, W. J. In Physical Properties of Polymers Handbook; Mark, J. E., Ed.; Am. Inst. Phys.: Woodbury, NY, 1996; pp 401-407.

29. Ruland, W. Acta Crystallogr. 1961, 14, 1180.

30. Mo, Z.; Zhang, H. J. Macromol. Sci., Rev. Macromol. Chem. Phys. 1995, C35, 555-580.

31. Johnson, T. W.; Ryan, C. L. In International SAMPE Symposium and Exhibition, 1986; Vol. 31, pp 1537-1548. 
32. Ballirano, P.; Caminiti, R.; D'Ilario, L.; Martinelli, A.; Piozzi, A.; Maras, A. Journal of Materials Science 1998, 33, 3519-3524.

33. Isasi, J. R.; Mandelkern, L.; Galante, M. J.; Alamo, R. G. J. Polym. Sci. B: Polym. Phys. 1999, 37, 323-334.

34. Yu, J.; Asai, S.; Sumita, M. Journal of Macromolecular Science, Physics 2000, B39, 279-296.

35. Auer, C.; Kalinka, G.; Krause, T.; Hinrichsen, G. Journal of Applied Polymer Science 1994, 51, 407-413.

36. Desio, G. P.; Rebenfeld, L. Journal of Applied Polymer Science 1992, 44, 1989-2001.

37. Lee, T. H.; Boey, F. Y. C.; Khor, K. A. Polymer Composites 1995, 16, 481-488.

38. Deporter, J.; Baird, D. G. Polymer Composites 1993, 14, 201-213.

39. Lopez, L. C.; Wilkes, G. L. ACS Polym. Div. Preprint 1986, 27, 288.

40. Lopez, L. C.; Wilkes, G. L. J. Polym. Sci., Polym. Lett. Ed. 1986, 24, 573.

41. Jog, J. P.; Nadkarni, V. M. Journal of Applied Polymer Science 1985, 30, 997-1009.

42. Lopez, L. C.; Wilkes, G. L. Polymer 1988, 29, 106-113.

43. Lopez, L. C.; Wilkes, G. L.; Geibel, J. F. Polymer 1989, 30, 147-155.

44. Kenny, J. M.; Maffezzoli, A. Polymer Engineering and Science 1991, 31, 607-614.

45. Maffezzoli, A.; Kenny, J. M.; Nicolais, L. Thermochimica Acta 1992, 199, 133-146.

46. Chung, J. S.; Cebe, P. Polymer 1992, 33, 2325-2333.

47. Chung, J. S.; Cebe, P. Journal of Polymer Science, Part B: Polymer Physics 1992, 30, 163-176.

48. Desio, G. P.; Rebenfeld, L. Journal of Applied Polymer Science 1992, 45, 2005-2020.

49. Mehl, N. A.; Rebenfeld, L. Journal of Applied Polymer Science 1995, 57, 187-199.

50. Caminiti, R.; D'Ilario, L.; Martinelli, A.; Piozzi, A. Macromolecular Chemistry and Physics 2001, 202, 2902-2914.

51. Lovinger, A. J.; Davis, D. D.; Padden, F. J., Jr. Polymer 1985, 26, 1595-1604.

52. Jog, J. P.; Bulakh, N.; Nadkarni, V. M. Bulletin of Materials Science 1994, 17, 10791089.

53. Hawkins, R. T. Macromolecules 1976, 9, 189.

54. Desio, G. P.; Rebenfeld, L. Annual Technical Conference - Society of Plastics Engineers 1991, 49th, 2088-2091.

55. Desio, G. P.; Rebenfeld, L. Journal of Applied Polymer Science 1990, 39, 825-835.

56. Lopez, L. C.; Wilkes, G. L. Polymer 1989, 30, 882-887.

57. Caramaro, L.; Chabert, B.; Chauchard, J.; Vu-Khanh, T. Polymer Engineering and Science 1991, 31, 1279-1285.

58. Yau, S.-S.; Rhodes, V. H.; Soules, D. A.; Cheng, P. J. In 23rd International SAMPE Technical Conference, 1991; Vol. 23.

59. Winkel, J. D.; Wareham, J. R.; Hagenson, R. L. In 35th International SAMPE Symposium, 1990; Vol. 35, pp 1628-1637.

60. Neyman, G.; Lando, J. B.; Ishida, H. Composite Interfaces 1994, 2, 351-363.

61. Hermans, P. H.; Hermans, J. J.; Vermaas, D.; Weidinger, A. J. Polym. Sci. 1948, 3, 1.

62. Stein, R. S. J. Polym. Sci. 1958, 31, 327.

63. White, J. L.; Spruiell, J. E. Polymer Engineering and Science 1981, 21, 859-868.

64. Maemura, E.; Cakmak, M.; White, J. L. Polymer Engineering and Science 1989, 29, $140-150$. 
65. Kelly, J.; Baird, D. G. International SAMPE Symposium and Exhibition 1991, 36, 15351544.

66. Nishihata, N.; Koizumi, T.; Ichikawa, Y.; Katto, T. Polymer Engineering and Science 1998, 38, 403-408.

67. Oya, N.; Hamada, H. Composites Part A 1997, 28A, 823-832.

68. Ye, L.; Scheuring, T.; Friedrich, K. Journal of Materials Science 1995, 30, 4761-4769.

69. Lustiger, A., Uralil, F., Newaz, G. Polym. Composites 1990, 11, 65.

70. Dreumel, W. V.; Ten Cate Advanced Composites: Personal Communication, 2003.

71. Galanty, P. G. a. R., J.J. In Engineering Materials Handbook, Vol 2 - Engineering Plastics; ASM International: Metals Park, Ohio, 1988; Vol. 2, p 172.

72. Davies, P.; Benzeggagh, M. L.; de Charentenay, F. X. In 32nd International SAMPE Symposium, 1987; pp 134-146.

73. Lu, D.; Yang, Y.; Zhuang, G.; Li, B. Macromol. Chem. Phys. 2001, 202, 734-738.

74. Ma, C. C.; Lee, C. L.; Chang, M. J.; Tai, N. H. Polymer Composites 1992, 13, 441-447.

75. Ma, C. C.; Huang, Y. H.; Chang, M. J.; Ong, C. L. In International SAMPE Symposium and Exhibition, 1991; Vol. 36, pp 872-885.

76. Spamer, G. T.; Brink, N. O. In 33rd International SAMPE Symposium, 1988; pp 284-295.

77. In Designing with Fortron Polyphenylene Sulfide, Design Manual FN-10; Ticona, 90 Morris Avenue, Summit, NJ, 1999.

78. Sepe, M. P. Annual Technical Conference - Society of Plastics Engineers 1992, 50th, 1152-1161.

79. Findley W.N. and Khosla, G. SPE Journal 1956, 12, 20.

80. Findley W.N. and Petersen, D. B. Proc. ASTM 1958, 58.

81. Carriere, C. J.; Bank, D.; Malanga, M. Journal of Applied Polymer Science 1998, 67, 1177-1183.

82. Boey, F. Y. C.; Lee, T. H.; Khor, K. A. Polymer Testing 1995, 14, 425-438.

83. Gibson, R. F.; Hwang, S. J.; Kathawate, G. R. In 23rd International SAMPE Technical Conference, 1991; Vol. 23.

84. Mandell, J. F. H., D.D.; McGarry, F.J. Polymer Composites 1981, 2, 144-151.

85. Karger-Kocsis, J. Polymer Bulletin (Berlin) 1991, 27, 109-116.

86. Loverich, J. S. R., Blair E.; Case, Scott W.; Reifisnider, Kenneth L. In Time Dependent and Nonlinear Effects in Polymers and Composites; ASTM Special Technical Publication, 2000; Vol. STP 1357, pp 310-317.

87. Lhym, C. J., Mat. Sci., Letters 1985, 4, 122-1224.

88. Hill, J., H.W. and Brady, D.G. In Encyclopedia of Chemical Technology; Wiley: New York, 1982; Vol. 18, p 793.

89. Lou, A. Y.; Murtha, T. P. In 17th National SAMPE Technical Conference, 1985; pp 274285.

90. Geibel, J.; Chevron Phillips Chemical Company LP: Personal Communication, 2004.

91. Ma, C. C.; Yur, S.-W. Polymer Engineering and Science 1991, 31, 34-39.

92. Brady, D. G. a. H., H.W., Jr. Modern Plastics 1974, 51, 60.

93. Ma, C.C.; Lee, C. L.; Tai, N. H., Polymer Composites 1992, 13, 435-440. 
This page left blank intentionally 
APPENDIX A. MECHANICAL PROPERTY GRAPHICAL RESULTS AND RAW DATA FROM TEN CATE 
This page left blank intentionally. 
Tensile Strength Warp, MPa (Data Provided By Ten Cate)

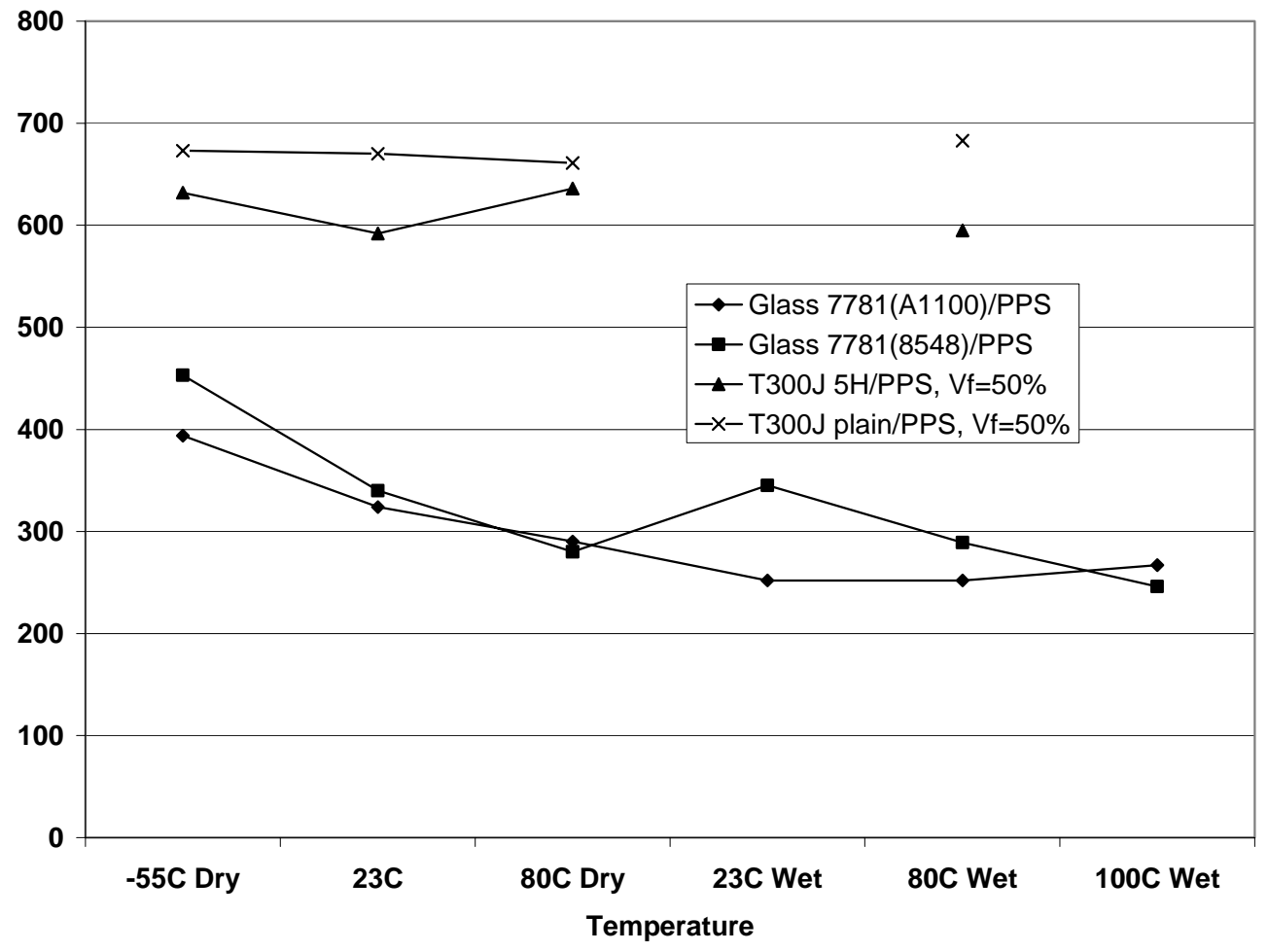

Tensile Strength Weft, MPa (Data Provided By Ten Cate)

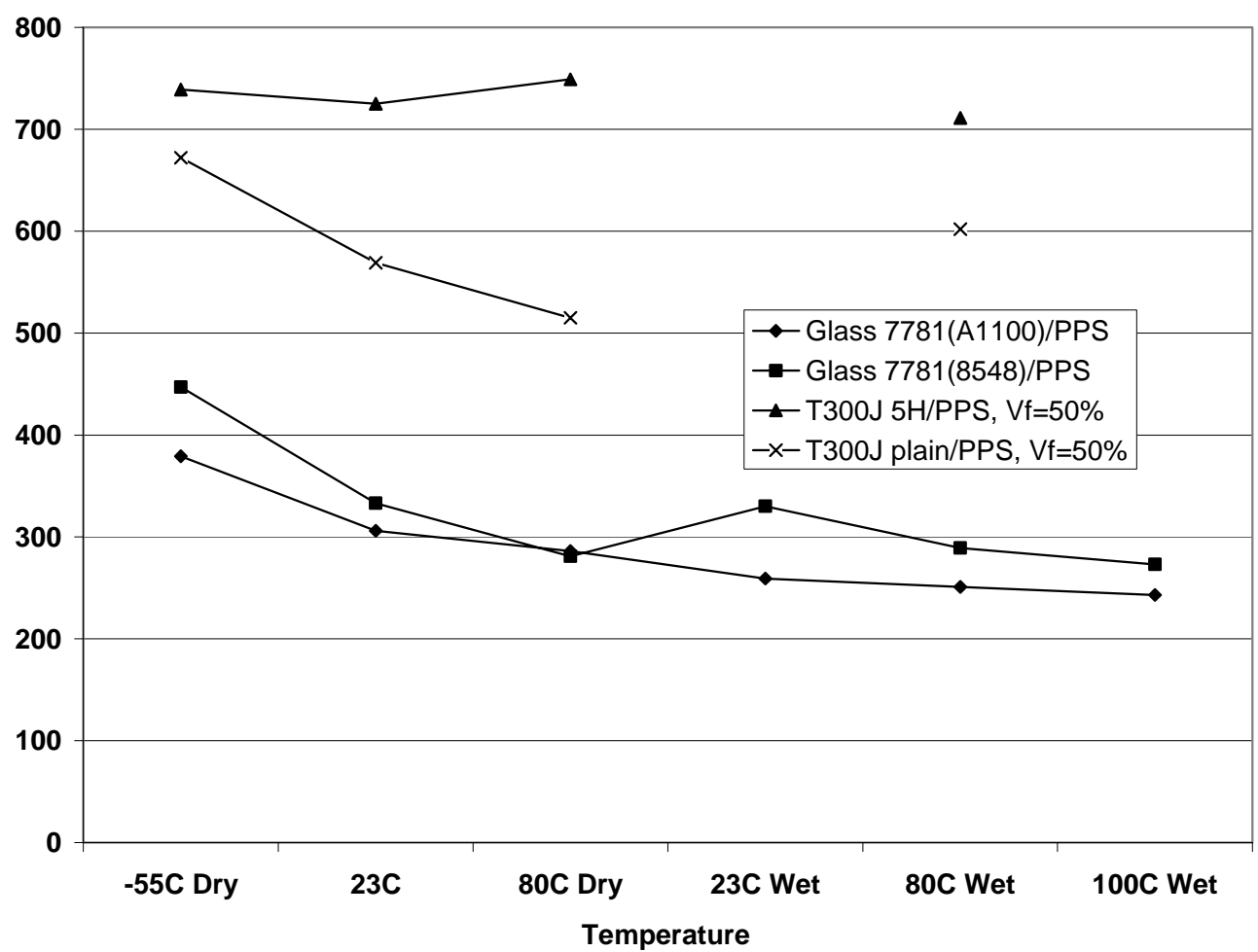


Tensile Modulus Warp, GPa (Data Provided By Ten Cate)

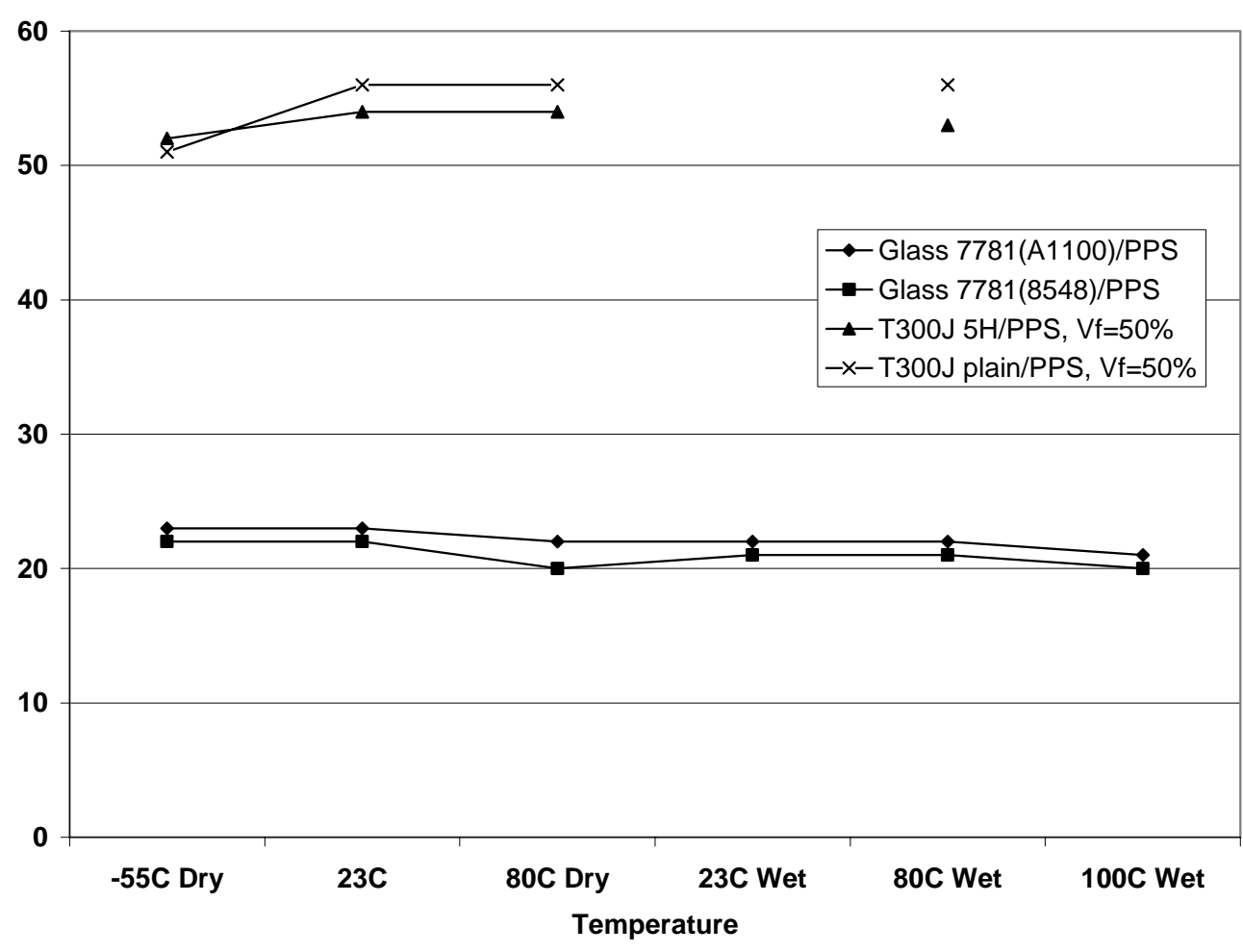

Tensile Modulus Weft, GPa (Data Provided By Ten Cate)

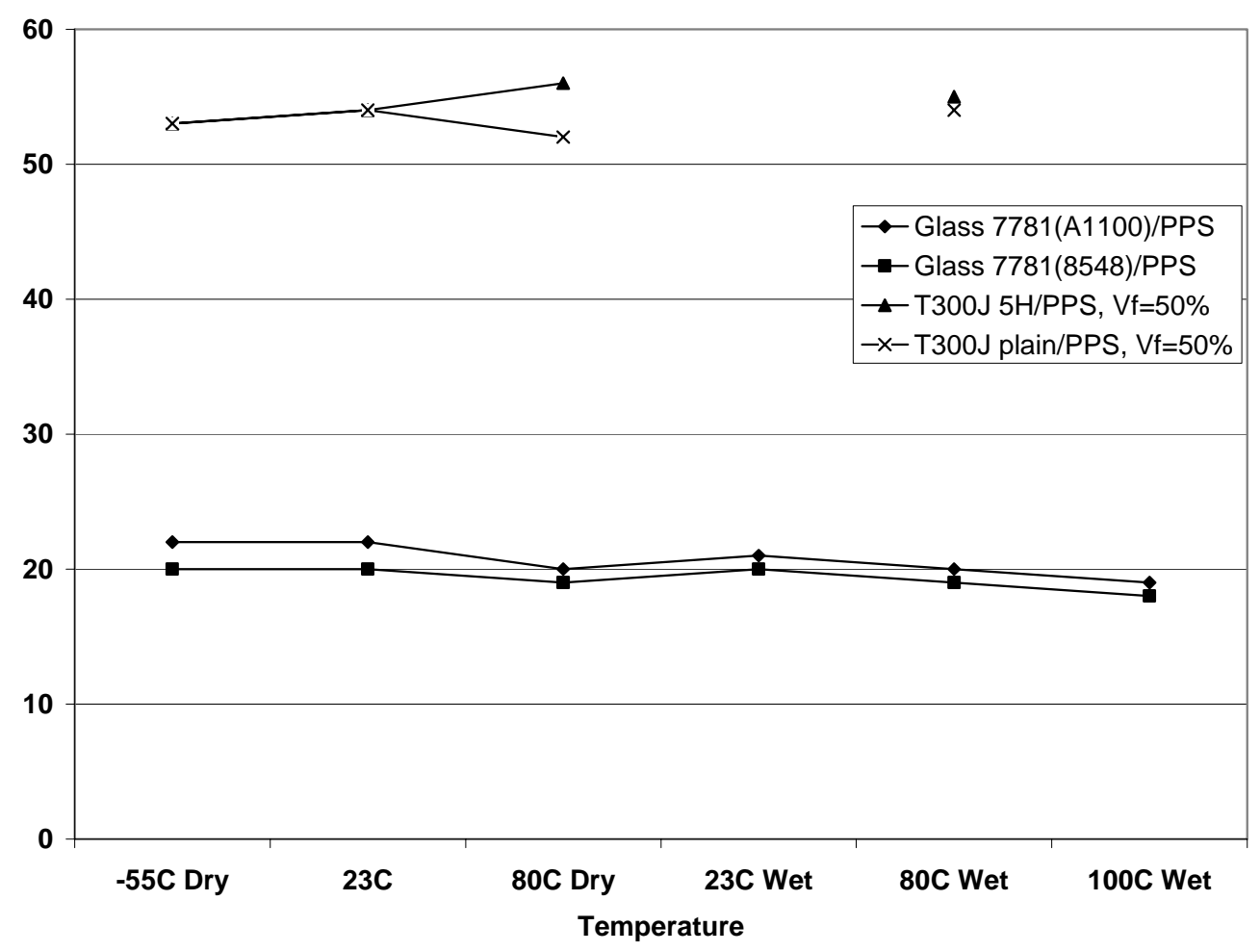



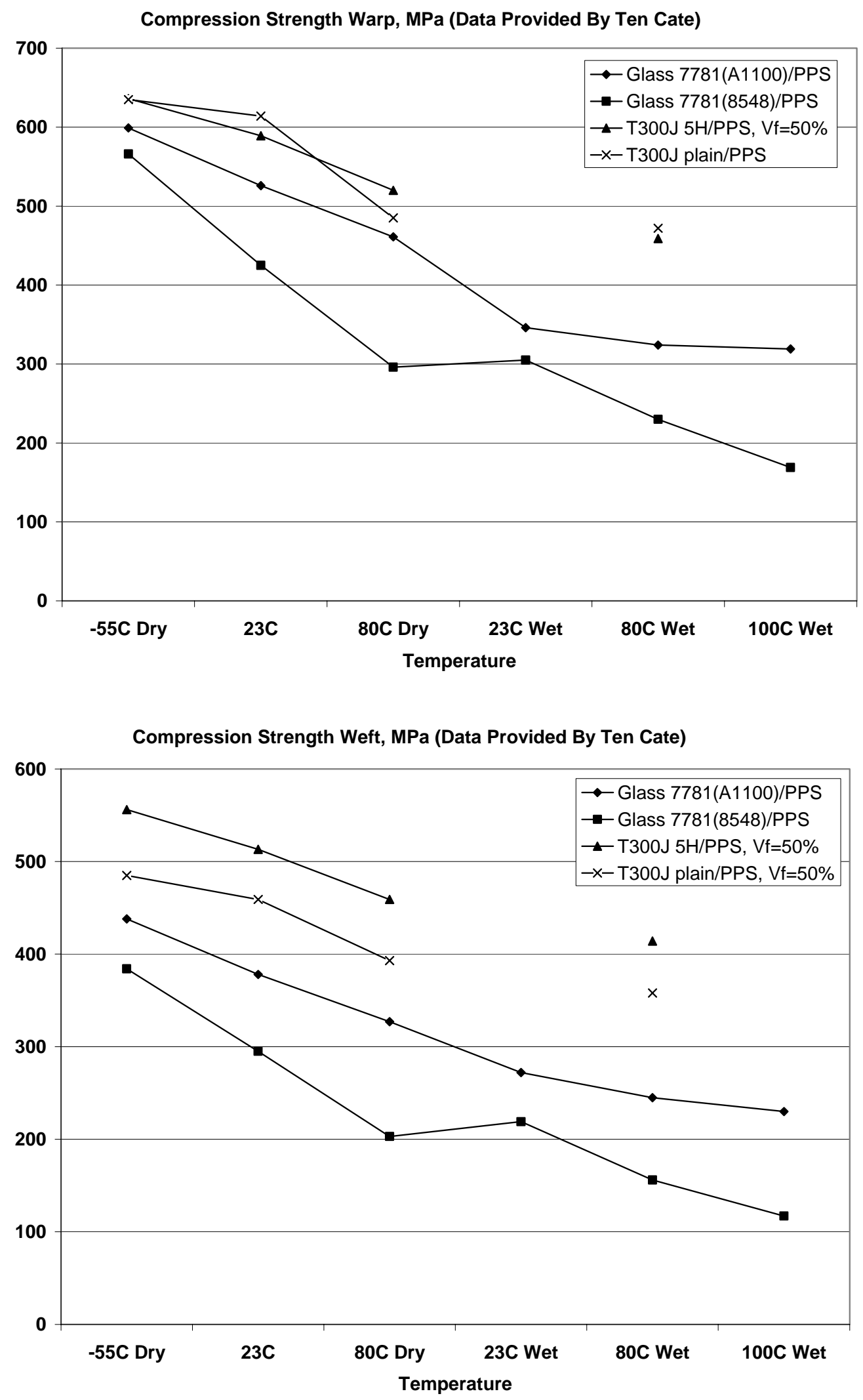

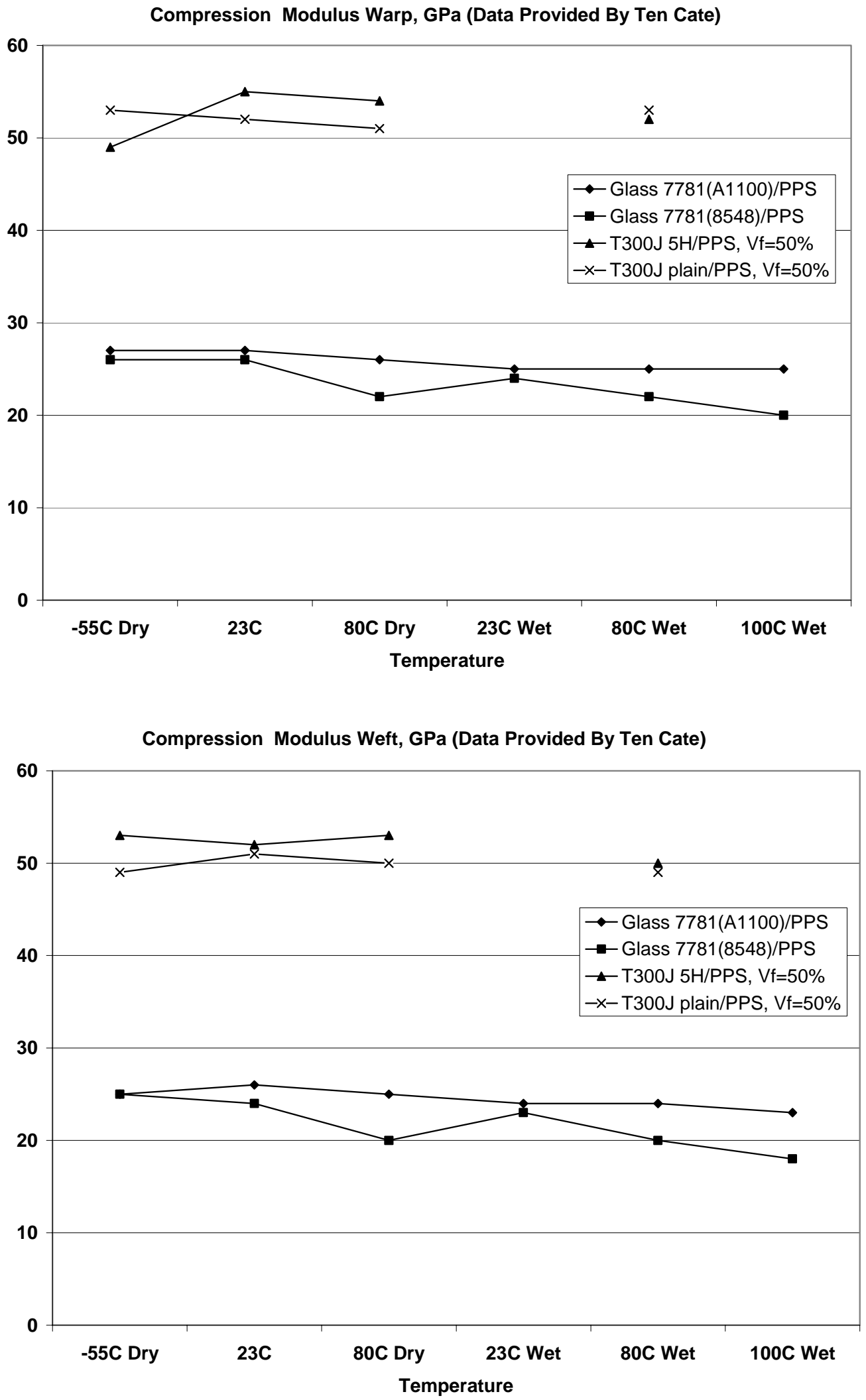
Flexural Strength Warp, MPa (Data Provided By Ten Cate)

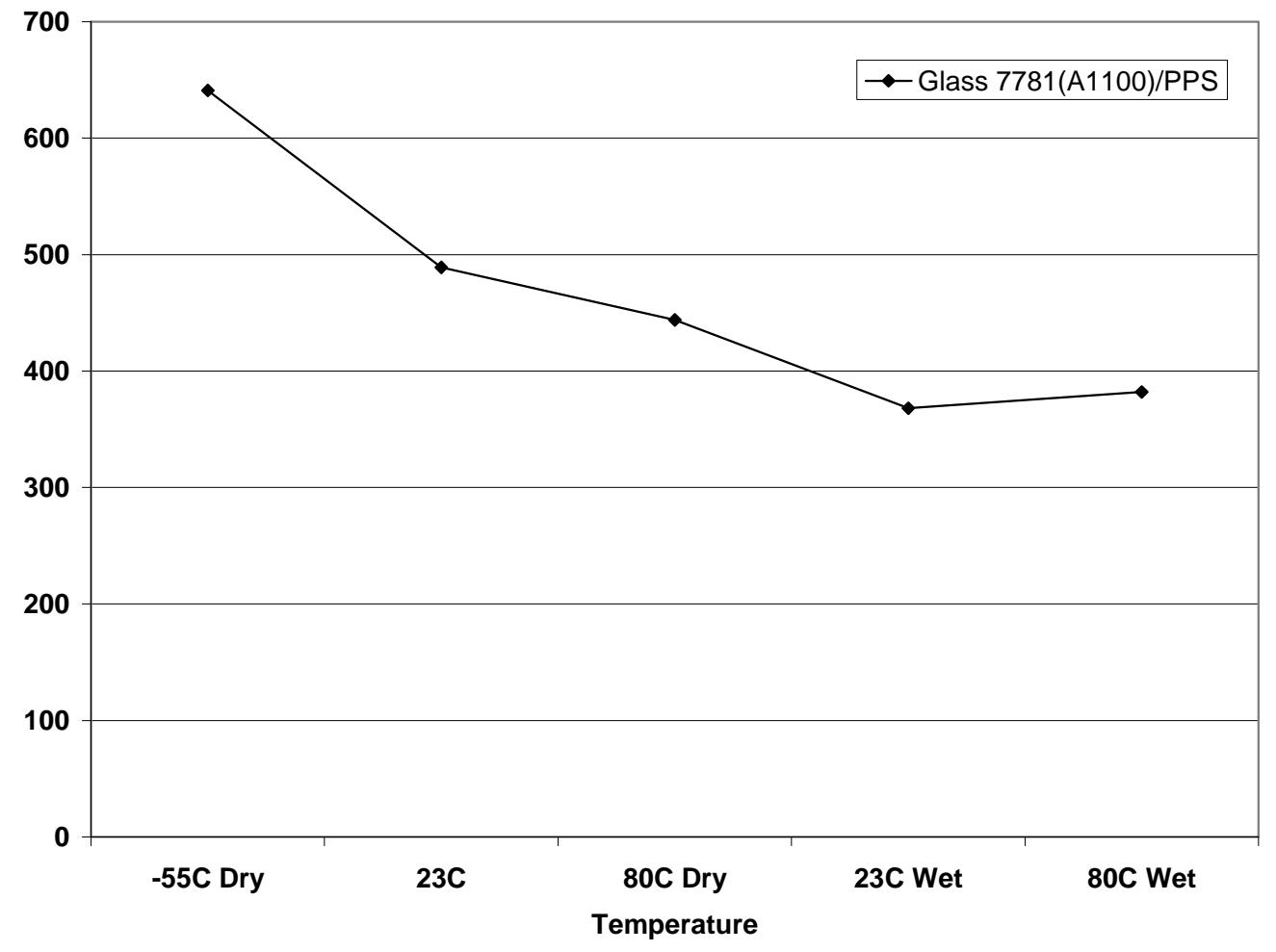

Flexural Modulus Warp, GPa (Data Provided By Ten Cate)

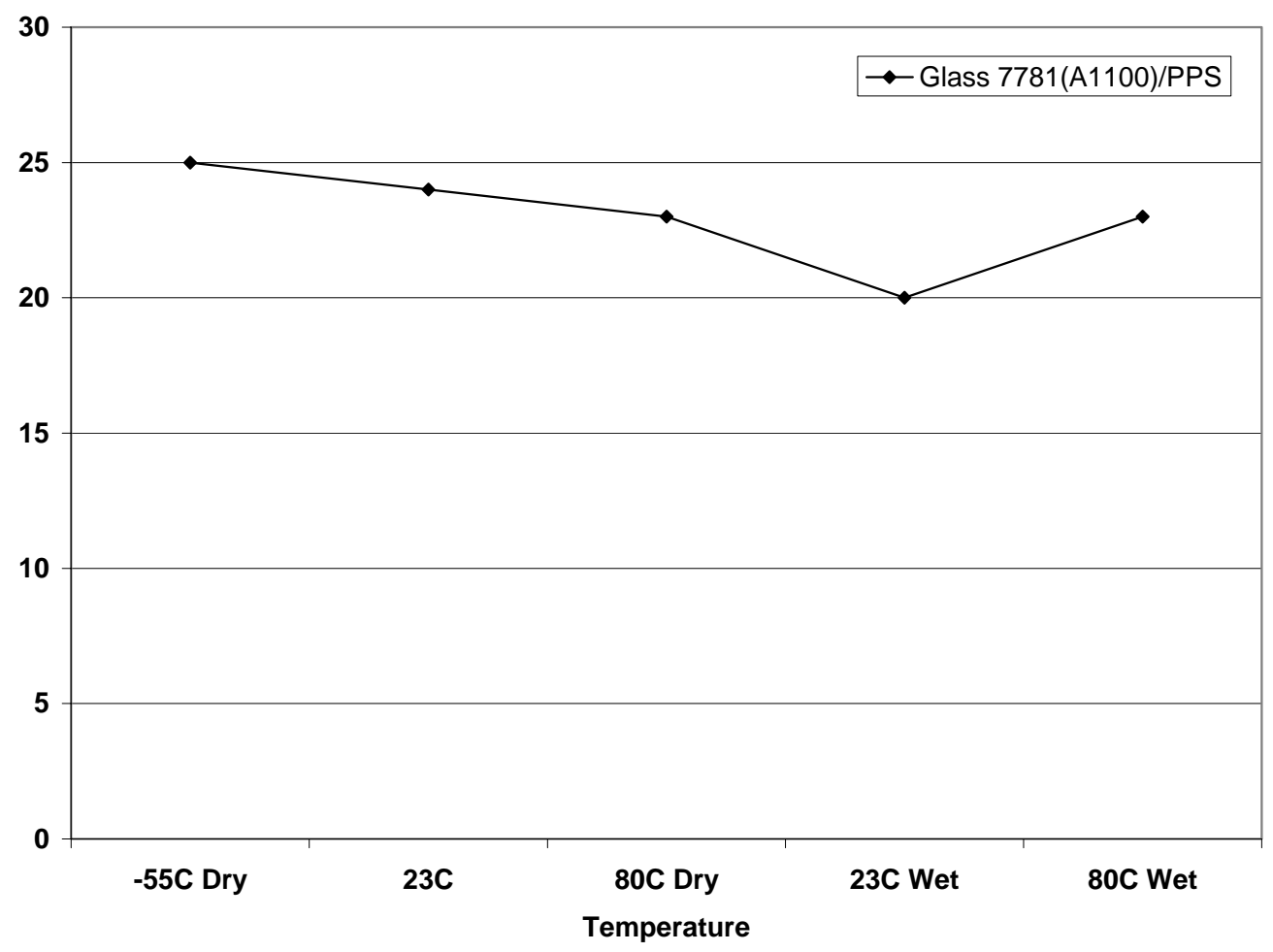




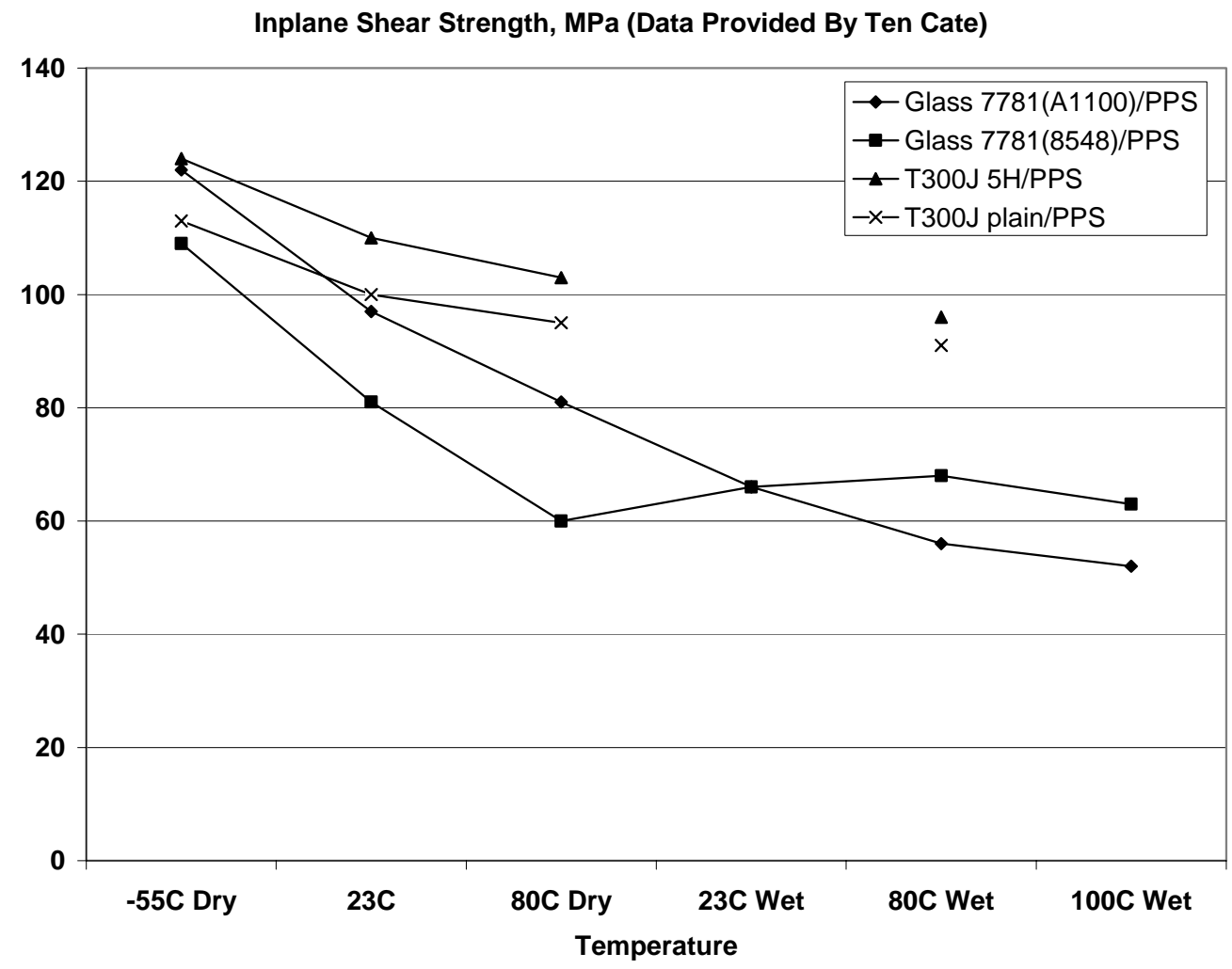

Inplane Shear Modulus, MPa (Data Provided By Ten Cate)

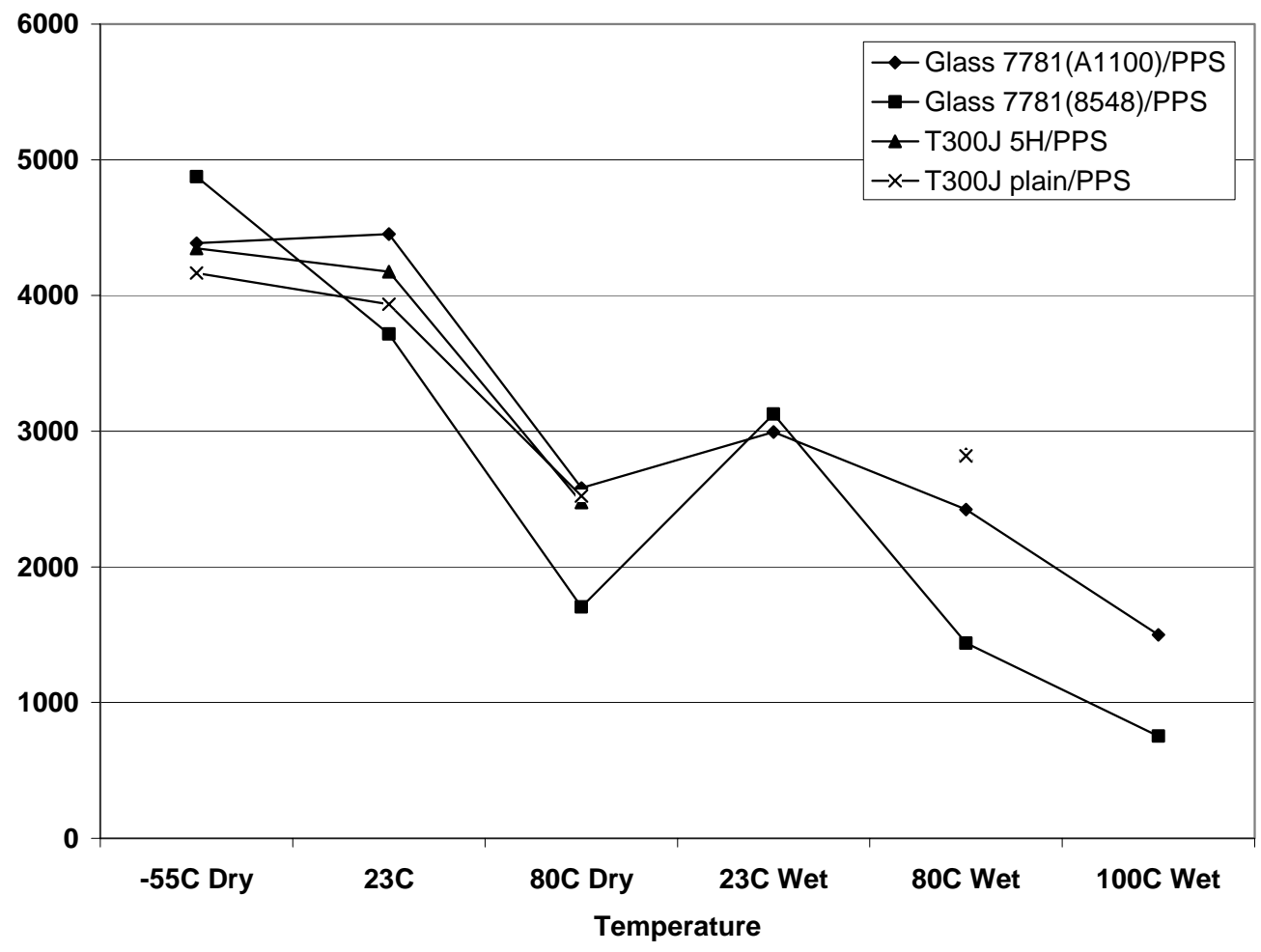



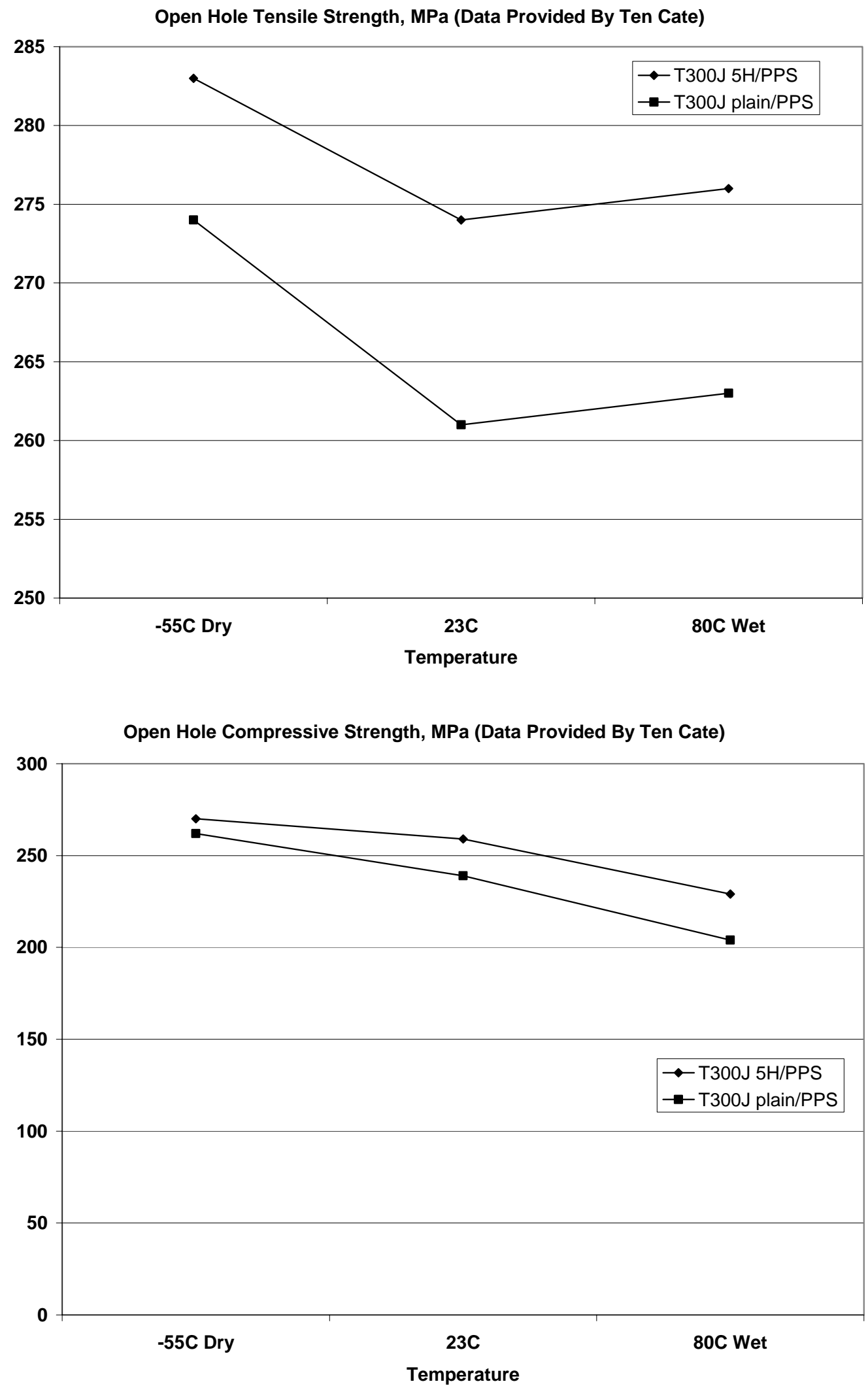

A-9 


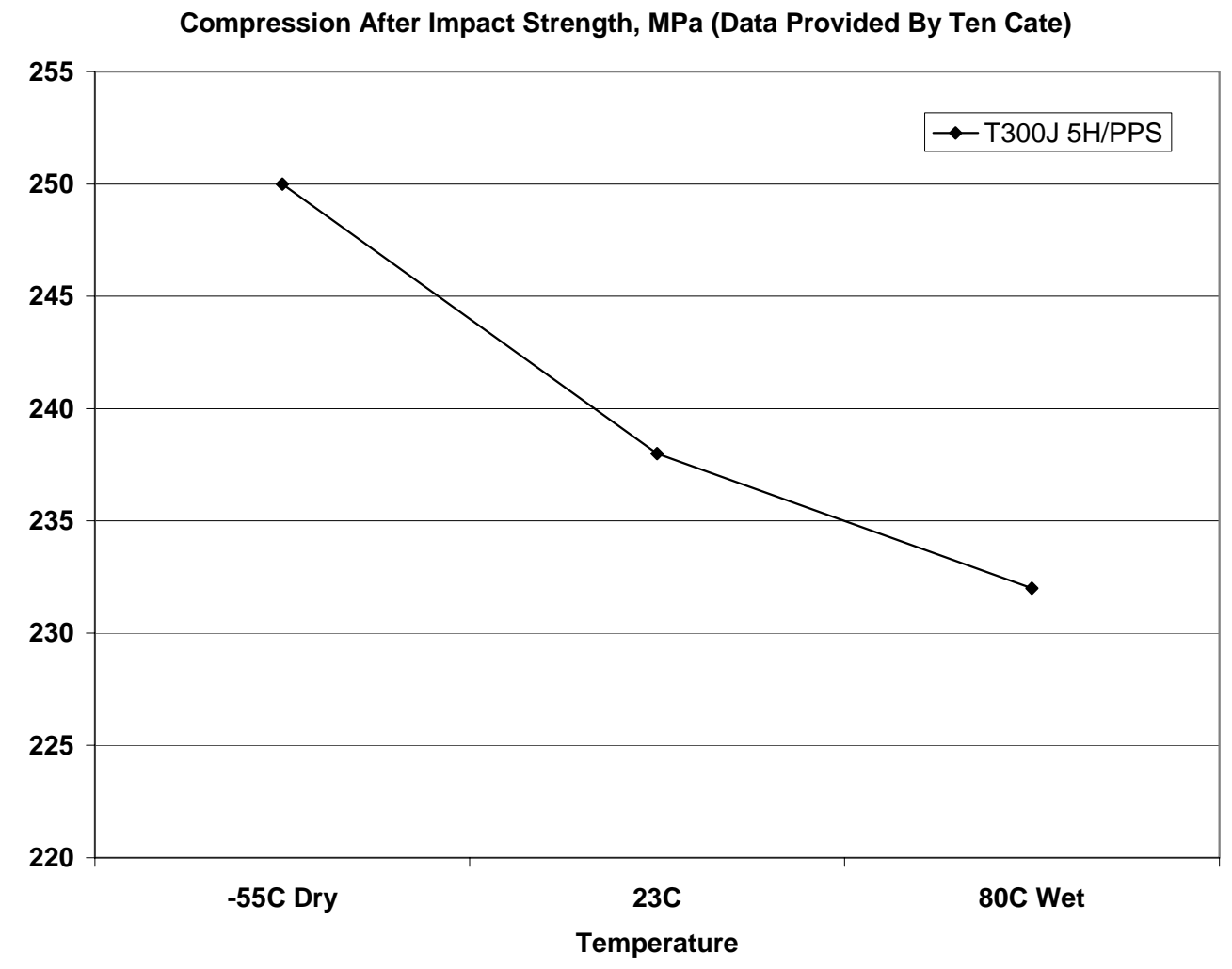

Ultimate Bearing Strength, MPa (Data Provided By Ten Cate)

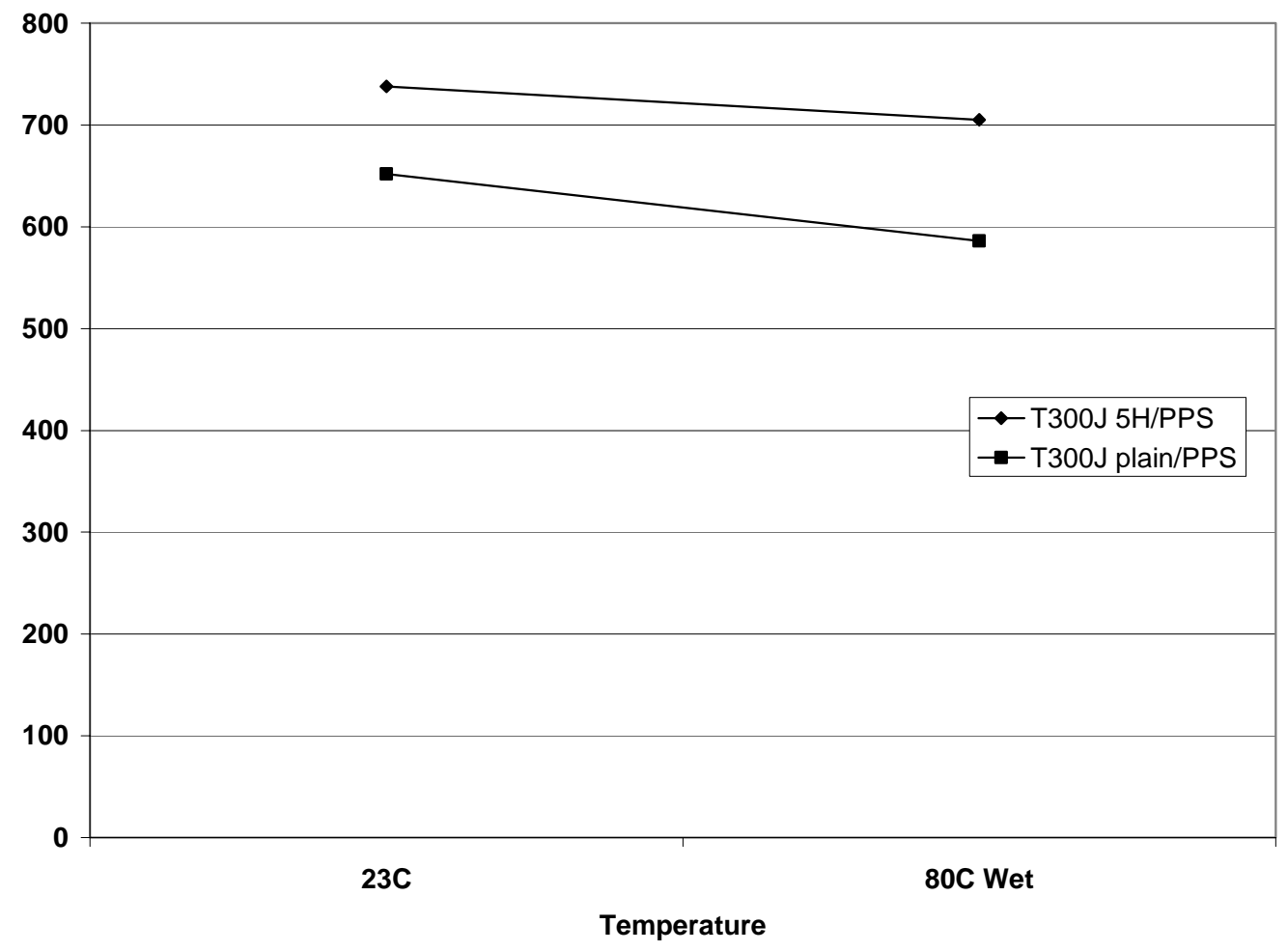




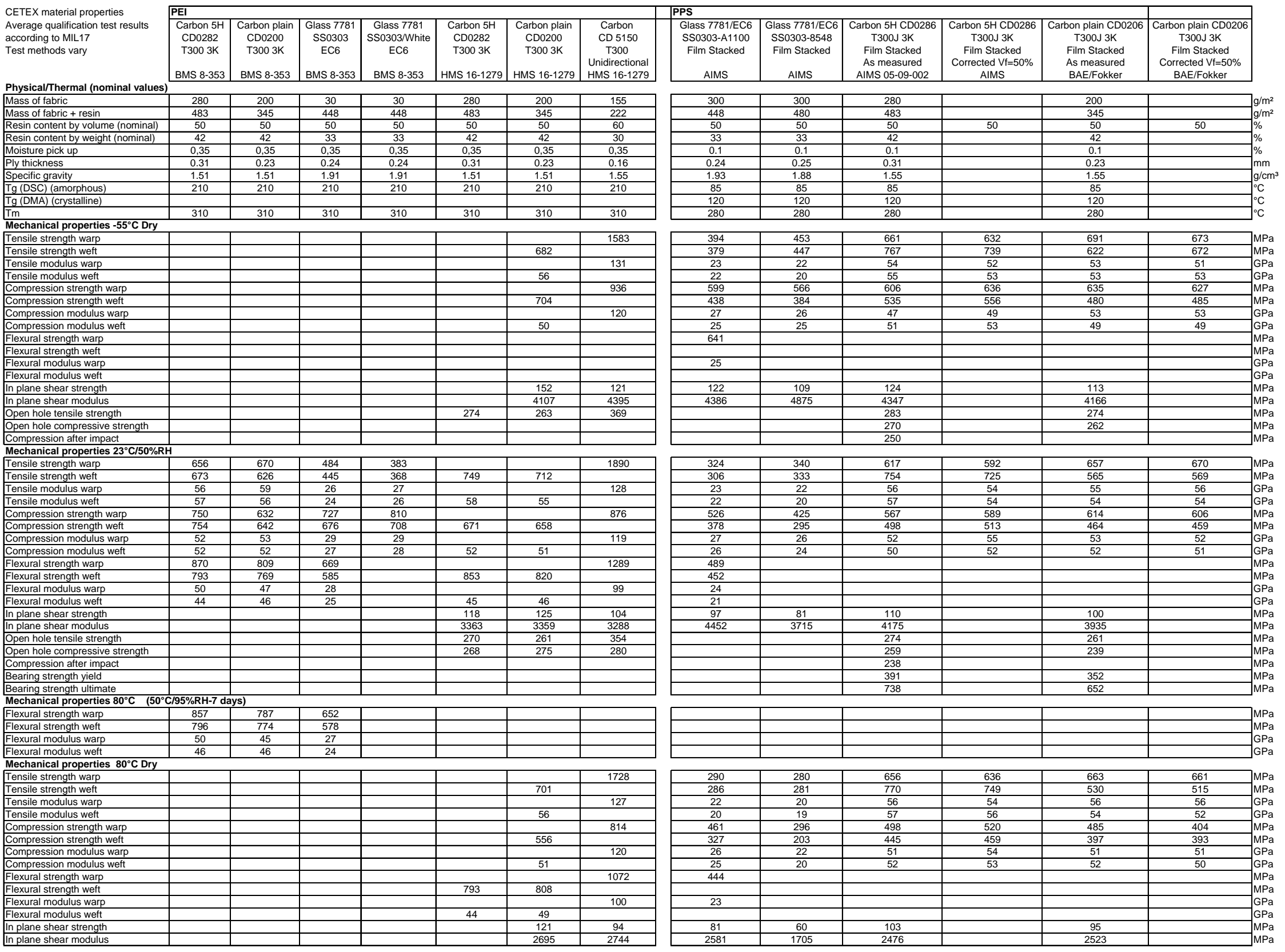




\begin{tabular}{|c|c|c|c|c|c|c|c|}
\hline \multirow[b]{2}{*}{$\begin{array}{l}\text { CETEX material properties } \\
\text { Average qualification test results } \\
\text { according to MIL17 } \\
\text { Test methods vary }\end{array}$} & \multicolumn{7}{|l|}{ PEI } \\
\hline & \begin{tabular}{|c|} 
Carbon 5H \\
CDO282 \\
T300 3K \\
BMS 8-353 \\
\end{tabular} & $\begin{array}{c}\text { Carbon plain } \\
\text { CD0200 } \\
\text { T300 3K } \\
\text { BMS 8-353 } \\
\end{array}$ & \begin{tabular}{|c|} 
Glass 7781 \\
SS00303 \\
EC6 \\
BMS 8-353
\end{tabular} & $\begin{array}{c}\text { Glass } 7781 \\
\text { SSO303/Nhite } \\
\text { EC6 } \\
\text { BMS 8-353 }\end{array}$ & \begin{tabular}{|c|} 
Carbon 5H \\
CDD282 \\
T300 3K \\
HMS 16-1279
\end{tabular} & \begin{tabular}{|c|} 
Carbon plain \\
CDD200 \\
T300 3K \\
HMS 16-1279
\end{tabular} & $\begin{array}{c}\text { Carbon } \\
\text { CD 5150 } \\
\text { T300 } \\
\text { Unidiriectional } \\
\text { HMS 16-1279 }\end{array}$ \\
\hline \multirow{2}{*}{\multicolumn{8}{|c|}{$\begin{array}{l}\text { Mechanical properties } 23^{\circ} \mathrm{C} \quad\left(70^{\circ} \mathrm{C} / 85 \% \mathrm{RH}\right) \\
\text { Tensile strength warp }\end{array}$}} \\
\hline \multirow{2}{*}{\multicolumn{8}{|c|}{\begin{tabular}{|l} 
Tensile strength weft \\
Tensile modulus warp
\end{tabular}}} \\
\hline & & & & & & & \\
\hline \multicolumn{8}{|l|}{$\begin{array}{l}\text { lenslue moduluu warp } \\
\text { Tensile modulus weft } \\
\end{array}$} \\
\hline \multirow{2}{*}{\multicolumn{8}{|c|}{$\begin{array}{l}\text { Compression strength warp } \\
\text { Compression strength weft }\end{array}$}} \\
\hline & & & & & & & \\
\hline \multicolumn{8}{|l|}{$\begin{array}{l}\text { Compression modulus warp } \\
\text { Compression modulus weft }\end{array}$} \\
\hline \multicolumn{8}{|l|}{$\begin{array}{l}\text { Flexural strength warp } \\
\text { Flexural strength weft }\end{array}$} \\
\hline \multicolumn{8}{|l|}{\begin{tabular}{|l} 
Flexural strength weft \\
Flexural modulus warp
\end{tabular}} \\
\hline \multirow{2}{*}{\multicolumn{8}{|c|}{ Flexural modulus weft }} \\
\hline \multirow{2}{*}{\multicolumn{8}{|c|}{$\begin{array}{l}\text { In plane shear strength } \\
\text { In plane shear modulus }\end{array}$}} \\
\hline & & & & & & & \\
\hline \multicolumn{8}{|c|}{ IIn plane shear modulus $\quad$ Mechanical properties $80^{\circ} \mathrm{C} \quad\left(70^{\circ} \mathrm{C} / 85 \% \mathrm{RH}\right)$} \\
\hline Tensile strength warp & & & & & & & 1605 \\
\hline Tensile strength weft & & & & & 773 & 641 & 26 \\
\hline \begin{tabular}{|l} 
Tensile modulus warp \\
Tensile modulus weft
\end{tabular} & & & & & 55 & 37 & $\frac{127}{8}$ \\
\hline Compression strength warp & & & & & & & 689 \\
\hline Compression strength weft & & & & & 605 & 526 & \\
\hline Compression modulus warp & & & & & & & 123 \\
\hline Compression modulus weft & & & & & 54 & 52 & \\
\hline Flexural strength & & & & & & & 1115 \\
\hline Flexural s $\mathrm{s}$, $\mathrm{s}$ & & & & & 745 & 752 & \\
\hline Flexural $\mathrm{m}$ & & & & & & & 97 \\
\hline Finexual in & & & & & $\frac{44}{109}$ & $\frac{45}{109}$ & \\
\hline In plane shear modulus & & & & & 2562 & $\frac{1034}{2534}$ & 2558 \\
\hline \multirow{2}{*}{\multicolumn{8}{|c|}{\begin{tabular}{|l|} 
Open hole tensile strength \\
Open hole compressive strength \\
\end{tabular}}} \\
\hline & & & & & & & \\
\hline \multicolumn{8}{|l|}{\begin{tabular}{|l|} 
Compression after impact \\
Bearing strength yield \\
\end{tabular}} \\
\hline \multirow{2}{*}{\multicolumn{8}{|c|}{\begin{tabular}{|l|l|} 
Bearninstringniny yela \\
Bearing strength ultimate \\
Mechanical properties $100^{\circ} \mathrm{C}\left(70^{\circ} \mathrm{C} / 85 \% \mathrm{RH}\right)$
\end{tabular}}} \\
\hline & & & & & & & \\
\hline \multicolumn{8}{|c|}{ 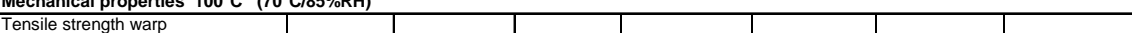 } \\
\hline \multirow{2}{*}{\multicolumn{8}{|c|}{$\begin{array}{l}\text { Tensile strength weft } \\
\text { Tensile modylus warn }\end{array}$}} \\
\hline \multirow{2}{*}{\multicolumn{8}{|c|}{\begin{tabular}{|l} 
Tensile modulus warp \\
Tensile modulus weft \\
\end{tabular}}} \\
\hline & & & & & & & \\
\hline \multicolumn{8}{|l|}{$\begin{array}{l}\text { Compression strength warp } \\
\text { Compression strenghth weft }\end{array}$} \\
\hline \multicolumn{8}{|l|}{\begin{tabular}{|l} 
Compression modulus warp \\
\end{tabular}} \\
\hline Compression modulus weft & & & & & & & \\
\hline In plane shear st & & & & & & & \\
\hline In plane shear modulus & & & & & & & \\
\hline
\end{tabular}

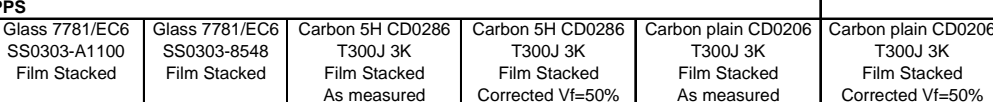

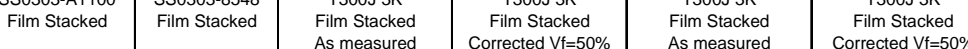

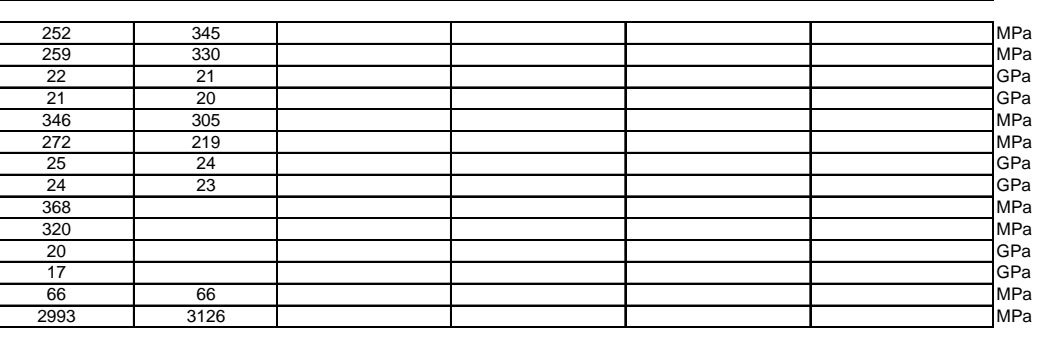

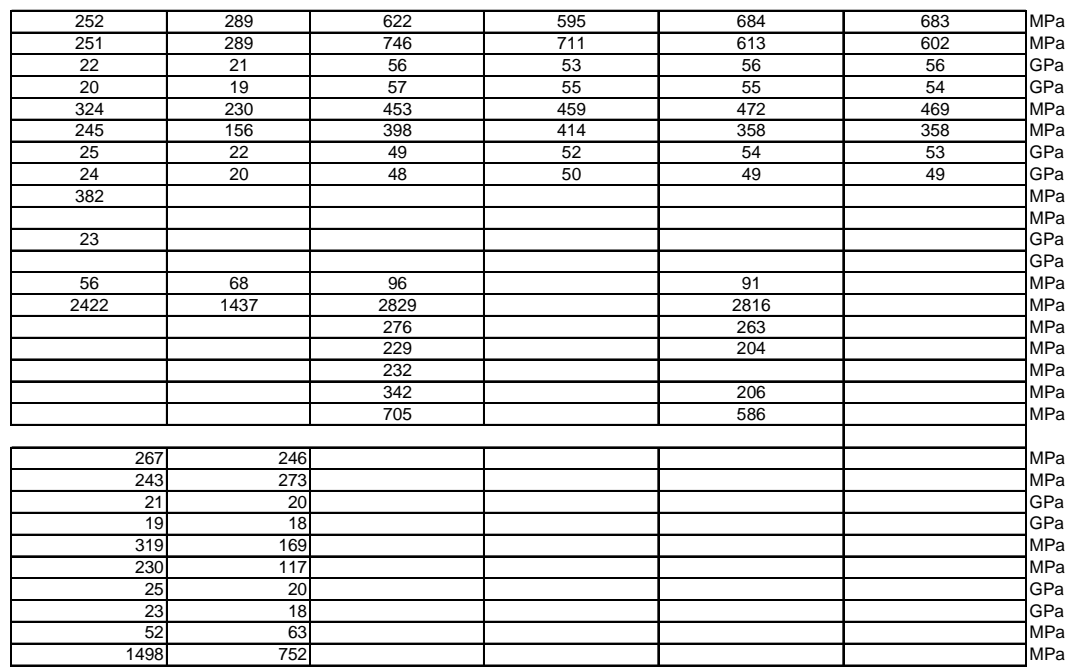


APPENDIX B. MECHANICAL PROPERTY RESULTS ON CARBON FABRIC/PEI AND CARBON FABRIC/PPS LAMINATES FROM TEN CRATE COMPANY. 
This page left blank intentionally.

B-2 
Tensile Strength Warp, MPa (Data Provided by Ten Cate)

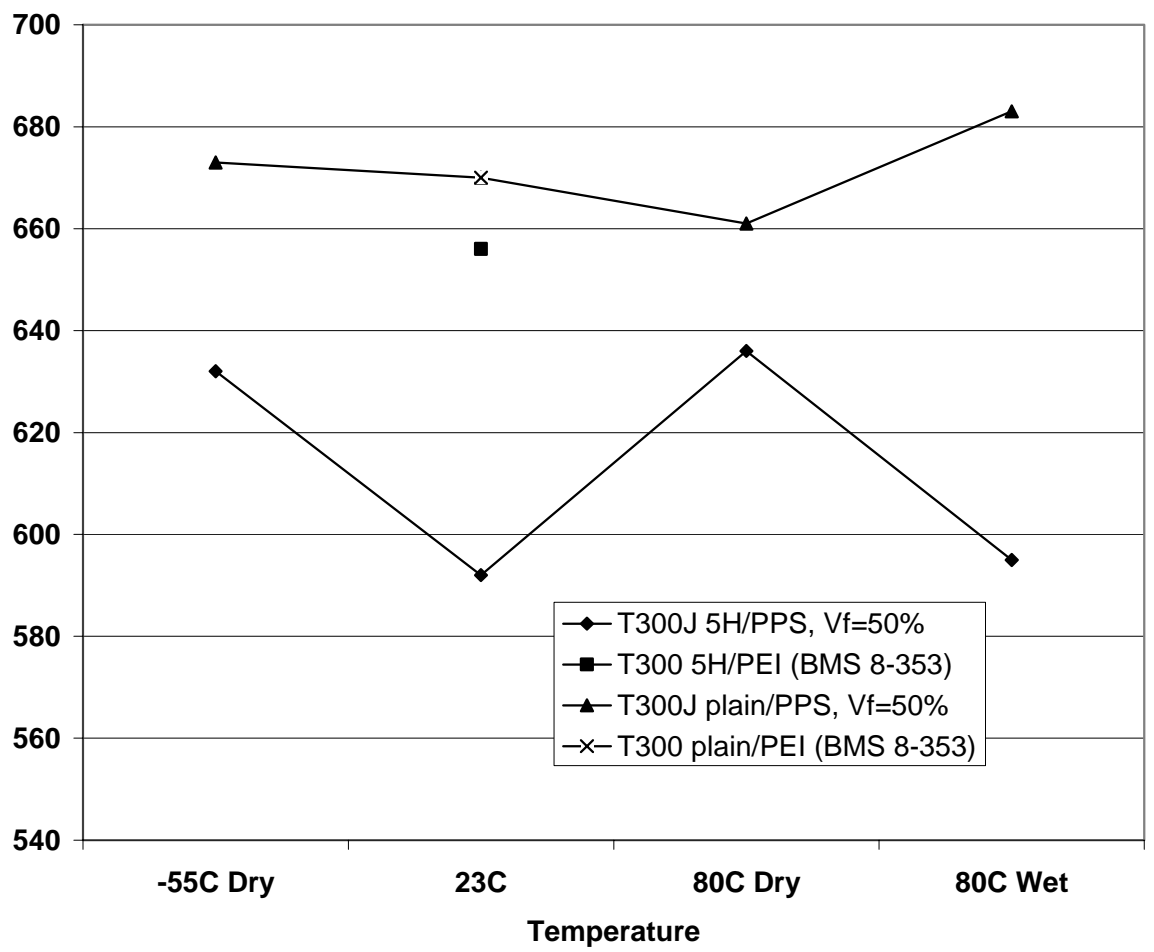

Tensile Strength Weft, MPa (Data Provided by Ten Cate)

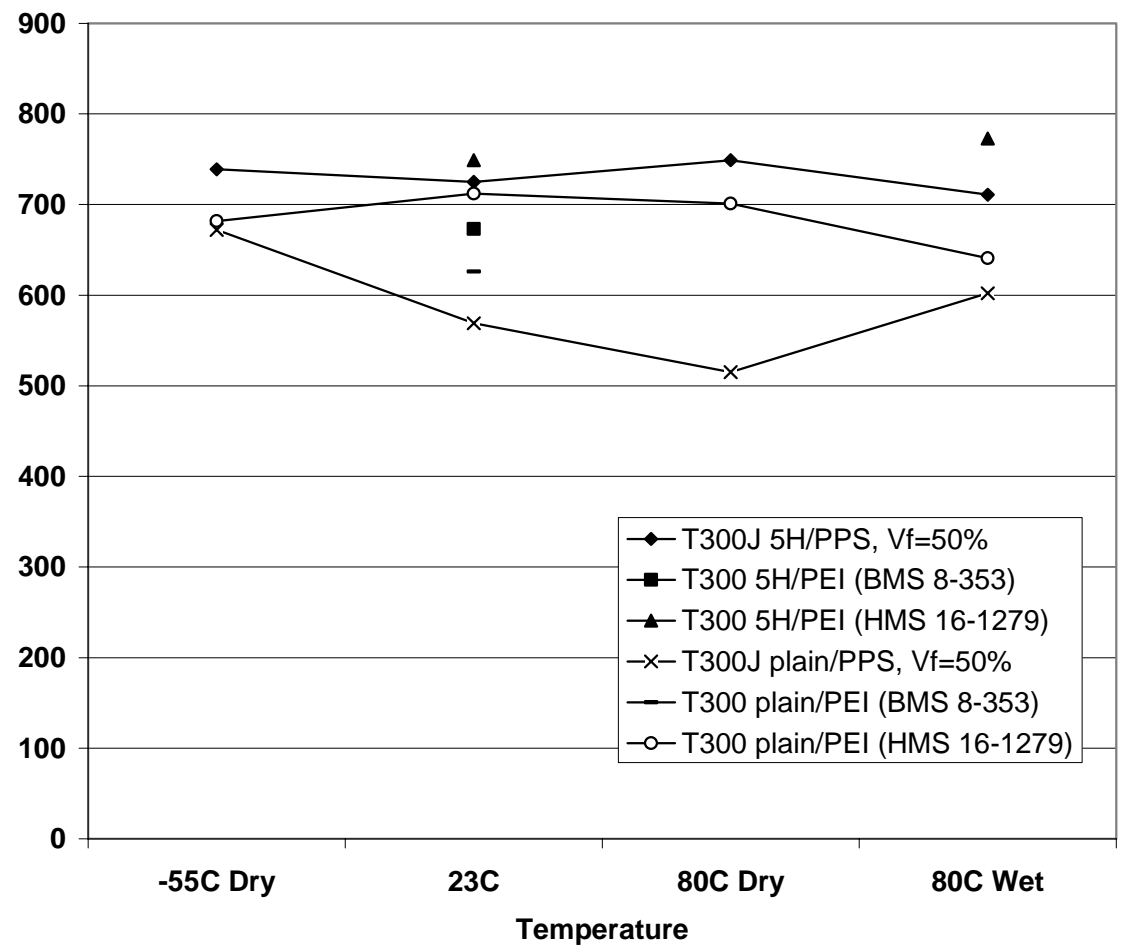

B-3 
Tensile Modulus Warp, GPa (Data Provided by Ten Cate)

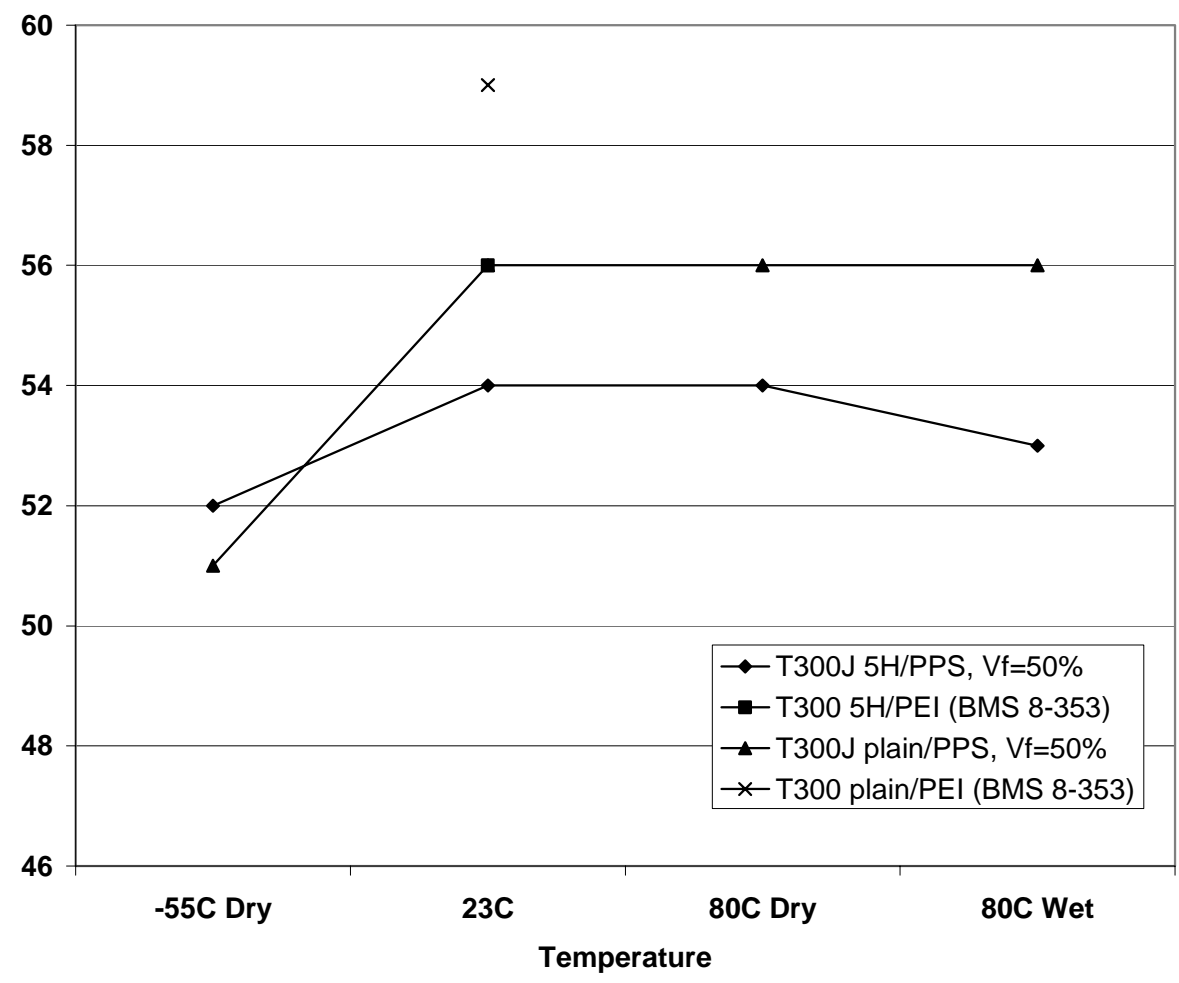

Tensile Modulus Weft, GPa (Data Provided by Ten Cate)

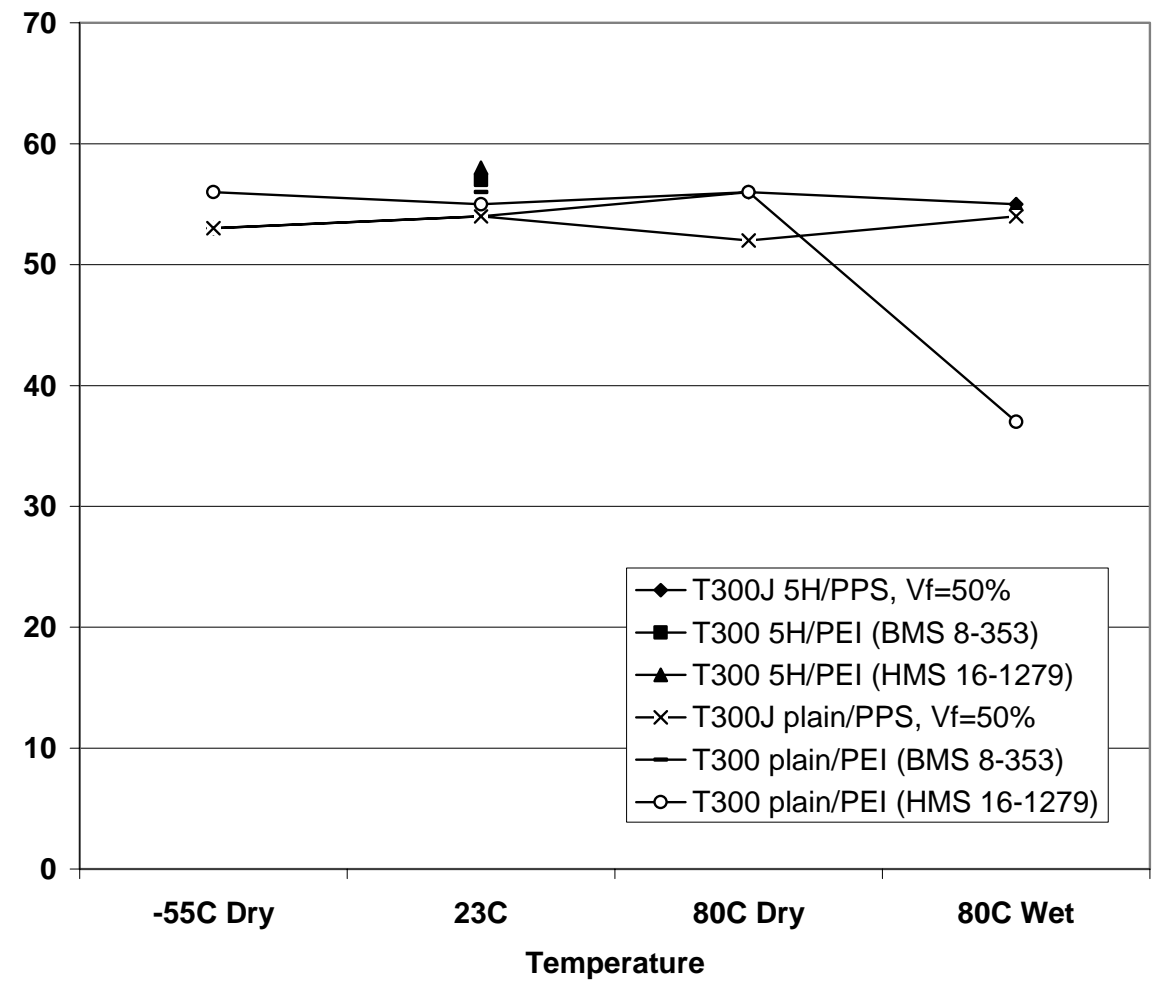




\section{Compression Strength Warp, MPa (Data Provided by Ten Cate)}

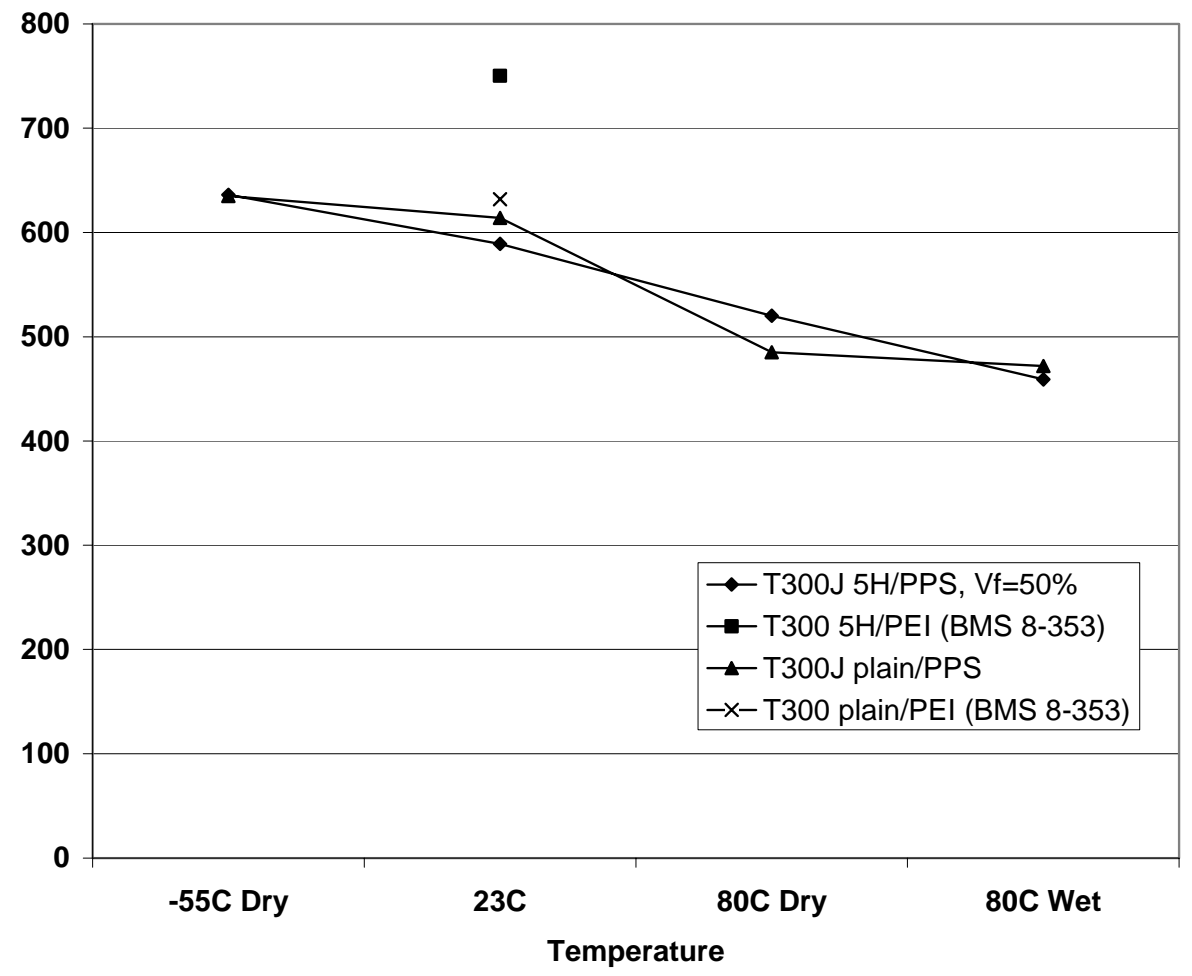

Compression Strength Weft, MPa (Data Provided by Ten Cate)

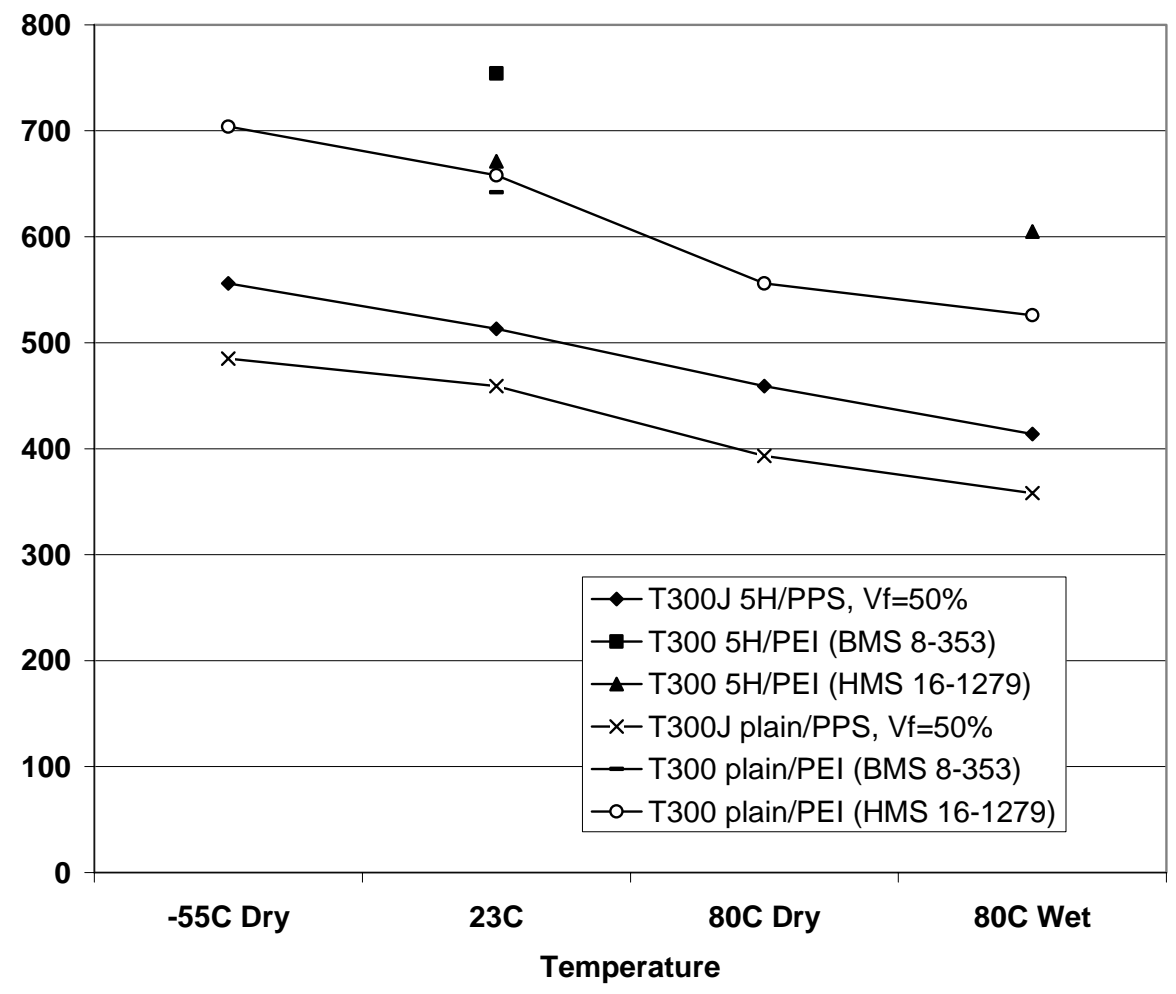




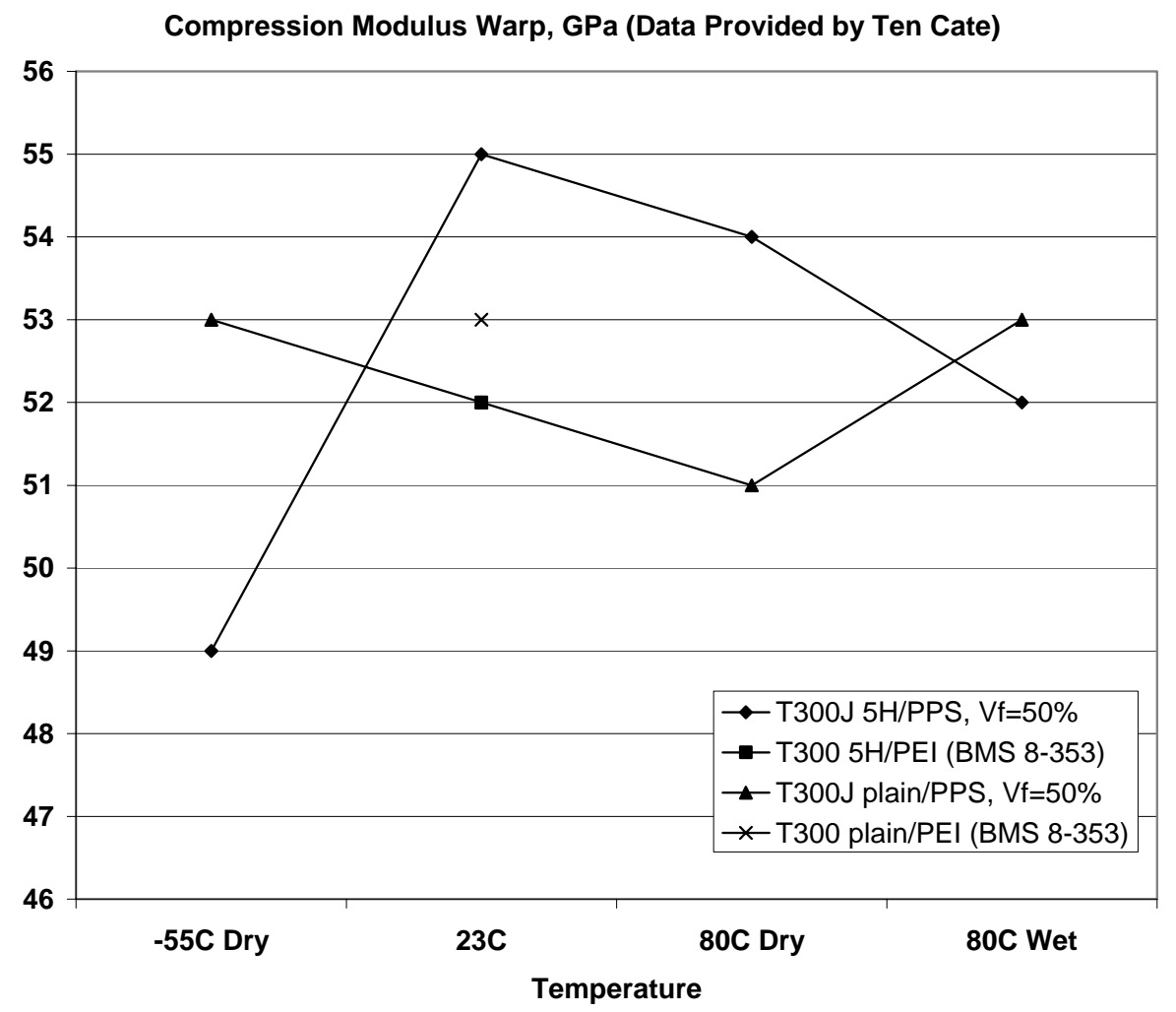

Compression Modulus Weft, GPa (Data Provided by Ten Cate)

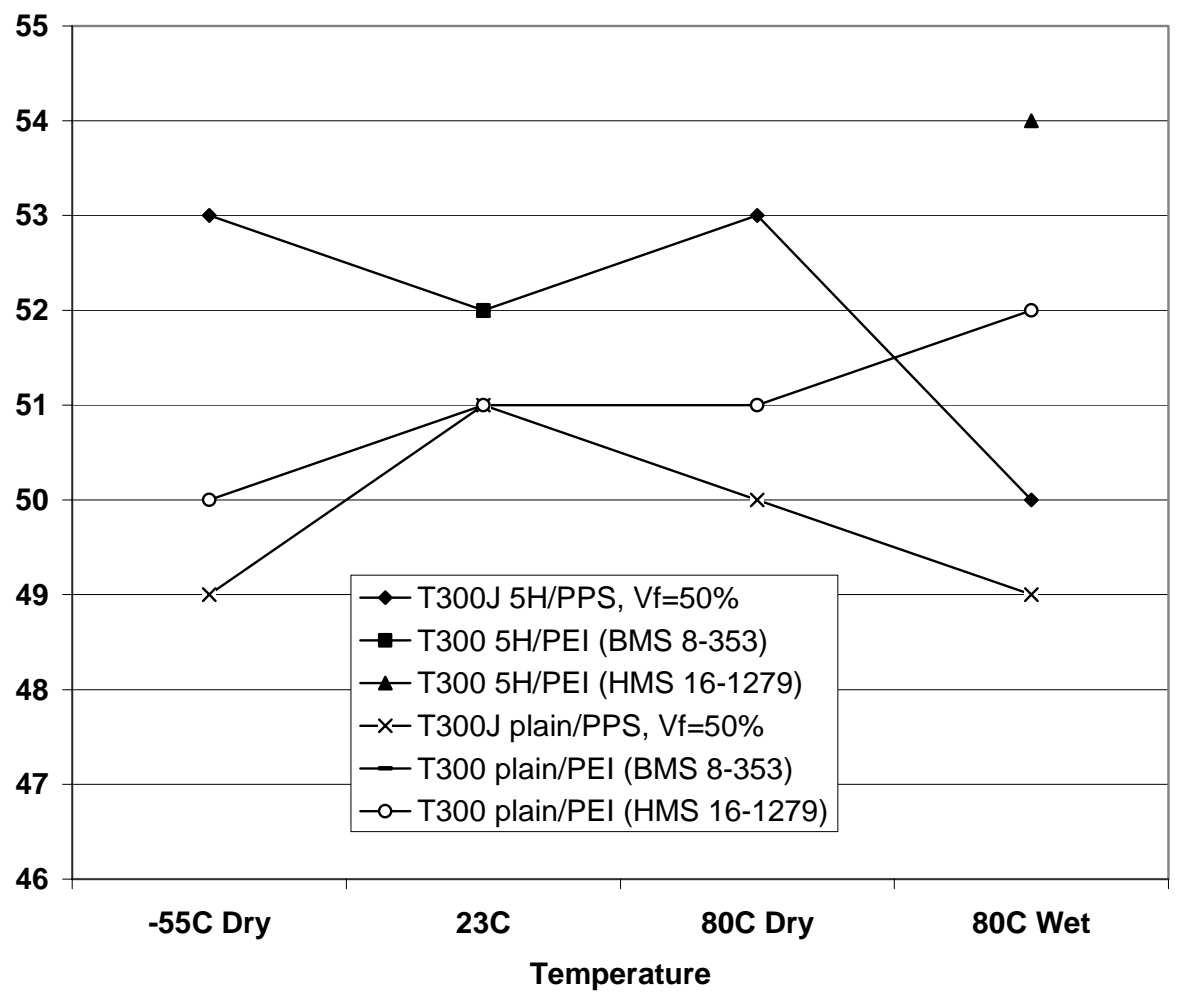

B-6 


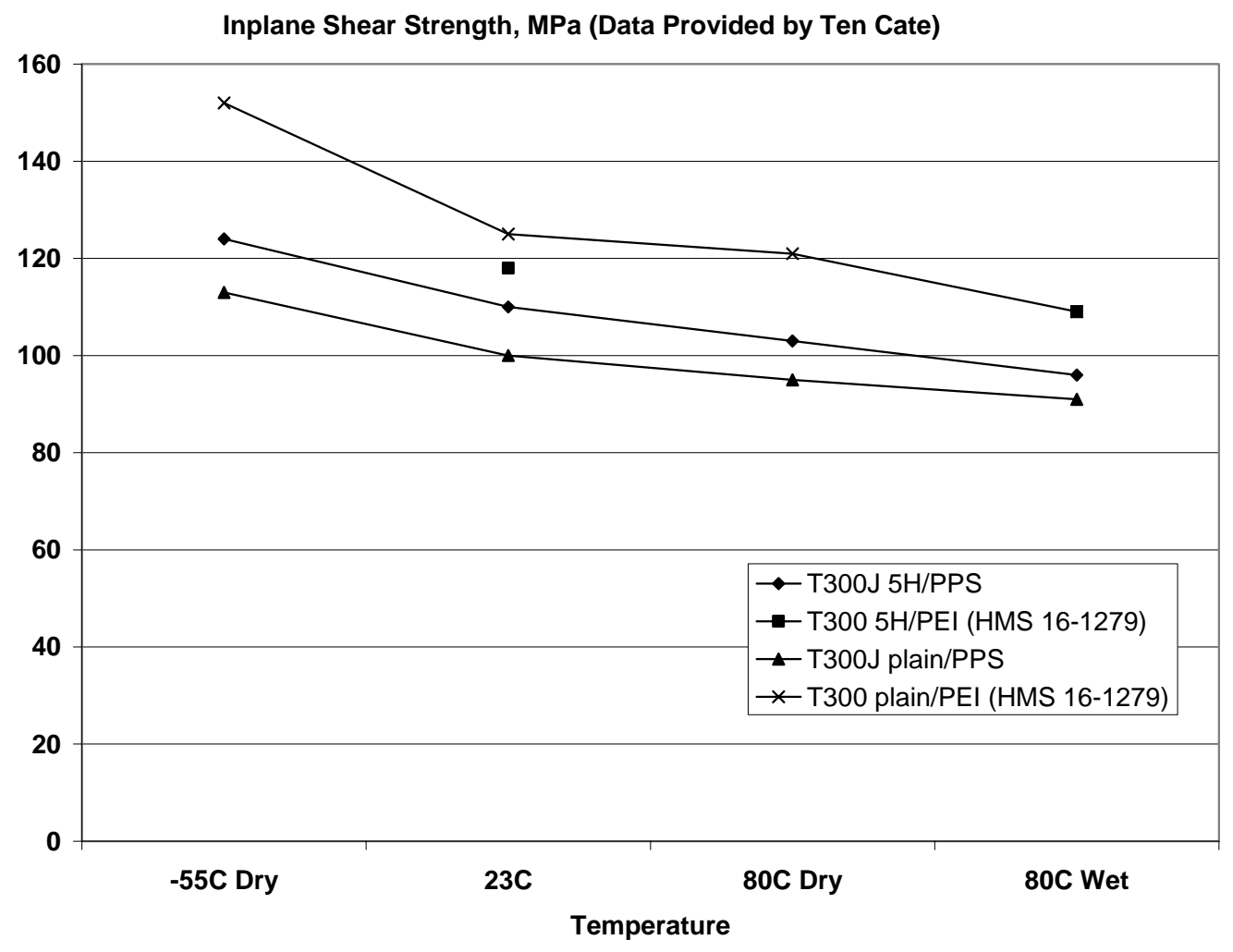

Inplane Shear Modulus, MPa (Data Provided by Ten Cate)

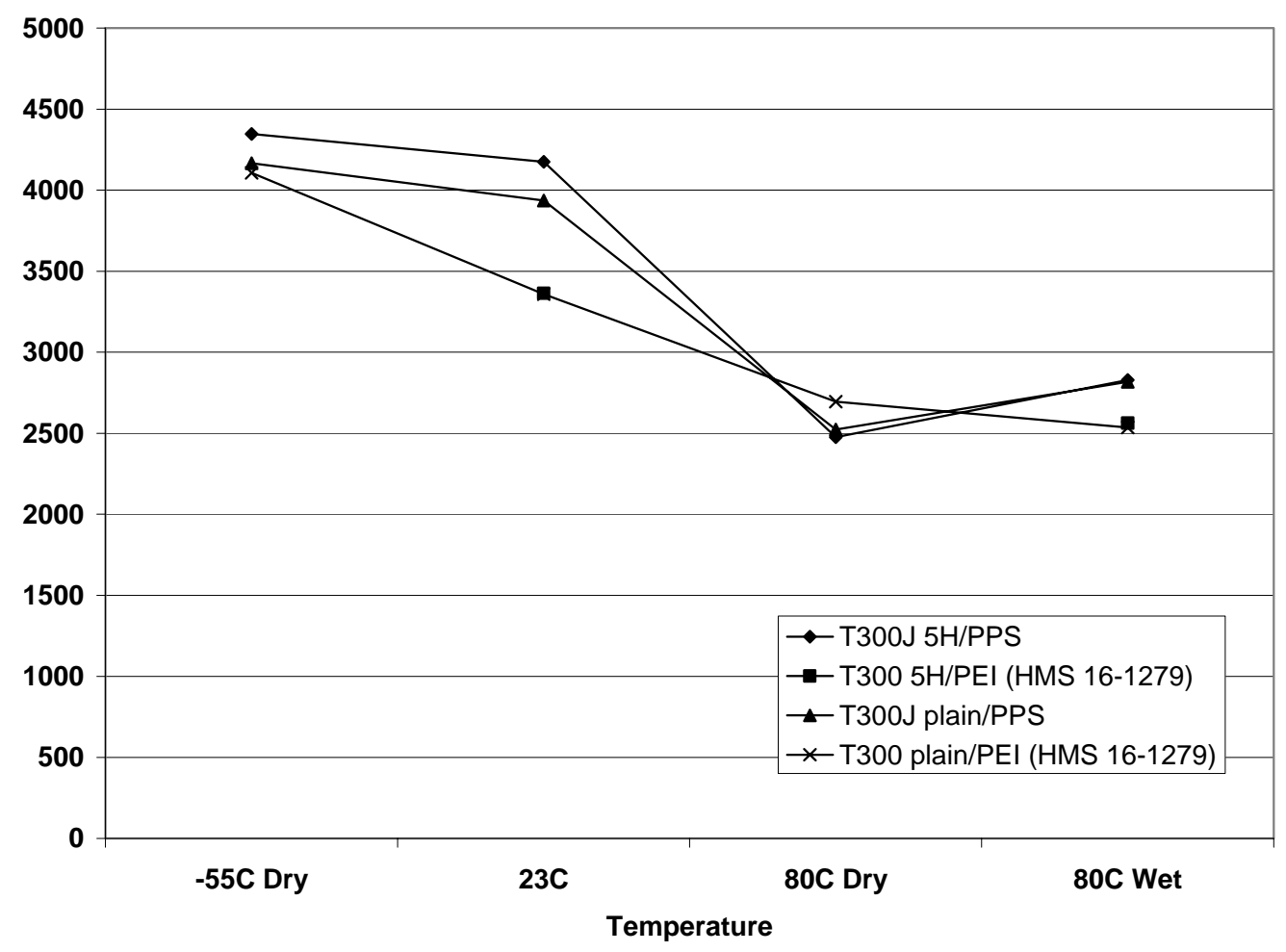

B-7 

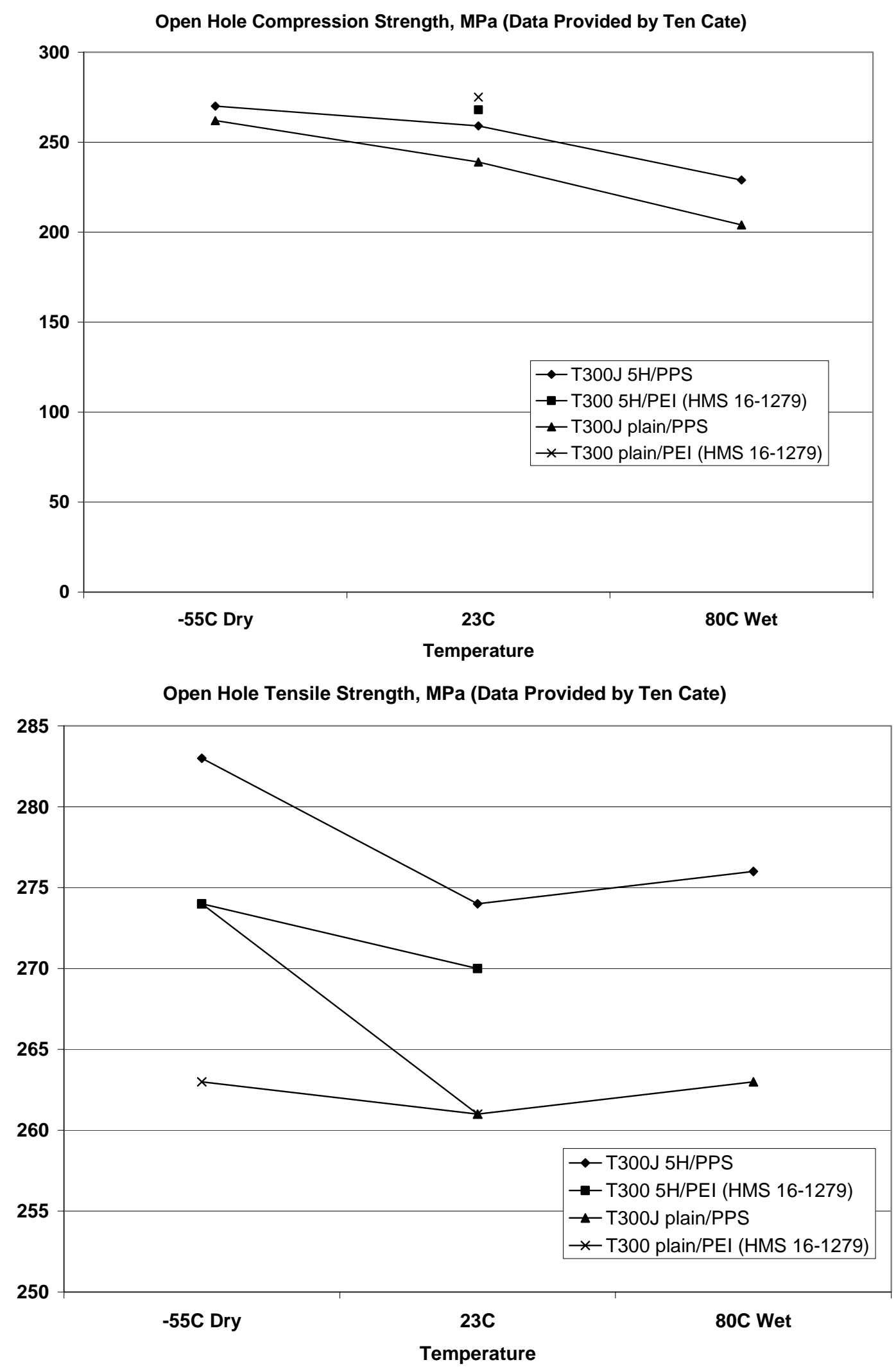

B-8 
ORNL/TM-2004/304

\section{INTERNAL DISTRIBUTION}

\author{
1.-2. R. L. Battiste \\ 3. R. G. Boeman \\ 4.-5. J. M. Corum \\ 6. C. C. Eberle \\ 7. D. L. Erdman \\ 8. B. J. Frame \\ 9. E. T. Grostick \\ 10. J. G. Hansen \\ 11.-15. C. J. Janke \\ 16. L. B. Klett \\ 17. V. Kunc \\ 18. E. Lara-Curzio
}

\author{
19.-30. D. J. Naus \\ 31. R. E. Norris \\ 32. F. L. Paulauskas \\ 33. S. Simunovic \\ 34. P. S. Sklad \\ 35.-37. J. E. Spruiell \\ 38. J. M. Starbuck \\ 39. C. D. Warren \\ 40.-41. Y. J. Weitsman \\ 42. Central Research Library \\ 43. ORNL Laboratory Records-RC \\ 44. ORNL Laboratory Records-OSTI
}

\section{EXTERNAL DISTRIBUTION}

45. M. Abdallah, Hexcel Carbon Fibers, Research and Technology, P.O. Box 18748, Salt Lake City, UT 84118-0748

46. M. M. Fisher, American Plastics Council, 1300 Wilson Boulevard, Suite 800, Arlington, VA 22209

47. R. B. Freeman, The Budd Company, 1515 Atlantic Boulevard, Auburn Hills, MI 48326

48. R. Gjerde, Textron Automotive Company, 100 Brady Road, Americus, GA 31709

49.-78. L. Berger, Automotive Composite Consortium, General Motors, 30500 Mound Road, Mail Code 480-106-710, Box 9055, Warren, MI 48090-9055

79. J. M. Henshaw, Department of Mechanical Engineering, The University of Tulsa, 600 S. College Avenue, Tulsa, OK 74104-3189

80. G. A. Holmes, National Institute of Standards and Technology, Bldg. 224, Room B116, Mail Stop: Room B108, Gaithersburg, MD 20899

81. S. H. Johnson, BP Amoco Polymers, Inc., 4500 McGinnis Ferry Road, Alpharetta, GA 30005-3914

82. D. Kossak, Cambridge Industries, 29333 Stephenson Highway, Madison Heights, MI 48071

83. F. G. Krautz, Vetrotex Certainteed, 4515 Allendale Road, Wichita Falls, TX 763102199

84. G. R. Miesel, Ashland Chemical Company, 900 Wilshire Drive, Suite 100, Troy, MI 48084

85. E. Ostwald, Dow Automotive, 1600 Harmon Road, Auburn Hills, MI 48326

86. B. Pierson, Department of Mechanical Engineering, The University of Tulsa, 600 S. College Avenue, Tulsa, OK 74104-3189

87. S. R. Reeve, National Composite Center, 2000 Composite Drive, Kettering, OH 45420 
88. C. R. Schultheisz, National Institute of Standards and Technology, Building 224, Room A209, Gaithersburg, MD 20899

89. T. D. Seagrave, Bayer Corporation, 100 Bayer Road, Pittsburgh, PA 15205

90. L. V. Smith, Washington State University, School of Mechanics and Materials Engineering, Pullman, WA 99164-2920

91. D. Stewart, Stewart Automotive Research, LLC, 1260 Shotwell Street, Houston, TX 77020

92. X. J. Xin, Department of Mechanical and Nuclear Engineering, Kansas State University, 338 Rathbone Hall, Manhattan, KS 66506-5205

93. S. J. Winckler, Cyclics Corporation, 747 Pierce Road, Clifton Park, NY 12065

94.-96. J. A. Carpenter, U.S. Department of Energy, 1000 Independence Avenue, SW, Washington, DC 20585

97. M. Rawlins, U.S. Department of Energy, Oak Ridge Site Office, Oak Ridge, TN 37831

98. S. Diamond, U.S. Department of Energy, 1000 Independence Avenue, SW, Washington, DC 20585 